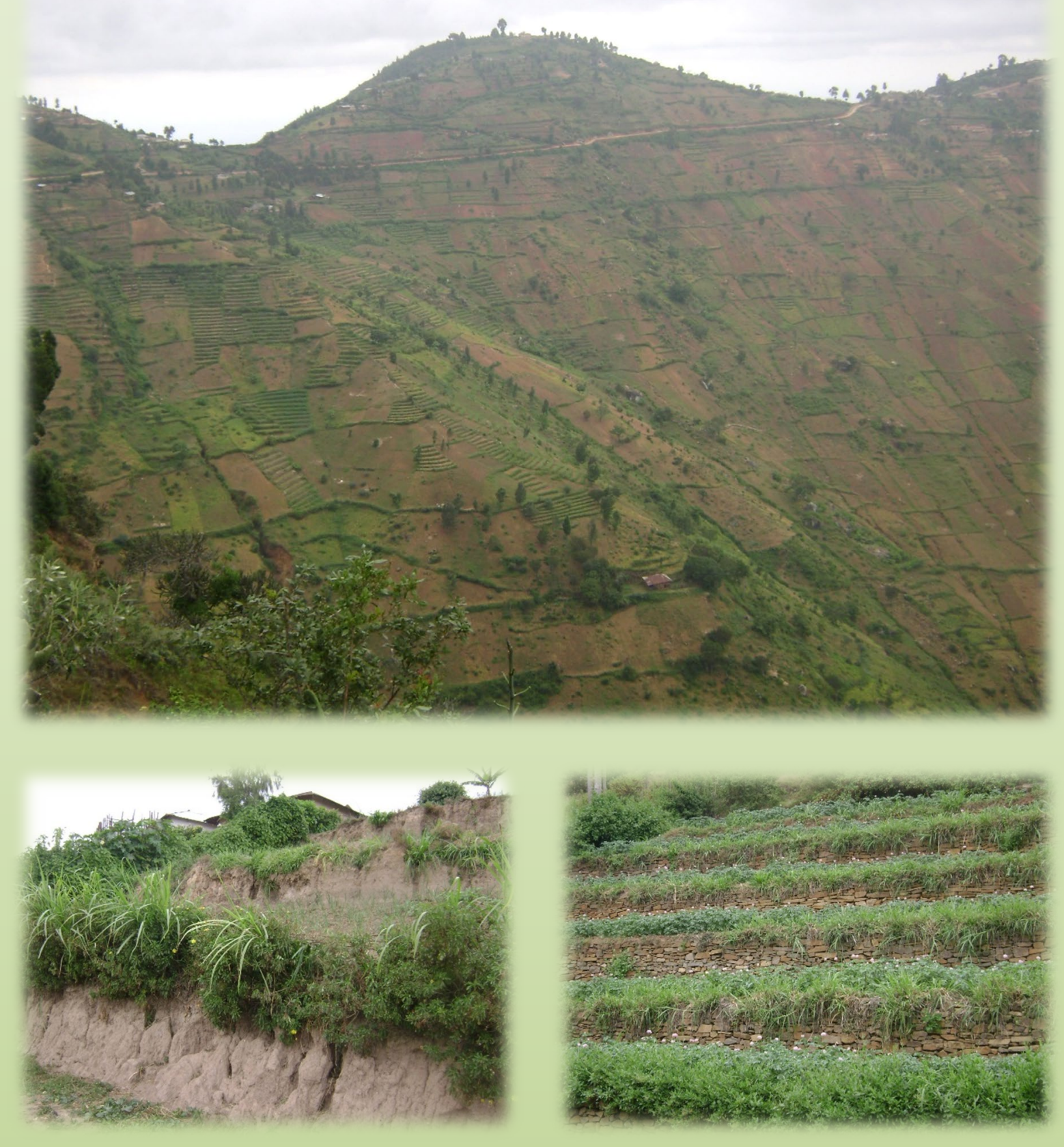

Influence of biophysical aspects on the performance of sustainable land management measures in the Usambara highlands of Tanzania

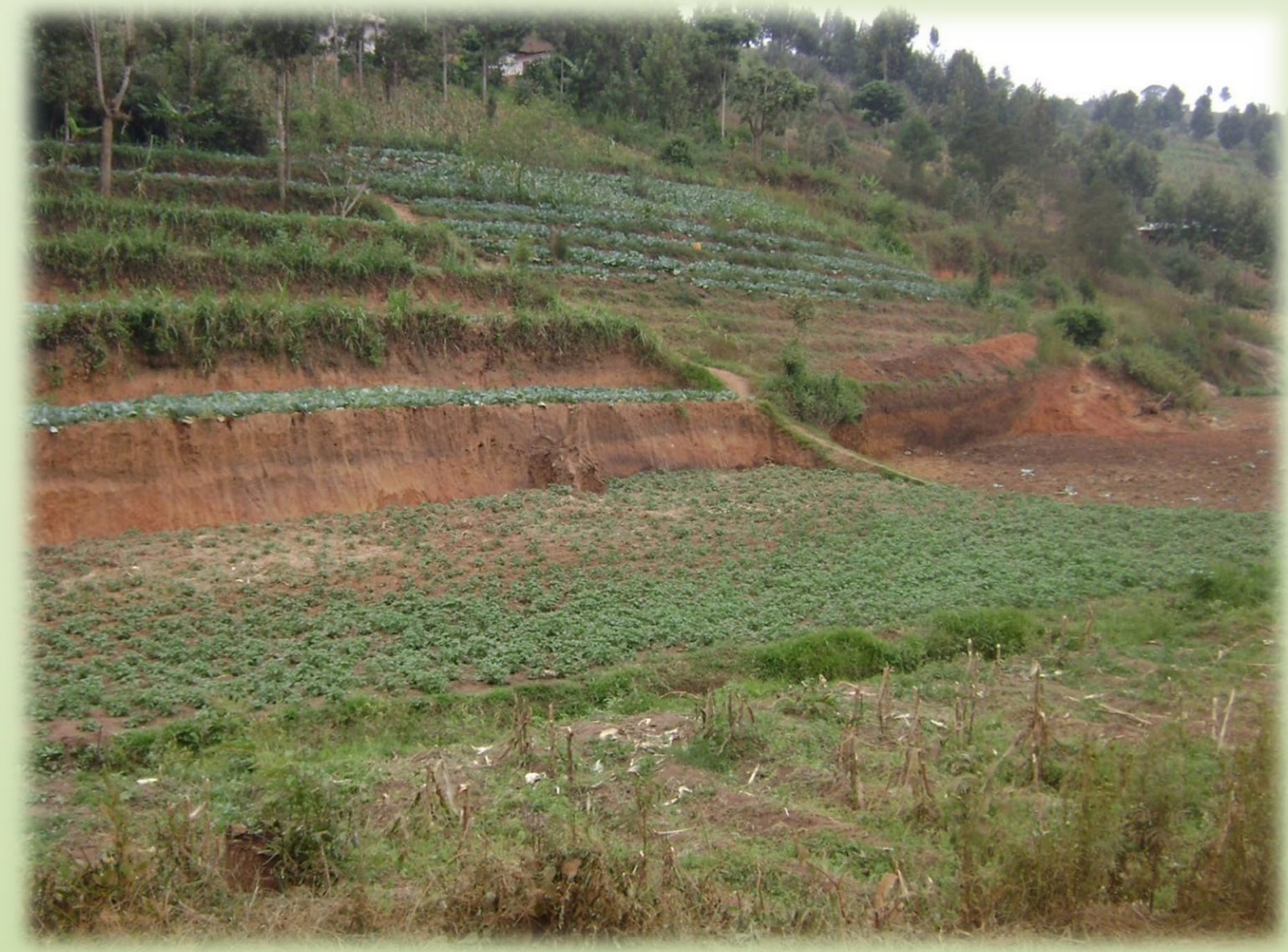

Juma Wickama 


\section{Propositions}

1. Bench terraces and grass strips are effective in reducing soil losses from smallholder fields of the West Usambara highlands in Tanzania, but they do not improve soil fertility of the respective fields

(this thesis)

2. Acceptance of sustainable land management measures in the West Usambara highlands of Tanzania can only be improved if biophysical variability of the landscape in which they are advocated is considered (this thesis)

3. The changing consumption lifestyle of its growing middle class population is a greater health threat in Africa than malaria or HIV

4. Unfair prices at both local and international markets are the main cause of poverty spread among smallholder farmer communities in Sub-Saharan Africa

5. Most resource-based conflicts in the East African region are not about limited availability, but rather about equitable resource sharing and use

6. The PhD studies at Wageningen University have two famous journeys, the technical for which we all are prepared and the social for which we learn along the way

Propositions belonging to the thesis entitled:

'Influence of biophysical aspects on the performance of sustainable land management measures in the Usambara highlands of Tanzania'

Juma Wickama

Wageningen, 20 February 2019 


\title{
Influence of biophysical aspects on the performance of sustainable land management measures in the Usambara highlands of Tanzania
}

\author{
Juma Wickama
}




\section{Thesis committee}

\section{Promotor}

Prof. Dr C.J. Ritsema

Professor of Soil Physics and Land Management

Wageningen University \& Research

\section{Co-promotors}

Dr G. Sterk

Associate Professor, Department of Physical Geography

Utrecht University

Dr C.A. Kessler

Assistant Professor, Soil Physics and Land Management Group

Wageningen University \& Research

\section{Other members}

Prof. Dr A.K. Bregt, Wageningen University \& Research

Dr E.M.A. Smaling, Wageningen University \& Research

Dr A. Vrieling, University of Twente, Enschede

Dr H. Posthumus, KIT Royal Tropical Institute, Amsterdam

This research was conducted under the auspices of the Research School for C.T. de Wit Graduate School for Production Ecology and Resource Conservation (PE\&RC) 


\title{
Influence of biophysical aspects on the performance of sustainable land management measures in the Usambara highlands of Tanzania
}

\author{
Juma Wickama
}

Thesis

submitted in fulfilment of the requirements for the degree of doctor

at Wageningen University

by the authority of the Rector Magnificus,

Prof. Dr A.P.J. Mol,

in the presence of the

Thesis Committee appointed by the Academic Board

to be defended in public

on Wednesday 20 February 2019

at 1.30 p.m. in the Aula. 
Juma Wickama

Influence of biophysical aspects on the performance of sustainable land management measures in the Usambara highlands of Tanzania,

154 pages.

PhD thesis, Wageningen University, Wageningen, the Netherlands (2019)

With references, with summary in English

ISBN: 978-94-6343-571-0

DOI:. https://doi.org/10.18174/467529 


\section{Table of contents}

\section{Chapter}

Chapter_1. General introduction .............................................................. 7

Chapter_2. Effectiveness of soil conservation measures at a landscape scale in the West Usambara highlands, Tanzania

Chapter_3. Modeling and mapping erosion in smallholder agro-ecosystems, Tanzania.

Chapter_4. Land degradation problems and adoption of sustainable land management in the West Usambara highlands, Tanzania

Chapter_5. Effectiveness of sustainable land management measures in West Usambara highlands, Tanzania

Chapter 6. Synthesis 109

Literature cited 125

Summary 143

Acknowledgements 147

About the author 


\section{DEDICATION}

I dedicate this work to two women whose contributions have affected my life irreversibly;

1. My late mother Fatuma Matinde Mobwe (d. July $\left.28^{\text {th }}, 1998\right)$

2. My late wife Grace Vida Lwiza (d. Nov., $30^{\text {th }}, 2002$ ) 


\section{General introduction}

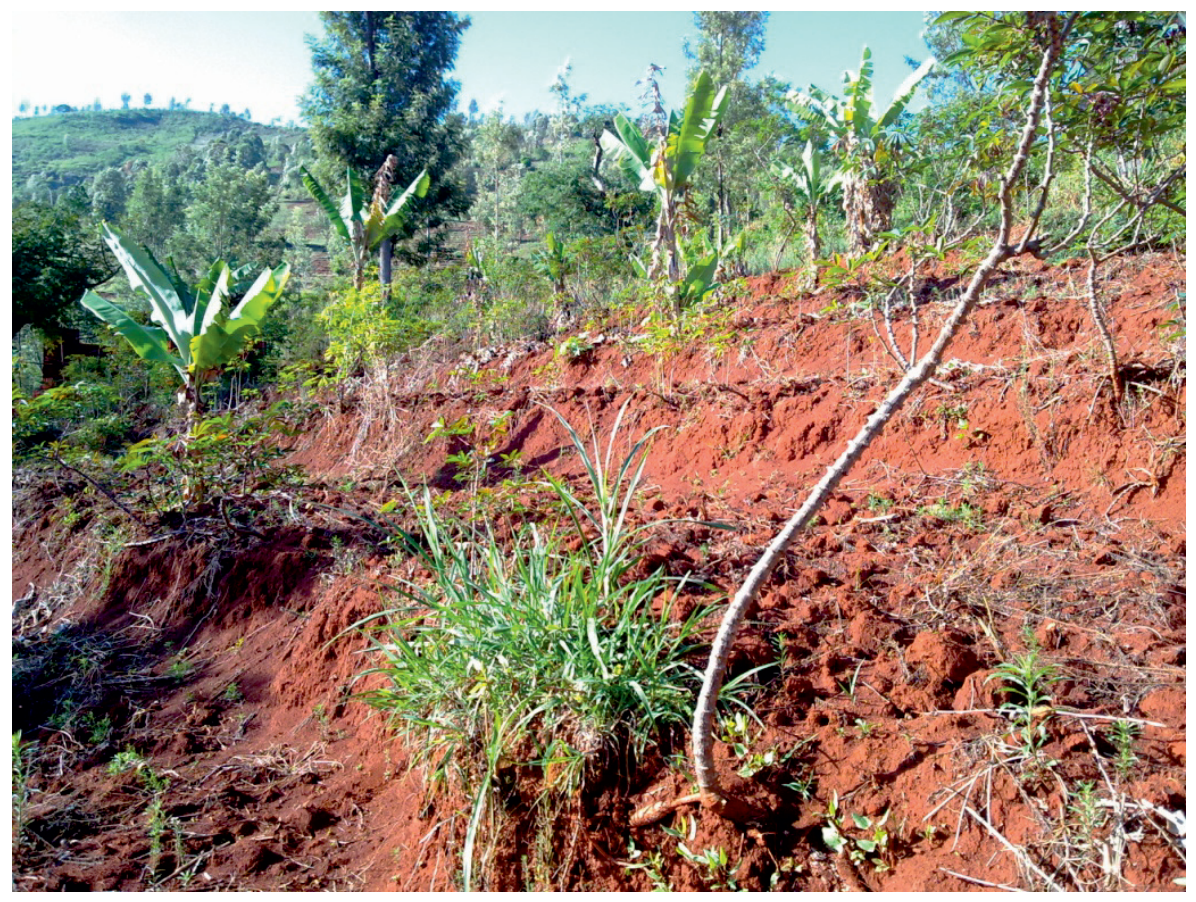




\subsection{Background}

Land degradation is one of the factors blamed for the global reduction of agricultural productivity (Meshesha et al., 2012). The recent Global Land Outlook (UNCCD, 2017) estimates that approximately $9 \%$ (or 1.38 million $\mathrm{km}^{2}$ ) of the global area with more than $50 \%$ per cent of cropland is suffering from land change processes that cause land degradation. Another $60 \%$ (8.9 million $\mathrm{km}^{2}$ ) of the global area with more than $50 \%$ of cropland is under potential threat of land degradation (UNCCD, 2017). The Global Land Outlook also shows that Africa, and in particular Sub-Saharan Africa, has a large share of this area suffering from land degradation. It has often been reported that land degradation and poverty are closely related (Gerber et al., 2014) and findings by the World Bank on SubSaharan Africa also demonstrated a positive correlation between poverty and deterioration of the local environment (Dasgupta, 1995). Many studies suggest that most of the degradation occurring across the croplands in Sub-Saharan Africa can be attributed to climate variability (Thornton et al., 2010), inefficient utilization of land resources (Grogan et al., 2013), deforestation (Butz, 2013), and inadequate management of soil nutrients (Turmel et al., 2015).

In Sub-Saharan Africa, one region that is particularly known for land degradation problems is the humid highlands of East Africa (Diwani et al., 2013). These Highlands are defined as areas above 1,200 meters above sea level. They occupy only a quarter of the collective area of Burundi, Ethiopia, Kenya, Rwanda, Tanzania, and Uganda, but are home to more than $50 \%$ of their combined population (IFPRI, 2001). People prefer these highlands because of adequate water, reliable precipitation, good soils, rich vegetation cover (Kassie et al., 2010) and minimal occurrence of diseases such as malaria (Himeidan and Kweka, 2012). However, this preference and related population growth has gradually contributed to land degradation caused by water erosion, as has been witnessed in Kenya (Saiz et al., 2016), Rwanda (Karamage et al., 2016), Burundi (Chirwa and Mahamane, 2017) and Uganda (Semalulu et al., 2015).

An area with a long history of land degradation caused by water erosion is Lushoto district, which covers roughly $70 \%$ of the West Usambara Highlands in the northeastern part of Tanzania. Past studies assessing soil erosion amounts in Lushoto district have all reported soil losses in the range of high to severe. The majority of these assessments reported soil losses in excess of 25 tons ha ${ }^{-1} \mathrm{yr}^{-1}$ (Buch, 1983; Pfeiffer, 1990; Tenge et al., 2011), which is high according to soil loss tolerance ratings (Stone and Hilborn, 2000). For some parts in Lushoto district considerably higher soil losses (>100 tons $\mathrm{ha}^{-1} \mathrm{yr}^{-1}$ ) were also reported (Mwango et al., 2016). 


\subsection{Problem description}

Documented reports linked soil erosion problems in Lushoto district to the introduction of cash crops (coffee, tea, temperate fruits and horticulture) in the early 1900s to mid 1900s (Johansson, 2001). This change in land use, while lifting the socio-economic well-being of the district, created a negative side effect of accelerating soil erosion. The situation became even more precarious when smallholder farmers also joined in the commercial cash cropping thus making soil erosion a serious problem in the district (Johansson, 2001).

The colonial authorities of that era made considerable efforts in tackling soil erosion in Lushoto district. Among its earliest efforts was the introduction of the Mlalo Basin Rehabilitation scheme in the 1930s (Mascarenhas, 2000). It is interesting to note that this scheme is reported as having failed because the local people and their leaders perceived it as a veiled attempt of resettling them on the lowlands and stealing their cattle through compulsory destocking programmes (Mascarenhas, 2000). But, the technical officers who actually implemented the scheme found its methodologies to be effective and bearing good results as they were based on research and surveys. The technical officers blamed its failure on frequent indecisions by their administrative managers (Watson, 1972).

A more recent attempt was the Soil Erosion Control and Afforestation Project (SECAP) between 1980-1999 (Shelukindo, 1995; Johansson, 2001). SECAP is a widely accredited project for its terracing efforts, large scale tree planting, introduction of dairy cows and many rural development initiatives (Quail et al., 2016). Around the same time, the Traditional Irrigation Improvement Programme (TIP) used irrigation water as an incentive towards advocating soil conservation (Shelukindo, 1995). The TIP project resulted in the construction of bench terraces in locations with irrigation water available. Other past programmes or projects which addressed soil erosion and land degradation problems include the Lushoto Integrated Development Programme (LIDEP), and the Tanga Integrated Rural Development Programme (TIRDEP) (Scheinman, 1986). But despite some limited successes, the efforts of these projects have not been able to stimulate large scale adoption of soil conservation structures across Lushoto district (Tenge et al., 2004). Hence, there is still a need for interventions that sustain the productive capacity of the land.

Sustainable Land Management (SLM) is an approach that combines technologies, policies and activities that bring together socio-economic principles with environmental issues that enhance production but at the same time reduce degradation to the environment and natural resources (Symth and Dumanski, 1993). Later, the SLM concept was also described as "a system of technologies and/or planning that aims to integrate ecological with socioeconomic and political principles in the management of land for agricultural and other 
purposes to achieve intra- and intergenerational equity" (Hurni, 1997). Recently, Dumanski and Peiretti (2013) described the SLM approach as encompassing other established approaches such as soil and water conservation (SWC), conservation agriculture, natural resources management, and integrated ecosystem management. In this $\mathrm{PhD}$ dissertation, SLM measures are considered those technologies which farmers implement in their fields as a package to improve farming conditions. Such package not only includes SWC measures, but also soil and nutrient management options to improve cropping conditions. Though considerable efforts had been made in advocating land management technologies in the West Usambara highlands, these technologies were usually not advocated as a package. Whether promoted as a package or as individual measures, there is no clear explanation as to why the adoption of the propagated SLM-like technologies is still low across Lushoto district.

A number of studies have indicated that farmers' choices of SLM measures are essentially a socio-economic decision (Nyanga et al., 2016; Tenge et al., 2007). Yet, for technologies that improve SLM, the difficulty in adopting them has also been reported to be rooted in their location-specificity such that one cannot generalize. For instance, Lee (2005) attributed the difficulty in adopting SLM-based technologies to their location-specificity such that each specific location may require its own array of SLM technologies, which not necessarily would work at other locations. A study by Harrington et al. (2002) proposed that adoption of SLMtechnologies is enhanced (i) with less risky and attractive practices, (ii) when research delivers what a community wants, (iii) when research provides feedback, (iv) when information is shared, (v) stakeholders are consulted, (vi) policy makers are engaged, and (vii) there is strong use of ICT tools like GIS and modeling.

One issue that generally has not been addressed extensively in the SLM adoption discussion is how the local biophysical factors impact on the effectiveness of different SLM types (Lefroy et al., 2000). For instance, in the West Usambara Highlands, it is generally recommended to adopt certain soil conservation measures depending on the slope steepness (Mshana, 2009). This recommendation assumes that slope steepness is the principal determinant of the effectiveness of the soil conservation measures, but adoption of soil conservation measures in the district has remained low irrespective of the desirable slopes (Lyamchai et al., 1998). Experience from other areas has shown that other biophysical conditions like soil type, field size, cropping system, agro-meteorology, etc. also play an important role in the adoption of SLM measures (Wolka, 2014).

If in areas like the West Usambara Highlands, relationships between biophysical conditions and SLM effectiveness exist, this could explain, at least partly, why adoption of selected SLM options is not always logical to a farmer. In the US, farm size, quality of soil resources, 
influence exerted by urban communities and location of the fields were found to considerably influence adoption of farm technologies (Isgin et al., 2008). Earlier, in the US too, it was observed that a close relationship existed between soil fertility, land quality, rainfall and other biophysical factors to the adoption and diffusion patterns of SLM technologies (Aldy et al., 1998). In Central America it was also reported that biophysical factors featured prominently in the adoption of Integrated Pest Management, agroforestry, and soil conservation technologies by farmers (Ramirez and Shultz, 2000). In Ethiopia, Ketema and Bauer (2012) reported that slopes and farm sizes were important factors considered by farmers before constructing soil conservation measures such as terraces in their fields. It seems therefore logical to relate biophysical conditions of a location to the adoption of SLM measures. For the West Usambara Highlands information on the effectiveness of SLM measures under varying biophysical conditions is lacking.

Another important area which has not received much attention in the West Usambara Highlands is the potential role of the agro-ecosystems practiced by smallholder farmers towards mitigating soil degradation. Though agro-ecosystems in neighbouring areas have been characterized and their role in mitigating soil erosion is adequately understood (Enfors and Gordon, 2007), for the West Usambara Highlands it is only the carbon sequestration role of the agro-ecosystems which has received recent attention (Winowiecki et al., 2016). Potential impact of these agro-ecosystems on soil erosion mitigation is largely unknown which undermines potential utilization of these systems for soil erosion control purposes. Therefore if the current agro-ecosystems in the West Usambara Highlands could be characterized such that their major components like crops, soil properties, erosion features, and extent of soil erosion are known, then such knowledge could be used as an additional tool in fighting the soil erosion problems in the area. Indeed, experience from India indicates that profitability of agro-ecosystems depended on factors like the natural fertility of soils, topography, climate and the length of the growing period (Shiferaw et al., 2009), which is currently the type of information that is lacking for Lushoto district.

\subsection{Objectives}

The aim of this study was to contribute towards a better understanding of the relation between biophysical conditions, adoption and effectiveness of SLM technologies in smallholder farming systems in Lushoto district of the West Usambara Highlands. The study also evaluated how the effectiveness and performance of such SLM measures motivated farmers to adopt, scale up or reject them. It was attempted to contribute knowledge towards a better understanding of how biophysical conditions impact both the adoption and effectiveness of SLM measures. The specific objectives defined for the study are: 
1. Locate existing SWC measures and determine their effectiveness in reducing soil erosion at the landscape scale;

2. Evaluate effectiveness of different agro-ecosystems in reducing soil erosion in Lushoto district;

3. Assess perceptions of farmers and agricultural development staff on land degradation problems and potential SLM impacts;

4. Determine the impacts of adopted SLM packages on soil conservation and crop yields.

\subsection{Study area}

Lushoto district is located within latitudes $04^{\circ} 22^{\prime}$ to $05^{\circ} 08^{\prime}$ and longitudes $38^{\circ} 05^{\prime}$ to $38^{\circ}$ $38^{\prime}$ and covers $3500 \mathrm{~km}^{2}$ of which $2200 \mathrm{~km}^{2}$ are arable (Mowo et al., 2002). Its present population is estimated at 470,000 thus giving the district a population density of 134 people per $\mathrm{km}^{2}$. The soils of Lushoto are deep $(>1 \mathrm{~m})$ and well drained with a stable structure. The major soil types in the district are Acrisols, Luvisols and Lixisols on the mountainous uplands while the valley bottoms are dominated with Fluvisols and some pockets of Gleysols (Meliyo et al., 2001). Soils of the district are derived from metamorphic rocks like schist, gneisses, and other forms of granulites (Geological Survey of Tanganyika, 1963).

Temperatures in Lushoto district can range from $0^{\circ} \mathrm{C}$ at night to a maximum exceeding $25^{\circ}$ $C$ during the day. Annual rainfall in Lushoto district varies roughly from 800 to $1300 \mathrm{~mm}$. There is a gradient of rainfall decrease from east to west and from south to north of the mountains. There are two major rainfall seasons, the long rains ("masika") which start around mid-March and last to the end of June, and the short rains ("vuli") which start in October and last till the end of December. The short rains account for $25 \%$ of the total rainfall being received on these highlands and are less reliable than the long rains, but they are the most important for growing annual crops like maize and beans. These crops require temperatures higher than $20^{\circ} \mathrm{C}$ that actually occur during the period of October to March (Mascarenhas, 2000). The district grows tea, coffee, maize, banana, beans, sugarcane, and a number of temperate fruits. Lushoto is dominated by smallholder, low input subsistence farmers. Landholdings for most households are below one hectare. 


\subsection{Thesis outline}

This thesis has six chapters, including this introductory chapter. The second chapter deals with effectiveness of SWC measures being used to combat soil erosion at the landscape scale. Remote sensing and water erosion modeling were applied to locate SWC measures and to estimate their effectiveness in reducing soil erosion. The chapter was published in the soil science journal Geoderma. Chapter three deals with soil erosion problems in major agro-ecosystems in Lushoto district. Through field surveys for data collection and water erosion modeling the existing agro-ecosystems are described and the related erosion levels were estimated for each of the agro-ecosystems. The chapter was published in the journal Land Degradation and Development. The fourth chapter addresses the land degradation and especially soil erosion issue in Lushoto district. It evaluates the perceptions of land degradation by different stakeholders such as the policy level officials, the agricultural development workers and local farmers. In this chapter the SLM packages used by farmers are described and the reasons for adoption or non-adoption have been evaluated. Results of this work were presented as a scientific conference paper during the $2^{\text {nd }}$ Annual General Assembly for the Inter-regional body called the Association for Strengthening Research in East and Central Africa (ASARECA) in Bujumbura, Burundi, in May 2013. The chapter was submitted for publication in the journal Land Use Policy. The fifth chapter deals with the effectiveness of the major SLM categories to control soil erosion and enhance crop yields at field level. Many bio-physical characteristics were measured in 60 fields covering four SLM categories to unravel the influence of bio-physical factors on the effectiveness of SLM measures on erosion control and crop productivity. This chapter was published in the journal Catena. The sixth chapter provides a synthesis of all results from this study. 


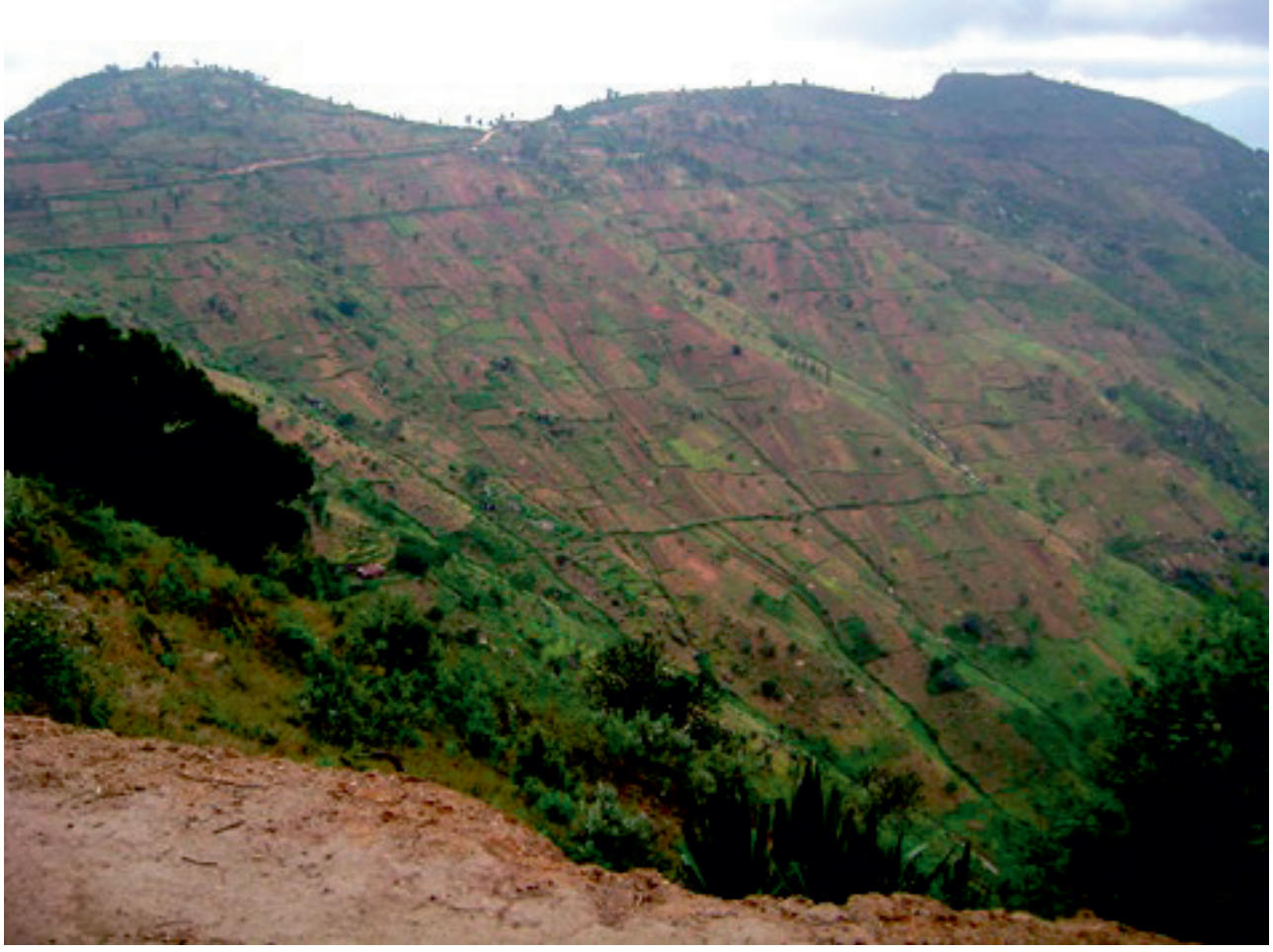




\section{Effectiveness of soil conservation measures at a landscape scale in the West Usambara highlands, Tanzania}

The adoption of soil and water conservation (SWC) technologies among small holder farmers in the East African highlands is an area which poses many challenges. When adoption occurs across a vast landscape, the locations and effectiveness of the adopted measures are often not adequately known. For this reason, the majority of SWC studies in the highlands of East Africa employed field surveys and experiments to locate and estimate effectiveness of the installed technologies. This approach however has certain limitations when applied at a landscape scale. Potentially, remote sensing techniques could be used for the purpose of locating soil conservation structures, while modeling can help in estimating the effectiveness of the implemented measures. This study therefore employed remote sensing and GIS techniques to 1) to locate SWC structures in two $100 \mathrm{~km} 2$ areas in the West Usambara highlands of Tanzania, and 2) to determine the effectiveness of the implemented measures in reducing soil erosion at a landscape scale. The study was conducted in the west Usambara highlands of north-eastern Tanzania as a paired plot design in which two blocks of $100 \mathrm{~km}^{2}$ each were studied using pixel (Maximum Likelihood Classification) and object-based image analysis (OBIA) remote sensing techniques to detect land use patterns and adoption of soil conservation technologies. Soil losses were modeled using the Universal Soil Loss Equation (USLE)-model while effectiveness of the measures was estimated from calculations. Results indicate that there are large differences in the adoption of soil conservation technologies between the two blocks. The study also finds the Maximum Likelihood Classifier to be reliable in generating land use thematic layer maps from which soil conservation measures can be studied with ease in mountainous areas. The OBIA-technique was found to be effective in identifying, classifying and mapping of the adopted SWC technologies. Effectiveness of the installed technologies remained comparable across the blocks but with higher indices for Sunga area. The study concludes that adoption of the SWC technologies in the two blocks is largely influenced by biophysical conditions within and between the two blocks and is not related to the quality of the technologies being implemented in either block

Based on:

J. Wickama, R. Masselink , G. Sterk. 2015. The effectiveness of soil conservation measures at a landscape scale in the West Usambara highlands, Tanzania, Geoderma, 241-242, 168179. 


\subsection{Introduction}

A global land degradation study found Africa south of the Equator to be among the most degraded areas (Bai et al., 2008). The major symptoms for this degradation included high rates of soil erosion, nutrient depletion, salinity, water scarcity, pollution, disruption of biological cycles, and loss of biodiversity. Another study reported that soil erosion in this region is particularly intense in mountainous areas where agriculture is undertaken without adequate soil protection (Tilahun et al., 2013). Earlier, soil erosion was reported to be a stumbling block towards sustained food security and improved livelihoods in the same region (Scherr, 1999).

Soil erosion is a major problem on cropland where repeated tillage exposes the soil. Though in the 1950s the U.S. Department of Agriculture (USDA) proposed soil-loss tolerance values (T values) of 5-12 tons ha-1 $\mathrm{yr}^{-1}$ as being "acceptable" (Bai et al., 2008) for agricultural lands, in most African regions the losses are already above that limit. In countries like Ethiopia for example, soil loss on the highlands is at an average of 42 tons ha-1 $\mathrm{yr}^{-1}$ (Hurni, 1993) which is considerably high. Higher rates of soil erosion have also been reported from other countries like Turkey (Gitas et al., 2009), China (Zhao et al., 2012) and India (Shrimali et al., 2001). In Tanzania higher soil losses in the similar range and above have been reported for mountainous areas like the West Usambara highlands (Buch, 1983).

The control of soil erosion is also a global challenge. Globally, soil erosion has been reduced through ridges, contour tillage, crop rotations, terraces, no-till technologies, mulching, agro-forestry, grass strips, cover crops and many other approaches. However, effectiveness of each technology in reducing soil losses in croplands varies and needs to be adequately understood. In the U.S., effectiveness of the different technologies used to reduce soil erosion was found to vary depending on the crop and the methods used in preparing croplands. But, a range of 57-99\% effectiveness for the different soil conservation technologies was observed in maize fields (Pimentel et al., 1995). In Tanzania, an effectiveness of $86 \%$ was reported for bench terraces on the humid highlands of West Usambara in Tanzania (Tenge et al., 2011).

Despite the reported effectiveness of physical structures like bench terraces, for smallholder farmers their acceptance for this technology has remained unsatisfactory. The high labor involved in installing physical structures like terraces (Tenge et al., 2011), inadequate improvement of soil fertility levels due to frequent depositions of infertile subsoils on terrace floors from collapsing terrace risers (Wickama et al., 2014) plus the high maintenance costs of such structures (Pacheco et al., 2014) has been a major hindrance in their wide spread adoption. 
In places where adoption of the physical structures for soil conservation has taken place, their uptake has remained sporadic and their spread has often been unclear. Consequently, the extent to which the soil and water conservation (SWC) technologies have been adopted is often not well understood. In many areas such estimations are dependent on actual field inspections which take considerable time and resources to organize and accomplish. In addition, field inspections are usually conducted only at plot, field, or hill slope scale. When soil erosion or intervention measures are quantified at larger scales, like the scale of a small catchment (10-1000 ha) or the scale of an entire landscape (> $1000 \mathrm{ha})$, use is often made of models in combination with spatial data sources stored in a geographical information systems (GIS). The Universal Soil Loss Equation (USLE)-model has been extensively used to assess soil erosion risks in many regions (Životić et al., 201 The USLE was originally developed to study soil erosion at a plot level. But in this study, it was used at a landscape scale because of its ease of use in a GIS, and its capability to assess the effectiveness of the adopted SWC measures.

Most of the spatial data used in erosion modeling, like topography and vegetation cover, comes from remote sensing (RS) imagery. In the past, low spatial resolution of the images made it difficult to use them effectively for erosion modeling or to assess patterns of adopting SWC measures (Meneguzzo et al., 2012). But, with the increase in spatial resolution of the RS imagery over the last decade, better data becomes available that creates new possibilities for erosion quantification at the landscape scale (Vrieling et al., 2011).

Experience shows that the use of high resolution RS imagery in combination with the objectbased image analysis (OBIA) techniques potentially allows us to identify different fine objects and their locations (Polychronaki and Gitas, 2012). Compared to traditional pixelbased analysis where each pixel covers one area at a time, OBIA analyzes objects at multiple scales of segmentation or scale levels using shape or color parameters which is a positive development for remote sensing analysis at a landscape scale (Urbanski, 2009). The segments in OBIA have additional spectral and spatial information on objects compared to pixel-based approaches which makes this technique useful (Blaschke, 2010). Further, in OBIA objects can be classified using their spatial relationships with adjacent or nearby objects (Gao and Mas, 2008). For terraced fields like in our study area this was an important advantage since terraces or other SWC structures often occur in the vicinity of other features. The use of error matrices in OBIA facilitates better mapping accuracies than in conventional pixel based analysis (de Pinho et al., 2012) and therefore the technique was used in this study. 
Though OBIA requires expensive software, substantial processing power and large amounts of available memory (Hay and Castilla, 2008) the potential of its use for the assessment of adoption patterns of soil conservation measures in places like the West Usambara highlands outweighed its limitations. Because, once the locations of the implemented measures are known, and other datasets are available erosion modeling could be applied to evaluate the effectiveness of the adopted soil conservation measures. For the West Usambara highlands though, despite many decades of fighting soil erosion and instituting many forms of interventions (Mascarenhas, 2000) this potential has not been exploited adequately. Consequently the extent to which the interventions have spread or been effective remains unclear. Hence, this study combined high resolution RS imagery techniques and soil erosion modeling with the following objectives: 1 ) to locate the implemented soil conservation technologies in two landscapes of $100 \mathrm{~km} 2$ each in the West Usambara highlands, and 2) to determine the effectiveness of the implemented soil conservation technologies in reducing soil erosion at the landscape scale.

\subsection{Materials and methods}

\subsubsection{Study area}

The study was conducted in the West Usambara highlands, northeastern Tanzania, in Lushoto district. Its topography is mountainous and highly dissected, with elevations ranging between 600 and $2300 \mathrm{~m}$ above sea level. The area of the district is approximately $3500 \mathrm{~km} 2$ (Mowo et al., 2002). Its current population density is estimated at 134 people per $\mathrm{km} 2$ (Daldo-Lushoto, 2012). Rainfall in the district is bimodal and varies from 800 to 1300 $\mathrm{mm}$ per annum depending on the agro-ecological zone (Mascarenhas, 2000). Soils in Lushoto district are dominated by Acrisols, Luvisols and Lixisols on slopes while the valley bottoms are dominated by Fluvisols with some pockets of Gleysols (Meliyo et al., 2001). Data was collected from two $10 \mathrm{~km} \times 10 \mathrm{~km}$ blocks located around the villages of Soni and Sunga (Figure 2.1). These blocks were selected on the basis of their contrasting agroecological conditions and adoption of sustainable land management measures (Wickama and Nyanga, 2009). Topography of the two blocks is representative of the mountainous and dissected terrain of the West Usambara highlands. The Sunga block is $54 \mathrm{~km}$ northwest of Lushoto town. The Soni block is $14 \mathrm{~km}$ east of Lushoto town. In comparison, the Soni block is more dissected with numerous steeper land units than the Sunga block (Geological Survey of Tanganyika, 1963).

Average annual temperature in Sunga ranges from 18 to $20^{\circ} \mathrm{C}$ while in Soni it is from 20 to $22{ }^{\circ} \mathrm{C}$. Both blocks have two major rainy seasons, the long rains ("masika") which start 
around mid-March and last to the end of June, and the short rains ("vuli") which start in October and last till the end of December. Both blocks are reported to receive 800-900 $\mathrm{mm} /$ year of precipitation (De Pauw, 1984). In both blocks smallholder agriculture is dominated by low input subsistence mode of production. Almost no fertilizers are applied to food crops on the hill lands. The main crops grown in both blocks are maize and beans. In Sunga though, potatoes, sugarcane, temperate fruits like pears and plums, and timber are also of commercial importance. Additionally, banana, coffee, tea, mango, and jack fruits are also well established. Incorporation of trees in the different forms of agro-forestry is practiced in both blocks. Also, a variety of SWC measures is in place in the two blocks. The Soni block has mainly bench terraces, grass strips and "fanya juu" terraces. In the Sunga block the amount of fanya juu terraces is negligible. The type of SWC is dependent on the steepness of the slope, for which general directions were given by the District Agricultural offices (Shelukindo, 1995). The valley bottoms occupy only $10 \%$ or less of the landscape but are an important source of revenue through horticultural produce. In the Soni block vegetable production is more commercialized and consequently valley bottom plots are often intensively cultivated, using manure, and sometimes even fertilizers.

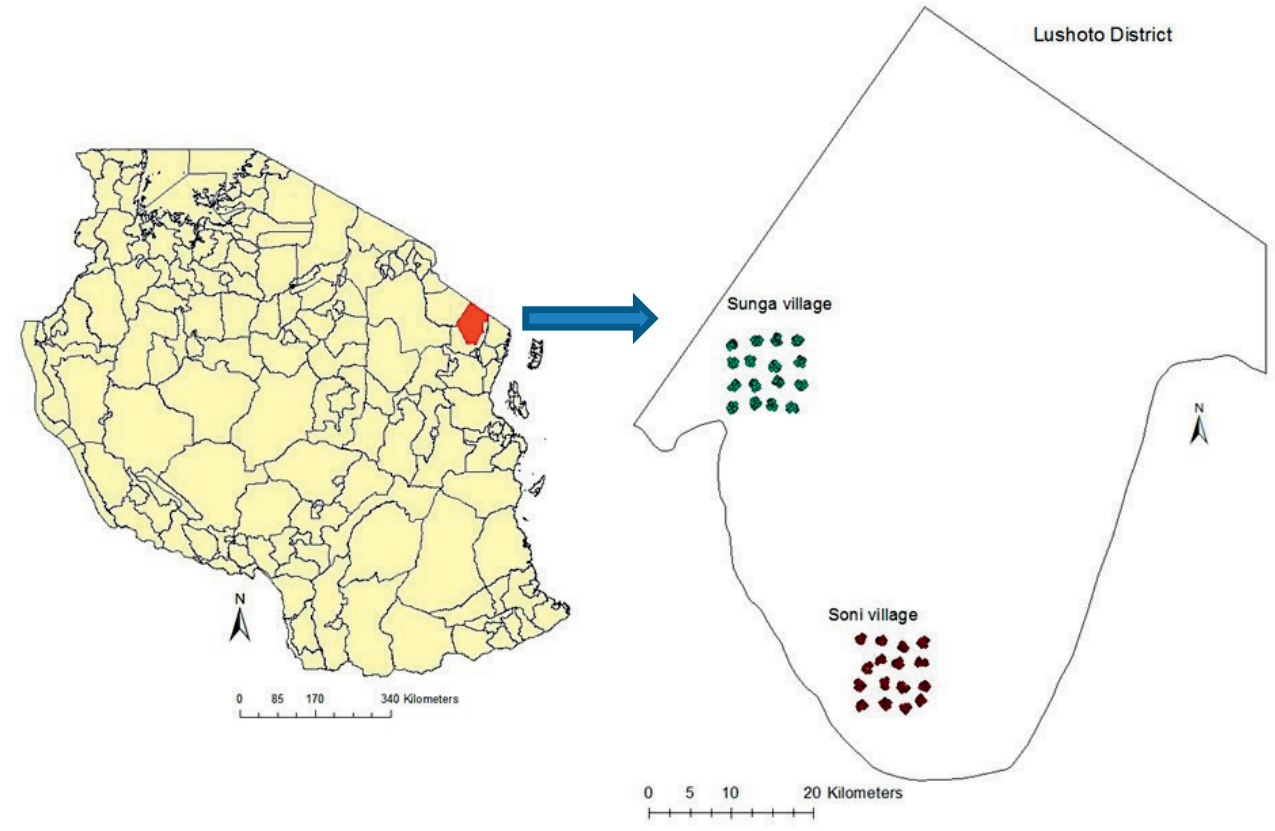

Figure 2.1 Location of the West Usambara highlands, study sites and Lusotho district, Tanzania. 


\subsubsection{Land use classification}

The spatial, spectral and temporal properties of the remote sensing images used in this study are in Table 2.1. The DEM was created from the ASTER satellite image of year 2005 with the resolution of $\mathbf{3 0}$ meters. Land use classification was done from two WorldView-2 (WV-2) satellite images of January 2010. Each image covered a $10 \times 10 \mathrm{~km}$ block. The two images came from Digital Globe, Longmont, CO, USA. These images had one panchromatic band with a resolution of $0.46 \mathrm{~m}$ at Nadir, and four VNIR bands (red, green, blue and NIR) with a resolution of $1.64 \mathrm{~m}$ at Nadir (Table 2.1). The images were pan-sharpened using the Gramm-Schmidt algorithm in ENVI (ITT, Boulder, CO, USA). This means that the information of the panchromatic band was combined with the RGB bands to obtain a higher resolution RGB image.

Table 2.1 Sensor and image characteristics of the satellite images used.

\begin{tabular}{|c|c|c|c|c|c|}
\hline Sensor & $\begin{array}{l}\text { Spatial } \\
\text { Resolution }\end{array}$ & $\begin{array}{l}\text { No. of spectral } \\
\text { bands }\end{array}$ & $\begin{array}{l}\text { Spectral } \\
\text { domain }\end{array}$ & Image date & Remarks \\
\hline ASTER & $30 \mathrm{~m}$ & 6 & VNIR, SWIR & 2005 & Used for input to create DEM \\
\hline WorldView-2 & $\begin{array}{l}0.46 \mathrm{~m} \text { (pan) } \\
1.64 \mathrm{~m}\end{array}$ & $\begin{array}{l}1 \\
4\end{array}$ & $\begin{array}{l}\text { VNIR } \\
\text { VNIR }\end{array}$ & 30th Jan 2010 & $\begin{array}{l}\text { Used for land use classification } \\
\text { and NDVI analyses }\end{array}$ \\
\hline
\end{tabular}

Land use classification was done through the maximum likelihood classifier approach (Lillesand et al., 2004), using a supervised classification technique. To undertake land use classification, training areas with known land uses were selected as reference areas for validating the classification accuracy. A total of 250 points in the Soni block were selected for this purpose. All the training areas contained more than 1000 pixels, which was in excess of the recommended $10 \mathrm{n}$ or $100 \mathrm{n}$ pixel approach ( $\mathrm{n}$ being the number of spectral bands) for a supervised classification (Lillesand et al., 2004). Training sites were not used for the Sunga block because of overall similarity between the blocks, and for logistics.

To improve on land use classification accuracy, selected land use subclasses were combined into the main land use classes for a better comparison. For example roads (light and dark colored) and houses (blue and red roofs) were all classified as built up areas, while different shades (light and dark) of bare fields were all classified as bare fields. Forests, bedrocks and agricultural fields had no subclasses. Land use maps were used as thematic layers and used in the procedure for locating the SWC measures in the OBIA. To assess accuracy of the classification, 100 sites were established in each block. Fifty sites had SWC measures and another 50 did not have SWC measures. These 200 points were used to verify accuracy of the classification by error matrices (Lillesand et al., 2004). 


\subsubsection{Locating SWC measures}

To locate the SWC measures in the two blocks, OBIA was used, which is a relatively new and revolutionary approach for the analysis of satellite or aerial imagery. With this technique objects are created from pixels, which are generated by one or more criteria of heterogeneity in one or more dimensions (Bielders et al., 2003). For image segmentation (creating objects) and classification, the software package eCognition (version 8.64, Trimble, München, Germany) was used. The segmentation algorithm in eCognition uses a bottom-up region-merging technique starting with one-pixel objects. In numerous subsequent steps smaller image objects are merged into bigger ones. In each step, the pair of adjacent image objects that would result in the smallest growth of the defined heterogeneity is merged. If the smallest growth exceeds the threshold defined by the scale parameter, the process stops (Benz et al., 2004). The scale parameter is user defined, and influences the size of the objects directly. The user can adapt it according to his/her needs depending on the application and the needs, where a larger value for the scale parameter means that larger objects will be created. Next to the scale parameter the user assigns weights of importance to shape and spectral characteristics for the segmentation process. The shape weight can be further subdivided into compactness and smoothness. The main advantage of this object-based method over pixel-based methods is that next to spectral information also shape information can be included. For a more detailed description of the image segmentation process, its algorithms and its (dis)advantages over pixel-based image analysis techniques refer to (Blaschke, 2010).

In the segmentation and the classification process, bedrock and built-up areas were masked out using the pixel based land use classification, as these areas do not contain SWC measures. The shape weight in the segmentation stage was given a higher value than that of the spectral characteristics, in order to accurately identify and classify bench terraces. The best ratio between these two was visually observed. In view of shape and spectral characteristics of the SWC measures in our two blocks, only grass strips and bench terraces were classified because other measures could not be detected. Since bench terraces and grass strips are generally elongated features, the compaction parameter was set to 0 , allowing elongated objects to be formed. Scale levels were evaluated visually to determine at which scale level individual fields were distinguishable.

For classifying the SWC measures, even smaller scale levels were used. To aid in choosing the correct scale parameters, samples of bench terraces and grass strips were manually measured across 29 different sites to establish size characteristics, which were compared to sizes of the objects created in the segmentation. Fields with grass strips and bench terraces were inspected first visually and then they were located on the satellite imagery. 
To improve on their classification, shadows formed from grass strips/terraces were treated as elevation drops because, those were clearly visible on the image and had a large difference in reflection with the surrounding field. These "elevation drops" were classified using differences in their spectral characteristics and those of their neighboring objects. The mean difference in their spectral response to those of neighboring objects in band 1 (blue) was calculated and the threshold value for the classification of the elevation drops was visually selected. Once the elevation drops of the SWC measures were classified the fields in which they are positioned were then classified as having "SWC measures", provided that the total surface of the elevation drops within one field made up more than a certain user defined threshold.

\subsubsection{Effectiveness of SWC measures}

To model soil loss, the Universal Soil Loss Equation-USLE (Wischmeier and Smith, 1978), which is the most extensively used soil erosion prediction model, was applied to estimate soil erosion rates in the two blocks. Despite its development being intended for plots of 22.1 m length (Wischmeier and Smith, 1978), the USLE has extensively been used at field level in the Eastern Africa region for erosion modeling (Mati et al., 2000). It therefore was considered suitable for assessing erosion quantities and determining effectiveness of the implemented SWC measures in our area. Data on rainfall and soil erodibility were collected in the field, while topographical factors, vegetation covers, and distribution of SWC measures were derived from the RS imagery. These data were needed as input for the model and were incorporated in a GIS environment using a $30 \mathrm{~m}$ grid cell size resolution.

The USLE is defined as (Wischmeier and Smith, 1978):

$A=R * K * C * L S * P$

where $A$ is the annual soil loss (ton ha-1), $R$ is the rainfall and runoff factor $\left(\mathrm{MJ} \mathrm{mm} \mathrm{ha} \mathrm{m}^{-1} \mathrm{~h}^{-1}\right.$ ), $\mathrm{K}$ is the soil erodibility factor (ton $\mathrm{ha}^{-1}$ per unit of $\mathrm{R}$ ), $\mathrm{L}$ is slope length factor (-), $\mathrm{S}$ is the slope steepness factor (-), C is the cover and management factor (-), and $\mathrm{P}$ is the support practice factor (-).

Typically, the rainfall and runoff (R-) factor is computed from data covering long time periods (> 20 years) to accommodate apparent cyclical rainfall patterns (Renard and Freimund, 1994). Such long-term rainfall data were not available and hence to determine R-factors for the two blocks, automatic weather stations (Delta Link version 2.6) were installed at the center of each $10 \times 10 \mathrm{~km}$ block. Rainfall data was collected on hourly basis 
for 30 months (from January 2010 to July 2012). Estimation of the R-factor was then based on work previously done in our region (Moore, 1979). The approach uses mean annual precipitation values to obtain the R-factor and has two steps. First, the kinetic energy of the annual rainfall is calculated using:

$Y=11.46 x-2226$

where $\mathrm{Y}$ is the kinetic energy $\left(\mathrm{J} / \mathrm{m}^{2}\right)$ of the rain, and $\mathrm{x}$ is the mean annual rainfall $(\mathrm{mm})$. The $\mathrm{R}$-factor is then calculated using a second equation (Moore, 1979):

$R=0.029 Y-26.0$

The final R-factor was converted into SI units by multiplying Eq. (2.3) by a conversion factor (17.02), as recommended by (Foster et al., 1981).

In the USLE model, the K-factor (ton ha-1 per unit of R) represents soil erodibility, and was estimated using the equation proposed for its determination (Lal and Elliot, 1994):

$K=2.8 * 10^{-7} * M^{1.14}(12-a)+4.3 * 10^{-3}(b-2)+3.3 * 10^{-3}(c-3)$

where $a$ is the \% organic matter content of the soil, $\mathrm{b}$ is the soil structure code 1 (for very fine granular) to 4 (for massive), and $\mathrm{c}$ is the soil profile permeability class 1 (for fast) to 6 (for very slow). $\mathrm{M}$ is the particle size parameter, which is defined as:

$M=(\%$ silt $+\%$ fine sand $) *(100-\%$ clay $)$

K-values from 46 and 42 different random locations in the Soni and Sunga blocks, respectively, were determined after their particle size distributions and organic matter content had been analyzed in a laboratory and their structure and field drainage conditions had been estimated in the field (Lal and Elliot, 1994). Positions of these locations were georeferenced using a GPS unit and then interpolated using inverse distance weighted interpolation to cover the respective blocks. Soil samples were collected before the short rains (Oct-Dec) of year 2010.

The combined slope length and steepness (LS-) factor is the expected ratio of soil loss per unit area from a field slope to that from a 22.1 meter length of uniform $9 \%$ slope under otherwise identical conditions (Wischmeier and Smith, 1978). The LS-factor was determined in two steps. First, the ASTER-DEM was used to generate a slope map for each of the two blocks through ArcGIS 10.1. Second, from these slope maps, LS-factor maps were developed 
by multiplying the combined LS-factor equation (Moore and Wilson, 1992) through the ArcGIS 10.1 Raster Calculator. This equation was preferred owing to its superior performance in steep landscape situations like our two study areas (Moore and Wilson, 1992).

$L S=\left(\frac{A s}{22.13}\right)^{0.4}\left(\frac{\sin \beta}{0.0896}\right)^{1.3}$

where LS is the combined factor for topography and slope, As is the length of the slope $(\mathrm{m})$, and $\beta$ is the slope of the surface $\left({ }^{\circ}\right)$.

The C-factor in the USLE equation reflects the ratio of soil loss from land cropped under specified conditions in comparison to land that has been clean tilled, bare or continuously fallowed. The factor also takes into account related vegetative cover and their management (Wischmeier and Smith, 1978). The C-factor measures the combined effect of all interrelated cover and management variables, and it is the factor that is most readily affected by human activities. Vegetation properties of an area can be determined by various vegetation indices derived from earth observing satellites. The most widely used index is the Normalized Difference Vegetation Index (NDVI) which is defined as (Lillesand et al., 2004):

$N D V I=\frac{N I R-R}{N I R+R}$

where, NIR is the spectral reflectance in the near-infrared band and $R$ is the spectral reflectance in the red band. The NDVI is useful in indicating health and status of plant chlorophyll which indicates plant vegetation cover of an area (Vrieling et al., 2011). The NDVI is used as a measure of how vegetation makes use of the photosynthetic active radiation (PAR) and ranges from -1 to +1 .oTinput NDVI values into the USLE model a number of conversion techniques are used to convert NDVI values into C-factor values. Among the most extensively used models for the conversion of NDVI into C-factor values include the regression equation tested for mountainous and less accessible areas (Suriyaprasit and Shrestha, 2008). This equation was developed by plotting NDVI values against canopy cover data collected in northern Thailand:

$C=0.227 \exp (-7.337 * N D V I)$

In China, this equation was used to overcome limitations associated with determining Cfactor values from linear equations with good results (Jianping, 2013). A later assessment of three equations used for determination of C-factor determination (Degayner, 2013) found this equation to be generating reliable C-factor values for soil erosion modeling. 
Degayner (2013) however recommended customization of its exponents to suit local conditions. In view of our study site being mountainous and suitable for this model we adopted Eq. (2.8) for soil erosion modeling. Further, because of having two rain seasons in our study area, the WorldView-2 satellite images of the two blocks were taken in the period between the two seasons to obtain average NDVI values. The NDVI values were then converted into $\mathrm{C}$-factors values using this equation but with a customized exponent to suit the local conditions in Lushoto district. The adjustment of this exponent was essential in view of the different resolutions of the input images used for erosion modeling. A study conducted in the Alpine region (Meusburger et al., 2010) reported that resolution of the satellite image used for erosion modeling had effect on the resultant vegetative indices (NDVI and C-factors). The TM satellite images used in Thailand (Suriyaprasit and Shrestha, 2008) for the development of Eq. (2.8) had a spatial resolution of $15 \mathrm{~m}$ whereas the WorldView images used in our study had a resolution of $0.46 \mathrm{~m}$. This difference in resolution therefore required adjustment of exponents for Eq. (2.8) as had been recommended by both studies (Degayner, 2013; Meusburger et al., 2010). Among the three exponents tested in this study, the exponent used in Eq. (2.9) was found to generate more realistic C-factor values and hence its adoption:

$C=0.227 \exp (-0.9965 * N D V I)$

The support practice factor $P$ represents effects of practices that help prevent soil loss by reducing the rate of water runoff. P-factor values are calculated as rates of soil loss caused by a specific support practice divided by the soil loss caused by row farming up and down a slope (Mati et al., 2000). Areas with SWC measures were located from the OBIA raster image sheet derived from the WorldView-2 satellite images. For inputting into the USLE model, these OBIA raster images for each of the study block were used to generate P-factor values for presence or absence of conservation measures in each block through the ArcGIS 10.1 raster calculator. Raster image cells without SWC measures were regarded as having a Pvalue of 1 . Those with SWC measures were given a P-factor value of 0.18 , being a compromise between 0.1 and 0.12 for terraces and 0.25 for grass strips (Mati et al., 2000). Finally, the effectiveness of the SWC measures was estimated by using:

$$
\operatorname{Effectiveness}(\%)=100 *\left(\frac{\alpha-\delta}{\alpha}\right)
$$

where $\alpha$ is the current soil loss without conservation measures (tons ha ${ }^{-1} \mathrm{yr}^{-1}$ ), and $\delta$ is soil loss with conservation (tons ha-1 year $^{-1}$ ). The effectiveness was calculated using the raster calculator of ArcGIS 10.1. 


\subsection{Results}

\subsubsection{Land use categories}

The major land use types in the studied blocks are described in Table 2.2. Their delineations are shown in Figure 2.2. Though the two blocks have similar land use systems, substantial differences exist in their proportions of forests, agricultural lands, and bedrocks/escarpments. In both blocks however, agricultural lands and forests account for the largest surface area.
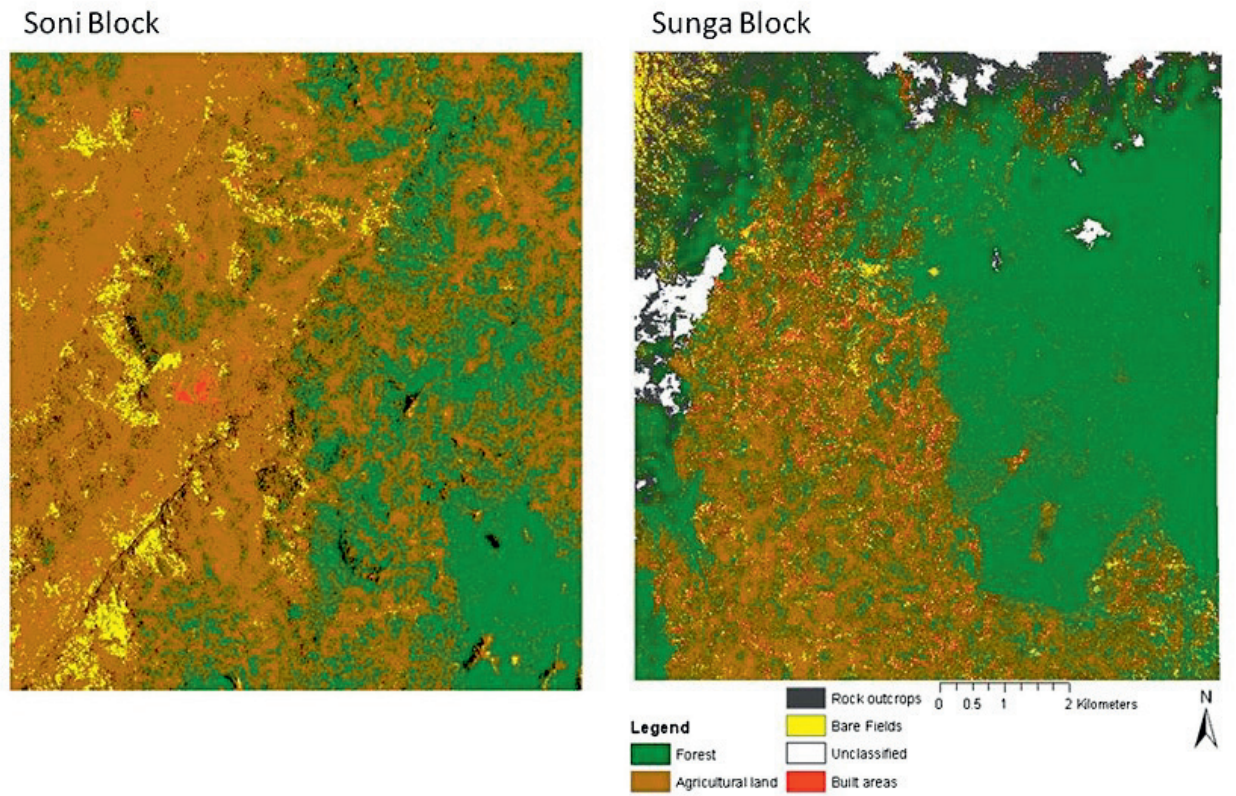

Figure 2.2 Land use maps for the Soni (left) and Sunga (right) blocks, Lushoto district, Tanzania.

Table 2.2 Areas of major land-use categories in Soni and Sunga blocks, Lushoto district, Tanzania.

\begin{tabular}{lll}
\hline Land use category & $\begin{array}{l}\text { Soni block } \\
\mathrm{km}^{2}\end{array}$ & $\begin{array}{l}\text { Sunga block } \\
\mathrm{km}^{2}\end{array}$ \\
\hline Forests & 10.7 & 34.2 \\
Agricultural land & 76.8 & 43.9 \\
Bare Fields & 4.8 & 3.1 \\
Built up areas & 3.1 & 2.4 \\
Rocky outcrop & 2.4 & 11.8 \\
Unclassified & 2.2 & 4.6 \\
Total & 100 & 100 \\
\hline
\end{tabular}


Forested areas were found in both blocks, where in Soni they are a bit dispersed, and in Sunga they are more consolidated (Figure 2.2). Local leaders in Soni block reported of uncontrolled encroachment and illegal logging in the nearby Ndelemai forest, which was actually noticed during the fieldwork for this study. It can be said that the forest in Soni still provides people around it with timber and firewood albeit in illegal terms.

In both blocks terraced fields showed regular shadows of elevation drop. Also terraced fields have bare and cultivated areas side by side (Figure 2.3) and hence relying on spectral signatures without field checks to classify such fields can be misleading. Setting a higher priority for shape and having their physical measurements allows proper distinguishing between soil conservation measures like terraces and grass strips from other different land cover types which is what has also been reported by other studies while using OBIA (de Pinho et al., 2012). The category "bare fields" has to be taken in the context of when the satellite image of the two blocks was taken. The image was taken in January 2010, which for both blocks coincided with clearing of the fields after the short rains (OctoberDecember) or preparing the fields for the long rains (March-June). In either case, many fields would be devoid of crops during that period. In this case many "bare lands" are actually agricultural fields. It is clear that there are more "bare" fields in the Soni area during this period. This was expected since the long rains are important for agriculture in the Soni area (Mascarenhas, 2000). But, on the other hand, the Sunga area attach more importance to the short rains due to better temperatures for field crops around that time (Mascarenhas, 2000). Hence most of its fields are not cleared in January. Much of the unclassified features in the Sunga block are clouds.

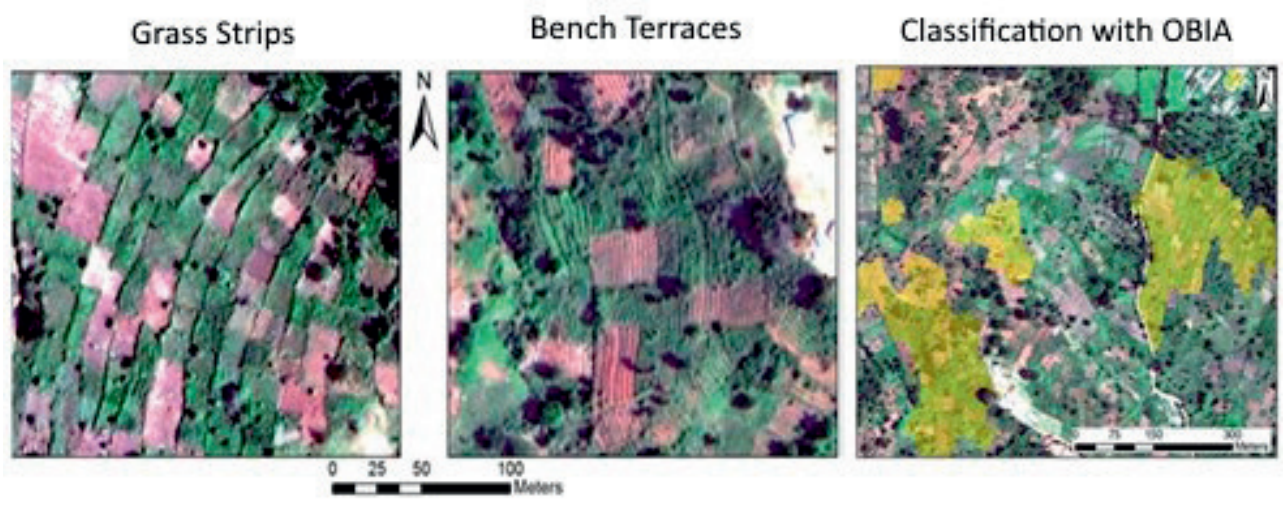

Legend: SWC Classification with OBIA
1. Before
2. After

Figure 2.3 SWC measures classification in Soni block, Lushoto district, Tanzania. 


\subsubsection{Location of SWC measures}

Dimensions of the studied SWC structures in the two blocks are depicted in Table 2.3. Field inspections showed that grass strips were less high, wider and longer than bench terrace fields. The majority of bench terraces were at least 1 meter in height. Both terraces and grass strips could be seen as elongated features with pronounced borders between the features. These borders enabled their identification, marking and classification (Figure 2.3) with considerable accuracy (Table 2.4). Their sizes (Table 2.3) and symmetry (central image-Figure 2.3), helped us separate them from other features.

Table 2.3 Dimensions of SWC measures in Soni and Sunga areas, Lushoto district, Tanzania.

\begin{tabular}{lllllll}
\hline Measure & \multicolumn{2}{c}{ Height $(\mathrm{m})$} & \multicolumn{2}{l}{ Width $(\mathrm{m})$} & \multicolumn{2}{l}{ Length $(\mathrm{m})$} \\
& Min & Max & Min & Max & Min & Max \\
\hline Grass strips & 0.1 & 0.4 & 7 & 20 & 15 & 180 \\
Bench terraces & 0.5 & 1.3 & 1.5 & 4 & 10 & 65 \\
\hline
\end{tabular}

Table 2.4 Mapping accuracy of the SWC measures in Soni and Sunga blocks, Lushoto district, Tanzania.

\begin{tabular}{|c|c|c|c|c|c|c|c|c|}
\hline \multirow[t]{3}{*}{ Classified-Data } & \multicolumn{4}{|c|}{ Soni Block-Reference data } & \multicolumn{4}{|c|}{ Sunga Block-Reference data } \\
\hline & SWC & No & Total & Accuracy (\%) & SWC & No & Totals & Accuracy (\%) \\
\hline & & SWC & s & & & SWC & & \\
\hline SWC & 30 & 20 & 50 & 60 & 34 & 16 & 50 & 68 \\
\hline No SWC & 5 & 45 & 50 & 90 & 6 & 44 & 50 & 88 \\
\hline Totals & 35 & 65 & 100 & 75 & 40 & 60 & 100 & 78 \\
\hline Overall accuracy & & & & 75 & & & & 78 \\
\hline
\end{tabular}

In OBIA, accuracy of mapping and classifying objects depends on the resolution of the DEM (Dronova et al., 2012), since a high resolution DEM gives better results. For identifying SWC structures, a DEM with a horizontal resolution of approximately $5 \mathrm{~m}$ or less would have been ideal. But in our case only a DEM of $30 \mathrm{~m}$ resolution was available, which also compromised accurate mapping of the SWC measures. The final accuracy in OBIA also depends on the level of ground verification. To improve the final accuracy, in this study, ground verification was done through 50 sites with SWC measures and another 50 without SWC measures (Table 2.4). The obtained levels of accuracy (75\% for Soni and $78 \%$ for Sunga) are reasonably high, but higher accuracies have been reported for OBIA-based classifications. For instance for the extraction of coast lines in Poland a final accuracy of $88 \%$ was reported (Urbanski, 2009).

The spatial distribution of soil conservation measures adopted in each block is presented in Figure 2.4. In the Sunga block, a lot more agricultural land has SWC measures compared to the Soni block (Table 2.5). In the Soni block, SWC measures occupy only $2.6 \%$ of the agricultural land. In Sunga it is close to $20 \%$. The higher adoption in the Sunga block can be attributed to the efforts by previous SWC projects in the Sunga area. The adopted SWC 
measures in Sunga are concentrated towards the central and near bottom part of that block. This position corresponds to the locations of Sunga, Masereka, Mambo and Tema villages. These villages were also mentioned as having these measures during a reconnaissance study in that area (Wickama and Nyanga, 2009). The right end side of that block is almost devoid of these measures because of the Natural and Planted forests (Shagayu). In the Soni block the SWC measures are concentrated in the lower end of the block which corresponds to Shashui and Magilla villages. In these two villages, donor funded projects "SECAP" and "TIP" (Shelukindo, 1995) were known to operate. The northern tip of the Soni Block though has few and scattered measures. These measures are more recent and are attributable to another initiative "African Highlands Initiative (AHI)" which operated in the area through the FARM Africa project (Wickama et al., 2006). Overall, adoption of the conservation measures is still low, with $80-97 \%$ of the agricultural land in both blocks being used without any conservation (Table 2.5 ).

Table 2.5 Adoption of SWC technologies in Soni and Sunga blocks, Lushoto district, Tanzania.

\begin{tabular}{lllll}
\hline Block & $\begin{array}{l}\text { Total area } \\
\left(\mathrm{km}^{2}\right)\end{array}$ & $\begin{array}{l}\text { Agricultural Area } \\
\left(\mathrm{km}^{2}\right)\end{array}$ & $\begin{array}{l}\text { Area containing SWC } \\
\text { technologies }\left(\mathrm{km}^{2}\right)\end{array}$ & $\begin{array}{l}\text { Agricultural area } \\
\text { containing SWC (\%) }\end{array}$ \\
\hline Soni & 100 & 81 & 2.09 & 2.58 \\
Sunga & 100 & 47 & 9.29 & 19.7 \\
\hline
\end{tabular}

\section{SWC measures}

Soni Block

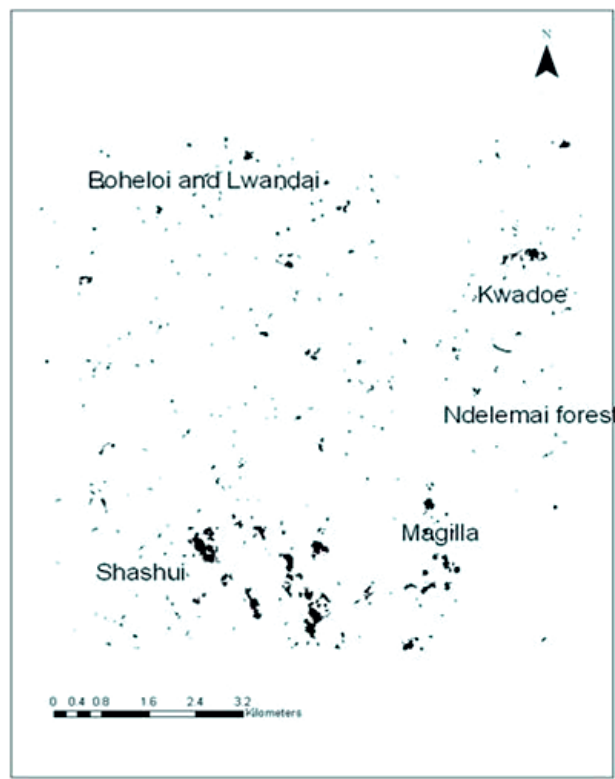

Sunga Block

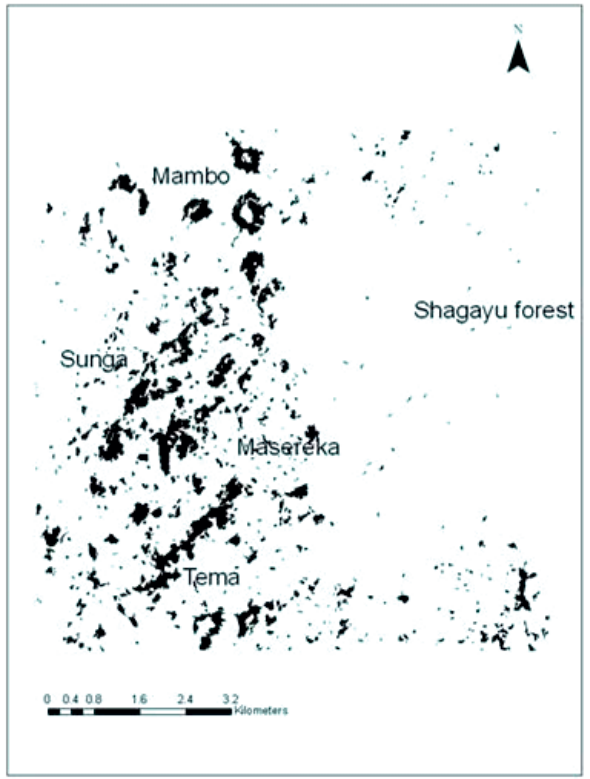

Figure 2.4 Distribution of soil conservation structures in Soni and Sunga blocks, Lushoto district, Tanzania. 
As for the location of the SWC measures, we found from the ArcGIS analysis that the SWC technologies in the Soni area are concentrated on slopes ranging from $12-35^{\circ}$ with an average of $14.9^{\circ}$. For the Sunga area this range is $16-28^{\circ}$ with an average of $21.9^{\circ}$. Detailed instructions for farmers in Lushoto district instructing them where to put SWC measures are available at the District Agricultural Offices (Shelukindo, 1995). This institutional role probably has a contribution to where farmers implement SWC measures.

\subsubsection{Effectiveness of SWC measures}

Climatic data recorded from the automatic weather stations from the two blocks served as input for the USLE R-factor. Across 30 months (January 2010-June 2012), the Soni block (Shashui weather station) recorded an average of $691.4 \mathrm{~mm}$ of precipitation while the Sunga block (Sunga weather station) recorded $704.3 \mathrm{~mm}$. With results from the weather stations, R-factors were calculated using Eqs. (2.2) and (2.3) , and resulted in 139 for Soni and 163 for Sunga. These are equivalent to 2365.8 and $2774.3 \mathrm{MJ} \mathrm{mm} \mathrm{ha} \mathrm{m} \mathrm{hr}^{-1} \mathrm{yr}^{-1}$ for the Soni and Sunga blocks when converted to SI units using the conversion factor of 17.02 (Foster et al., 1981). These R-factor values are similar to those reported from other places with similar climate across East Africa (Moore and Wilson, 1992; Vrieling et al., 2010). In Zimbabwe, R-factor values of $2800 \mathrm{MJ} \mathrm{mm} \mathrm{ha}{ }^{-1} \mathrm{hr}^{-1} \mathrm{yr}^{-1}$ were also reported from areas receiving annual rainfall between 700 and $800 \mathrm{~mm}$ (Mulengera and Payton, 1999).

In both blocks, K-factor values ranged from 0.011 to 0.080 tons $\mathrm{ha}^{-1}$ per unit R. For Soni block, the K-factor values ranged from 0.015 to 0.080 tons ha ${ }^{-1}$ per unit $\mathrm{R}$, while for Sunga it ranged from 0.011 to 0.062 tons $\mathrm{ha}^{-1}$ per unit $\mathrm{R}$. In Soni, K-factor values were generally higher in the eastern part of the block where it is more dissected and vegetated. Higher Kfactor values (0.070-0.080 tons $\mathrm{ha}^{-1}$ per unit $\mathrm{R}$ ) were observed on the slopes surrounding Mount Kwamongo on the south-east part of the block and areas having proximity to the fragmented Ndelemai forest. This eastern side of the Soni block also grows more coffee, tea and fruit trees hence its soils have more vegetation cover which probably allows soils in the area accumulate more organic matter. Lower K-factor values $\left(0.015-0.030\right.$ tons ha ${ }^{-1}$ per unit R) were observed towards the western and northern parts of the block towards the areas of Kwamwenda, Mbuzii and Kisiwani where seasonal cropping of maize and beans predominates. A study from the central Kenyan highlands in Kianjuki area reported K-values between 0.016 and 0.018 tons ha ${ }^{-1}$ per unit R (Angima et al., 2003), which are similar to those observed in our study.

Despite having comparable C-factor averages in both blocks, the Soni Block (0.084-0.613) had a wider range and a slightly lower $\mathrm{C}$-factor average than Sunga (0.115 to 0.483$)$. This 
result was not expected since a significant proportion of the Sunga block is under forest cover. However, in Sunga most of its agricultural land is devoid of meaningful vegetation for the period between the two rain seasons unlike Soni where there is the presence of permanent crops on a considerable portion of agricultural land.

The LS-factors ranged from 1.02 to 3.82 for the Soni block. For the Sunga block the range was $0.72-3.56$. The average for the LS-factor was higher for Soni and is probably related to its steeper and more dissected landforms (Geological Survey of Tanganyika, 1963). Locations which are conserved were derived from the SWC location map (Figure 2.4). Pfactor values in this study therefore reflected the level of adoption of soil conservation measures between the two blocks. A low P-factor value reflects a better SWC-adoption. The P-factors ranged from 1 for non-conserved areas to 0.18 for areas with bench terraces or grass strips. The average USLE factor values used for the two blocks are shown in Table 2.6.

Table 2.6 Mean values of the USLE factors in the Soni and Sunga blocks, Lushoto district, Tanzania.

\begin{tabular}{|c|c|c|c|c|c|}
\hline Block & $\begin{array}{l}\text { R-factor } \\
\text { (MJ mm ha-1 } \mathrm{hr}^{-1} \text { year }^{-1} \text { ) }\end{array}$ & $\begin{array}{l}\text { K-factor } \\
\text { (ton ha-1 } \mathrm{R}^{-1} \text { ) }\end{array}$ & $\begin{array}{c}\text { C-factor } \\
-\end{array}$ & $\begin{array}{l}\text { LS-factor } \\
-\end{array}$ & $\begin{array}{c}\text { P-factor } \\
-\end{array}$ \\
\hline Soni & 2365.8 & 0.03 & 0.19 & 2.23 & 0.99 \\
\hline Sunga & 2774.3 & 0.04 & 0.20 & 2.15 & 0.94 \\
\hline
\end{tabular}

Four scenarios of SWC adoption across the two blocks were modeled. Scenario 1 is zero conservation, meaning that the P-factor was set to a value of 1 for the entire block. Scenario 2 represents the current mixed and dismal adoption of SWC measures in the district. This scenario was captured by adjusting the P-factor values according to where the implemented SWC measures are located. Scenario 3 refers to areas where the current levels of erosion are already severe enough to justify targeted conservation efforts by the district council of Lushoto. This scenario was captured by focusing on areas whose P-factor values were $<1$ but $>0.18$. Scenario 3 represents a pragmatic approach to the SWC problem in the district where the few resources available are directed to areas which need them most. Scenario 4 represents a situation in which all the agricultural land is conserved. In practice, scenario 4 assumed all areas to have P-values b 0.18 . This ambition refers to the current district policy which strives to achieve district-wide conservation (DALDO-Lushoto, 2012).

Results indicate (Table 2.7) that the most eroding situation occurs with scenario 1 where no conservation is undertaken. Soil losses in scenario 1 are at a mean of 32.6 to 45 tons ha ${ }^{-1}$ $\mathrm{yr}^{-1}$ for Soni and Sunga respectively. These losses are already severe and easily reach a maximum of 173.9 and 155.8 tons $\mathrm{ha}^{-1} \mathrm{yr}^{-1}$ in steeper and bare portions in each block. When adoption improves to scenario 2 (the current adoption levels) soil losses are only reduced slightly to the range of 32-42 tons $\mathrm{ha}^{-1} \mathrm{yr}^{-1}$ for the Soni and Sunga blocks. The dismal reduction in soil losses was obviously contributed by the current low levels of adoption for 
the SWC measures (Table 2.5) in both blocks. In scenario 2, the Sunga block had higher soil losses probably because of its higher R-factor values and more erodible soils (Table 2.6). The mean soil losses for both blocks however, were comparable to those reported earlier by other studies in Lushoto district (Pfeiffer, 1990). For both blocks, maximum losses in scenario 2 were 154.5 and 146.2 tons $\mathrm{ha}^{-1} \mathrm{yr}^{-1}$ for Soni and Sunga which represented 11.1 and $6.2 \%$ reductions in soil losses compared to no-conservation (scenario 1 ).

Table 2.7 Soil erosion rates and effectiveness of SWC measures in Soni and Sunga blocks, Lushoto district, Tanzania.

\begin{tabular}{|c|c|c|c|c|c|c|}
\hline \multirow[t]{2}{*}{ Block } & \multicolumn{4}{|c|}{ Soil Loss } & \multicolumn{2}{|c|}{ Effectiveness } \\
\hline & $\begin{array}{c}\text { No SWC } \\
\text { (ton ha-1 } \mathrm{yr}^{-1} \text { ) }\end{array}$ & $\begin{array}{l}\text { Current SWC } \\
\text { (ton } \mathrm{ha}^{-1} \mathrm{yr}^{-1} \text { ) }\end{array}$ & $\begin{array}{l}\text { Erosion prone areas } \\
\text { (ton } \mathrm{ha}^{-1} \mathrm{yr}^{-1} \text { ) }\end{array}$ & $\begin{array}{c}\text { Full SWC } \\
\text { (ton } \mathrm{ha}^{-1} \mathrm{yr}^{-1} \text { ) }\end{array}$ & $\begin{array}{c}\text { Current SWC } \\
\text { (\%) }\end{array}$ & $\begin{array}{c}\text { Full SWC } \\
\text { (\%) }\end{array}$ \\
\hline \multicolumn{7}{|l|}{ Soni } \\
\hline Max. & 173.9 & 154.5 & 146.1 & 22.7 & & \\
\hline Min. & 5.5 & 1.3 & 4.3 & 0.90 & & \\
\hline Mean & 32.6 & 32.1 & 27.3 & 5.0 & 1.3 & 84.6 \\
\hline \multicolumn{7}{|l|}{ Sunga } \\
\hline Max. & 155.8 & 146.2 & 134.9 & 21.8 & & \\
\hline Min. & 6.7 & 1.7 & 3.6 & 0.76 & & \\
\hline Mean & 45.0 & 41.6 & 36.0 & 5.8 & 7.6 & 87.1 \\
\hline
\end{tabular}

In the Soni block, higher losses for scenario 2 were again observed on bare fields around Mbuzii, Nkaloi hamlet and on slopes of Mount Kwamongo (Figure 2.5). In the Sunga block higher soil losses were observed in the hamlets of Kalumele, Sunga and Masereka. Further, in Sunga, all escarpments surrounding that block had high soil losses. Generally, minimal soil losses in scenario 2 were observed in parts of Soni block where soil losses were below 2 tons $\mathrm{ha}^{-1} \mathrm{yr}^{-1}$. Such losses occurred in its central, southern and easterly portions where there is more vegetation cover and the landscape is less dissected. Though the lowest losses for scenario 2 occurred in forested areas, still the modeled minimal soil losses were high for forests (Table 2.7) and were not expected.

Examination of satellite images for the two blocks revealed human activities inside the major forests found in the two blocks. In Sunga, a saw mill is bordering the natural forest and a number of bare "grounds" litter the Shagayu forest (possible encroachment). In Soni block illegal logging was witnessed in the Ndelemai forest and smallholder fields around Magilla village slowly annex part of the forestlands. Human activities can contribute to elevated soil losses in forests (Luce and Black, 2001).

Overall, factors which contribute to reducing soil losses in Sunga block despite its highly erodible soils include its relatively better adoption of the soil conservation measures (Table 
2.5), which contribute to its lower P-value and its relatively less dissected landscape which lowers its LS value (Table 2.6) compared to the Soni block. The four scenarios give the soil conservation measures the current mean effectiveness of 1.3-7.6\% (Table 2.7) for the Soni and Sunga blocks respectively. This was caused by the low adoption of the SWC measures (Table 2.5). Effectively, soil losses for scenario 3 ranged from a maximum of 146.1 and 134.9 tons ha ${ }^{-1} \mathrm{yr}^{-1}$ to a minimum of 4.3 and 3.6 tons ha ${ }^{-1} \mathrm{yr}^{-1}$ for Soni and Sunga blocks. Mean soil losses however remained higher for the Sunga block at 35.9 tons ha-1 $\mathrm{yr}^{-1}$ compared to Soni 27.2 tons ha ${ }^{-1} \mathrm{yr}^{-1}$ though in essence the losses were lower by 16.4 and $13.3 \%$ for both blocks in comparison to no conservation. In practice therefore, the district government can currently focus on all areas which lose more soils than the current average for scenario 3 to achieve this goal. In both blocks, areas with scenario 3 situation are on steeper landscapes and less covered with vegetation because of annual cropping. When adoption of the SWC is full (scenario 4), mean soil losses were significantly reduced to $<6$ tons ha ${ }^{-1} \mathrm{yr}^{-1}$ and the effectiveness of the installed measures rose from 84.6 to $87.1 \%$ for Soni and Sunga which was similar to effectiveness of same measures at a plot level as earlier reported from neighbouring sites in the West Usambara highlands (Tenge et al., 2011).
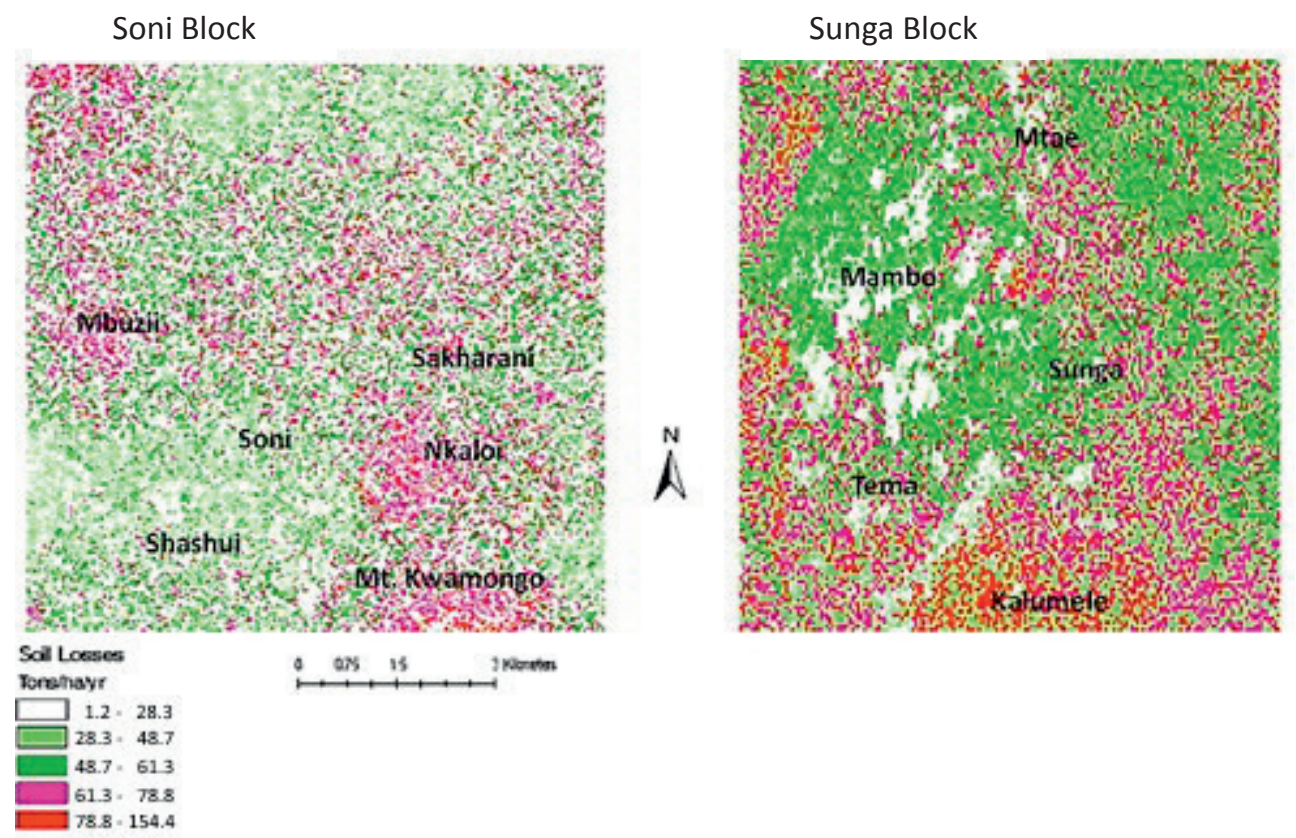

Figure 2.5 Current soil losses in Sunga and Soni blocks, Lushoto district, Tanzania. 


\subsection{Discussion and conclusions}

Results from this work show that the OBIA technique is indeed accurate enough to locate bench terraces and grass strips at a landscape scale. In our situation, despite covering such a large area $\left(100 \mathrm{~km}^{2}\right)$ the final accuracy of $75-78 \%$ (Table 2.4 ) was obtained in the detection of bench terraces and grass strips. This technique is thus reasonably reliable and can be used to assess adoption of SWC technologies in a time saving and cost effective manner. Other regions also reported consistent potential of this approach albeit in a variety of situations. For example, an accuracy of $82 \%$ was achieved in the segmentation and classification accuracy when reference datasets were included in the segmentation processes (Verbeeck et al., 2012). In Poland, OBIA was used to detect changes in the coastline due to sea level changes (Urbanski, 2009). In that study, accurate changes could be detected to the point of about $1 \mathrm{~m}$ per year. In India (Kumaraperumal et al., 2007), OBIA was applied to study the impact of tsunami devastation. Further, our results support other findings which showed that combined use of pixel and object based approaches still give accurate results (Joshi, 2010).

There are however, known limitations in the use of OBIA some of which were encountered in this study. One is that there are no real objects recognized in OBIA, but rather image objects, which can be spectrally confused and its accuracy depends on the quality of segmentation (Blaschke, 2010). Though the segmentation scales used for classifying terraces and grass strips in our study were done on trial and error basis, it is worth to note that there are no established scales for weighting combinations for the task. Since the quality of segmentation depends on the precision of delineation, then differences in delineation may prompt differences which do not necessarily mean the objects being classified are actually different (Urbanski, 2009). Because of these limitations, it was not possible to use OBIA to map SWC measures like agro-forestry, mulching and multi-story traditional cropping systems since these practices could not produce unique shapes, colour, or spectral signatures despite their reported effectiveness in reducing soil erosion (Marais and Wannenburgh, 2008). Since there are no standard sizes for terraces and grass strips, we found the current dimensions of these conservation measures in the two blocks to be large enough for detection by using OBIA. In Georgia (USA), symmetry was used in OBIA to classify other objects with considerable success (Baatz et al., 2008). In the detection of SWC, this principle can still be used.

When assessing differences in soil losses between these two study blocks, it is important to consider biophysical differences between them. An earlier study in the two blocks (Wickama and Nyanga, 2009) reported significant $(P<0.05)$ differences between them in terms of landscape steepness and soil particle size distributions. Further, modelling of erosion in this 
case used the USLE model. There are several precautions which must be considered when modelling erosion with this model and which may have affected our results. In our study, the C-factor was studied only once through the obtained satellite imagery of January 2010. Unavailability of rainfall data for the past years before this study for both blocks encouraged us to minimize time window frame to this period. Given this background, we only used Cfactor values for satellite images (year 2010). The other precaution which must be taken is that the USLE model when used under GIS environment calculates soil erosion for each individual grid cell but does not allow a continuous flow of sediments to include sedimentation (Jain et al., 2001). Therefore the modelled 32-42 tons $\mathrm{ha}^{-1} \mathrm{yr}^{-1}$ for both blocks may not necessarily mean all that soil left the field. The losses however are serious enough to cause concern. In Spain, soil losses $>40$ tons ha-1 $\mathrm{yr}^{-1}$ were reported as being severe enough (Martinez-Graña et al., 2014) to warrant intervention planning. In our study areas, the mean soil losses (30-40 tons $\mathrm{ha}^{-1} \mathrm{yr}^{-1}$ ) are already beyond the "T values (15-20 tons)" which call for intervention. However, the K-factor for the Sunga block was higher and it differed significantly $(P<0.05)$ from that of Soni. This is consistent with what was reported earlier from the area that the Sunga block has more erodible soils (Ezaza, 1988). Despite soils of the two areas being predominantly Acrisols, the geological map covering the two areas (Geological Survey of Tanganyika, 1963) shows the Sunga area to also be composed with higher levels of granulites, hornblendes and pyroxene. These minerals often cause coarser textured soils (Msanya et al., 2001) rich in silt making them more erodible.

Considering that Lushoto district is a vast area $\left(3500 \mathrm{~km}^{2}\right)$, scenario 3 models a situation in which the district would direct its conservation efforts in a few selected areas whose soil erosion risks are in excess of the current levels, instead of conserving the entire agricultural area. These results indicate that such a move would reduce soil erosion rates from the current levels by an additional 15.1 and $13.5 \%$ for the Soni and Sunga blocks, respectively (Table 2.7). Though the reduction is not big, but given the meagre resources available to the district, it is an option worth considering.

When we look at the adoption of SWC structures in the studied blocks, we see that despite many years of combating soil erosion and advocating adoption of soil conservation measures, it is only $3-20 \%$ of agricultural land which is conserved (Table 2.5). This casts doubt as to the willingness of target communities to take on board the advocated technologies though same measures are reported to be technically sound at both landscape scale and plot level (Tenge et al., 2011). Low adoption of the SWC measures does not necessarily reflect poor effectiveness of same measures. In the neighbourhood of our Soni Block, effectiveness of the soil conservation technologies was found to be varying with rainfall seasonality for similar slope positions as in our study sites. Bench terraces were found to be $75-84 \%$ effective against soil losses (Tenge et al., 2011). That study though, was 
conducted at a plot level with bench terraces installed for that reason. In our case however, the two blocks have only dismal adoption of the SWC measures (Table 2.5).

The current effectiveness of the measures in reducing erosion at the scale of this study was estimated at 1.3 and $7.6 \%$ for Soni and Sunga respectively. When adoption of the SWC measures is enhanced to the entire block then effectiveness of the SWC measures in both blocks changed to $84-87 \%$ for Soni and Sunga blocks, respectively (Table 2.7 ) which is similar to effectiveness levels observed at a plot level in the neighbouring areas (Tenge et al., 2011). It is important to note that despite the effectiveness of terraces, there are studies which have reported difficulties associated with this technology. An earlier study in the same area (Wickama et al., 2014) reported of collapsing walls of terrace risers which eventually deposited infertile sub-soils on terrace floors and effectively masked effect of added manure plus the laborious task of seasonally "cleaning" the terrace floors by smallholder farmers. A similar observation has been reported from Portugal where terraces established in vineyards were found to be unstable in the presence of precipitation levels exceeding $90 \mathrm{~mm}$ within $24 \mathrm{~h}$ (Pacheco et al., 2014). According to that study, the slumping of terrace risers was found to cause $14 \%$ significantly higher costs of maintaining them apart from the buried fertile top soils. In another study carried out in Portugal (Valle Junior et al., 2014 ) it was reported that though terraces effectively reduced nearly $30 \%$ of the soil erosion risk, they had five times more likelihood of slumping if located on steep slopes or in areas with soil losses exceeding 50 tons ha ${ }^{-1}$ year $^{-1}$. These findings indicate that terraces have higher maintenance costs which are unaffordable to many farmers which subsequently discourage farmers from adopting them. Though these studies were conducted on different soil types, it is worthwhile to note that structural instability of terraces is a potential hindrance for their adoption.

The slightly higher effectiveness of the SWC measures adopted in the Sunga area indicates favourability of the Sunga block in parameters important for effectiveness of the SWC measures including its lower costs in constructing terraces compared to Soni. The generally higher effectiveness of the SWC measures for the Sunga area could be contributed by a number of factors inclusive of positive marginal returns on crops cultivated, favourable soil conditions, physical location of the respective places, and marginal construction costs of the measures in the target areas (Gebremedhin and Swinton, 2003). In our case these factors seem to favour the effectiveness of the SWC measures towards the Sunga area against Soni because, its soils are more fertile, its location is more remote and hence costs associated with construction of terraces are lower, and its rainfall regime is comparable.

Results from other studies indicate that there are several factors which influence adoption of soil conservation technologies. Factors which are positively correlated with adoption of 
SWC technologies include; soil quality, slope of farmland, and plot size (Amsalu and de Graaff, 2007). In Ethiopia plot sizes, soil fertility, and positive marginal returns on crops were also observed to correlate positively with adoption of soil conservation technologies. For example, field sizes in Sunga are significantly $(P<0.05)$ larger than in Soni and soil fertility indicators in Sunga are better than in Soni (Wickama and Nyanga, 2009) and hence the observed higher adoption of SWC technologies in Sunga block than Soni could be related to this observation. However, across the district, areas with similar indicators can be identified and targeted for SWC technologies since they hold a higher chance for success. The difference in land management between the two blocks also reflects differences in the past institutional efforts. In Sunga, there has been a longer experience and contact with programs fighting soil erosion. These exposures probably contributed to the observed readiness of Sunga farmers in the adoption of the soil conservation measures. We can therefore conclude that while broad land use practices across the two blocks are similar, there are significant differences in the proportions of the land utilization types across the two blocks. The differences are contributed by existing differences in biophysical conditions between the two blocks but also by different human population densities which each block accommodates. For the Soni block, the higher population density has already resulted into tiny household fields, encroached forests and a shift to cultivating high value crops like vegetables in the valley bottoms. In Sunga block, their commercial lifeline is in the cultivation of round potatoes because soils of the area are coarse and support it. Consequently the two places need water for different industries and for which they need SWC structures if it is on the hillands.

The proportions of adopted SWC measures in each block are also significantly different. In the past, quantification of this adoption had only relied on ground observations, but this study has shown that it is indeed possible to study this variable albeit on a landscape scale by using remote sensing techniques. The use of OBIA approach in the detection of such measures was limited to bench terraces and grass strips because they are physically distinguishable. New techniques must be derived for agro-forestry, mulching and other diffuse practices. Nevertheless the use of OBIA in Lushoto district for SWC detection paved the way for newer opportunities of studying adoption of SWC structures in highland ecosystems seeing that we had a mapping accuracy of $75-78 \%$.

This study has also shown that soil erosion is still a problem in the West Usambara highlands. These results however show that the magnitude of soil erosion variation from one location to another may be comparable. This is largely dependent on dominant biophysical conditions on the ground. In the case of the two blocks the relatively higher soil losses for the Sunga block were probably related to its higher level of precipitation, more erodible soils and its more exposed agricultural land. Though many studies in the area 
(Mascarenhas, 2000; Pfeiffer, 1990) have reported a higher precipitation for the Soni area our own observations suggest that this assumption need to be verified closely. Another reason for the higher soil loss in Sunga area was its lower vegetation cover on the agricultural land compared to Soni area though Sunga has $40 \%$ of its area under forest. Though the soil losses of 32-42 tons/ha per annum for Soni and Sunga Blocks fell within the reported projections for Lushoto district by past studies (Pfeiffer, 1990), these losses are already severe (Martinez-Graña, 2014) to the extent intervention actions must be planned by the district authorities. The higher soil losses for Sunga were not expected considering that the block has more conservation structures than Soni Block. Our results show that biophysical conditions in Sunga like more precipitation, more erodible soils and longer escarpments on its boundaries were probably contributing to these losses (Figure 2.5) in Kalumele, Western Mamboleo and Masereka hamlets which served as accelerators for continued soil losses from that block. 


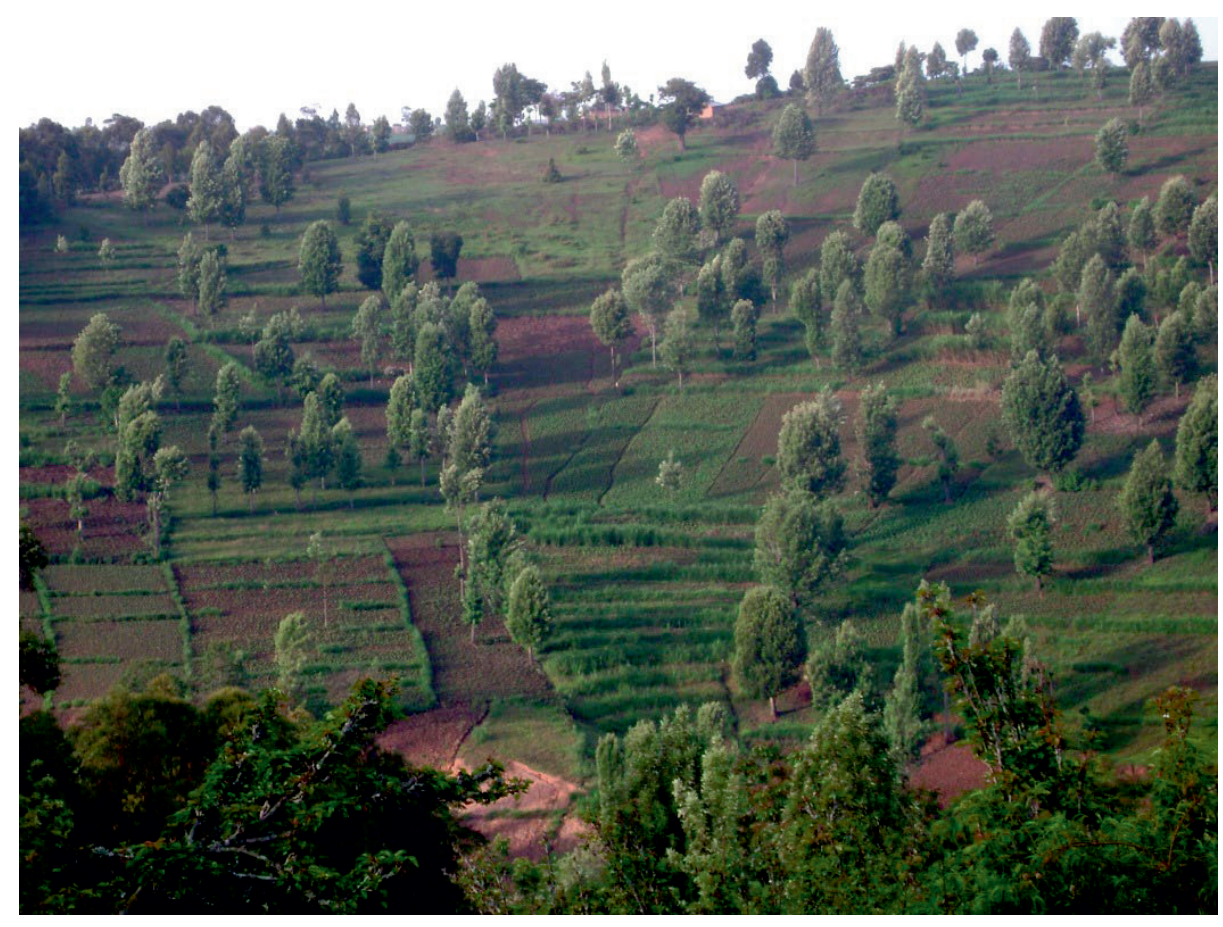




\section{Modeling and mapping erosion in smallholder agro-ecosystems, Tanzania}

The West Usambara Highlands in north-eastern Tanzania have many smallholder agroecosystems with unknown composition, management and vulnerability to erosion. Their specific locations and spatial extent are difficult to trace by satellite images or remote sensing imagery alone. To address these limitations, we combined ground soil surveys, GIS and erosion modelling to (i) locate and map smallholder agro-ecosystems; (ii) determine their biophysical characteristics; and (iii) model their soil losses. Land resource information was collected from 301 random 0.1-hectare plots sampled from a total area of $200 \mathrm{~km}^{2}$. Annual soil losses were estimated using the Universal Soil Loss Equation (USLE). The study located six dominant agro-ecosystems with the following spatial extent: Maize-Bean (24.9\%); Maize-Bean-Agroforestry (31.2\%); Maize-Bean-Agroforestry-High Value Trees (18.9\%); Tree farms (7.0\%); Forests (15.6\%); and Grazing lands (2.3\%). Agroforestry and other tree-based agro-ecosystems dominate the area due to historical land use change and later institutional interventions. This study finds combined use of soil surveys, GIS and modeling to be reliable in locating, mapping and assessing soil losses in smallholder agro-ecosystems. The agro-ecosystems differ significantly $(p<0.05)$ in slope, vegetation cover, soil conditions and soil losses. Soil loss in the Maize-Bean agro-ecosystem (28.3 tons ha $\mathrm{yr}^{-1}$ ) was 18 times higher compared to Natural Forests (1.57 tons ha ${ }^{-1} \mathrm{yr}^{-1}$ ) due to lower soil cover and inefficient conservation and cultivation practices. Results show that adoption of soil conservation measures and improved vegetation cover technologies across the agro-ecosystems reduces soil losses by $37 \%$ and increases organic carbon levels by $16 \%$.

Based on:

Wickama, J., Kessler, A., and Sterk, G. 2018. Modelling and mapping erosion in smallholder agro-ecosytems, Tanzania. Land Degradation \& Development 29, 2299-2309. 


\subsection{Introduction}

Agro-ecosystems are communities of plants and animals interacting with their physical and chemical environments to produce food, fiber, fuel and other products for human consumption and processing (Altieri, 2002). Though agro-ecosystems are important for food and nutritional security in sub-Saharan Africa, their capacity to produce food is currently undermined by many factors, including soil degradation (Tamene and Le, 2015). Soil erosion is the most visible form of degradation in smallholder agro-ecosystems, and has been widely linked to inefficient land management and resource utilization by farmers (Adgo et al., 2013). However, for East African highlands, the extent and magnitude of soil erosion in specific smallholder agro-ecosystems has not been adequately studied. Furthermore, due the variation in agro-ecosystems in the region, erosion is location specific and cannot be generalized (Grogan et al., 2013).

The West Usambara Highlands (WUH) in Tanzania are among the most eroded mountains in East Africa (Wickama and Nyanga, 2009). A recent study in the area linked current erosion to land management practices by smallholder farmers (Winowiecki et al., 2016). Past studies in the area indicate that farming in the WUH is mainly based on smallholder farming in the following agro-ecosystems: Maize-Bean, Traditional Agroforestry and Maize-BeanAgroforestry (Johansson, 2001); Maize-Bean and Coffee-Banana-High Value Trees (Tenge et al., 2004); Tree Farms (Wickama and Nyanga, 2009); and Natural Forests and Agropastoralist systems (Mbogoni, 2010). Though most soil erosion reports covering the WUH (Vigiak et al., 2005; Vrieling et al., 2006) conclude that soil erosion in the area is a land management problem, most have not considered the complex composition of existing agroecosystems.

Information about spatial extent and complexity of agro-ecosystems is very useful for planning soil erosion interventions. This knowledge is scant in places like the WUH. Application of remote sensing (RS) techniques could potentially assist in classifying and mapping agro-ecosystems. However, the generally high vegetation cover, the similarity in vegetation types and the scattered distribution of the agro-ecosystems make it very difficult to detect and map them adequately. As a result, most RS applications used in East Africa for detecting erosion in different agro-ecosystem have only discriminated between natural forests, agricultural crop land and grazing land (Bezuayehu and Sterk, 2008; Biazin and Sterk, 2013). This also counts for two other recent studies in the WUH (Vrieling et al., 2006; Wickama et al., 2015) which used the Normalized Difference Vegetation Index (NDVI), a slope map and object based image analysis (OBIA) to predict soil erosion risk and detect soil and water conservation (SWC) measures at a landscape scale. As both studies did not discriminate between different agro-ecosystems, there is a knowledge gap concerning 
composition, location and magnitude of soil losses in the different agro-ecosystems of the area. In order to fill this knowledge gap, this study applied ground based soil surveys, GIS tools and soil erosion modeling to (i) establish composition of smallholder agro-ecosystems of the WUH (ii) locate and map the mentioned agro-ecosystems (ii) determine bio-physical characteristics of dominant agro-ecosystems; and (iii) assess soil losses in these agroecosystems.

\subsection{Materials and Methods}

\subsubsection{Description of study area}

This study was conducted in the Lushoto District in Tanzania, within latitudes $4^{0} 22^{\prime}$ to $5^{\circ} 08^{\prime}$ South and longitudes $38^{0} 5^{\prime}$ to $38^{\circ} 38^{\prime}$ East. The district is $3500 \mathrm{~km}^{2}$ in size with a population density of 134 people per $\mathrm{km}^{2}$ (Wickama et al., 2014). Its topography is mountainous, with an altitude that varies from 600-2300 meters above sea level (Wickama et al., 2015). Its major soils are Acrisols, Luvisols and Lixisols on the hills and mid slopes, while valley bottoms are dominated by Fluvisols with pockets of Gleysols (Wickama et al., 2014). The district has two rainfall seasons. The long rains ("masika") start mid-March to end of June while short rains ("vuli") start mid-October ending late December. Annual rainfall varies from 800-1300 $\mathrm{mm}$ depending on the agro-ecological zone (Mascarenhas, 2000). Agriculture in the district is low-input subsistence farming. The study considered six agro-ecosystems commonly found in the WUH, namely (1) Maize-Bean, (2) Maize-Bean-Agroforestry, (3) Maize-BeanAgroforestry-High Value Trees, (4) Tree Farms, (5) Natural Forests, and (6) Grazing Lands. Natural Forests were also used as a control group for comparison of soil conditions and erosion levels with the other agro-ecosystems.

Field data were collected from two villages (Soni and Sunga) covering an area of $100 \mathrm{~km}^{2}$ each. These villages were selected because all six agro-ecosystems are found in each village, their soil characteristics are typical of the WUH, and both have good accessibility. Furthermore, they represent the typical ecological and smallholder land use challenges commonly found in the East African region as has been reported from Kenya (Vigiak et al., 2005), Ethiopia (Tamene et al., 2017b), and Rwanda (Kagabo et al., 2013). For this reason, results obtained in these two sites were considered representative and up-scalable. Soni village is located 12 kilometers east of Lushoto town while Sunga is 50 kilometers NorthWest of Lushoto (Figure 3.2). For Soni, data were collected from a square area $\left(4^{\circ} 48^{\prime}-4^{\circ}\right.$ $53^{\prime}$ South and $38^{\circ} 20^{\prime}-38^{\circ} 25^{\prime}$ East) surrounding the village. Similarly for Sunga the data were collected from the square defined by $4^{\circ} 29^{\prime}-4^{\circ} 34^{\prime}$ South and $38^{\circ} 12^{\prime}-38^{\circ} 17^{\prime}$ East. 


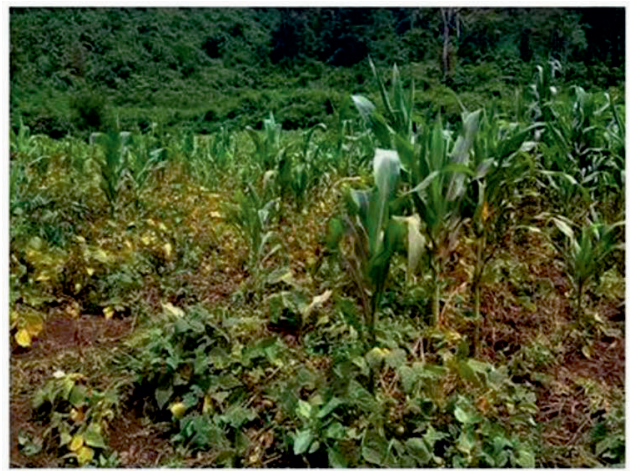

Maize-Bean

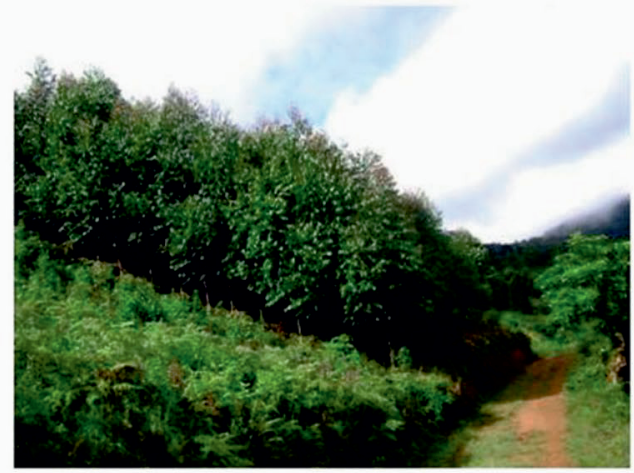

Tree Farms

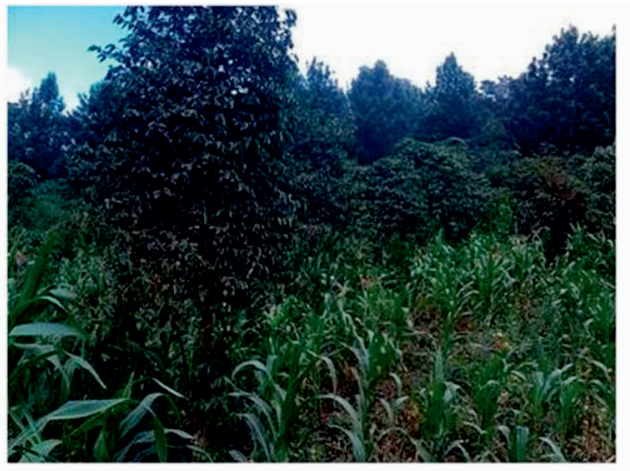

Maize-Bean-HVT

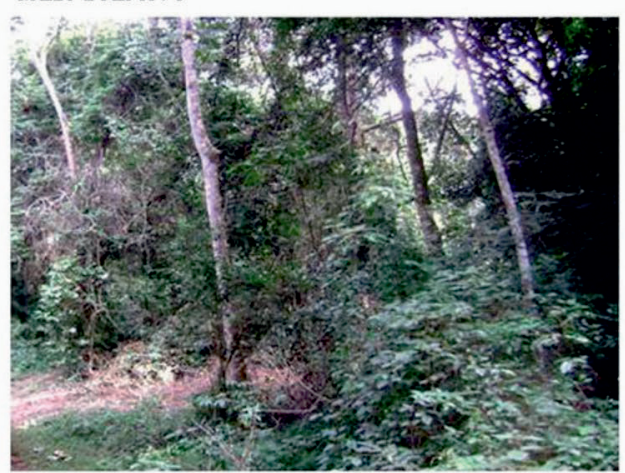

Natural Forest

Figure 3.1 Selected agro-ecosystems in the West Usambara Highlands, Tanzania.

To locate and map agro-ecosystems, two ground-based soil surveys were conducted covering 301 randomly selected plots: 160 in Soni and 141 in Sunga. These plots were established following the approach described (Vågen et al., 2004) for their detection. First, 16 primary sampling units (PSU) were randomly selected from each $100 \mathrm{~km}^{2}$ study site (Figure 3.2). Then, 10 plots of 0.1 ha each were randomly sampled from each of these PSUs. In each of these plots, measurement of altitude (by GPS unit), surface slopes (inclinometer), vegetation types and cover (visual assessment), major crops (visual assessment) and dominant erosion features (visual) were taken following methods modified from that used in Scotland (Watson, 1985) (Table 3.1). Maize and bean yields (number of 90-kg bags harvested per acre) were estimated from farmers own data. These bags were later converted arithmetically into an equivalent of $\mathrm{kg} / \mathrm{ha}$. Each random plot was classified as belonging to any of the six agro-ecosystems if at least $50 \%$ of observed features on the plot belonged to that agro-ecosystem. 

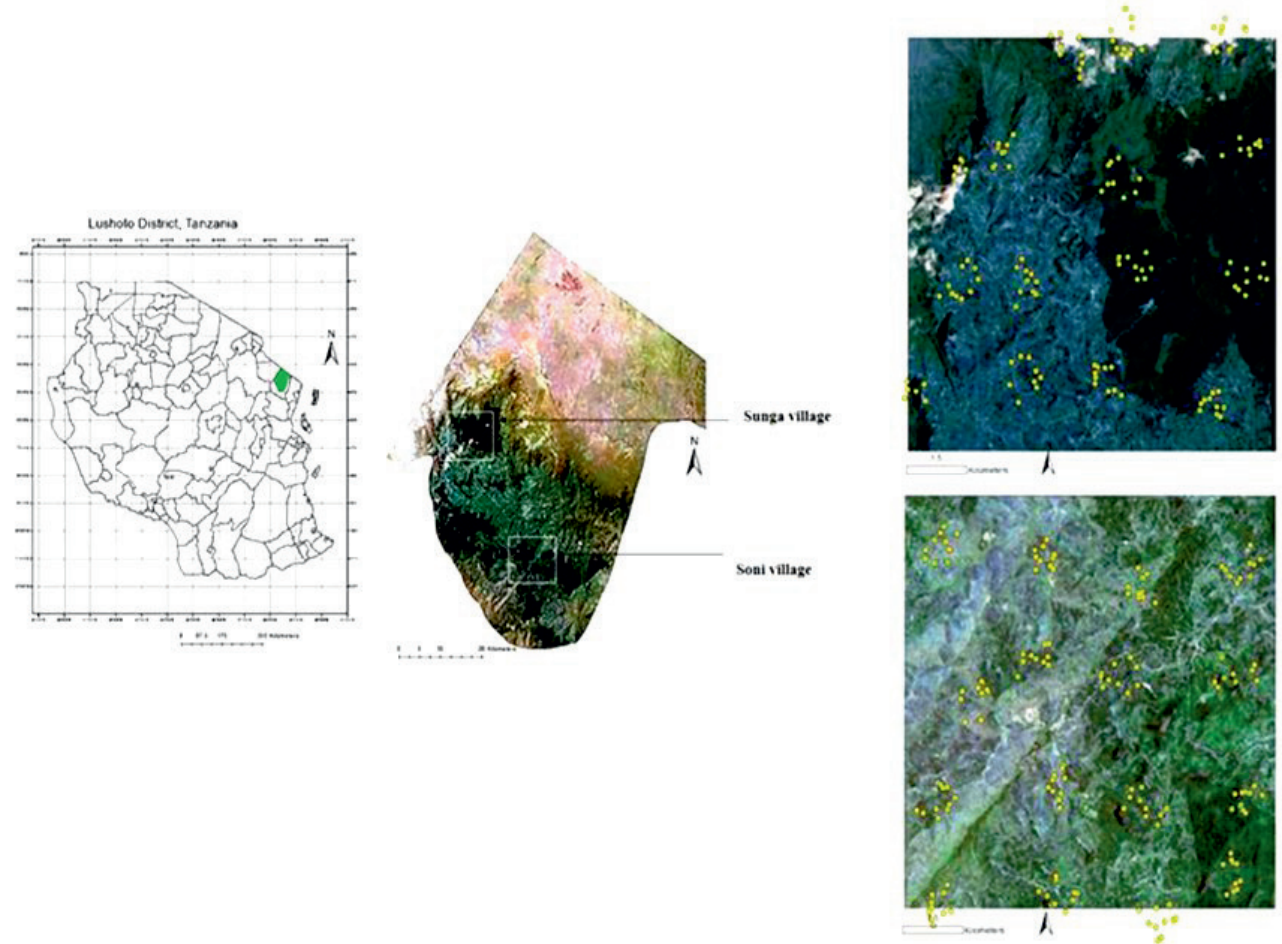

Figure 3.2 Location of Lushoto district, the two study villages and sampled locations (yellow dots) in each of the 16 random clusters.

Table 3.1 Criteria of scoring soil erosion features in Lushoto District, Tanzania.

\begin{tabular}{ll}
\hline Visible erosion features & Score \\
\hline None & 1 \\
Sheet erosion & 2 \\
Rills & 3 \\
Sheet \& Rills & 4 \\
Gullies & 5 \\
\hline Source: Adapted from Watson (1985)
\end{tabular}

\subsubsection{Collection and analysis of soils}

Soil samples were collected from the 301 plots at two depths: $0-20 \mathrm{~cm}$ for top soils and $30-$ $50 \mathrm{~cm}$ for sub-soils. These two depths were used because they represent the active root zone for most tropical crops. Samples were composite, meaning that 4 topsoil samples from different locations within a random plot were sampled and mixed as one. The same was done for the sub-soil samples. Collected soils were air dried and sieved ( $2 \mathrm{~mm}$ sieve). A small portion (10\%) of the soil samples was analyzed for particle size distribution, soil reaction $(\mathrm{pH})$, Soil Organic Carbon (SOC), Total Nitrogen (TN), exchangeable bases, and available 
phosphorus (Av. P). Respective analytical methods used for each parameter are described in a manual detailing their analyzes (Page, 1982). Analytical results of the $10 \%$ portion were then used for calibration and analysis of the remaining $90 \%$ through Near Infra-Red (NIR) spectroscopy (Brown et al., 2006). NIR analysis was used for the same soil properties as for standard laboratory analysis, except for soil texture.

\subsubsection{Modeling of soil erosion}

Soil losses were estimated by the Universal Soil Loss Equation (USLE) model (Wischmeier and Smith, 1978). Despite known limitations in representing erosion and hydrologic processes (Morgan, 2005), this model is still preferred for soil erosion modeling (Renard et al., 1991). The USLE has also been widely used in the East African highlands (Angima et al., 2003a; Mati et al., 2000) thus enabling comparison of our results to those obtained elsewhere in the region. It is defined as:

$A=R * K * C * L S * P$

where $A$ = annual erosion (ton ha ${ }^{-1} \mathrm{yr}^{-1}$ ), $R=$ Rainfall and runoff factor (MJ $\mathrm{mm} \mathrm{ha}^{-1} \mathrm{hr}^{-1} \mathrm{yr}^{-1}$; $K=$ Soil erodibility factor ( $\mathrm{t} \mathrm{ha}^{-1}$ per unit of $R$ ), $L=$ Slope length factor $(-) ; S=$ Slope steepness factor (-), $C=$ Cover and management factor (-); $P=$ Support practice factor (-). Rainfall data were collected from automatic weather stations installed in each village for 30 months (January 2010 - June 2012). Annual mean rainfall during this period was $691.3 \mathrm{~mm}$ and 700.4 $\mathrm{mm}$ for Soni and Sunga, respectively. $R$-factors were calculated as recommended for our East African region (Moore, 1979) in which:

$Y=11.46 x-2226$

Where $Y$ represents kinetic energy $\left(\mathrm{J} \mathrm{m}^{-2}\right)$ of the rain, and $x$ represents the mean annual rainfall $(\mathrm{mm})$. Then the $R$-factor ( $\mathrm{MJ} \mathrm{mm} \mathrm{ha} \mathrm{m} \mathrm{hr}^{-1} \mathrm{yr}^{-1}$ ) was calculated as:

$R=0.029 Y-26.0$

The $K$-factor (ton ha-1 per unit of $R$ ) was calculated from the equation proposed for its determination by (Lal and Elliot, 1994):

$K=2.8 * 10^{-7} * M^{1.14}(12-a)+4.3 * 10^{-3}(b-2)+3.3 * 10^{-3}(c-3)$ 
where, $a$ is the percentage soil organic matter, $b$ is a soil structure class ( 1 to 4 ), $c$ is a soil profile permeability class ( 1 to 6 ). $M$ is the particle size parameter, which is calculated using the mass fractions of clay, silt and fine sand:

$M=(\%$ silt $+\%$ fine sand $) *(100-\%$ clay $)$

For all locations we used the soil structure class with a value of 2 (meaning moderate), and the soil permeability class with a value of 3 (meaning moderately slow). $K$-factors were calculated from sampled soils. $C$-factor values were derived from vegetation cover at each random plot. Values of vegetation cover (cov in \%) at each random plot were converted into $C$-factor values by using an equation tested in China (Ma et al., 2003). Choice of this equation was based on its convenience of collecting vegetation cover data in the field during soil survey assessments instead of soliciting satellite imagery for each location:

$C=0.6508-0.343 \log c o v$

This equation works best for vegetation cover not exceeding 78.3\%. For those cases where vegetation cover exceeded this limit, a recommended $C$-factor value was adopted from the USLE-manual (Wischmeier and Smith, 1978). In our study, collection of vegetation cover data was conducted during off-rain-season periods to enable logistical access and to accurately estimate erosion risk of individual locations without influence of seasonal crop cover. The L-factor was estimated using Wischmeier \& Smith (1978):

$L=\left(\frac{\lambda}{22.13}\right)^{0.5}$

where, $\lambda$ is slope length $(\mathrm{m})$. For this study $\lambda$ was assumed to be $12.23 \mathrm{~m}$ after making adjustments for slope (Walsh et al., 2006). An exponent value of 0.5 was chosen because of steep slopes (> 30\%) in both villages. S-factor values were calculated using the following equation proposed by Ma et al. (2003):

$S=0.8252 \times 8.5319 \sin \theta$

where, $\vartheta$ is slope angle $\left(^{\circ}\right)$. This $S$-factor equation was chosen for its strength of reducing exaggeration of $L S$ values in steep landscapes (Ma et al., 2003). The $P$-factor represents soil loss in the absence of SWC measures. Specifically, plots without bench terraces or grass strips were given a $P$ value of 1 . Those with bench terraces or grass strips were given $P$ values ranging from 0.10 to 0.18 (Mati et al., 2000). $P$-factor values of 0.10 were assigned to random plots with more than 40 bench terraces or grass strips. All USLE values $(R, K, L, S$, $C$ and $P$ ) were computed in Microsoft EXCEL. These losses were then summarized into soil 
losses per agro-ecosystem. Spatial distribution of the agro-ecosystems and their corresponding soil losses were mapped using ArcGIS 10.1. Severity of soil losses was classified using a criterion proposed for its categorization (Stone and Hilborn, 2000).

\subsubsection{Statistical analyses}

Statistical analyses were conducted using the Microsoft EXCEL Data Analysis toolbox and R software. Student $t$-tests and one-way ANOVA (ANalysis Of VAriance) were used to compare means of samples (slope, vegetation cover, soil properties) originating from the six agroecosystems. The means of the non-parametric erosion classes and the numbers of SWC measures in the random plots were compared using the Wilcoxon rank sum test in R. All tests were done using a significance level $(\alpha)$ of 0.05 . Correlation analysis between modeled annual soil losses and several bio-physical properties was carried out using the Pearson correlation coefficient for parametric data and the Spearman's rank correlation coefficient for non-parametric data.

\subsection{Results}

\subsubsection{Location and spatial extent of agro-ecosystems}

Locations of the studied agro-ecosystems are presented in Figure 3.3. Their respective spatial extent, altitude and estimates of maize and bean yields are given in Table 3.2. Average altitude for agro-ecosystems located in Sunga is higher (1781.6 masl) than in Soni (1408.6 masl), while average temperature in Sunga $\left(20^{\circ} \mathrm{C}\right)$ is lower than in Soni $\left(22^{\circ} \mathrm{C}\right)$. Annual rainfall for agro-ecosystems in Sunga is slightly higher (700.4 $\mathrm{mm} \mathrm{yr}^{-1}$ ) compared to Soni (691.3 $\mathrm{mm} \mathrm{yr}^{-1}$ ) (Wickama et al., 2015). In Soni village, the Maize-Bean agro-ecosystem occupied central locations in close proximity to Maize-Bean-Agroforestry fields. Tree Farms and Natural Forests were on eastern fringes of Soni village. In both areas Tree Farms and Natural Forests occupied highest altitudes. In Sunga village, unlike Soni, the Maize-Bean agro-ecosystem occupied peripheral areas of the village and was more fragmented (Figure 3.2) whereas Natural Forests and Tree Farms in Sunga village occupied eastern and central locations. In both villages, Maize-Bean-Agroforestry-High Value Trees fields were located closer to Tree farms and Natural forests than were Maize-Bean and Maize-BeanAgroforestry fields. In Sunga, Natural Forests (Shagayu Forests) occupied approximately $20 \%$ of the village area, while in Soni village; the forest (Ndelemai Forest) occupied $11 \%$ of the village. Tree Farms were twice as large in Sunga (Table 3.2) compared with those in Soni village, due to the presence of a commercial plantation (Shagayu Plantation) and a saw mill 
in Sunga. Grazing lands had no specific locations but were small in size and often in small pockets of open areas between major landscape units.

Overall, different types of Maize-Bean-Agroforestry fields dominated both villages ( $>30 \%$ ). In Soni village this most basic agro-forestry system occupied about $42 \%$ of the area, whereas its more advanced form (the Maize-Bean-Agroforestry-High Value Trees agro-ecosystem) occupied only 9.4\%. In Sunga the Maize-Bean-Agroforestry fields cover 19.2\% (Table 3.2) while the Maize-Bean-Agroforestry-High Value Trees fields are more widespread (29.8\%) than in the Soni area. Grazing lands covered less than $4 \%$ in both villages, thus making free grazing difficult.
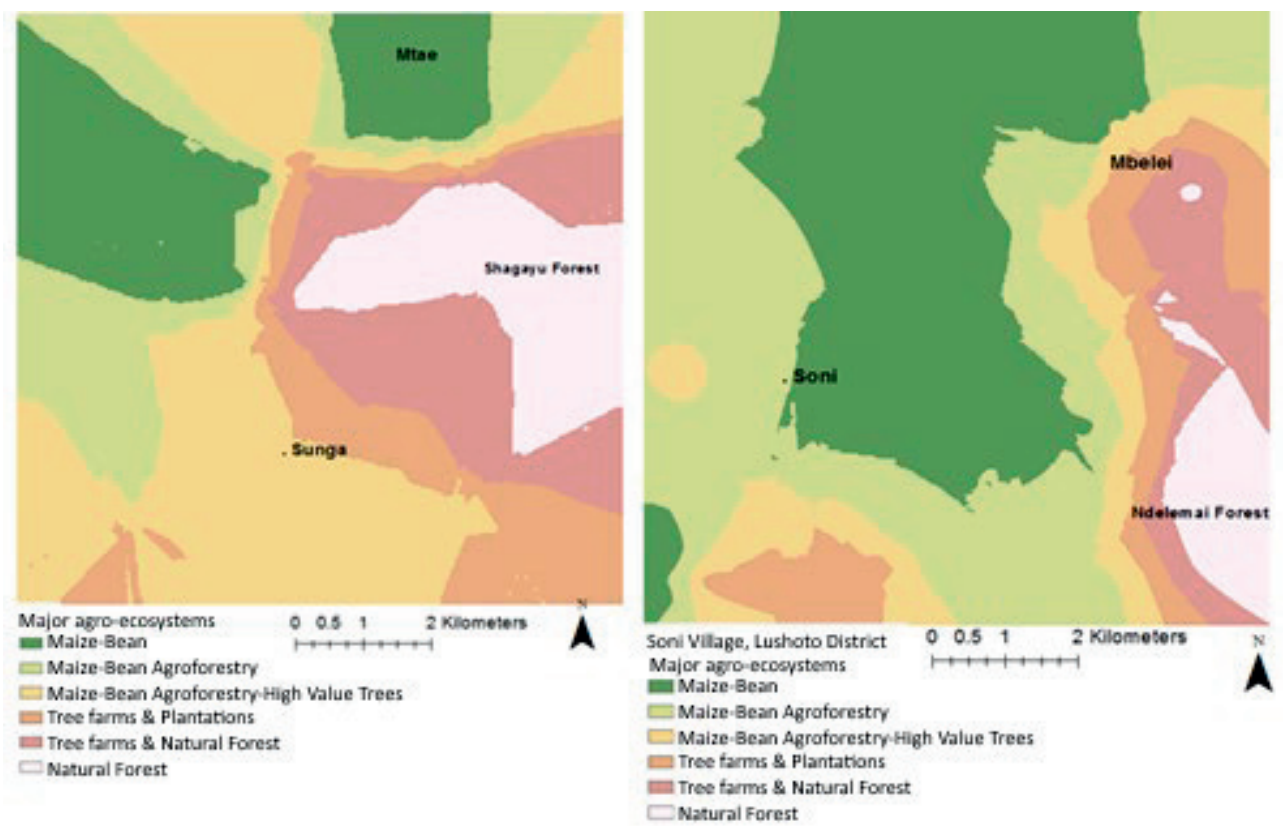

Figure 3.3 Location of major agro-ecosystems in Sunga and Soni villages (Lushoto District Tanzania). 
Table 3.2 Spatial extent, altitude and estimates of maize and bean yields of major agro-ecosystems in Soni and Sunga villages (Lushoto District, Tanzania).

\begin{tabular}{|c|c|c|c|c|c|c|c|c|c|c|}
\hline \multirow{4}{*}{$\begin{array}{l}\text { Agro- } \\
\text { ecosystem }{ }^{1}\end{array}$} & \multicolumn{5}{|l|}{ Soni } & \multicolumn{5}{|l|}{ Sunga } \\
\hline & \multirow{3}{*}{$\begin{array}{l}\text { Plots } \\
\mathrm{n}\end{array}$} & \multirow{3}{*}{$\begin{array}{l}\text { Extent } \\
\%\end{array}$} & \multirow{3}{*}{$\begin{array}{l}\text { Altitude } \\
\text { masl }\end{array}$} & \multicolumn{2}{|l|}{ Yield } & \multirow[t]{2}{*}{ Plots } & \multirow[t]{2}{*}{ Extent } & \multirow[t]{2}{*}{ Altitude } & \multicolumn{2}{|l|}{ Yield } \\
\hline & & & & Maize & Bean & & & & Maize & Bean \\
\hline & & & & $\mathrm{kg} \mathrm{ha}^{-1}$ & $\mathrm{~kg} \mathrm{ha}^{-1}$ & $\mathrm{n}$ & $\%$ & masl & $\mathrm{kg} \mathrm{ha}^{-1}$ & $\mathrm{~kg} \mathrm{ha}^{-1}$ \\
\hline Ma-Be & 51 & 31.9 & 1313 & 596 & 455 & 24 & 17.0 & 1615 & 770 & 728 \\
\hline Ma-Be-Af & 67 & 41.9 & 1377 & 648 & 468 & 27 & 19.2 & 1632 & 887 & 792 \\
\hline $\begin{array}{l}\text { Ma-Be-Af- } \\
\text { HVT }\end{array}$ & 15 & 9.4 & 1486 & 642 & 414 & 42 & 29.8 & 1822 & 860 & 720 \\
\hline Tree Farms & 7 & 4.4 & 1535 & 218 & 120 & 14 & 9.9 & 1963 & 243 & 196 \\
\hline $\begin{array}{l}\text { Natural } \\
\text { Forests }\end{array}$ & 18 & 11.3 & 1693 & - & - & 29 & 20.6 & 1920 & - & - \\
\hline $\begin{array}{l}\text { Grazing } \\
\text { lands }\end{array}$ & 2 & 1.3 & 1303 & - & - & 5 & 3.6 & 1741 & - & - \\
\hline
\end{tabular}

\subsubsection{Bio-physical characteristics of the dominant agro-ecosystems}

Bio-physical characteristics of the six major agro-ecosystems are shown in Table 3.3. Except for Grazing lands, all agro-ecosystems are on steep (>35\%) slopes, with Maize-Bean and Maize-Bean-Agroforestry fields being located on the steepest slopes (>40\%). Vegetation cover was highest in Natural Forests (average of 94.7\%) and lowest in the Maize-Bean agroecosystem (23.8\%). Vegetation cover was significantly higher in the Maize-BeanAgroforestry and Maize-Bean-Agroforestry-High Value Trees systems than in the MaizeBean systems. Erosion was most serious in the Maize-Bean, Grazing lands and Maize-BeanAgroforestry agro-ecosystems. In the Maize-Bean and Maize-Bean-Agroforestry agroecosystems this can be explained by the relatively steeper slopes and lower vegetation cover. In the case of Grazing lands, livestock trampling causes topsoil compaction, which reduces the infiltration capacity of the soil, resulting in high erosion rates. The lowest erosion scores were obtained in Tree Farms and Natural Forests, where high vegetation cover protects soils from erosion. SWC measures were most abundant in the Maize-BeanAgroforestry-High Value Trees agro-ecosystems, followed by Maize-Bean-Agroforestry and Maize-Bean. 
Table 3.3 Bio-physical characteristics of the major agro-ecosystems of Lushoto District, Tanzania.

\begin{tabular}{|c|c|c|c|c|c|c|c|c|}
\hline \multirow{3}{*}{$\begin{array}{l}\text { Agro- } \\
\text { ecosystem }{ }^{1}\end{array}$} & \multirow{3}{*}{$\begin{array}{l}\text { Plots } \\
\mathrm{n}\end{array}$} & \multirow{3}{*}{$\begin{array}{l}\text { Slope } \\
\%\end{array}$} & \multirow{3}{*}{$\begin{array}{l}\begin{array}{l}\text { Erosion } \\
\text { class }\end{array} \\
\text { Average } \\
\text { Score }\end{array}$} & \multicolumn{4}{|c|}{ SWC measures } & \multirow{3}{*}{$\begin{array}{l}\text { Vegetation } \\
\text { cover } \\
\%\end{array}$} \\
\hline & & & & \multirow{2}{*}{$\begin{array}{l}\text { Average } \\
\text { Number }\end{array}$} & \multirow{2}{*}{$\begin{array}{l}\text { Max } \\
\text { Number }\end{array}$} & \multicolumn{2}{|c|}{$\begin{array}{l}\text { Plots without } \\
\text { SWC }\end{array}$} & \\
\hline & & & & & & $\mathrm{n}$ & $\%$ & \\
\hline Ma-Be & 75 & $40.1 a^{2}$ & $2.33 a$ & $5.93 a$ & 38 & 52 & 69.3 & $23.8 \mathrm{a}$ \\
\hline Ma-Be-Af & 94 & $40.3 a$ & $2.10 a b$ & $8.71 b$ & 47 & 49 & 52.7 & $34.2 \mathrm{~b}$ \\
\hline Ma-Be-Af-HVT & 57 & $35.8 \mathrm{~b}$ & $2.02 b$ & $10.53 b c$ & 34 & 26 & 45.6 & $35.8 b$ \\
\hline Tree Farms & 21 & $39.0 a b$ & $1.48 \mathrm{c}$ & $2.86 a$ & 34 & 17 & 81.0 & $60.7 c$ \\
\hline $\begin{array}{l}\text { Natural } \\
\text { Forests }\end{array}$ & 47 & $37.1 b$ & $1.31 \mathrm{c}$ & $\mathrm{Od}$ & 0 & 47 & 100 & $94.7 d$ \\
\hline Grazing lands & 7 & $10.8 c$ & 2.14abd & $2.57 a b$ & 10 & 5 & 71.4 & $48.7 \mathrm{bc}$ \\
\hline
\end{tabular}

Table 3.4 Soil properties in the major agro-ecosystems of Lushoto District, Tanzania.

\begin{tabular}{|c|c|c|c|c|c|c|c|c|c|}
\hline Agro-ecosystem ${ }^{1}$ & $\begin{array}{l}\text { Soil depth } \\
\mathrm{cm}\end{array}$ & $\begin{array}{l}\text { Clay } \\
\%\end{array}$ & $\begin{array}{l}\text { Ex. Ca } \\
\text { me/100g }\end{array}$ & $\begin{array}{l}\text { Ex. K } \\
\text { me/100g }\end{array}$ & $\begin{array}{l}\text { Ex. Mg } \\
\text { me/100g }\end{array}$ & $\begin{array}{l}\text { Av. P } \\
\mathrm{mg} / \mathrm{kg}\end{array}$ & $\begin{array}{l}\text { SOC } \\
\%\end{array}$ & $\begin{array}{l}\mathrm{pH} \\
-\end{array}$ & $\begin{array}{l}\text { Total N. } \\
\%\end{array}$ \\
\hline \multirow[t]{2}{*}{ Ma-Be } & $0-20$ & 38.5 & 8.66 & 0.74 & 0.49 & 2.40 & 2.04 & 5.9 & 0.14 \\
\hline & $30-50$ & 43.6 & 8.28 & 0.72 & 0.47 & 2.40 & 2.01 & 5.9 & 0.14 \\
\hline \multirow[t]{2}{*}{ Ma-Be-Af } & $0-20$ & 37.3 & 7.25 & 0.77 & 0.41 & 2.43 & 2.10 & 5.9 & 0.14 \\
\hline & $30-50$ & 44.0 & 7.05 & 0.80 & 0.40 & 2.46 & 2.16 & 5.9 & 0.15 \\
\hline \multirow[t]{2}{*}{ Ma-Be-Af-HVT } & $0-20$ & 29.7 & 5.89 & 1.01 & 0.36 & 2.53 & 2.37 & 5.7 & 0.15 \\
\hline & $30-50$ & 41.1 & 5.68 & 1.05 & 0.35 & 2.54 & 2.38 & 5.7 & 0.15 \\
\hline \multirow[t]{2}{*}{ Tree Farms } & $0-20$ & 23.3 & 5.76 & 1.04 & 0.33 & 2.60 & 2.77 & 5.6 & 0.17 \\
\hline & $30-50$ & 32.7 & 6.25 & 1.10 & 0.37 & 2.55 & 2.69 & 5.6 & 0.17 \\
\hline \multirow[t]{2}{*}{ Natural Forests } & $0-20$ & 10.6 & 4.49 & 1.74 & 0.20 & 3.19 & 5.37 & 5.1 & 0.49 \\
\hline & $30-50$ & 51.2 & 5.17 & 1.36 & 0.23 & 2.87 & 4.60 & 5.2 & 0.37 \\
\hline \multirow[t]{2}{*}{ Grazing lands } & $0-20$ & 36.0 & 4.85 & 1.05 & 0.24 & 2.71 & 3.01 & 5.6 & 0.23 \\
\hline & $30-50$ & 36.1 & 4.78 & 0.90 & 0.25 & 2.51 & 2.40 & 5.6 & 0.17 \\
\hline
\end{tabular}

${ }^{1} \mathrm{Ma}-\mathrm{Be}=$ Maize-Bean; Ma-Be-Af = Maize-Bean-Agroforestry; Ma-Be-Af-HVT = Maize-Bean-Agroforestry-High Value Trees.

Main soil properties in the six agro-ecosystems are given in Table 3.4. Except for clay content, which is in most cases much higher in sub-soils (B horizon) than in top soils, most soil properties are nearly equal within the first $50 \mathrm{~cm}$ of the soil. The only exception is for Natural Forests, where top soils had substantially higher organic matter levels (SOC) than the sub-soil, resulting in higher $\mathrm{N}, \mathrm{P}$ and $\mathrm{K}$ levels. When considering the main agroecosystems, there were only marginal differences between Maize-Bean, Maize-BeanAgroforestry and Maize-Bean-Agroforestry-High Value Trees systems. 


\subsubsection{Soil erosion in agro-ecosystems}

The USLE-related soil erosion factors as well as the calculated annual soil losses per ha for each agro-ecosystem are presented in Table 3.5. The different number of random plots in the two villages for the same agro-ecosystem (Tables $3.2 \& 3.3$ ) caused the average $R$-factor being different for each agro-ecosystem. $C$-factor values were high in Maize-Bean agroecosystem and low in Natural Forests. LS-factor values were highest in Maize-BeanAgroforestry and Maize-Bean agro-ecosystems, and low in Grazing lands which are located on more moderate slopes. The lowest $P$-factor values were observed in Maize-BeanAgroforestry-High Value Trees due to the higher number of SWC measures observed in this agro-ecosystem. The low presence of such measures in Maize-Bean and Grazing lands resulted in relatively high $P$ values, while the highest values were obtained for Tree Farms $(P=0.84)$ and Natural Forests $(P=1)$.

Table 3.5 Variation of USLE-soil erosion factors and predicted soil losses for the major agro-ecosystems in Lushoto district, Tanzania.

\begin{tabular}{|c|c|c|c|c|c|c|c|}
\hline Agro-ecosystem ${ }^{1}$ & Property & $\begin{array}{l}\text { R-factor } \\
\text { (MJ mm ha-1 } \\
\mathrm{hr}^{-1} \mathrm{yr}^{-1} \text { ) }\end{array}$ & C-factor & LS-factor & P-factor & $\begin{array}{l}\text { K-factor } \\
\text { (ton }{ }^{-1} \text { ha }^{-1} \\
\text { per unit of } \\
\text { R) }\end{array}$ & $\begin{array}{l}\text { Soil loss } \\
\text { (ton }^{-1} \mathrm{ha}^{-1} \\
\mathrm{yr}^{-1} \text { ) }\end{array}$ \\
\hline \multirow[t]{4}{*}{ Ma-Be } & Mean & $2499.8 b 2$ & $0.2210 a$ & $2.0034 a b$ & $0.74 b c$ & $0.0332 b c$ & $28.3 a$ \\
\hline & Min & 2369.62 & 0.1346 & 0.73 & 0.11 & 0.0143 & 1.2 \\
\hline & Max & 2776.32 & 0.3448 & 3.01 & 1 & 0.0738 & 112.8 \\
\hline & Stdev & 189.71 & 0.0400 & 0.57 & 0.4 & 0.0125 & 25.7 \\
\hline \multirow[t]{4}{*}{ Ma-Be-Af } & Mean & $2486.4 b$ & $0.1673 b$ & $2.0185 a$ & $0.59 \mathrm{~cd}$ & $0.0355 b$ & $17.8 b$ \\
\hline & Min & 2369.62 & 0.0637 & 0.73 & 0.1 & 0.0019 & 0.21 \\
\hline & Max & 2776.32 & 0.2844 & 3.01 & 1 & 0.0738 & 112.8 \\
\hline & Stdev & 184.02 & 0.0409 & 0.53 & 0.43 & 0.01449 & 20.3 \\
\hline \multirow[t]{4}{*}{ Ma-Be-Af-HVT } & Mean & $2669.3 a$ & $0.1679 b$ & $1.8055 c$ & $0.53 d$ & $0.0400 \mathrm{a}$ & $17.9 b$ \\
\hline & Min & 2369.62 & 0.0095 & 1.01 & 0.11 & 0.0019 & 0.2 \\
\hline & Max & 2776.32 & 0.2573 & 3.11 & 1.00 & 0.0594 & 99.4 \\
\hline & Stdev & 179.09 & 0.0587 & 0.49 & 0.43 & 0.0135 & 21.1 \\
\hline Tree Farms \& & Mean & $2640.8 a$ & $0.0921 \mathrm{c}$ & $1.95 a b c$ & $0.84 b$ & $0.0426 a$ & $16.4 \mathrm{bc}$ \\
\hline \multirow[t]{3}{*}{ Plantations } & Min & 2369.62 & 0.0192 & 0.82 & 0.11 & 0.01841 & 0.5 \\
\hline & Max & 2776.32 & 0.2492 & 3.21 & 1.00 & 0.05380 & 78.3 \\
\hline & Stdev & 191.72 & 0.0758 & 0.55 & 0.33 & 0.00888 & 17.9 \\
\hline \multirow[t]{4}{*}{ Natural Forests } & Mean & $2620.6 a$ & $0.0101 d$ & $1.87 \mathrm{bc}$ & $1.00 \mathrm{a}$ & $0.0309 c$ & $1.6 \mathrm{~d}$ \\
\hline & Min & 2369.62 & 0.0018 & 1.01 & 1.0 & 0.0206 & 0.2 \\
\hline & Max & 2776.32 & 0.0314 & 2.71 & 1.0 & 0.0493 & 7.6 \\
\hline & Stdev & 197.7 & 0.0074 & 0.43 & 0.0 & 0.0081 & 1.42 \\
\hline \multirow[t]{4}{*}{ Grazing Lands } & Mean & $2660.1 \mathrm{a}$ & $0.1561 b$ & $0.56 d$ & $0.7657 b c$ & $0.0391 \mathrm{ab}$ & $6.6 \mathrm{~cd}$ \\
\hline & Min & 2369.62 & 0.0018 & 0.37 & 0.18 & 0.0237 & 0.04 \\
\hline & Max & 2776.32 & 0.2947 & 0.64 & 1.00 & 0.0594 & 22.5 \\
\hline & Stdev & 183.73 & 0.1204 & 0.09 & 0.37 & 0.0097 & 8.0 \\
\hline
\end{tabular}

${ }^{1} \mathrm{Ma}-\mathrm{Be}=$ Maize-Bean; Ma-Be-Af = Maize-Bean-Agroforestry; Ma-Be-Af-HVT = Maize-Bean-Agroforestry-High Value Trees.

${ }^{2}$ Values in column followed by same letter are not significantly ( $\left.\alpha=\begin{array}{lll}0 & .0 & 5\end{array}\right)$ different. 
Annual calculated soil losses ranged from a minimum of 0.04 ton $\mathrm{ha}^{-1} \mathrm{yr}^{-1}$ in Grazing lands to a maximum of 112.8 ton ha $^{-1} \mathrm{yr}^{-1}$ in Maize-Bean agro-ecosystem and occurred in three groups of magnitude. The highest soil losses were obtained in the Maize-Bean agroecosystem (28.3 ton $\mathrm{ha}^{-1} \mathrm{yr}^{-1}$ ). The next group, with soil losses varying from 16.4 to 17.9 ton $\mathrm{ha}^{-1} \mathrm{yr}^{-1}$, comprises Maize-Bean-Agroforestry, Maize-Bean-Agroforestry-High Value Trees and Tree Farms agro-ecosystems. Smallest erosion losses were predicted for Natural Forests and Grazing lands which had soil losses of less than 6.6 tons ha ${ }^{-1} \mathrm{yr}^{-1}$. Most modeled values followed the erosion scores that were observed in the random plots (Table 3.3). However, Grazing lands received an average erosion score similar to Maize-Bean-Agroforestry, while modeled erosion for Grazing lands was much lower. This discrepancy is probably because the model does not include effects of trampling on the soil and resulting reduction in infiltration capacity. In the case of Tree Farms its moderately high erosion values were caused by the relatively high values of $L S$ in that agro-ecosystem.

Results from correlation analysis (Figure 3.4) shows that for all agro-ecosystems, soil losses were negatively correlated to the percentage of vegetation cover and the number of SWC measures present in a random plot. Except for Grazing lands, which had low values for slopes and LS-factor (Tables 3.3 \& 3.5), the slope showed only a moderate positive correlation with annual soil loss. In both villages, severe erosion was observed in hamlets where Maize-Bean agro-ecosystems dominated (Figure 3.5). However, soil losses were small in locations with Natural Forests, Tree Farms, Grazing lands and Maize-BeanAgroforestry-High Value Trees. Smaller soil losses were also observed in areas with high concentrations of SWC measures.

\subsection{Discussion}

Predominance of agro-forestry-related systems in our study villages is related to afforestation efforts from the early 1980s to 2000 through a project called Soil Erosion Control and Afforestation Project (SECAP). Through SECAP 10 million trees were planted and 79,000 ha of farmland were put under agro-forestry (Johansson, 2001). The combined proportion of Natural Forests observed in this study (15.95\%, derived from Table 3.2) corresponds to the $14,7 \%$ forest cover remaining in the WUH in general, as reported by an earlier study (Newmark, 1998). This similarity indicates the reliability of combining soil surveys, GIS and modeling in mapping and delineating agro-ecosystems. Further, similarity of these proportions almost 20 years later indicates that by-laws for gazetting natural forests in Lushoto District are effective in stopping rampant deforestation. 


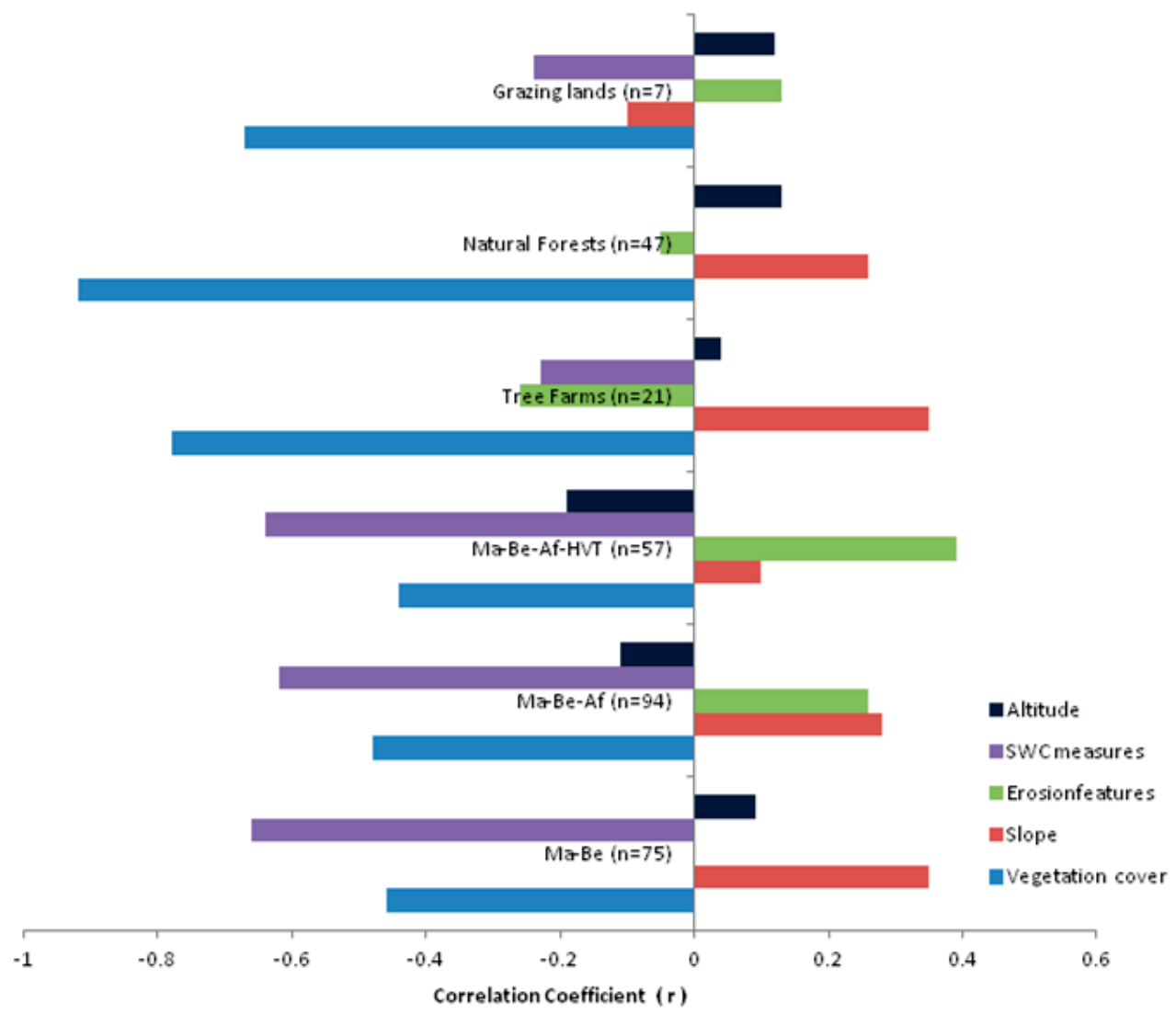

Figure 3.4 Correlation ( $r$ ) between modeled annual soil loss and selected biophysical properties in major agro-ecosystems of Lushoto District, Tanzania.

Furthermore, our methodology of randomization of locations from which to collect data proved useful in this study. If these locations were sampled differently or with bias - as often happens in soil survey assessments - then potentially different proportions for each agroecosystem would have resulted. Differences observed in spatial extent, slopes, vegetation cover and erosion features of agro-ecosystems (Tables 3.2 and 3.3) are related to varying geo-ecological conditions across the WUH (Ezaza, 1988) and the land use history in the area, whereby prime forests were allocated to farmers as agricultural land after independence of Tanganyika in the 1960s. Similarly, in New Hampshire (United States), historical land use disturbances also culminated with altitudinal arrangements of natural plant communities (Sperduto et al., 2004). Variations ( $p<0.05$ ) observed in top/sub soil conditions in our study were expected because of movements of soil constituents across soil depths and nutrient recycling processes through defoliation and tillage practices (Winowiecki et al., 2016). 


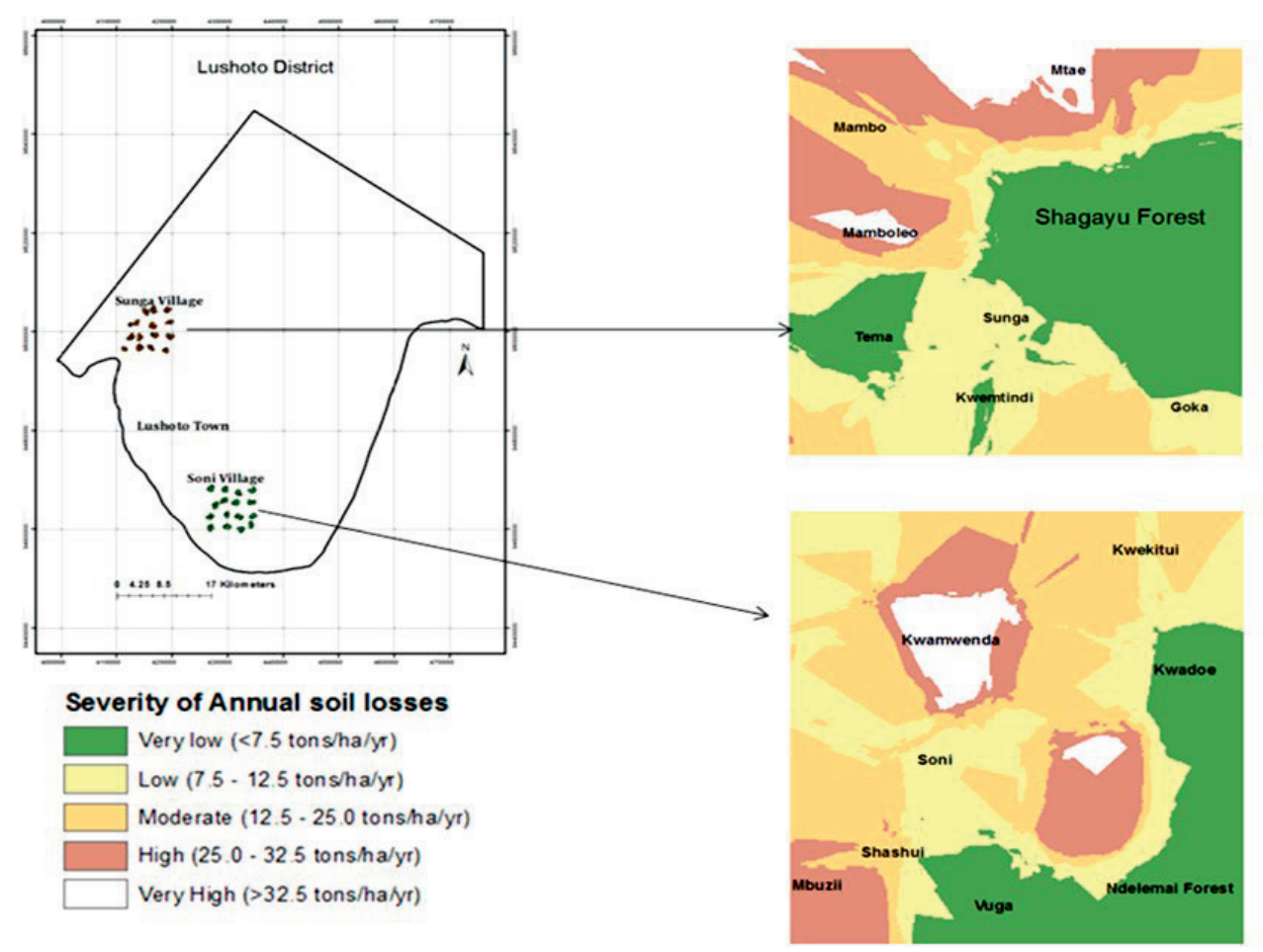

Figure 3.5 Severity of soil erosion in Soni and Sunga villages, Lushoto Tanzania.

The predicted annual soil losses in the Maize-Bean agro-ecosystem (with an average of 28.3 tons $\mathrm{ha}^{-1} \mathrm{yr}^{-1}$ ) are high to severe in most locations. These losses are higher than those reported from a nearby village of Kwalei (22.9 tons $\mathrm{ha}^{-1} \mathrm{yr}^{-1}$ ) for maize fields (Tenge et al., 2011), but similar (32.3 tons $\mathrm{ha}^{-1} \mathrm{yr}^{-1}$ ) to erosion rates reported earlier in Lushoto for unconserved macro-contour lines for erosion control (Pfeiffer, 1990). These soil losses in Maize-Bean agro-ecosystem in our study were almost 18 times higher as natural erosion rates in nearby forests (Table 3.5). This implicates that tillage practices in the two villages enhance soil erosion, and that priority in soil conservation efforts should be directed to locations dominated with Maize-Bean agro-ecosystem (Figure 3.4). However, our soil losses estimates were lower than those reported from other agro-ecosystems in Uganda (Lufafa et al., 2003), where an annual loss of 93 tons $\mathrm{ha}^{-1} \mathrm{yr}^{-1}$ in Maize-Legume agro-ecosystem was estimated. In Rwanda, soil losses around 41.5 tons $\mathrm{ha}^{-1} \mathrm{yr}^{-1}$ were recorded in maize-potatoes agro-ecosystems (Kagabo et al., 2013), and in Ethiopia soil losses ranging from $0.4-88$ tons $\mathrm{ha}^{-1}$ were reported from maize-based smallholder agro-ecosystems (Tamene et al., 2017b). Therefore, soil losses predicted in our study, though typical for East African Highlands, are generally lower than reported by other studies. 
From our erosion modeling results it can also be deduced that installation of 100 bench terraces or grass strips per ha would reduce soil losses by 7.8 tons ha- $\mathrm{yr}^{-1}$. Similarly, each $1 \%$ increase in surface slope would result into a $1.53 \%$ increase in soil loss, which is similar to what was reported from Ethiopia (Tamene et al., 2017a). Our results also show that each $10 \%$ increase in vegetation cover eventually would reduce soil loss by 5.2 tons $\mathrm{ha}^{-1} \mathrm{yr}^{-1}$. In Malawi, agro-forestry hedges on a 44\% slope reduced soil losses by $97 \%$ within 6 years (Banda et al., 1994) due to increased vegetative cover. From these results it can be deduced that agro-ecosystems with conservation measures reduce soil losses by up to $37 \%$ and build organic carbon levels by at least $16 \%$ compared to un-conserved agro-ecosystems (Tables 3.4 \& 3.5). However, given that the model we used (USLE) is unable to predict concentrated linear soil erosion adequately (Renard et al., 1991), we recommend to continue evaluating soil losses in these agro-ecosystems, and monitor how erosion maps change in time and due to management considering. Furthermore, it would also be preferable to actually measure soil losses in some of these agro-ecosystems in order to establish any contradiction between modeled and observed soil losses, and to evaluate the accuracy of the models used.

\subsection{Conclusions}

This study has demonstrated that when ground soil surveys are complimented with GIS and soil erosion modeling, it is possible to map spatial distribution, management practices and soil erosion situations in smallholder agro-ecosystems. This is particularly interesting in circumstances in which such an assessment is impossible by means of satellite imagery and remote sensing techniques alone. Soil erosion rates predicted by this approach are comparable and within range to those generated by alternative approaches in the region, which proves that the approach is useful. Furthermore, the results of the erosion modeling show that $40 \%$ of the areas under annual crops (maize and beans) have annual soil losses exceeding 25.5 tons $^{-1}$ ha $^{-1}$. These losses are nearly 18 times higher compared with those in nearby natural forests. Hence, agro-ecosystems with annual cropping practices are major contributors to soil erosion in the West Usambara Highlands, and should receive priority in any soil conservation effort. Proper tillage and effective agronomic practices should therefore be promoted among smallholder farmers, alongside effective soil and water conservation measures. 


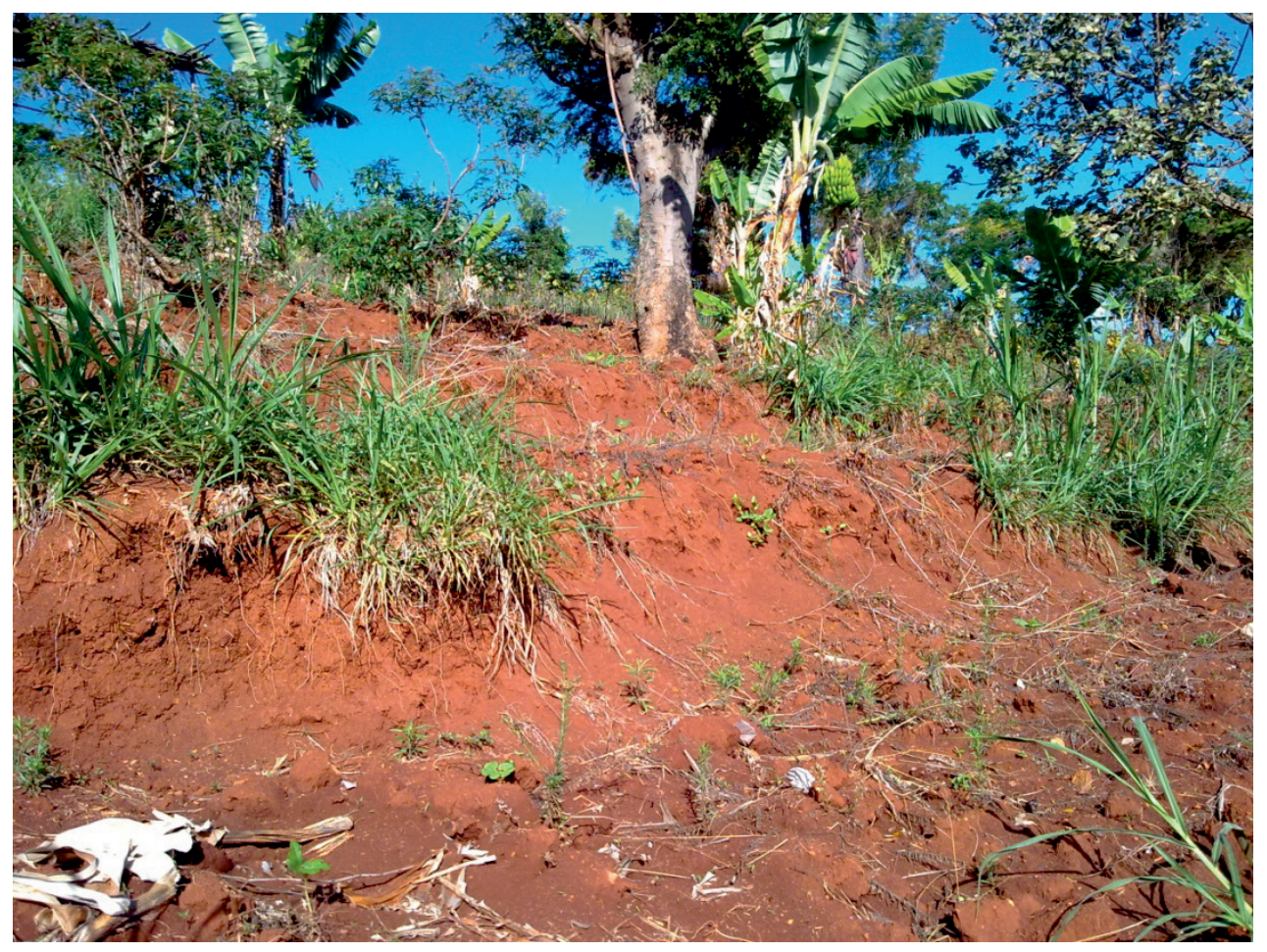




\section{Land degradation problems and adoption of sustainable land management in the West Usambara highlands, Tanzania}

Two farming communities with contrasting adoption of soil conservation structures, located 70 kilometers apart in the West Usambara Mountains of Tanzania were studied with three specific objectives ; i) to compare perceptions of administrative leaders, agricultural development staff and smallholder farmers towards land degradation ii) to identify and categorize the Sustainable Land Measures (SLM) being used in those villages; and (iii) to evaluate factors that stimulate or limit the adoption of the SLM practices in the villages studied. The study covered 130 farmers. Descriptive statistics were used to explain population and group properties while T-tests were used to detect differences on grouped data between the two communities. Results show that (i) though farmers and administrative \& extension personnel have comparable perceptions on land degradation outcomes and interventions required against it, they differ in the way they perceive its causes (ii) the two villages similarly differ significantly $(p<0.05)$ in their perceptions on the magnitude of causes, outcomes, and the required interventions against land degradation (iii) the two communities also considerably on how they perceive effectiveness of selected SLM measures and influence of some factors on the adoption of SLM measures. This study recommends a tailored other than a blanket approach towards advocating adoption of SLMs for reducing land degradation in the West Usambara Mountains. We recommend verification of the SLM categories used in the two villages, their impact in the fields where they are adopted as well as determine severity of soil erosion across the district.

Based on:

Wickama, J. and Sterk, G. 2018. Land degradation problems and adoption of sustainable land management in the West Usambara highlands, Tanzania, Land Use Policy Journal (under review). 


\subsection{Introduction}

It has often been reported that sustained land degradation and household poverty are related (Jamu et al., 2011). Land degradation and particularly soil erosion is a major problem in smallholder farming systems (Kangalawe and Lyimo, 2010) and manifests itself in the form of loss of soil nutrients and organic matter, reduction in capacity of the soil to store plant-available water, increased soil bulk densities, increased surface crusting, loss of soil depth, increased acidity of the soil, reduced soil micro-faunal and floral populations and declining crop yields (Kassie et al., 2010). The link between land degradation and community behavior has been reported in many studies and efforts of understanding how farmers perceive and deal with it have been numerous and diverse (Akinnagbe and Umukoro, 2011). While farmers have been able to relate land degradation to reduced crop yields, soil quality and increased landscape stoniness, the way they perceive land degradation influences their readiness and types of efforts they can use at adopting conservation measures (Mengstie, 2009). Understanding how farmers perceive land degradation allows those planning its intervention to take on board farmers' need when drawing programs and projects aimed at reducing land degradation at farmers' level (Kessler and Stroosnijder, 2006). Though farmers can identify and describe land degradation, understand its consequences, and describe its causes, it does not necessarily lead to adoption of measures to control it (Bezuayehu and Sterk, 2008; Okoba et al., 2007; Tenge et al., 2011). The control of land degradation depends on the adoption of resource efficient land management practices (Kassie et al., 2010). Such practices can be grouped under the concept of sustainable land management (SLM). SLM measures are defined as "a system of technologies and/or planning that aim to integrate ecological with socio-economic and political principles in the management of land for agricultural purposes to achieve intra- and intergenerational equity" (Hurni, 1997). SLM measures include soil fertility amendments, soil and water conservation (SWC), agro-forestry, conservation tillage, etc. Smallholder farmers adopt SLM practices on the basis of their perceptions and, biophysical / socio-economic circumstances prevailing in their areas (Shiferaw et al., 2009).

Farmers can reject an SLM measure depending on how they perceive it. In Kenya for example, farmers' rejection of bench terraces was associated with their perception of terraces as harboring rodents, reducing cultivation space and making oxenization difficult, which contrasted what extension personnel believed (Bustos-Griffin et al., 2012). In Tanzania, a famous soil conservation scheme (Mlalo Basin Rehabilitation Scheme) also collapsed after farmers developed ill perceptions of its true intentions (Mascarenhas, 2000), despite its implementing officers reporting of achievable results (Watson, 1972). Across this spectrum, the complex contribution of biophysical conditions on farmers perception on 
land degradation; its causes, consequences and its necessary control measures have not been adequately considered (Lu and Stocking, 2000).

While the meaning and scope of land degradation for technical personnel is often clear (Scherr and Yadav, 1996), the way farmers perceive it remains unclear and cannot be generalized (Ali, 2004). Understanding such perceptions will help design effective measures against land degradation which are realistic and match with perceptions of the affected communities. For the West Usambara Mountains, despite the widely reported land degradation problems (Vigiak et al., 2005; Vigiak et al., 2006; Vrieling et al., 2006), it is still unclear whether policy and administrative leaders in that area perceive the problem of land degradation on the same footing as the affected farmers. In a study which covered socioeconomic conditions affecting SLM adoption in two villages of Lushoto district (Nyanga et al., 2016), farmers' willingness to invest in SLM measures was found to be influenced by four key factors: 1 . Access to support services by farmers; 2 . Experiences with collective action; 3. Revenues gained from crop sales; and 4. The forward driven attitude of individual farmers. However, that study did not answer as to why the adoption rates of SLM measures were so different between those villages since another study in the same villages (Wickama et al., 2015), had earlier showed that implementation of SWC measures differed strongly between them. Given that the two villages are both in the West Usambara Mountains, and only $70 \mathrm{~km}$ apart, it could be argued that socio-economic factors reported by Nyanga et., al (2016) are not that different between the two areas to explain the different adoption rates of the SLM measures between these two locations. In Ethiopia (Adimassu et al., 2013), institutional, socio-economic and biophysical factors were found to have a combined influence on perceptions related to land degradation and the investments required to reverse it. In Lushoto however, this relationship is not adequately known. Therefore, in this study we are evaluating how adoption of SLM measures in Lushoto partially relate to socioeconomic and bio-physical perceptions on land degradation by its district leaders and farmers. The objectives of this study were therefore i) to compare perceptions of administrative leaders, agricultural development staff and smallholder farmers towards land degradation ii) to identify and categorize the Sustainable Land Measures (SLM) being used in those villages; and (iii) to evaluate factors that stimulate or limit the adoption of the SLM practices in the villages studied. 


\subsection{Materials and Methods}

\subsubsection{Description of the study sites}

This study was conducted in Lushoto district, West Usambara Mountains in north eastern Tanzania, within latitudes $4^{\circ} 22^{\prime}$ to5 $8^{\circ}$ ' and longitudes $3085^{\circ}$ to $38^{\circ} 38^{\prime}$ (Figure 4.1 ). The district covers approximately $3500 \mathrm{~km}^{2}$ (Mowo et al., 2002). The major geological materials from which the soils of Lushoto are derived include metamorphic rocks like schists and gneisses. These cover the bulk of the district (Geological Survey of Tanganyika, 1963). The dominant soil types are Humic and Chromic Acrisols, Luvisols and Lixisols for mountainous hillands while valley bottoms have Fluvisols and pockets of Gleysols (Meliyo et al., 2001).

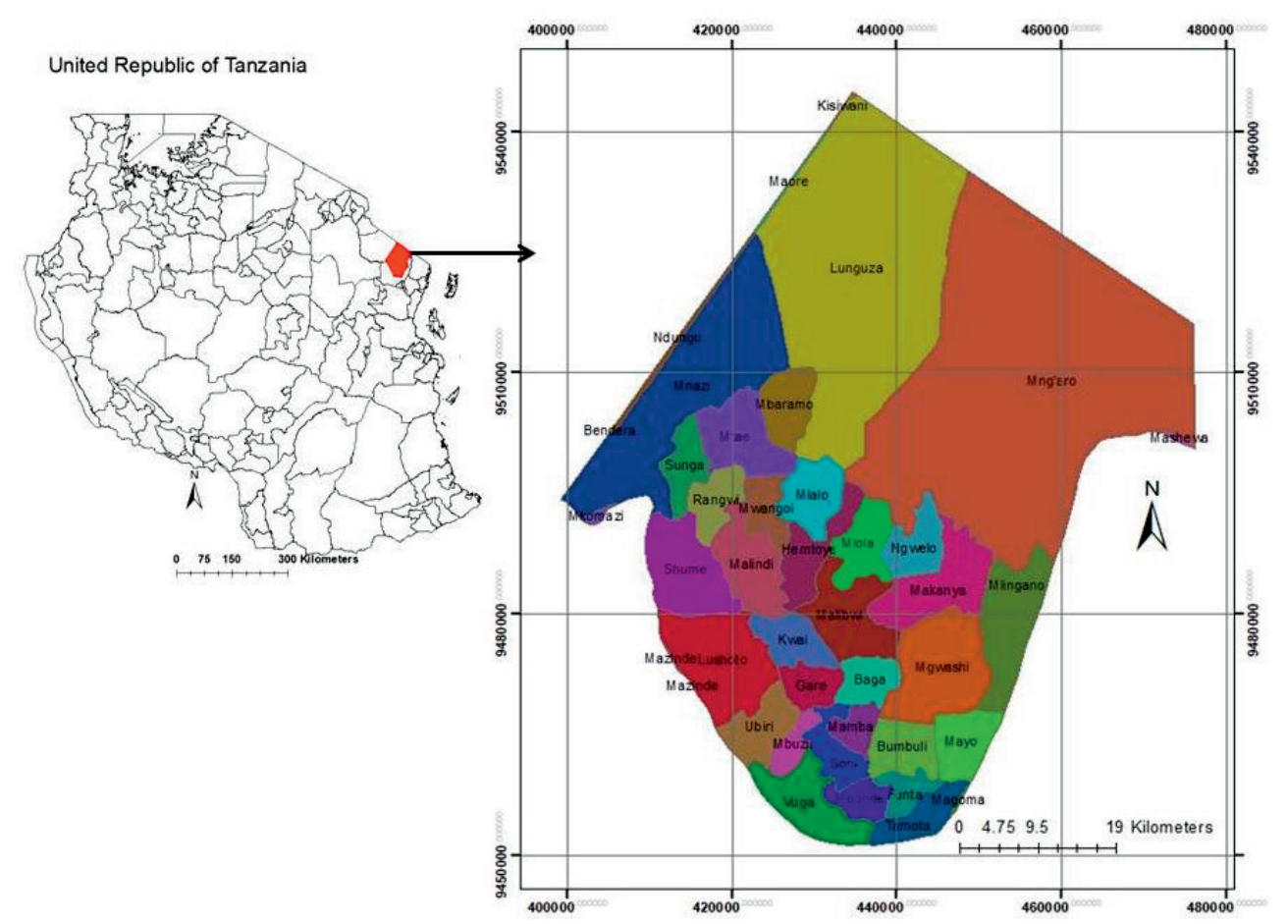

Figure 4.1 Left: Location of Lushoto district and its administrative areas.

Nearly $70 \%$ of West Usambara Mountains are located in Lushoto district (Halperin and Shear, 2005). Population density in the district is currently close to 134 people per $\mathrm{km}^{2}$ (DALDO-Lushoto, 2012), while its altitude varies from 600 meters on plains surrounding the mountains to 2300 meters above sea level (Pfeiffer, 1990). Records from the District Agricultural Office in Lushoto provide information about food insecurity and amount of food relief received across Lushoto district. During the period 2002-2007 on average $12.5 \%$ of 
the district's population was depending on food aid, and a total of 943 tons of food were provided to the needy households. This dependence however, was due to inadequate rainfall in parts of the district during that period. To fight land degradation problems, records at the District Agricultural Office in Lushoto show that during the years 2002-2007 the district had installed nearly 219 kilometers of SWCs (Table 4.1). Almost 22\% were installed in Mtae Division. Bench terraces formed almost $70 \%$ of the adopted SWCs. Stone bench terraces are only located in Kalumele, a hamlet also located in Mtae division.

Table 4.1 Lengths and proportions of SWC measures installed across Lushoto District in the period 20022007.

\begin{tabular}{llllll}
\hline & $\begin{array}{l}\text { Bench } \\
\text { Terraces }\end{array}$ & $\begin{array}{l}\text { Fanya Juu } \\
\text { Terraces }\end{array}$ & $\begin{array}{l}\text { Cut-off } \\
\text { Drains } \\
(\mathrm{m})\end{array}$ & $\begin{array}{l}\text { Stone } \\
\text { Terraces } \\
(\mathrm{m})\end{array}$ & $\begin{array}{l}\text { Total } \\
\text { Lengths SWCs }(\mathrm{m})\end{array}$ \\
\hline Sivision & 25434 & 7032 & 3100 & 0 & 35566 \\
Bumbuli & 12620 & 4113 & 1900 & 0 & 18633 \\
Lushoto & 22324 & 5050 & 3182 & 0 & 30556 \\
Mlalo & 33640 & 10150 & 2076 & 0 & 45866 \\
Mlola & 5458 & 2170 & 1838 & 0 & 9466 \\
Umba & 4250 & 1800 & 1136 & 0 & 7186 \\
Mgwashi & 9120 & 3423 & 1240 & 0 & 13783 \\
Mtae & 46410 & 8210 & 2013 & 1800 & 58433 \\
\hline Total & 159256 & 41948 & 16485 & 1800 & 219489 \\
Proportion (\%) & 72.6 & 19.1 & 7.5 & 0.8 & 100.0 \\
\hline
\end{tabular}

Source: Records at the District Agricultural Office, Lushoto (2010)

\subsubsection{Description of the study villages}

Two villages were selected for this study. Their salient features are in Table 4.2. These villages (Shashui and Sunga) were chosen on the merit of good accessibility, contrasting agro-ecological conditions (Pfeiffer, 1990), known soil erosion problems (Tenge et al., 2011), similar forest resources (Shagayu in Sunga, Ndelemai in Shashui) and contrasting adoption of soil conservation technologies (Wickama and Nyanga, 2009).

Table 4.2 Salient biophysical features between Shashui and Sunga villages, Lushoto Tanzania.

\begin{tabular}{lll}
\hline Characteristic/Location & $\begin{array}{l}\text { Soni Division } \\
\text { (Shashui village) }\end{array}$ & $\begin{array}{l}\text { Mtae Division } \\
\text { (Sunga village) }\end{array}$ \\
\hline Major forest(Halperin and Shear, 2005) & Ndelemai (1401ha) & Shagayu (6887ha) \\
Distance from district headquarters (km) & $14 \mathrm{~km}$, South east & 50km, North west \\
Agro-ecological zone (Pfeiffer, 1990) & humid \& warm & dry \& cold \\
Annual Rainfall (mm/yr) (Pfeiffer, 1990) & $800-1700$ & $500-800$ \\
Altitude (masl) (Pfeiffer, 1990) & $800-1800$ & $1700-2100$ \\
Temperature $\left({ }^{\circ} \mathrm{C}\right)$ (Pfeiffer, 1990) & 20 & 16 \\
Proportion of Area Conserved (\%) (Masselink, 2011) & 2.59 & 19.6 \\
\hline
\end{tabular}




\subsubsection{Data collection}

Qualitative data was collected through 3 types of meetings. The first meeting was a researchers-district leaders' meeting which was initiated in the $3^{\text {rd }}$ week of September 2009 in the form of a kick-off workshop. The workshop was held in Lushoto town at the Montessori Sisters' Convent. This workshop brought together these authors, district leaders and agricultural development personnel in the district. District leaders included heads of Government Departments and their assistants from Departments of Agriculture and Livestock Development; Forestry and Beekeeping; Planning and Community Development. Others included Division Secretaries and Ward Executive Officers. A total of 24 district leaders and agricultural development personnel attended this workshop. The objectives of this workshop were; (i) to confirm if land degradation especially soil erosion was a problem in Lushoto district; (ii) to document causes, consequences and common SLM interventions against it from a technical and resource persons' point of view and; (iii) to select two villages in the district where the final field works would be implemented. This type of information was collected through group discussions and also through voting by individual leaders whenever it was essential that responses are documented by percentages. A second type of meeting was a researchers-key informants meeting held in the two villages proposed by district leaders. Key informants were elected village leaders, like the village chairman (elected position), village executive officer (government employee) and members of the village council (elected positions). Meetings with the villages key informants were used to establish how farmers were organized (if at all) with reference to land degradation/soil erosion problems. Meetings with village leaders and key informants produced a list of SLM measures which farmers use to combat land degradation/soil erosion problems in the two villages. These meetings also classified common farmers' practices into different SLM categories and then estimated the proportions of farmers/households (in percentages) that belonged to such categories. Meetings with key informants were conducted as group discussions. In Sunga village a researchers-key informants meeting was held on the $24^{\text {th }}$ September 2009. Eight key informants attended. In Shashui village this meeting was held on the $28^{\text {th }}$ September 2009 where seven key informants also attended.

The third type of meeting was a researchers-farmers community meeting in each village. In Sunga village community meetings were conducted a day after meeting key informants. In Shashui village community meetings were conducted on the $30^{\text {th }}$ September 2009 being two days after holding a meeting with key informants. No criteria were preset for attendance. Community meetings were first used to verify district leaders' perceptions on land degradation, their causes, effectiveness of the SLM measures used to combat the degradation and factors enhancing or limiting farmers adopt them. During community meetings data was largely collected through group discussions and voting. However, in 
issues related to causes of land degradation, consequences and effectiveness of SLM measures used to combat land degradation each farmer was provided a piece of paper in which he/she responded to issues proposed by district leaders as they applied in his/her respective village by using a 5-point Likert scale rating (Likert, 1932), varying from 1 (strongly disagree) to 5 (strongly agree). Likert scoring was also extended to factors which farmers considered as stimulating or limiting adoption of SLM measures in their areas. A total of 130 farmers were covered in this study. From Shashui 65 farmers (47 men, 18 women) took part, and 117 farmers (69 men, 48 women) from Sunga participated. Second, community meetings were also used to verify the SLM categories and the proportion of farmers adopting them which were first proposed by village leaders/key informants. Same meetings also listed/verified the common SLM measures found in each SLM category. Finally through community meetings farmers classified their fellows into specific SLM categories. A village register was used to assist in the classification.

Quantitative data on ecological and biophysical conditions were collected through field inspections, measuring and recording data directly from smallholder fields during transect walks. In each village, a transect team composed of six people; these authors (2), three knowledgeable farmers and a member of the village government. Field transects were chosen with guidance from knowledgeable farmers such that the team would encounter fields belonging to all the proposed SLM categories. During these transects, only 20 fields representing all the SLM categories in each village were studied. Field transects were from hill top to hill top and crossed a valley. For Shashui village the transect walk was performed on the $1^{\text {st }}$ October 2009. This was roughly two weeks before onset of the short rains. This timing was chosen to allow the transect teams assess erosion features before fields were cultivated afresh. The transect in Shashui was roughly 2.2 kilometers long and started on the eastern portion of the village in Mzungu hamlet (Alt. 1470m UTM 0430695S, 9459949E) and ended at the western edge of the village in Kisiwani hamlet (Alt. 1378 UTM 0428738S 9464799E). This transect passed through the Mkuzu/Soni river valley and crossed 54 smallholder fields. In Sunga village, the transect walk was conducted right after community meeting $\left(25^{\text {th }}\right.$ September 2009). This transect took the northeast-southwest direction, starting on the north-eastern edge of the village (Alt.1920m UTM 0415508S, 9500446E) and ended at the southwest edge in the Tema hamlet (Alt. 1711m, UTM 0412518S, 9498832E). The walk crossed the Sunga-Tema valley and was 3.1 kilometers long. This transect walked through 63 smallholder fields.

The selected fields $(n=40)$ represented a sample of 5 fields for each of the SLM categories. Fields were studied for major crops, crop yields and selected biophysical characteristics (like surface slopes-, field sizes, erosion severity). Field sizes were estimated by measuring approximate lengths and widths of individual fields by using measuring tapes (meters). 
Records were also taken on; presence of SWC measures (bench terraces, Fanya juu terraces, grass strips), tree cover, and other characteristics of the house hold (no. of cattle, no. of fields owned). Locations of the fields were geo-referenced from their centre by using a hand-held GPS unit. Crop yields were estimated from each owner by recollection of the number of $90 \mathrm{~kg}$ bags harvested per growing season from the respective field for up to 3 years. These numbers were later converted later into equivalent yields in $\mathrm{kg} \mathrm{ha}^{-1}$. For soil erosion, soil losses per field were categorized as either: 1 ) negligible; 2 ) moderate; 3 ) severe. In many cases the transect walk team deliberated until a majority decision was reached before moving to another field.

\subsubsection{Statistical analyses}

The study was conducted as a paired plot design in which the 40 fields around the two villages were compared. As the number of farmers in the two villages differed (Shashui 65; Sunga 117), a random selection of 65 farmers was taken from the 117 farmers in Sunga to have two populations of equal size. Descriptive statistics were used to characterize selected parameters between the SLM groups and the two villages. F-tests for equality of variances and $t$-tests for comparisons of means were used to analyze differences in biophysical variables between the two villages and the SLM categories. However, farmers' responses on non-parametric issues were collected as percentages or by use of a Likert scale (Likert, 1932). The Likert scores were only averaged for each individual factor.

\subsection{Results}

\subsubsection{Condition of the studied fields}

Biophysical conditions of the 40 fields visited during transect walks are in Table 4.3. The altitude on which these fields were located, was significantly $\left(\alpha<\begin{array}{lll}0 & 0 & 5\end{array}\right)$ different between the two villages, with higher elevations of the fields around Sunga. Mean surface slopes varied significantly ( $\left.\alpha<\begin{array}{lll}0 & 0 & 5\end{array}\right)$ from 3 3n. \$upgig to $40.6 \%$ in Shashui. The major crops in these fields were maize (zea mays) and ground beans (phaseolus vulgaris). Most fields (92\%) cultivated these two crops as intercrops. In Shashui village, maize was planted at the beginning of the long rains season (Mar.-June) and when it reached 6-8 weeks it was intercropped with beans. In Sunga village, the maize was planted during short rains (Oct.Dec.) when it was relatively warmer. The minor crops grown in both villages included potatoes, cassava, sweet potatoes and other legumes like cowpeas. Potatoes were grown as a second crop on the same fields during the periods when both maize and beans were 
not growing. Potatoes were of cash importance and often irrigated in Sunga village but rain fed in Shashui village. Some households also planted cassava and sweet potatoes in their fields especially when soil fertility had deteriorated considerably.

Table 4.3 Biophysical features of 40 fields in Shashui and Sunga villages, Lushoto district, Tanzania.

\begin{tabular}{|c|c|c|c|c|c|}
\hline \multirow[t]{2}{*}{ Feature } & \multicolumn{2}{|c|}{ Shashui $(n=20)$} & \multicolumn{2}{|l|}{ Sunga $(n=20)$} & \multirow[t]{2}{*}{ Difference $^{\dagger}$} \\
\hline & Average/total & StDev & Average/total & StDev & \\
\hline Field elevation (masl) & 1297.7 & 93.0 & 1793.1 & 50.4 & * \\
\hline Slope of field (\%) & 40.6 & 10.4 & 33.1 & 11.3 & $*$ \\
\hline Field sizes (ha) & 0.36 & 0.12 & 0.50 & 0.17 & $*$ \\
\hline Fields owned & 4.6 & 2.1 & 3.9 & 2.2 & ns \\
\hline \multicolumn{6}{|l|}{ Fields with SWC structures } \\
\hline (\%) & 5 & - & 45 & - & \\
\hline Crop yield & 596.0 & 212.5 & 770.2 & 203.4 & * \\
\hline $\begin{array}{l}\text { Maize (kg/ha) } \\
\text { Bean (kg/ha) }\end{array}$ & 455.7 & 113.2 & 728.3 & 178.3 & $*$ \\
\hline Livestock per household & 2.2 & 1.4 & 1.6 & 1.6 & ns \\
\hline Trees/household & 20.2 & 14.5 & 57.5 & 92.5 & $*$ \\
\hline \multicolumn{6}{|l|}{ Erosion severity of fields } \\
\hline Negligible (\%) & 35 & - & 55 & - & \\
\hline Moderate (\%) & 40 & - & 40 & - & \\
\hline Severe (\%) & 25 & - & 5 & - & \\
\hline
\end{tabular}

$\dagger^{*}=$ significant difference at $\alpha=0.05 ; \mathrm{ns}=$ non-significant difference

The average field size per household was significantly $(\alpha<0 \quad .0$ 5m)aller in Shashui than in Sunga. The number of fields owned per household, however, did not differ significantly. In addition, in Shashui village, households owned significantly $(\alpha<0$.0 Sewver trees than in Sunga village. In Shashui village, households owned between 1 and 72 trees (mean 20.2) while in Sunga village, tree ownership ranged from 4 to 452 trees (mean 57.5). At the timing of the survey, the two villages had comparable levels of livestock per household. Farmers in both villages though reported that the livestock ownership is lower than 10-20 years before. Only $5 \%$ of the fields inspected in Shashui had bench terraces (Figure 4.2), which contrasted sharply with the $>45 \%$ of fields in Sunga area which had bench terraces (Figure 4.3). The contrast in adoption level between the two villages was also observed by Wickama et al. (2015), who used remote sensing techniques to locate bench terraces and grass strips in the same regions. In Kenya, during the 1990s, smallholder communities used collective action to install bench terraces across delineated hydrological catchments in what was named as the Catchment Approach (Thompson and Pretty, 1996). In Sunga, farmers reported to have also used an equivalent of the catchment approach to construct bench terraces on many fields simultaneously. This collective action was facilitated by a 20-year German-funded Soil Erosion Control and Agroforestry Project (SECAP) which provided among its incentives, food and irrigation water for bench terrace constructors. This approach was not adopted in 
Shashui village and not surprisingly, our transect walks revealed more fields with severe erosion in Shashui village than in Sunga (Table 4.3). Five fields in Shashui village were found to have severe forms of erosion (prominent rills \& sheet erosion). In Sunga village, only one field was encountered to have similar features. It was also observed that for fields which had bench terraces, slumping of the terrace walls was a common problem. Despite the importance of other factors like steeper slopes and higher amount of annual rainfall the higher amount of erosion around Shashui is the result of its lower adoption of SWC measures compared to Sunga. Generally, soils in both villages are deep, well drained and developed from gneiss and other related metamorphic rocks. Soils are predominantly Acrisols (Wickama et al., 2014), which tend to have an unstable structure and are easily eroded unless soil erosion control measures are taken into account (Donahue et al., 1995).

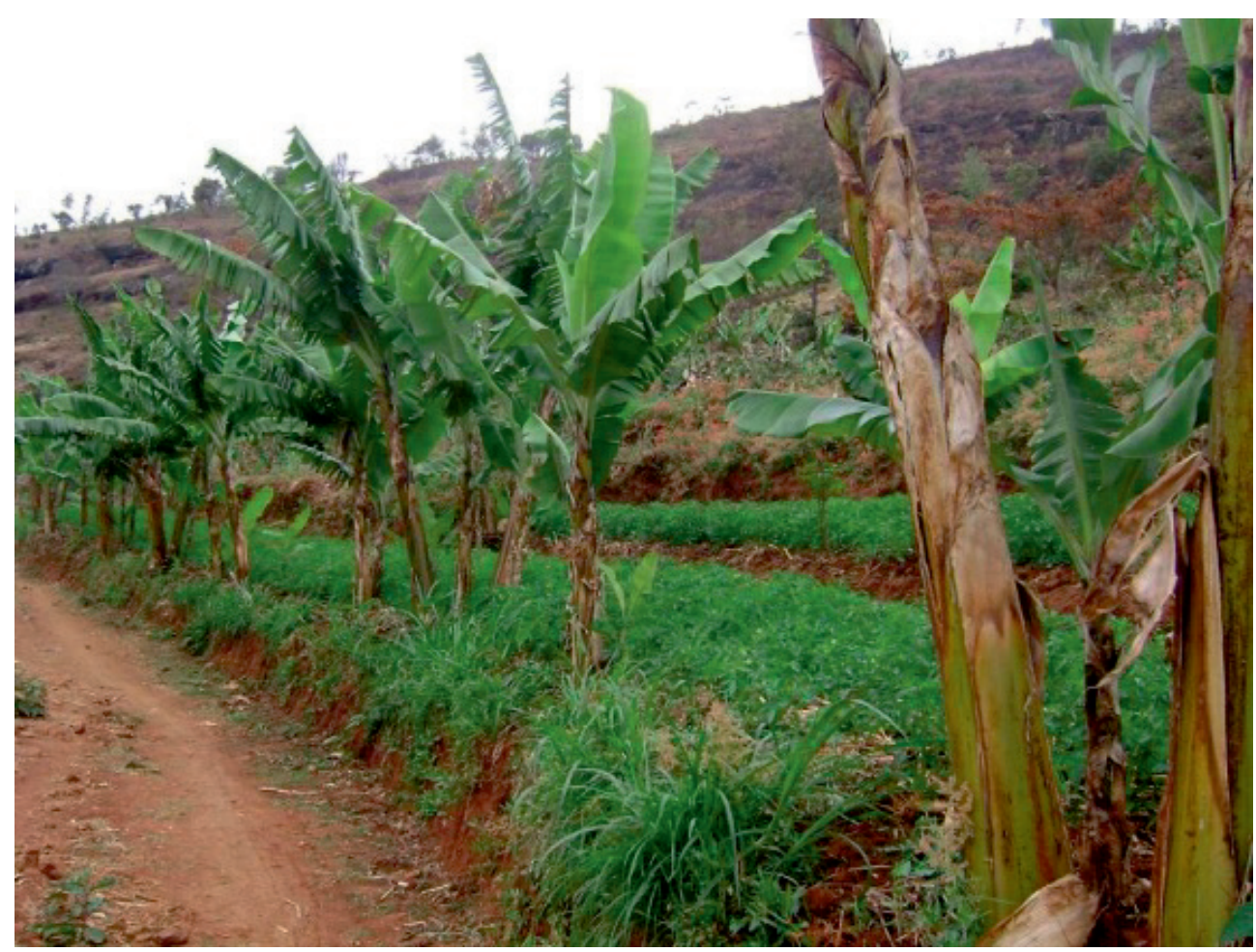

Figure 4.2 Bench terraces in smallholder fields in Shashui village, Lushoto district, Tanzania. 


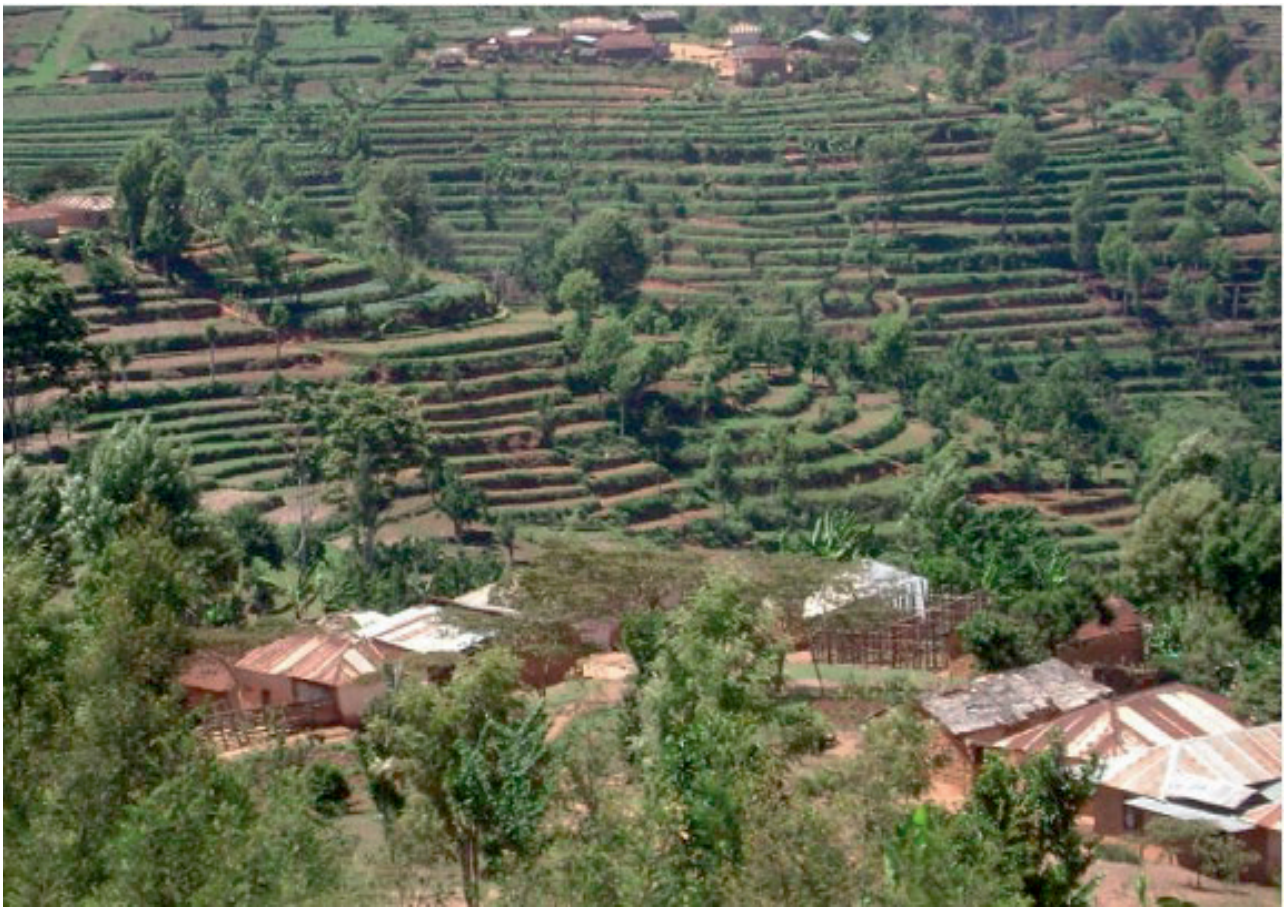

Figure 4.3 Bench terraces near Sunga village, Lushoto district, Tanzania.

\subsubsection{Perceptions on land degradation}

In the discussions with district leaders and agricultural development workers (meeting 1), the majority (82\%) perceived land degradation was a major problem in Lushoto district (Table 4.4). Participants then identified three factors which they perceived as contributing to land degradation in the West Usambara Mountains: 1. soil erosion, 2. declining soil fertility, and 3. deforestation (Table 4.4). These causes were blamed as contributing towards a number of agricultural problems, such as weakening of soil structure, increased appearance of rocks/stones in the landscapes, declining crop yields, growing dependence on inorganic fertilizers, declining household incomes, reduced natural vegetation and frequent floods.

To stop land degradation, district leaders and agricultural development workers reported that the district has a history of supporting all efforts geared at improving vegetative cover in the district. An example is the 20-year German-funded Soil Erosion Control and Agroforestry Project (SECAP), which planted over ten million trees (Johansson, 2001). Accordingly, the district has continued to support other projects with tree planting components across the district. For instance, in one catchment (Baga Catchment), 48000 
tree seedlings were distributed to farmers in the year 2007 alone by another programme called African Highlands Initiative (AHI) (Hussein and Wickama, 2007). District leaders and agricultural development staff (82\%) also associated post-independence (early 1960s) clearance of prime forests for expansion of agricultural land to the reduction of rainfall in places like Mtae division (where Sunga village is located) where food insecurity has become an increasing problem. District leaders and agricultural development staff (72\%) also believed that infertile and eroded lands in Lushoto district were more food insecure. Coincidentally, records from the District Agricultural Office in Lushoto on food relief in the district for periods 2000-2007 indicate Mtae area to be most food insecure in the district.

Table 4.4.Perceived causes of land degradation by district leaders/agricultural development staff and farmers in Lushoto district, Tanzania.

\begin{tabular}{lll}
\hline \multirow{2}{*}{ Cause } & $\begin{array}{l}\text { District leaders/agricultural development } \\
\text { staff } \\
\%(\mathrm{n}=24)\end{array}$ & $\begin{array}{l}\text { Farmers } \\
\%(\mathrm{n}=130)\end{array}$ \\
\hline Soil erosion & 87.5 & 87.7 \\
Poor soil fertility & 62.5 & 36.2 \\
Deforestation & 95.8 & 82.3 \\
\hline Mean & 81.9 & 68.7 \\
Stdev & 14.2 & 23.1 \\
\hline
\end{tabular}

Generally, $83 \%$ of farmers in Shashui and Sunga $(n=130)$ agreed that land degradation is a problem in their two villages. During group discussions with farmers of Shashui village land degradation was defined as the declining ability of the soil to support strong crop growth and support livelihoods. In Sunga farmers gave a more detailed description of the manifestations of land degradation in their area. This included: low crop yields; poor crop performance; soil erosion; frequent floods; declining household incomes; poor soil fertility; declined natural vegetation; dependence on external nutrient sources (e.g. industrial fertilizer); weakening of soil structure (light soils); deforestation; appearance of rock or stones. To reverse land degradation the farmers of Sunga and Shashui recommended a number of measures which are considered to conserve the soil: reforestation; planting grass strips; use of animal manure; use of cut-off drains in affected areas; educating farmers on soil conservation; formulation and enforcement of SLM related bylaws which protect the environment and ecological resources. In Lushoto, as are all districts in Tanzania village laws which protect natural resources at village level are formulated at village level and eventually passed by the District Councils (represents a local government body) and are collectively referred to as "bylaws". Once legally endorsed, these bylaws are enforced by the respective village government through a Government representative at village level known as the village executive officer

Most farmers ( $80 \%$ Shashui, $69 \%$ Sunga) believed soil erosion and deforestation played a major role in degrading the landscape. They were however skeptical that poor soil fertility 
caused land degradation and differed with district leaders/agricultural development staff on this point (Table 4.4). Farmers (62\% Shashui; $76 \%$ Sunga) believed that soil erosion and poor land management of fields caused soil fertility to drop. The major perceptions on how development personnel and farmers of the two villages perceive causes of land degradation are in Tables 4.5-4.7. A comparison of perceptions on causes of land degradation between the two farming communities is presented in Table 4.5. It is clear that the perceptions on the causes of land degradation in the two village areas are not much different. In both villages soil erosion is considered the most important reason for degradation of the environment, closely followed by deforestation. As mentioned earlier, the majority of farmers in both villages believed that poor soil fertility is a consequence of land degradation, and not a cause (Table 4.5).

Table 4.5 Farmers' perceptions on land degradation causes in two village areas, Lushoto district, Tanzania.

\begin{tabular}{|c|c|c|c|c|c|c|c|c|c|c|c|c|}
\hline \multirow[t]{3}{*}{ Cause } & \multicolumn{6}{|c|}{ Shashui $(n=65)$} & \multicolumn{6}{|c|}{ Sunga $(n=65)$} \\
\hline & \multicolumn{5}{|c|}{ Likert score ${ }^{\S}$} & \multirow[b]{2}{*}{ Mean } & \multicolumn{5}{|c|}{ Likert score } & \multirow[b]{2}{*}{ Mean } \\
\hline & 1 & 2 & 3 & 4 & 5 & & 1 & 2 & 3 & 4 & 5 & \\
\hline Soil erosion & 2 & 2 & 4 & 18 & 39 & 4.38 & 3 & 5 & 11 & 15 & 31 & 4.02 \\
\hline Poor soil fertility & 16 & 19 & 6 & 13 & 11 & 2.75 & 14 & 21 & 6 & 14 & 10 & 2.77 \\
\hline Deforestation & 2 & 9 & 7 & 8 & 39 & 4.12 & 7 & 4 & 10 & 12 & 32 & 3.89 \\
\hline
\end{tabular}

§Likert score 1 means strongly disagree; score 5 means strongly agree.

When the consequences of land degradation are considered (Table 4.6), the majority of farmers in both villages perceived that land degradation results in poor crop development (74\%), and lower crop yields (70\%). Most farmers (74\%) also agreed that this makes them more dependent on fertilizers, and that their household income is negatively affected (70\%). No clear differences between the two villages existed, except for the weakening of soil structure and the degradation of natural vegetation. Both consequences of land degradation were perceived as a bigger problem in Shashui (soil structure: 68\%; natural vegetation: $80 \%$ ) than in Sunga (soil structure: 54\%; natural vegetation: $66 \%$ ). Farmers of Shashui cultivate soils with a heavier soil texture due to higher clay contents (Wickama et al., 2014). Their concerns about the weakening soil structure is probably related to the fact that erosion is a selective process that disproportionally removes fine soil particles (clay and silt) and leaves an increasingly coarse soil texture which weakens the soil structure (Chartier et al., 2013). For this reason these concerns in the weakening of soil structure in the fields of Shashui are reflective of consequences of soil erosion in these fields which farmers could only relate to general land degradation and not soil erosion per se. The most likely reason for the stronger worry about natural vegetation decline in Shashui is probably that the Shashui area used to be quite rich in natural vegetation compared to the Sunga area. However, since Shashui village is exposed to more commercial opportunities, this exposure has often triggered illegal logging in the natural forests surrounding it thus making vegetation disappearance in that village become more visible. Similar concerns were 
mentioned by farmers in a nearby village of Kwalei for the same reasons (Wickama, 2007). Only $34 \%$ of farmers from both villages thought floods in their villages could be linked to land degradation. This was perceived as a bigger problem in Sunga (42\%) than in Shashui $(26 \%)$.

Table 4.6 Farmers' perceptions of land degradation consequences in two village areas, Lushoto district, Tanzania.

\begin{tabular}{|c|c|c|c|c|c|c|c|c|c|c|c|c|}
\hline \multirow[t]{3}{*}{ Consequence } & \multicolumn{6}{|c|}{ Shashui $(n=65)$} & \multicolumn{6}{|c|}{ Sunga $(n=65)$} \\
\hline & \multicolumn{5}{|c|}{ Likert score } & \multirow[b]{2}{*}{ Mean } & \multicolumn{5}{|c|}{ Likert score } & \multirow[b]{2}{*}{ Mean } \\
\hline & 1 & 2 & 3 & 4 & 5 & & 1 & 2 & 3 & 4 & 5 & \\
\hline Low crop yields & 3 & 2 & 6 & 17 & 37 & 4.28 & 5 & 6 & 5 & 13 & 36 & 4.06 \\
\hline $\begin{array}{l}\text { Rock or stones } \\
\text { appearance }\end{array}$ & 1 & 9 & 22 & 23 & 10 & 3.49 & 9 & 10 & 12 & 18 & 16 & 3.34 \\
\hline $\begin{array}{l}\text { Low household } \\
\text { incomes }\end{array}$ & 4 & 5 & 13 & 8 & 35 & 4.00 & 2 & 7 & 8 & 22 & 26 & 3.97 \\
\hline $\begin{array}{l}\text { Poor crop } \\
\text { performance }\end{array}$ & 3 & 2 & 7 & 23 & 30 & 4.15 & 3 & 9 & 10 & 15 & 28 & 3.86 \\
\hline $\begin{array}{l}\text { Dependence on } \\
\text { fertilizers }\end{array}$ & 2 & 5 & 9 & 13 & 36 & 4.17 & 6 & 4 & 8 & 18 & 29 & 3.92 \\
\hline $\begin{array}{l}\text { Weakening of soil } \\
\text { structure }\end{array}$ & 4 & 9 & 8 & 11 & 33 & 3.92 & 13 & 10 & 7 & 16 & 19 & 3.28 \\
\hline $\begin{array}{l}\text { Declined natural } \\
\text { vegetation }\end{array}$ & 5 & 2 & 6 & 9 & 43 & 4.28 & 5 & 7 & 10 & 19 & 24 & 3.77 \\
\hline Frequent floods & 6 & 18 & 24 & 9 & 8 & 2.92 & 14 & 21 & 3 & 9 & 18 & 2.94 \\
\hline
\end{tabular}

During community meetings, a majority of farmers (89\% Shashui; $92 \%$ Sunga) reported that land degradation (esp. soil erosion) has increased in recent times. The elderly farmers (6 in Shashui, 4 in Sunga) recalled that in the early 1940's most of the currently cultivated land was under forest and was given to them after independence (1960s). It was after the opening of this land for cultivation and not being able to rotate the fields that current soil losses and reduced crop yields were noticed. In addition, farmers (87\% Shashui, 82\% Sunga,) reported that there are fewer livestock numbers per household today than 30-40 years ago. Though on comparison, the number of livestock kept per household in each village was not significantly different (Table 4.3), according to farmers actual numbers of livestock in each village have been declining progressively over the years.

When looking at the five top most proposed interventions against land degradation (Table 4.7 ), there was agreement among farmers ( $>75 \%$ of both villages combined) on only three SLM measures' effects on land degradation (bench terraces, contour cultivation and planting, application of manure). The two villages differed on the effectiveness of the remaining SLMs. Tree planting and fallowing were considered measures to reduce land degradation by less than $35 \%$ of all farmers which was unexpected, because the Shashui farmers had mentioned re-afforestation as a possible measure to control land degradation 
in their community meeting. In addition, a traditional way of conserving land in the West Usambara Mountains is by traditional agro-forestry (Johansson, 2001). A possible reason for the negative perception could be that trees need many years to mature and provide full protection to soils, and hence their immediate impact on land degradation reduction is minimal. Further, another possible reason is that farmers often think of re-afforestation more as something done in upland areas while tree-planting relates more to planting trees in their fields (Bewket, 2003). For farmers, the two concepts are frequently distinct.

Table 4.7 Farmers' perceived effectiveness of measures used to reduce land degradation in two village areas, Lushoto district, Tanzania.

\begin{tabular}{|c|c|c|c|c|c|c|c|c|c|c|c|c|}
\hline \multirow{3}{*}{$\begin{array}{l}\text { Conservation } \\
\text { practice }\end{array}$} & \multicolumn{6}{|c|}{ Shashui $(n=65)$} & \multicolumn{6}{|c|}{ Sunga $(n=65)$} \\
\hline & \multicolumn{5}{|c|}{ Likert score } & \multirow[b]{2}{*}{ Mean } & \multicolumn{5}{|c|}{ Likert score } & \multirow[b]{2}{*}{ Mean } \\
\hline & 1 & 2 & 3 & 4 & 5 & & 1 & 2 & 3 & 4 & 5 & \\
\hline Bench terraces & 2 & 2 & 4 & 18 & 39 & 4.38 & 5 & 5 & 6 & 19 & 30 & 3.98 \\
\hline Tree planting & 16 & 19 & 6 & 13 & 11 & 2.75 & 14 & 21 & 6 & 14 & 10 & 2.77 \\
\hline Fanya juu terraces & 2 & 9 & 7 & 8 & 39 & 4.12 & 11 & 9 & 5 & 4 & 36 & 3.69 \\
\hline Grass strips & 2 & 3 & 3 & 19 & 38 & 4.35 & 11 & 16 & 12 & 22 & 4 & 2.88 \\
\hline Cut off drains & 6 & 8 & 4 & 15 & 32 & 3.91 & 3 & 4 & 5 & 12 & 41 & 4.29 \\
\hline $\begin{array}{l}\text { Application of } \\
\text { manure }\end{array}$ & 3 & 2 & 6 & 17 & 37 & 4.28 & 5 & 3 & 5 & 24 & 28 & 4.03 \\
\hline Mulching & 4 & 5 & 13 & 8 & 35 & 4.00 & 2 & 7 & 10 & 22 & 24 & 3.91 \\
\hline Crop rotation & 3 & 2 & 7 & 23 & 30 & 4.15 & 3 & 9 & 12 & 13 & 28 & 3.83 \\
\hline Use of compost & 2 & 5 & 9 & 13 & 36 & 4.17 & 6 & 4 & 9 & 18 & 28 & 3.89 \\
\hline $\begin{array}{l}\text { Knowledge on } \\
\text { fertilizer, soils and } \\
\text { crops }\end{array}$ & 5 & 2 & 6 & 9 & 43 & 4.28 & 5 & 7 & 12 & 17 & 24 & 3.74 \\
\hline Fallowing & 6 & 18 & 24 & 9 & 8 & 2.92 & 14 & 21 & 4 & 9 & 17 & 2.91 \\
\hline Irrigation & 3 & 5 & 9 & 18 & 30 & 4.03 & 2 & 4 & 8 & 17 & 34 & 4.18 \\
\hline $\begin{array}{l}\text { Contour cultivation } \\
\text { and planting }\end{array}$ & 6 & 3 & 3 & 11 & 42 & 4.23 & 2 & 5 & 10 & 12 & 36 & 4.15 \\
\hline
\end{tabular}

Major differences between the two villages existed on three measures to control land degradation. $88 \%$ of the famers in Shashui had good expectations of the use of grass strips, while only $40 \%$ of the Sunga farmers appreciated grass strips. In addition, the Shashui farmers also had better expectations of crop rotation (82\%) and good information on the appropriate use of fertilizers (80\%). In Sunga, only $63 \%$ of the farmers believed that crop rotation and fertilizer information would help to reduce land degradation. 


\subsubsection{Categories of SLM measures}

In this study, a Sustainable Land Management (SLM) category is a package of measures that a farmer usually implements in his/her field as part of routine means of managing the land. During group discussions with key-informants (meeting 2) and farmers (meeting 3 ) in the two villages, measures that improve crop production and reduce land degradation were listed and categorized from poor to excellent SLM. Across the two sites there was a close similarity in the characteristics which farmers used to create these SLM categories. There was reference to soil and moisture conservation, protection of the land against deforestation, soil erosion problems, adoption of sound agricultural advice, livestock keeping, nutrient application and high value cropping. The SLM categories from the two villages were then combined and four distinct categories of SLM were defined (Table 4.8). SLM 1 means excellent land management, which sustains agricultural production now and in the future. SLM 4 on the other hand is a category that barely invests in the land, but some measures are there to control land degradation and improve crop production.

All four SLM categories were present in the village areas of Shashui and Sunga, but the adoption of SLM categories (1 and 2) was better in Sunga (Table 4.8). These contrasting levels of adoption of SLMs between the two villages was first mentioned by administrative leaders of Lushoto district (Wickama and Nyanga, 2009). This disparity was later confirmed by use of remote sensing techniques for the mapping of grass strips and bench terraces in the two areas (Wickama et al., 2015).

\subsubsection{Factors affecting adoption of SLM measures}

The farmers were asked what factors limited them to adopt good SLM practices (Table 4.9). In Shashui, the most limiting factors to SLM adoption were i) weak enforcement of SLM bylaws; ii) limited access to knowledge on land conservation; iii) lack of willingness of the community to acquire and practice the advocated measures; and iv) the costs of maintenance of the advocated measures. In Sunga village, the most limiting factors were i) lack of livestock; ii) dependence on non-farm income; iii) limited resource capacity e.g. money and labor, and iv) distance of field from farm. These limiting factors will be discussed in more detail in the general discussion. 


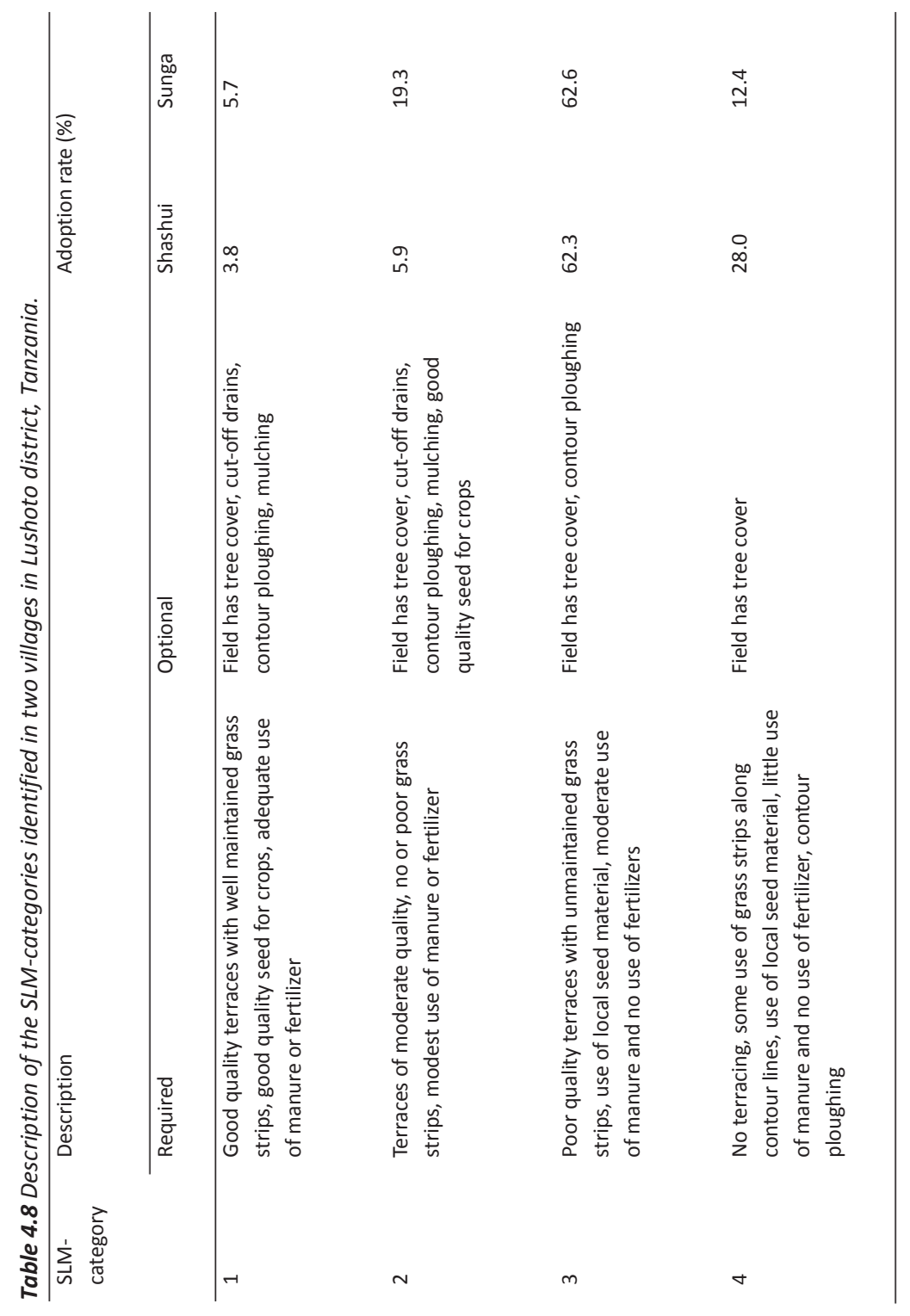


Table 4.9 Farmers' perceptions on factors limiting adoption of SLM measures in Shashui and Sunga village areas, Lushto district, Tanzania.

\begin{tabular}{lll}
\hline Limiting factor & $\begin{array}{l}\text { Shashui }(n=65) \\
\%\end{array}$ & $\begin{array}{l}\text { Sunga }(n=65) \\
\%\end{array}$ \\
\hline Cost of maintenance of SLM measures & 73.8 & 44.6 \\
Limited resource capacity e.g. money and labor & 13.8 & 83.1 \\
Lack of livestock & 18.5 & 90.8 \\
Dependence on non-farm income & 33.8 & 84.6 \\
Distance of field from farm & 26.2 & 78.5 \\
Lack of farming plans & 52.3 & 58.5 \\
Lack of willingness of community to acquire and practice SLM & & \\
measures & 84.6 & 32.3 \\
Limited access to knowledge on land conservation & 86.2 & 32.3 \\
Weak enforcement of by-laws & 92.3 & 46.2 \\
\hline
\end{tabular}

Farmers also rated factors that stimulated them to adopt the SLM measures of Table 4.8. Again a large difference between the two villages was obtained (Table 4.10), which is discussed in more detail in the general discussion of this article. The three factors that were most stimulating to the Shashui farmers were i) improvement of environmental quality; ii) contribution of measure to household food self-sufficiency; and iii) capability of measure to improve yields. In Sunga, farmers were more positively influenced by i) existence of facilitating agency; ii) owning valley bottom land parcels; and iii) availability of irrigation water. Irrigation water has a higher priority as an incentive towards adopting SLM measures in Sunga than in Shashui. This is understandable given the fact that their area is in the drier agro-ecological zone of Lushoto district (Pfeiffer, 1990). Sunga village was the first to receive support from an NGO called TIP (Traditional Irrigation Improvement Program) for installation of terraces and supply of irrigation water. Support for Shashui only came later (Mshana, 2009). For farmers in Shashui village the reasons were much different since the area belongs to another agro-ecological zone which enjoys better rainfall compared to Sunga. Besides, the Soni area is among those areas of Lushoto district that produce vegetable which are sold in the markets of Dar-es-Salaam (DALDO-Lushoto, 2012). In Lushoto district, vegetables are mainly cultivated in the valley bottoms. Though these valley bottoms occupy only $5 \%$ of the area, they produce $75 \%$ of financial household needs (Lyamchai et al., 1998). This makes farmers of Shashui less reliant on their hill slope lands for household needs, which lowers their motivation for SLM measures on those fields.

It can be seen that though availability of irrigation water was a factor which ranked high as a determinant of whether a family would adopt SLM measures or not, it was not a condition that qualified any SLM. The importance of irrigation stems from differences in the amounts of annual rainfall available to each village and field conditions of their soils. Sunga village receives annually less than $700 \mathrm{~mm}$ rainfall and generally has soils with a lighter texture than soils in Shashui village (Wickama et al., 2014). This makes profitable production of cash 
crops (vegetables and round potatoes) nearly impossible without irrigation water to overcome soil moisture deficiency in the area.

Table 4.10 Farmers' perceptions of factors stimulating adoption of SLM measures in Shashui and Sunga village areas, Lushoto district, Tanzania.

\begin{tabular}{lll}
\hline Stimulating factor & $\begin{array}{l}\text { Shashui }(n=65) \\
\%\end{array}$ & $\begin{array}{l}\text { Sunga }(n=65) \\
\%\end{array}$ \\
\hline Availability of irrigation water & 30.8 & 83.1 \\
Existence of facilitating agency e.g. TIP, SECAP & 47.7 & 92.3 \\
Owning valley bottom land parcels & 15.4 & 90.8 \\
Capability of measure to improve yields & 63.1 & 21.5 \\
Contribution of measure to household food self-sufficiency & 83.1 & 32.3 \\
Improvement of environmental quality & 86.2 & 44.6 \\
\hline
\end{tabular}

\subsection{Discussion}

\subsubsection{Perception on land degradation and sustainable land management}

The fact that $>80 \%$ of Lushoto district leaders/agricultural development staff and $62 \%$ of farmers in our two sites were of the opinion that land degradation (esp. soil erosion) was high in their area, actually supports findings from past studies in the district that the West Usambara Mountains have soil erosion problems (Buch, 1983; Ezaza, 1988; Mwango et al., 2016). These findings also support earlier concerns that the East African Highlands represent a region where land degradation is actively happening and threatening livelihood of its farming communities (Sanchez, 1994). The proportions of farmers perceiving land degradation in Lushoto are also similar to those observed in Arumeru District, northern Tanzania where $70 \%$ of smallholder farmers in that area perceived land degradation to be severe (Kajembe et al., 2005). This implies that nearly two thirds of smallholder farmers in the West Usambara Mountains perceive land degradation to be taking place in their fields and villages. When causes of land degradation (Table 4.4) and their magnitude are considered, it is difficult to visualize what caused differences in perception between district leaders/agricultural development staff and farmers of the two villages. Perceptional mismatch between farmers and technical personnel or policy leaders on land degradation issues have been attributed to among other reasons on experience and specificity of effect/impact (Räsänen et al., 2017). That is, while technical personnel are often of general perception towards resource degradation, farmers tend to harbor specific perceptions based on local experience. In our case, district personnel and leaders were referring to degradation of the entire district while farmers were considering their own villages. However, it will also be recalled that for a longtime (>80 years), the West Usambara Mountains have received many soil and water conservation projects. Some of these projects 
(like SECAP and TIP) have also benefited the local economies in Lushoto and the recipient villages. It seems logical conclude that this long and historical contact with institutional support may have "colored" district officer perceptions/responses as well as from those farmers/villages like Sunga into higher responses regarding severity of land degradation or its causes. For example, though $82 \%$ of district leaders, agricultural development staff associated post-independence clearance of prime forests to the declining amounts of rainfall in the district, these claims are not supported by a 61-year long record of rainfall (1928-2004) available at the District Agricultural Offices in Lushoto. Rather, these opinions are only shaped by past reports describing clearance of forests in Lushoto district (Conte, 1999; Ezaza, 1992; Johansson, 2001) and its assumed impact on rainfall patterns in the area.

These results have also revealed that smallholder farmers in Lushoto harbor concerns on the quality of enforcement of bylaws which protect natural resources in their villages (Table 4.9). It will be noticed that extension personnel and leaders did not mention this weak spot as contributing to land degradation in the district. This omission is possibly related to their own involvement in supervising the enforcement. Earlier, a study covering five villages close to Shashui (Wickama, 2007) also reported that degradation of natural resources in their villages was because of inadequate enforcement of existing by-laws which protected- these resources which led to destructive agricultural land use practices and increase of illegal activities. In Arumeru district, northern Tanzania, only 52 percent of farmers believed those by-laws were effective. The rest felt that degradation in their village happened because of inadequate enforcement of village bylaws (Kajembe et al., 2005). It seems therefore degradation of land resources in most areas like the West Usambara Mountains was not caused by absence of policy or bylaws but because of inadequate enforcement of existing by-laws.

It seems that farmers/villages tend to respond more towards SLM measures which they have tested or have experienced their effectiveness. For instance, the higher perception for grass strips in Shashui (Table 4.3) was linked with households in that village owning more livestock. Hence grass strips in that village not only reduce soil reduce soil erosion on the slopes but also provide forages for their animals. On the other hand, their high regard for fertilizer application was most probably linked to the relatively poor fertility of their soils compared with Sunga (Wickama et al., 2014). For Sunga village, the higher appreciation for irrigation water was because the village is located in a drier agro-ecological zone (Pfeiffer, 1990), which has relatively coarse-textured soils (Wickama et al., 2014) and thus a lower water holding capacity. For this reason, irrigation water in Sunga is crucial for farmers to harvest any meaningful crops from their gardens. The low perception of trees as reducing land degradation in Shashui village was unexpected (Table 4.7) because farmers had mentioned re-afforestation as a possible measure to control land degradation in the 
community meeting. A possible reason for this perception could be that in Shashui farmers have smaller plots (Table 4.3) for which they can ill-afford to reduce field space by planting more trees. Farm sizes have often been linked to adoption or non-adoption of certain technologies (Mendoza-Escalantea et al., 2003) and farm trees in Shashui could be the case unlike Sunga village where field sizes were larger and trees were of commercial value due presence of a saw mill which bought trees from farmers.

\subsubsection{Categories of SLM measures}

What makes the SLM categories observed in the West Usambara Mountains of Tanzania unique is that they are not based on household wealth ranking but on the effort a farmer invests in making the field remain productive. Further, the SLM categories in the West Usambara Mountains comprise of measures which are optional for each category. Absence of these optional measures does not mean the farmer in that category is a poor manager but only that circumstances of enterprises on his/her field were different. For example, while mulching of vegetable plots is considered an important practice which would earn a farmer a superior SLM category, it was impractical that the same farmer would mulch a twoacre maize field on a hill slope and therefore its absence in the maize plot would not lower the SLM category standing of this farmer. This makes the SLM categories in Lushoto differ with SLM categories from Malawi (Tamene et al., 2016) where socio-economic factors such as household wealth, household members, type of off-farm employment and number of years the household head has been involved in farming decision making were used to classify smallholder farmers. The SLM categories in Lushoto district also differ with those recently reported from Ethiopia (Asrat and Simane, 2017) in which farmers were categorized based on their adoption of SLM measures that coped with climate change impacts. A recent study in Tajikistan also classified smallholder farmers based on the area of their fields (small, medium and large) and the number of animals they were keeping as a proxy towards understanding and predicting the SLMs they were adopting (Ruppen et al., 2016).The SLM categories observed in the West Usambara Mountains are similar to those reported from Egypt (El-Nahry and Abdel Kawy, 2013) where four SLM classes were also identified. The major criterion used to separate SLM categories in Egypt was the sustainability of farming practices. Like in West Usambara Mountains, the majority of farmers (63.4\%) in Egypt were found to have management practices which were not sustainable. It seems therefore that in most smallholder societies, farmers who do not adopt the recommended and most sustainable technologies actually form the majority. 


\subsubsection{Factors affecting adoption of SLM measures}

The relatively low adoption of superior SLM measures in the West Usambara Mountains (Table 4.8) is not something unique. A project advocating conservation agriculture (CA) in Tanzania also complained of low adoption rates (2-21\%) for technologies it was disseminating with the majority adopting the CA technology by $<10 \%$ (Ndah et al., 2012). For Shashui, the contrast with Sunga in the adoption of bench terraces could be related to past institutional focus of the water-for-terrace scheme (Mshana-2013, personal communication) in which the primary focal area for that scheme was Sunga village where it wanted to draw project lessons first. It is probably for this reason that farmers in Shashui always had feelings that their fellows in Sunga were better trained in soil conservation than themselves. However, a recent study has reported that the low willingness to acquire and practice SLM measures in Shashui can also be linked to their better access to commercial opportunities and supportive socio-ecological conditions compared to Sunga village. These opportunities discourage many households in Shashui from adopting SLM measures like bench terraces because many households are involved in non-farm incomes (Nyanga et al., 2016). When we single out a factor which contributed most to the terracing in the two villages, probably no other factor has played a major role in the contrasted adoption of SWCs in the two villages than irrigation water and indirectly the prevailing rainfall amounts in each village. In Shashui village, farmers voluntarily dug a 6-kilometre canal to bring irrigation water onto their bench terraced gardens with the help from the TIP Program. In Sunga village, farmers dug a $10-\mathrm{km}$ canal and eventually established bench terraces covering $40 \%$ of their area for similar reasons (Figure 4.3) which supports what was earlier reported from Ethiopia (Shiferaw et al., 2009) that availability of irrigation water enhanced adoption of soil conservation technologies.

\subsection{Conclusions}

These results have shown that land degradation is a problem affecting Lushoto district and a number of its villages. Though district leaders and agricultural development workers in the district blame its occurrence on; soil erosion, declining soil fertility and deforestation, farmers in Lushoto dispute role of declining soil fertility which they see as the result. The point on which both parties concur is that the current degradation is contributing towards reduced soil qualities, declining crop yields, chronic dependence on inorganic fertilizers, declining household incomes, reduced natural vegetation and frequent floods. Further, both administrative leaders and smallholder farmers have comparable perceptions on the type of SLM measures that can control the degradation. There are however, significant differences in biophysical conditions between the two villages used in this study (Sunga and 
Shashui) in terms of rainfall received, elevation, surface slopes, field sizes, extent of conservation, crop yields, domestication of trees, and severity of erosion which make Sunga village in dire need of SWCS for food security reasons. The higher adoption of SWCs in Sunga village is therefore attributable to the challenging biophysical conditions facing it.

Based on the four effort-based categories (SLM category 1 through 4) observed in our area, it can be concluded that $<5 \%$ of farmers have excellent land management practices (SLM category 1 ) that sustain agricultural production. A small proportion (SLM category 2; 12.6\%) has fields with good tree cover, cut-off drains, contour ploughing, mulching, good quality seed for crops. Though a majority (SLM category $3 ; 62.3 \%$ ) have also adopted some SLM measures, these measures are of poor quality which casts doubt on their effectiveness for soil erosion control. A sizeable proportion of farmers have invested very little in their fields and form almost a fifth (SLM category $4 ; 20.2 \%$ ) of farmers in the two villages. Based on farmers' testimonies, it can be concluded that the factor which contributed most to them terracing/not terracing their fields is availability of irrigation water. Rainfall differences between these two villages are the major determinant that has dictated the observed contrast in their adoption of SLM measures especially installation of bench terraces.

Despite results obtained in our study, there are certain gaps and limitations which can benefit from future research. For instance, considering that the fight against erosion and land degradation in Lushoto is $>80$ years old while only $5 \%$ of farmers have high quality SLM measures (SLM category 1), it is important that the extension services in the district tailor their approaches to consider the diversity of biophysical conditions in Lushoto district. These observations therefore imply that the extension services need to immediately target farmers belonging to SLM category 3 since they are the majority (>60\%) and they have at least adopted SWCS only that the quality of these SLM measures need to be improved. A long term plan of engagement would then suit those with minimum investment in SWC measures (SLM category 4). Further, though key informants and farmers have grouped famers into various SLM categories, it is not adequately known how vulnerable these categories are in terms of soil erosion and crop yields. Also, smallholder farmers in Lushoto cultivate their gardens in the form of agro-ecosystems for which not much is documented and assessed in terms of erosion. Control of soil erosion in the district can benefit from knowledge generated to seal such gaps. 


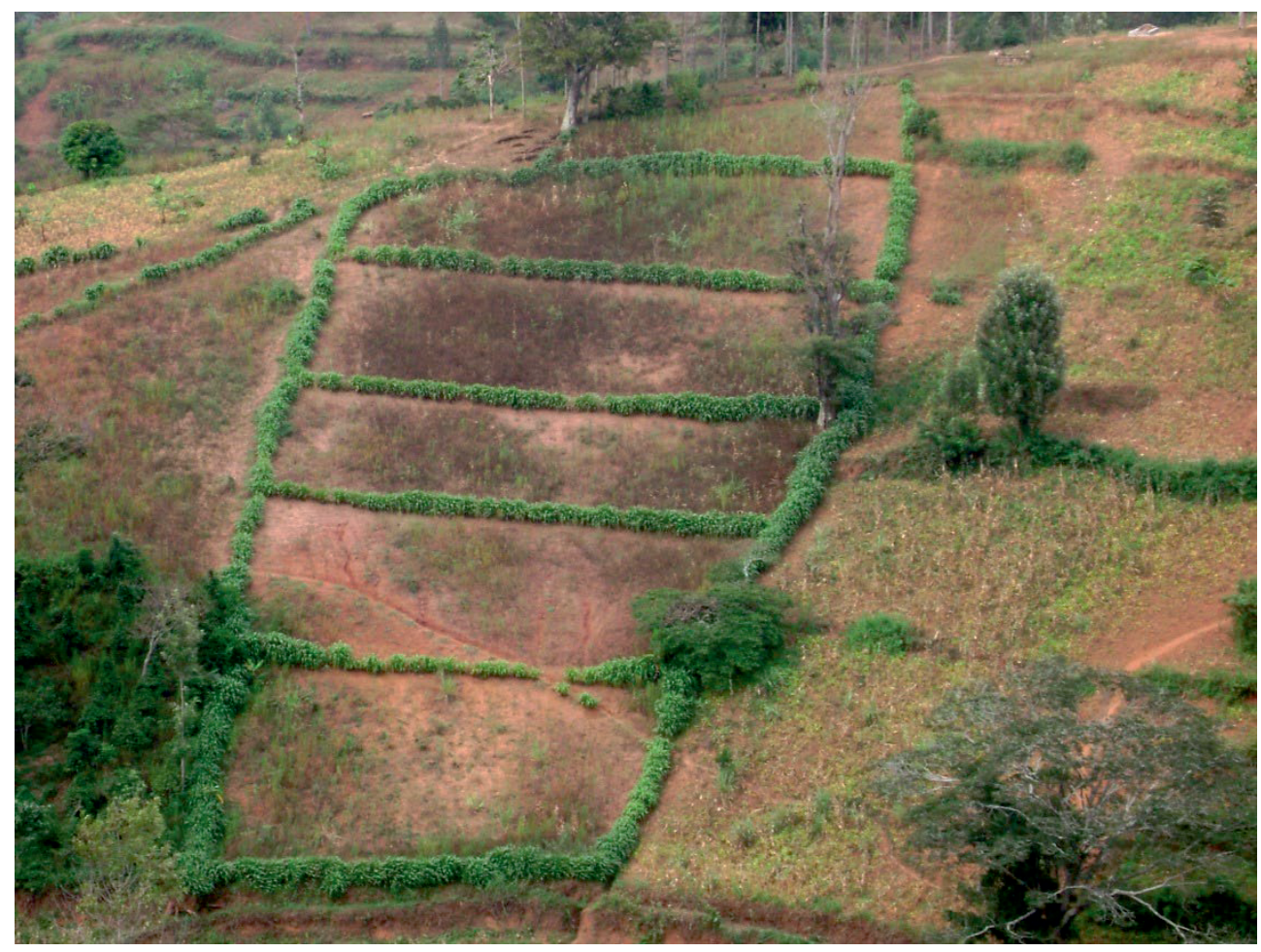




\section{Effectiveness of sustainable land management measures in West Usambara highlands, Tanzania}

Soil erosion is a serious problem that affects food security and social livelihoods in the highlands of East Africa. Sustainable land management (SLM) measures have been widely promoted to reduce erosion and increase crop yield, but the adoption of SLM measures has remained low. In order to understand the contribution of biophysical factors on adoption, this study was carried out to (i) determine the biophysical conditions of fields with SLM measures; (ii) assess the impact of different SLM measures on soil degradation; (iii) determine the effects of SLM measures on crop productivity. The study was conducted in Lushoto district, north-eastern Tanzania. Sixty fields with five different SLM categories were studied. The five SLM categories ranged from no intervention at all (SLM 5 - control plots), to excellent land and crop management, including well-constructed bench terraces and application of farmyard manure (SLM 1). SLM 2 also has terraces, but the management is not as good as for SLM 1. SLM 3 has some poorly maintained terraces or grass trips, while SLM 4 has only poorly maintained grass strips. The bio-physical properties of the fields were determined, and measurements of meteorology, soil properties, soil erosion and crop yield were carried out during the period October 2009 June 2011. The results showed that the better SLM categories (SLM 1 and 2) are preferentially implemented on less steep slopes, and they do stabilize the slope and reduce soil losses by water erosion significantly. The use of high amounts of farmyard manure ( $>$ 6.0 ton $\mathrm{ha}^{-1} \mathrm{yr}^{-1}$ ) on the terraces of SLM 1 and 2 category fields resulted in a 3 to 4 times higher yield of maize compared to the control plots (SLM 5), while yield of beans increased 6 to 7 times compared to the control plots. Despite the use of farmyard manure on better managed fields, no significant improvements of soil fertility were found. This is probably because the amounts applied are too small to allow build-up of soil nutrients.

Based on:

Wickama J, Okoba B., and Sterk G. (2014). Effectiveness of sustainable land management measures in West Usambara Highlands, Tanzania. Catena 118 (2014) 91-102. 


\subsection{Introduction}

The East African highlands occupy only one quarter of the collective area of Burundi, Ethiopia, Kenya, Rwanda, Tanzania, and Uganda, but are home to more than 50 percent of their combined population (Kassie et al., 2010; Nyssen et al., 2009). The agro-socioecological importance of these highlands is their adequate water, reliable precipitation, good soils, rich vegetation cover and minimal occurrence of malaria. This favourable rating has drawn in many people to settle and exploit natural resources, leading to high population densities of sometimes more than 300 people per $\mathrm{km}^{2}$. Unfortunately, the growing population coupled with poor resource-use practices have resulted in widespread land degradation problems, which now contribute to the agricultural crisis in the East African highlands. Land degradation in highland agro-ecosystems have been reported from Kenya (Gachene et al., 1997), Rwanda (Byiringiro, 1995) and Tanzania (Tenge, 2005).

The West Usambara highlands in Tanzania are one of the East African Highland zones that suffer from land degradation (Conte, 2004). They consists of crystalline block mountains which are part of the Eastern Arc Mountains located in north-eastern Tanzania. Massive land degradation in this region began with the introduction of commercial crops and establishment of related estates (Johansson, 2001). Within a few years of establishing crop plantations and introduction of commercial crops, serious soil erosion from both the plantations and the new cash crop fields was reported. Not just commercial land use activities suffered from soil degradation. Also, the many smallholder farmers who cultivate small plots ( $<1 \mathrm{ha}$ ) on steep slopes to grow food crops experience problems of soil erosion (Tenge, 2005).

Numerous soil conservation schemes since the 1930s were implemented in the West Usambara highlands to reverse soil degradation though many of them failed because of being implemented by coercion (Maddox, 2006). On the other hand, even schemes which were implemented through a participatory manner have also reported a dismal adoption of the advocated technologies (German et al., 2010), which suggests that problems may not be purely methodological. Other studies have also indicated adoption of technologies to be constrained by socio-economic conditions (Matata et al., 2010), policy issues (Marenya et al., 2012), institutional issues (Komakech and van der Zaag, 2011) and biophysical conditions (Mbilinyi et al., 2007).

Sustainable land management (SLM) measures are described as "a system of technologies and/or planning that aims to integrate ecological with socio-economic and political principles in the management of land for agricultural and other purposes to achieve intra- 
and intergenerational equity" (Hurni, 1997). In this study, SLM means technologies which farmers implement in their fields as a package to improve farming conditions. During a reconnaissance survey, SLM measures which farmers in the West Usambara highlands use to combat land degradation were found to include: tree planting; bench terraces; fanya juu terraces; contour grass strips; cut-off drains; application of livestock manure; application of good agricultural husbandry (use of high quality seeds, following extension advice in their agricultural enterprises); mulching; crop rotation; use of compost; livestock keeping (a source of manure); use of fertilizer (for good crop cover and yields). Typically, the SLM technologies consisted of a few of these measures as a package. However, only five percent of farmers in the survey had adopted such SLM packages (Wickama and Nyanga, 2009).

A number of studies have indicated that farmers' choices of SLM measures is essentially a socio-economic decision (Mascarenhas, 2000; Tenge et al., 2007). Yet, for technologies to improve natural resource management, the difficulty in adopting them is reported to be rooted in their location-specificity such that one cannot generalize (Lee, 2005). One issue that has not been addressed extensively in the SLM adoption discussion is how the local biophysical factors impact on the effectiveness of certain SLM types (Lefroy et al., 2000). For instance, in the West Usambara highlands, it is generally recommended to adopt certain soil conservation measures depending on the slope steepness. It is assumed that slope steepness is the principal determinant of the effectiveness of the soil conservation measures. Yet, adoption of the advocated measures has been little perhaps because other biophysical conditions (soil type, field size, cropping system, agro-meteorology, etc.) play an important role as well. If relationships between biophysical conditions and SLM effectiveness exist, this could explain, at least partly, why adoption is not always logical to a farmer.

Experience from India indicates that profitability of natural resource investments was observed to depend on factors like the natural fertility of soils, topography, climate and the length of the growing period (Shiferaw et al., 2009). In the United States, it was also reported that adoption of farm technologies depended on such factors like farm size, farmer demographics, soil quality, urban influences, farmer status of indebtedness, and location (Isgin et al., 2008). It should be noted that soil quality, farm size and location are biophysical factors. Earlier, it had been observed that a close relationship exists between soil fertility, land quality, rainfall and other local/regional biophysical factors to the adoption and diffusion patterns of conservation tillage, Integrated Pest Management (IPM) and fertilizer application (Aldy et al., 1998). It has also been reported that biophysical factors featured prominently in the adoption of IPM, agro-forestry, and soil conservation technologies among Central American farmers (Ramirez and Shultz, 2000). In Ethiopia, it has been reported that slope and farm size were important factors considered by farmers before 
constructing soil conservation measures such as terraces in their fields (Ketema and Bauer, 2012).

In view of the above, it may be assumed that biophysical factors are important for both the performance and the effectiveness of SLM measures, but it is not sufficiently known which specific biophysical factors are dominant in influencing effectiveness of such SLM-measures. Hence, studying the effectiveness of SLM measures across different biophysical conditions can increase our knowledge on the relation between biophysical factors and SLM effectiveness. Such knowledge may assist in promoting effective SLM measures that successfully reduce soil degradation in areas with similar biophysical conditions. Therefore, the aim of this study was to determine the effectiveness of the SLM measures as practiced by local farmers in the West Usambara highlands in relation to biophysical conditions. Specifically the study addressed the following objectives:

1. Determine the biophysical conditions of fields where SLM measures have been adopted;

2. Assess the extent to which the different SLM measures reduce soil degradation;

3. Establish the impact of SLM measures on crop productivity in relation to the different biophysical conditions.

\subsection{Materials and Methods}

\subsubsection{Description of the study area}

The West Usambara highlands are located in north-eastern Tanzania, between latitudes $4^{\circ}$ $23^{\prime}$ to $5^{\circ} 08^{\prime}$ South and longitudes $38^{\circ} 05^{\prime}$ to $38^{\circ} 40^{\prime}$ East. They rise from the surrounding plains at $600 \mathrm{~m}$ to $2300 \mathrm{~m}$ above sea level (Pfeiffer, 1990). The study was conducted in Lushoto District, Tanga region, which covers approximately $70 \%$ of the West Usambara highlands. The topography of Lushoto district is mountainous and highly dissected in some parts. The parent materials from which the soils are derived are metamorphic rocks like gneisses, schist and other forms of granulites (Geological Survey of Tanganyika, 1963). Soils are generally deep (>1 m), and the major soil types in Lushoto district are Humic, Haplic and Chromic Acrisols, Luvisols and Lixisols for most of the mountainous uplands. Fluvisols with some pockets of Gleysols dominate the valley bottoms (Meliyo et al., 2001). Lushoto district has an area of approximately $3500 \mathrm{~km}^{2}$ and a population density of 134 people per $\mathrm{km}^{2}$, making it one of the most densely populated districts in Tanzania (Mascarenhas, 2000). Lushoto has a number of protected natural forests in which most of the naturally occurring vegetation is found. Approximately $2000 \mathrm{~km}^{2}$ of the district are used for arable crop production (Mowo et al., 2002). The district grows tea, coffee, maize, banana, beans, 
sugarcane, and a number of temperate fruits. Lushoto is dominated by smallholder, low input subsistence type of land use. Landholdings have shrunk to one hectare or less per household. The most intensive cultivation takes place in the valley bottoms (representing $10 \%$ of the entire landscape) where high-value vegetables are grown.

Temperatures in Lushoto district can range from $0^{\circ} \mathrm{C}$ at night to a maximum exceeding $25^{\circ}$ $C$ during the day. There are two major rainfall seasons, the long rains ("masika") which start around mid March and last to the end of June, and the short rains ("vuli") which start in October and last till the end of December. The short rains account for $25 \%$ of the total rainfall being received on these highlands and are less reliable than the long rains, but they are the most important for growing annual crops like maize and beans. These crops require temperatures higher than $20^{\circ} \mathrm{C}$ that actually occur during the period of October to March (Mascarenhas, 2000). In terms of spatial rainfall distribution, there is a gradient of rainfall decrease from east to west and from south to north of the mountains. The annual amount of precipitation depends on the agro-ecological zone (AEZ), of which there are four in Lushoto district (Figure 5.1) (De Pauw, 1984). The study was conducted in the AEZ's E12 and E2. Zone E12 is a high altitude zone located in the north western flanks of the district. The zone is characterized by high altitudes (1200-2000 masl) with relatively low temperatures $\left(16^{\circ} \mathrm{C}\right)$. Zone E2 is characterized by moderate altitude (800-1800 masl), with average daily temperatures of $20^{\circ} \mathrm{C}$ or more and is mostly found in the central and eastern flanks of the district. Levels of precipitations in zones E12 and E2 are about $800-1000 \mathrm{~mm}$ per year (De Pauw, 1984).

In both AEZ's, two villages with contrasting levels of adoption of SLM measures were selected for a detailed study. The villages of Shashui $\left(38.40^{\circ}\right.$ East and $4.90^{\circ}$ South) and Kisiwani ( $38.36^{\circ}$ East and $4.85^{\circ}$ South) were selected from agro-ecological zone E2. These two villages are 14 and 12 kilometers east of Lushoto town, respectively. The topography around them is mountainous and highly dissected. Two other villages, Tema (38.20 East and $4.52^{\circ}$ South) and Sunga ( $38.23^{\circ}$ East and $4.52^{\circ}$ South) were selected from agroecological zone E12. These villages are located 59 and 55 kilometers north-west of Lushoto town, respectively. Their topography is also mountainous but less dissected. A total of 60 fields were selected for this study. In the surroundings of each of the four study villages 15 fields were selected, representing three landscape zones: 1) foot slopes, 2) mid slopes, and 3) uplands (higher parts). In each landscape zone, five fields were located, and each of these five fields was representing one category of SLM measures. Five categories of SLM measures (Table 5.1) were identified during a reconnaissance survey in the four villages (Wickama and Nyanga, 2009). 


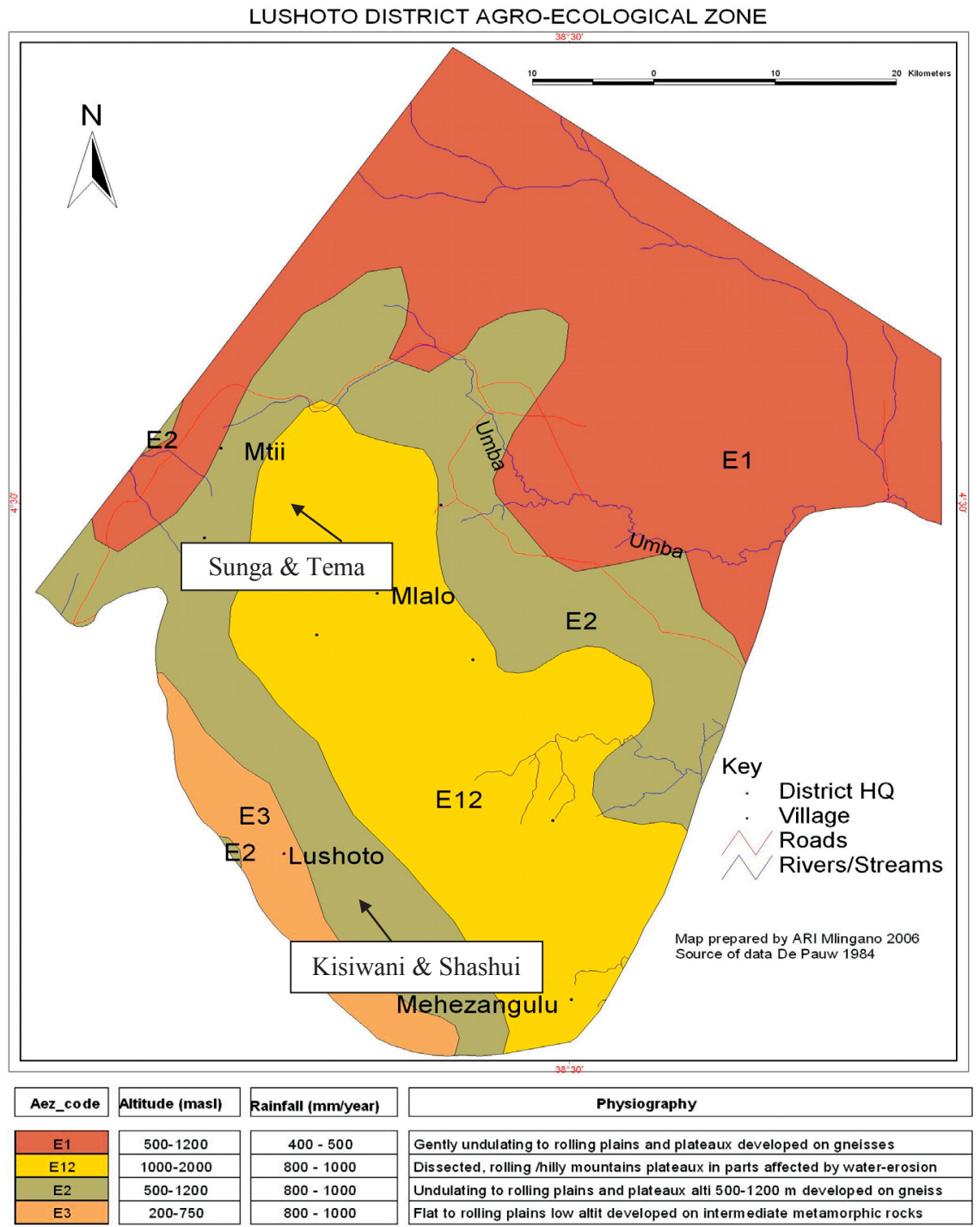

Figure 5.1 Location of the study villages and the agro-ecological zones, Lushoto District, Tanzania Source: (De Pauw, 1984).

In the field, the best way of recognizing the SLM categories is the quality of the different SLM practices (see Figure 5.2). The SLM 1 category must have well-constructed and well maintained terraces, in combination with other good crop management practices such as nutrient application and use of good quality seed. Category SLM 2 does similar practices but the quality is a bit lower than that of SLM 1. This includes planting own seed, instead of grade seed. Category SLM 3 does not perform some of the measures completely. Their fields have poor terracing, not well cared grass lines, and irregular application of manure. The 
major characteristic of a category SLM 4 field is that it is not cared. It is left as a fallow for part of the year until when the rainy season starts. But, ploughing is applied along the contour. All the four SLM categories (SLM 1 - 4) may have optional technologies (Table 5.1), such as tree cover (either planted or naturally occurring), showing that fields falling in one SLM category may not entirely look the same. Finally category SLM 5 is the field which receives no SLM whatsoever.
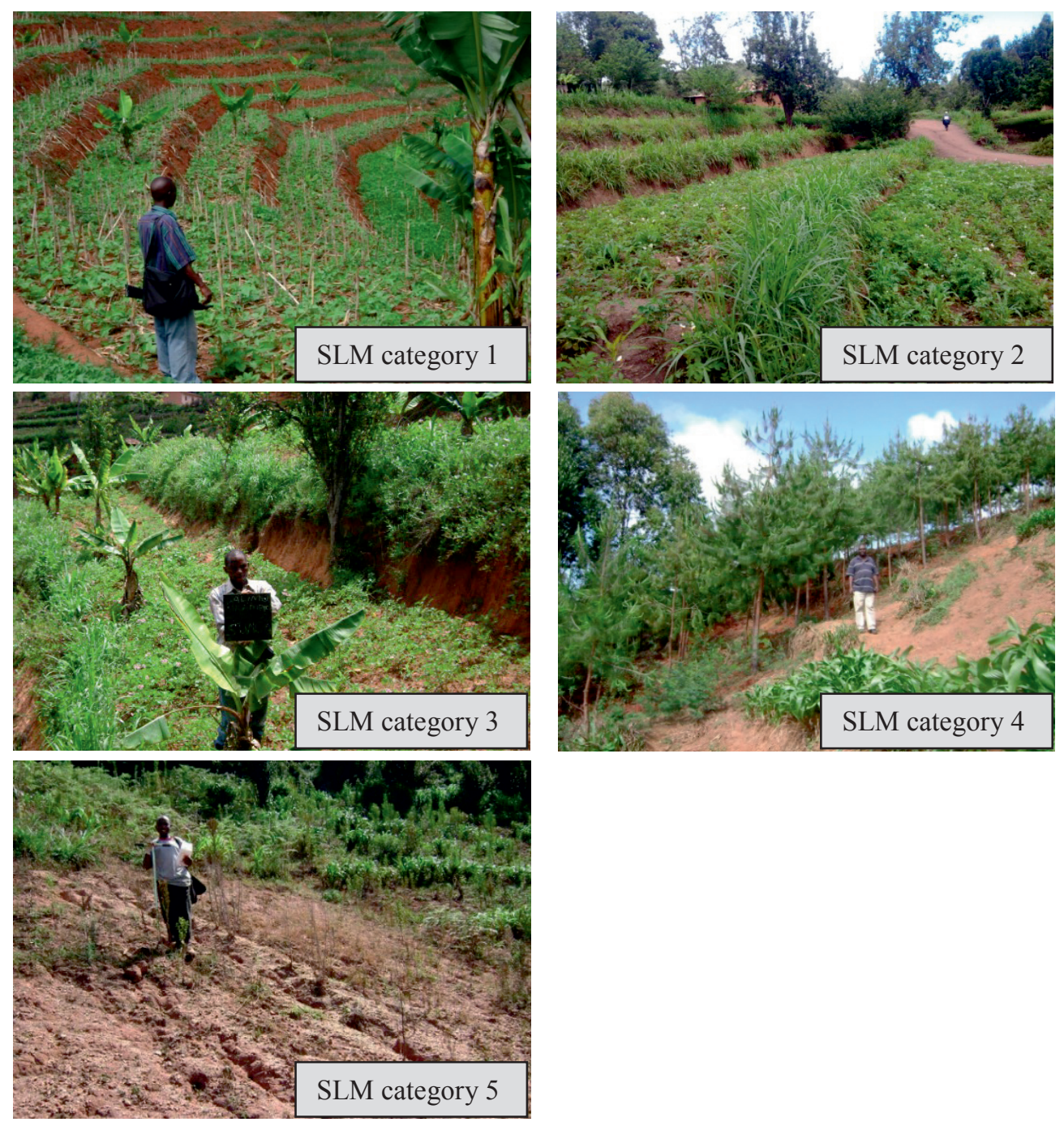

Figure 5.2 Pictures of the different SLM categories in Lushoto district, Tanzania. 
Table 5.1 Description of the SLM-categories identified in four villages in Lushoto District, Tanzania.

\begin{tabular}{|c|c|c|}
\hline \multirow[t]{2}{*}{ SLM-category } & \multicolumn{2}{|l|}{ Description } \\
\hline & Required & Optional \\
\hline 1 & $\begin{array}{l}\text { Good quality terraces with well maintained grass } \\
\text { strips, good quality seed for crops, adequate use of } \\
\text { manure or fertilizer }\end{array}$ & $\begin{array}{l}\text { Field has tree cover, cut-off drains, } \\
\text { contour ploughing, mulching }\end{array}$ \\
\hline 2 & $\begin{array}{l}\text { Terraces of moderate quality, no or poor grass strips, } \\
\text { modest use of manure or fertilizer }\end{array}$ & $\begin{array}{l}\text { Field has tree cover, cut-off drains, } \\
\text { contour ploughing, mulching, good } \\
\text { quality seed for crops }\end{array}$ \\
\hline 3 & $\begin{array}{l}\text { Poor quality terraces with unmaintained grass strips, } \\
\text { use of local seed material, moderate use of manure } \\
\text { and no use of fertilizers }\end{array}$ & Field has tree cover, contour ploughing \\
\hline 4 & $\begin{array}{l}\text { No terracing, some use of grass strips along contour } \\
\text { lines, use of local seed material, little use of manure } \\
\text { and no use of fertilizer, contour ploughing }\end{array}$ & Field has tree cover \\
\hline 5-control & $\begin{array}{l}\text { No terracing, no grass strips, use of local seed material, } \\
\text { little use of manure and no use of fertilizer, no tree } \\
\text { cover }\end{array}$ & \\
\hline
\end{tabular}

\subsubsection{Measurements}

Field measurements were conducted from October 2009 through June 2011. This period covered four rainy seasons; the October-December 2009 (short rains); March-June 2010 (long rains); October-December 2010 (short rains) and March-June 2011 (long rains). The initial phase (October-December 2009) was mostly a reconnaissance one which concentrated in the Kisiwani-Shashui site. In the other periods, data was also collected from the other agro-ecological zone (Sunga and Tema). Four major types of measurements were conducted: 1) biophysical factors; 2) soil characteristics; 3) soil erosion; and 4) crop management and yield. The biophysical factors measured were field slopes (using an inclinometer), field sizes including slope lengths (using a measuring tape), field elevations (using a GPS), distances between the SLM fields and the farm houses (also using a GPS), and meteorology. For the latter, two weather stations were installed, one in the Sunga/Tema site and one in the Kisiwani/Shashui site. At those stations, daily temperature, relative humidity, wind speed, precipitation and solar radiation were measured every hour. For soil characterization, the soils in each field were sampled from $0-20 \mathrm{~cm}$ depth and at 3 positions (up-slope, mid-slope and down-slope). The depth of the topsoil (A-horizon) was visually determined and measured. These depths varied (4-19 centimetres) depending on how eroded the fields were. For soil texture and chemical analyses approximately one kilo of the soil was collected. The soil samples were air dried ( 8 days), ground and sieved through a 2 $\mathrm{mm}$ sieve. Analysis of soil particle size distribution was done by use of the hydrometer 
method (Gee and Bauder, 1986) after dispersing the soil using calgon. For chemical properties, the analyses included soil pH (McLean, 1982), organic carbon (Nelson and Sommers, 1982), total nitrogen (Bremner and Mulvaney, 1982), bases (Thomas, 1982) and the available phosphorus using the Bray-Kurtz 1 (Olsen and Sommers, 1982). Water infiltration tests were done using the double ring method after pre wetting the soils for 3 minutes. The infiltration measurements were carried out just once at the beginning of the long rains season (April 2011), and at two positions in each field. These positions were at the upslope and down slope parts of the field.

Soil erosion in the 60 fields was assessed using the Assessment of Current of Erosion Damage (ACED) methodology (Herweg, 1996). With ACED, the depth, width and length of erosion rills was measured to estimate the magnitude of soil loss in the 60 fields. Also the dimensions of slumps on terrace risers were measured to determine the stability of the terraces, which was regarded as an indication for terrace maintenance. If sedimentation of upslope eroded material was observed, this was also measured. The study fields were surveyed with ACED thrice in each growing season (before the rains, mid rainy season and after the harvests) to determine the changes in soil loss or gain over time. For rills, the total volume of the erosion features was regarded as representing the actual soil loss which occurred during the growing season. For slumps (on terraced fields), volume of the slumps on the last terrace riser was regarded as the soil actually lost from the field. Slumps on the higher terrace risers were regarded as not actually lost from the field, because this sediment is deposited on the immediate down slope terrace. If sedimentation from run-on was measured, this would be withdrawn from the soil loss, to determine the actual mass balance for the field.

The only crop management factor observed was the amounts of farmyard manure (FYM) applied on the different fields by the farmers. This was done by recording the amounts of manure farmers applied in buckets. These observations were partly done in the field, but in many cases it was based on interviewing the farmer, as it was impossible to monitor all 60 fields at the same time. The number of buckets was converted to final weights $(\mathrm{kg})$ of manure by measuring 20 buckets, and taking the average for conversion. Crop grain yields $(\mathrm{kg})$ of maize and beans were either measured at the end of the season by using a normal measuring weight balance, or by asking the farmers the number of buckets they had obtained. Again the number of buckets was converted to mass by measuring the weight of 20 bucket for each crop and taking the average value for the conversion. Measurement of total biomass proved too difficult since farmers harvested the crops irregularly at the end of the season, as the different portions of the fields matured differently, and they could not really tell the amounts they had harvested. 


\subsubsection{Data analysis}

The study was analyzed as a randomized complete block design carried out in a two factor factorial layout. The arrangement was such that the two study sites (Sunga/Tema vs. Kisiwani/Shashui) were assigned the main factor (factor A) and the SLM categories (treatments) were assigned the second factor (B). The collected data were stored in Excel 2003 spread sheets and were analyzed using the Analysis Toolbox. Two-way ANOVA, oneway ANOVA and $t$-tests were used to detect any significant differences, using $5 \%$ level of significance ( $\alpha=0.0$ ).5Correlation analysis and linear regression analysis were used to determine significant relations between crop performance and biophysical variables for the five SLM categories.

\subsection{Results}

Population numbers, village land size and the area conserved by SLM measures were provided by the village leaders of the respective villages (Table 5.2). Shashui village had a high level of SLM adoption compared to Kisiwani village (Table 5.2). Here, Tema had higher levels of adoption of SLM measures than Sunga (Table 5.2). The 60 fields belonged to 60 different male and female farmers. Those farmers generally owned more than one field. The lowest number of fields owned by a household in all villages was one. The highest was 11 (in Tema village). The majority of households however had 3-5 fields, but only fields with a certain SLM category were used for this study.

Table 5.2 Characteristics of the four study villages in Lushoto District, Tanzania.

\begin{tabular}{llllll}
\hline Village & AEZ & Population & $\begin{array}{l}\text { Area } \\
\mathrm{km}^{2}\end{array}$ & $\begin{array}{l}\text { Population density } \\
\text { people } / \mathrm{km}^{2}\end{array}$ & $\begin{array}{l}\text { Conserved Area } \\
\mathrm{km}^{2}\end{array}$ \\
\hline Kisiwani & E2 & 1450 & 4.0 & 362.5 & 0.53 \\
Shashui & E2 & 2703 & 5.5 & 487.9 & 1.41 \\
Sunga & E12 & 2652 & 14.3 & 172.0 & 1.65 \\
Tema & E12 & 2575 & 9.3 & 277.0 & 3.21 \\
\hline
\end{tabular}

a. AEZ = Agro-Ecological Zone

\subsubsection{Biophysical conditions of the sixty fields}

A summary of physical and chemical conditions of the 60 fields is given in Table 5.3. The fields around Kisiwani village (Figure 5.1) are located at a lower altitude than any of the other three villages. Altitude varied from 1166 - 1387 masl. For Shashui village this range was 1216 - 1462 masl. In Tema village fields were between 1711 - 1817 masl, while the fields around Sunga village had the highest elevation range (1829 - 1947 masl). The 
difference in the altitude of the fields is related to the AEZ in which they occur. The AEZ for Kisiwani/Shashui area is E2 (De Pauw, 1984). This is an AEZ whose altitude ranges from 5001200 meters on average. Similarly, the fields in Sunga and Tema belong to an E12 AEZ which is on an average altitude of $1000-2000$ meters. The agro-ecological conditions in the two AEZ closely match those described elsewhere in Lushoto district (Pfeiffer, 1990).

Meteorology data were collected from the two weather stations at the two study sites, from January 2010 until December 2011. The Kisiwani/Shashui area received more rain $(632 \mathrm{~mm}$ per year), and had a higher average temperature $\left(19.6^{\circ} \mathrm{C}\right)$ than the Sunga/Tema site, which received $503 \mathrm{~mm}$ rainfall per year and had an average temperature of $15.3^{\circ} \mathrm{C}$. These results are partly in agreement with those reported earlier (Pfeiffer, 1990), who referred to the Shashui area as belonging to a "warm humid zone" that receives $800-1700 \mathrm{~mm}$ per annum of rainfall, while the Sunga/Tema area belongs to a "cold dry zone" receiving 500-800 mm of rainfall per annum. So, during the period of data collection, the Kisiwani/Shashui area received below average rainfall, while the Sunga/Tema site received an amount equal to the lower limit as defined by (Pfeiffer, 1990). The average field size in the Kisiwani/Shashui site was 0.36 ha, and significantly ( $\alpha<0 \quad 05$ ) smaller thæmbimga/Tema site, where the average field size was 0.51 ha. The largest fields were in Tema, averaging 0.58 ha (CV = $33.2 \%$ ), while the smallest fields were in Kisiwani, where on average the field size was 0.31 ha $(C V=51.2 \%)$. Based on the population densities of the four villages (Table 5.2), the differences in field size can be explained by higher pressures on the land in Kisiwani and Shashui. But, it should be noted that most farmers in our sample have more than one field, and thus the observed field sizes are not fully representative for farm size. The fields located in the higher landscape zone (= zone 3 ) were generally larger than the fields in the lower two zones (Table 5.3 ). But, only in the Kisiwani/Shashui site a significant $\left(\begin{array}{lll}0 & 0 & 5\end{array}\right)$ ) differenc between landscape zone 1 and 3 was obtained. All other differences in field sizes were nonsignificant. 


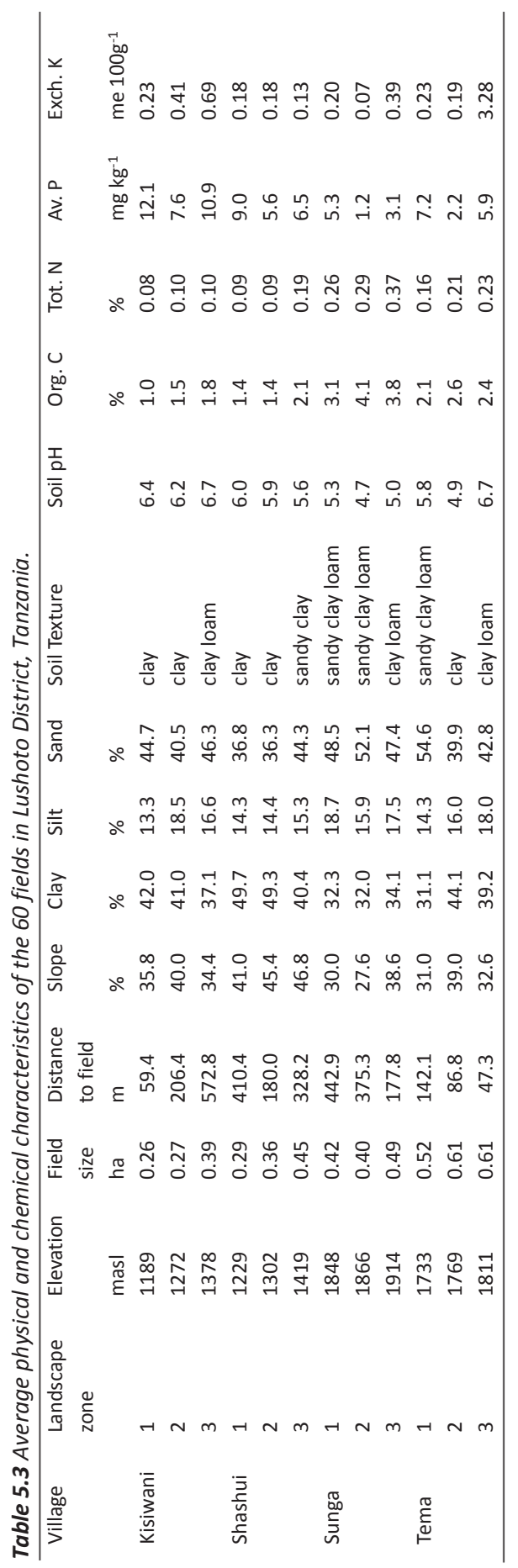


The fields in the two study areas are characterized by steep slopes, with 26 fields having a slope of more than $40 \%$. The average slopes of the fields (with actual ranges in parentheses) across the four villages were: Kisiwani - 36.9\% (range $9-53 \%$ ), Shashui - 46.8\% (34 - 52\%), Sunga $-31.7 \%(2-55 \%)$ and Tema $-34.3 \%$ (18 - 56\%). Hence, the steepness of the landscapes where the study fields were located was higher in the Kisiwani/Shashui site than in the Sunga/Tema site. This difference in slope steepness between the two sites is significant ( $\left.\alpha<\begin{array}{lll}0 & 0 & 5\end{array}\right)$, and can be explained by the geology of the study area. The geological map covering the study area shows that the Kisiwani/Shashui site has numerous fault lines, and is more dissected than the Sunga/Tema site (Geological Survey of Tanganyika, 1963). It is important to note that the level of adoption of SLM-measures in each site coincided with the slope steepness, meaning better adoption when slopes are steeper. A higher level of SLM adoption occurred in Shashui compared with Kisiwani, while the level of adoption in Tema was higher than in Sunga (Table 5.2). However, there is also a relation with the population density, meaning a better adoption rate when population density is higher. So, Shashui and Tema have higher population densities and better adoption rates than Kisiwani and Sunga, respectively. All selected SLM fields were within $1 \mathrm{~km}$ from the homesteads (Table 5.3). The closest fields from the homesteads were in Tema village (AVG $=92.1 \mathrm{~m}, \mathrm{CV}$ $=112.6 \%$ ) followed by Kisiwani (AVG = $234.4 \mathrm{~m}, \mathrm{CV}=117 \%$ ), Shashui (AVG = $304.6 \mathrm{~m}, \mathrm{CV}=$ $90.9 \%$ ) and Sunga ( $A V G=332.0 \mathrm{~m}, \mathrm{CV}=82.9 \%$ ). When combined, the distance to the fields for the Kisiwani/Shashui site (AVG $=270.8 \mathrm{~m}, \mathrm{CV}=103.93 \%$ ) are longer than those of Sunga/Tema site (AVG $=212.0 \mathrm{~m}, \mathrm{CV}=97.76 \%$ ), but this difference is not significant $(\alpha<$ $0.05)$.

The soil type of all the sixty fields was Haplic Acrisols. This soil type is characterized by an argic $B$ horizon, which is enriched in clay compared to the overlaying $A$ horizon (FAO, 2006). In the Kisiwani/Shashui site top soils were predominantly of clayey soil texture while those in the Sunga/Tema site soils were sandy clay loams and clays. Clay contents varied in Kisiwani village from 25 - 51\%, and in Shashui village from $37-60 \%$. In Sunga village the range for clay content was $23-43 \%$, while in Tema village clay levels ranged from $17-68 \%$.

According to the rating of (Baize, 1993), the two sites have poor to moderate chemical fertility. Both sites had slight to medium acid (pH 5.8 - 6.3) soils with moderate levels of organic matter. The fields in the Sunga/Tema site had soils with significantly $\left(\begin{array}{lll}\alpha & 0 & 5\end{array}\right)$ higher organic matter content compared to those in the Kisiwani/Shashui site. The higher occurrence of the organic matter in these soils is most likely associated with the higher elevation and thus cooler conditions of the Sunga/Tema site, resulting in lower oxidation rates of carbon. Soil total nitrogen was very low $(0.09-0.12 \% \mathrm{~N})$ at the Kisiwani/Shashui site, but medium at the Sunga-Tema site (0.20-0 .3 $0 \% \mathrm{~N}$ ). This difference was also significant ( $\alpha$ $<0.05)$. The $\mathrm{CN}$ ratios of the top soils varied only slightly between villages: Kisiwani $-\mathrm{AVG}=$ 
15.2, CV = 29.0\%; Shashui - AVG $=15.8, C V=33.9 \%$; Sunga - AVG = 13.7, CV = 46.6\%; Tema - AVG $=13.5, C V=33.5 \%$. This indicates that the quality of organic matter across the four villages was comparable (Baize, 1993). Available phosphorus was also significantly ( $\left.\alpha<\begin{array}{lll}0 & .0 & 5\end{array}\right)$ different between the two sites, with its availability being only medium at the Kisiwani/Shashui site ( $8.6 \mathrm{mg} \mathrm{P} / \mathrm{kg}$ soil) and low in the Sunga/Tema site $(4.2 \mathrm{mg} \mathrm{P} / \mathrm{kg}$ soil). The latter can be explained, at least partly, by the generally lower $\mathrm{pH}$ values (Table 5.3), which immobilizes phosphorus in the soil. There were no significant differences in exchangeable potassium between the two sites. However, levels of exchangeable potassium at the Kisiwani/Shashui site were already limiting (0 .2 $9 \mathrm{cmols}(+) \mathrm{K} / \mathrm{kg}$ ). In fact at Shashui village, soil exchangeable potassium was very low (0 .1 6 cmols $(+) k$ kd). The Sunga/Tema site had medium (0 .6 7 cmols (+) K/ kg) potassium lev(\$9ize, 1993; Landon, 1991). But there was a large discrepancy between the two villages. In Tema, three fields had received fertilizer in the recent past, which resulted in a high potassium level in landscape zone 3 (Table 5.3). This had a large influence on the average value for the site, while in Sunga the potassium was already limiting ( $0.22 \mathrm{cmols}(+) \mathrm{K} / \mathrm{kg}$ ). Summarizing, it can be stated that the soil fertility conditions of the selected fields in Kisiwani/Shashui was lower than those in the Sunga/Tema area.

\subsubsection{SLM categories and biophysical conditions}

The data on the relationship between the SLM categories and biophysical conditions of the 60 study fields are in Table 5.4. The elevation on which the fields were located was not found to significantly differ across the categories. This was expected since the categories were selected from each landscape zone on the basis of elevation. This is supported by the low CVs for elevation across the categories. In addition, the field sizes were not significantly different ( $\alpha<0.05$ ) between the SLM categories. It was generally observed that average distances of the fields increased with the SLM categories (Table 5.4). The fields with SLM categories 1 and 2 were on average closer to the homesteads than the other SLM categories. However, these differences were non-significant $\left(\alpha<\begin{array}{lll}0 & 0 & 5\end{array}\right)$ and thus it cannot be concluded that the distance of fields from the homestead does actually influence the SLM category that is implemented by the farmer. But it should be mentioned that the measured distance is the Euclidian distance between the GPS coordinates of the field and the homestead. Actual distances by foot could substantially differ due to the topography of the areas, and possibly does show significant differences with the different SLM categories, but data to evaluate this were not available.

There were no significant differences $\left(\alpha<\begin{array}{lll}0 & 0 & 5\end{array}\right)$ between SLM categories for soil nutrients $(\mathrm{N}, \mathrm{P}, \mathrm{K})$, and topsoil clay content. So apparently the soil fertility and texture were not 
influencing the implementation of the SLM categories. However, there existed significant differences between topsoil clay contents at $\alpha<0.11$ level, but those differences will be discussed in the section on the relation between SLM categories and land degradation. Also differences in organic matter content were observed, with the highest organic matter levels occurring in SLM 1 and 2 categories and the lowest in SLM 4 and 5 categories (Table 5.4). However, only the difference between SLM 1 and SLM 4 was significant at $\alpha<0.05$; all other differences were non-significant because of the relatively high variances of the organic matter contents. Still the declining trend from SLM 1 to SLM 5 is obvious, and will be discussed further under the relation between SLM's and soil degradation and yields.

Slopes of the fields on which the SLMs were located showed some differences. In general the SLM 1 and SLM 2 categories were on fields with lower slopes than the SLM 4 and SLM 5 categories. Significant differences ( $\left.\alpha<\begin{array}{lll}0 & 0 & 5\end{array}\right)$ exist between SLM 1 and SLM 4 , between SLM 2 and SLM 4, and between SLM 2 and SLM 5. The difference between SLM 1 and SLM 5 was only significant at the $\alpha<0.10$ level. Thisplins that slope is a determining factor in the type of SLM measures being adopted in the study area. It also indicates that the investment in terraces which are usually undertaken by the SLM 1 and SLM 2 categories are more likely to be undertaken if the fields are located on moderate slopes instead of steep slopes. This is in line with the observations made in Ethiopia (Ketema and Bauer, 2012), on the implications of biophysical factors such as slopes and farm sizes in the cost of constructing soil conservation measures such as terraces. No differences were found between SLM categories for the measured water infiltration rates (data not shown). The generally high infiltration rates with final infiltration rates exceeding $100 \mathrm{~mm} \mathrm{~h}^{-1}$ shows that infiltration is not a limiting factor in the studied fields. However, the type of infiltration measurement, using the double ring infiltrometers, is not fully representative for the natural infiltration process when raindrops strike the soil surface. It excludes crust formation, and therefore may overestimate the actual infiltration rates (McKenzie et al., 2002). This issue is discussed in more detail in the coming sections.

\subsubsection{Impact of SLM measures on soil degradation}

The relation between soil degradation and the different SLM categories can be based on two main properties: the depth of topsoil (A-horizon) and the observed soil losses (Table 5.5). The average topsoil depth across the sixty fields was $9.6 \mathrm{~cm}(\mathrm{CV}=36.4 \%)$. Maximum topsoil depth was $18.7 \mathrm{~cm}$, which was observed in a SLM 1 field near Shashui village. The minimum observed topsoil depth was $4.1 \mathrm{~cm}$, which was observed in a SLM 5 field in the Kisiwani area. There were significant differences $\left(\alpha<\begin{array}{lll}0 & 0 & 5\end{array}\right)$ in topsoil depths between all five SLM categories, except between the SLM categories 3 and 4. The SLM categories 1 and 2 
had the deepest top soils (>10 cm), while SLM categories 3 through 5 had shallow $(<10 \mathrm{~cm})$ top soils. These differences are probably associated with the different soil and water conservation measures as part of the SLM categories, which reduce the soil erosion on the field. There were no significant differences $\left(\alpha<\begin{array}{lll}0 & 0 & 5\end{array}\right)$ in topsoil depths betwethe two sites.

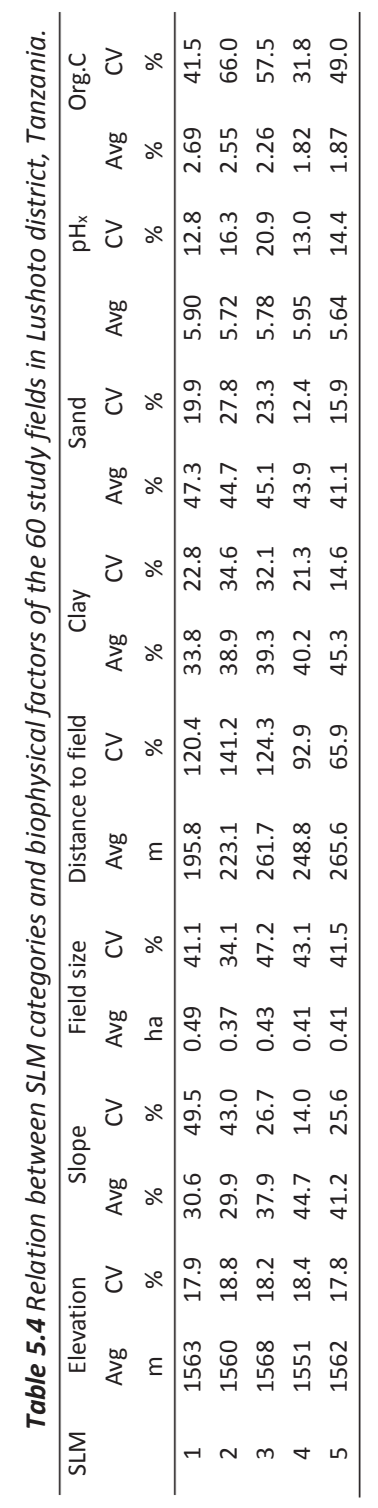


Table 5.5 Relation between SLM categories and soil degradation indicators, farm yard manure (FYM) use and crop yields of the 60 study fields in Lushoto district, Tanzania.

\begin{tabular}{|c|c|c|c|c|c|c|c|c|c|c|}
\hline \multirow[t]{3}{*}{ SLM } & \multicolumn{2}{|c|}{ Topsoil depth } & \multicolumn{2}{|l|}{ Soil loss ${ }^{a}$} & \multicolumn{2}{|l|}{ FYM use } & \multicolumn{2}{|c|}{ Maize yield } & \multicolumn{2}{|l|}{ Bean yield } \\
\hline & Avg & $\mathrm{CV}$ & Avg & $\mathrm{CV}$ & Avg & $\mathrm{CV}$ & Avg & $\mathrm{CV}$ & Avg & $\mathrm{CV}$ \\
\hline & $\mathrm{cm}$ & $\%$ & ton ha-1 $\mathrm{y}^{-1}$ & $\%$ & $\mathrm{~kg} \mathrm{ha}^{-1} \mathrm{y}^{-1}$ & $\%$ & $\mathrm{~kg} \mathrm{ha}^{-1} \mathrm{y}^{-1}$ & $\%$ & $\mathrm{~kg} \mathrm{ha}^{-1} \mathrm{y}^{-1}$ & $\%$ \\
\hline 1 & 14.8 & 20.9 & 1.0 & 152.4 & 8245 & 31.7 & 2263 & 23.0 & 1360 & 58.6 \\
\hline 2 & 11.2 & 17.7 & 4.7 & 126.7 & 6039 & 22.2 & 1857 & 26.0 & 1250 & 61.9 \\
\hline 3 & 8.7 & 27.8 & 4.1 & 116.0 & 3440 & 44.3 & 1439 & 34.9 & 404 & 64.2 \\
\hline 4 & 7.4 & 19.9 & 15.0 & 170.3 & 1099 & 67.9 & 859 & 31.5 & 243 & 30.1 \\
\hline 5 & 5.9 & 24.6 & 26.8 & 134.3 & 432 & 116.1 & 612 & 36.0 & 199 & 52.8 \\
\hline
\end{tabular}

a. Conversion of soil layer depth to mass was based on a measured bulk density of $1230 \mathrm{~kg} \mathrm{~m}^{-3}$.

The differences in topsoil depths can explain, at least partly, the increasing clay contents and decreasing organic C contents with SLM category (Table 5.4). The soil samples were taken from the $0-20 \mathrm{~cm}$ depth interval, which means that both topsoil and subsoil material was collected. The latter is from the argic $B$ horizon, which is rich in clay and poor in organic $C$ compared with the overlaying $A$ horizon. Hence the shallower the topsoil, the more material from the argic B horizon was collected during sampling. On average, this resulted in soil samples enriched in clay but progressively poorer in organic $C$ when going from SLM 1 fields to fields from higher SLM categories.

The results of the ACED method revealed soil losses only, as sedimentation from run-on was never observed in any of the 60 fields. The obtained soil losses (Table 5.5) show that the average soil loss increased substantially when going from SLM 1 to SLM 5 category fields. However, except for the differences between SLM 1 and SLM 5 categories, the differences were non-significant at the $\alpha=0.05$ level, due to the large seatin the data. But at the $\alpha$ $=0.10$ level there was significantly less erosion in the SLM 1, 2 and 3 categories, compared with the SLM 5 (control) category. The categories 1, 2 and 3 are using terraces or other physical structures (bunds, tree cover) and soil management (contour ploughing) (Table 5.1) that reduces soil erosion, even on generally steep slopes. These results are similar to those of (Tenge, 2005), who measured soil losses of 0.2 ton ha-1 $\mathrm{y}^{-1}$ from terraced fields in the Kwalei catchment in Lushoto district. The lack of such measures (SLM 4 and 5) results in generally high erosion rates (Table 5.5). It was also observed in the fields that soil losses in SLM 1 and 2 categories were mainly due to slumping of terraces, while in SLM 4 and 5 category fields the main erosion features observed were rills. In SLM category 3 fields both slumping and rill erosion were responsible for the observed soil losses. There were no significant differences $(\alpha<0.05$ ) between the observed soil losses in the Kisiwani/Shashui site $(A V G=8.4$ ton ha-1 $)$ and the Sunga/Tema site $\left(A V G=12.1\right.$ ton ha $\left.{ }^{-1}\right)$.

The observed soil losses using the ACED method have been compared with the estimated soil losses over a period of 52 years. This period was used because in 1960-1962 most 
farmers in Lushoto district were given these forest lands when the then Tanganyika colony became independent from Great Britain. The distribution of land was done to fulfil political promises made during the struggle for independence (Ezaza, 1992). By referencing the original soil depths across these fields from the nearby forests at 30 centimeters, and using the bulk densities of the soils collected from the two sites $\left(1230 \mathrm{~kg} \mathrm{~m}^{-3}\right)$, topsoil losses by erosion were estimated (Table 5.6). These estimates of soil loss are much higher than the observed losses in the 60 fields using the ACED methodology (Table 5.5). The most likely reasons for these differences will be discussed in the chapter 6 .

Table 5.6 Estimated long-term soil erosion ${ }^{a}$ from the 60 study fields with different SLM categories in Lushoto district, Tanzania.

\begin{tabular}{lllll}
\hline SLM & $\begin{array}{l}\text { Topsoil depth } \\
\mathrm{cm}\end{array}$ & $\begin{array}{l}\text { Lost soil depth } \\
\mathrm{cm}\end{array}$ & $\begin{array}{c}\text { Annual soil loss } \\
\mathrm{mm} \mathrm{ha}^{-1} \mathrm{y}^{-1}\end{array}$ & $\begin{array}{c}\text { Annual soil loss } \\
\text { ton ha-1 } \mathrm{y}^{-1}\end{array}$ \\
\hline 1 & 14.8 & 15.2 & 2.9 & 35.9 \\
2 & 11.2 & 18.8 & 3.6 & 44.5 \\
3 & 8.6 & 21.4 & 4.1 & 50.5 \\
4 & 7.4 & 22.6 & 4.3 & 53.5 \\
5 & 5.9 & 24.1 & 4.6 & 56.9 \\
\hline
\end{tabular}

a. Soil depth in nearby forests was determined at $30 \mathrm{~cm}$ and used to calculate the soil losses from fields.

b. Conversion of soil layer depth to mass was based on a measured bulk density of $1230 \mathrm{~kg} \mathrm{~m}^{-3}$.

In general the soil losses are characterized by a large variation, which is notable from the CV's in Table 5.5, and is also shown in Figure 5.3, where the soil losses per SLM category are plotted against slope. For SLM categories 1, 2 and 3, no relation with slope is discernible. This is expected, as these categories have terracing which stabilize the slope and result in low erosion rates, even for very steep slopes (>30\%).

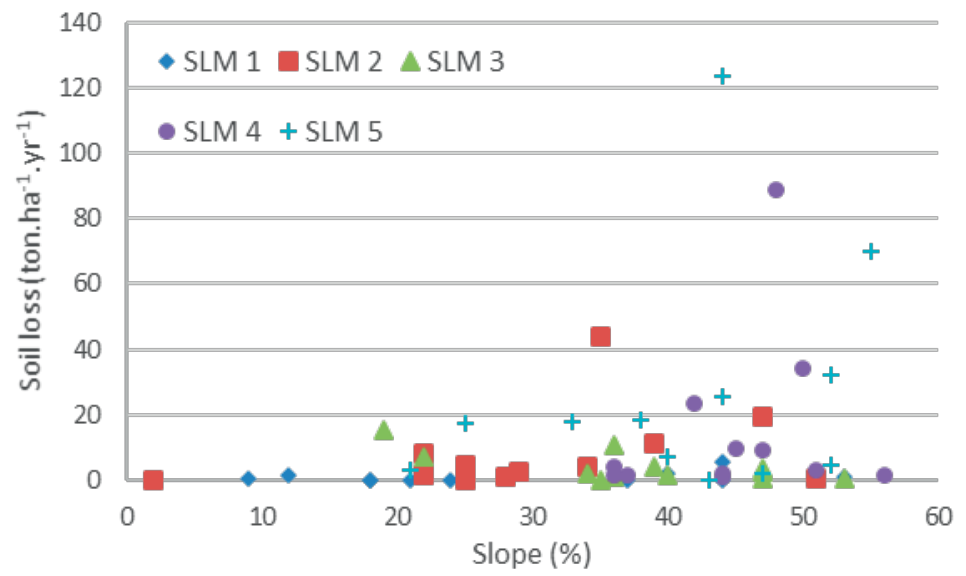

Figure 5.3 Relation between slope and soil loss of 60 fields with different SLM categories implemented, Lushoto district, Tanzania. 
For SLM categories 4 and 5 weak relations between slope and soil loss are notable, but by no means clear. The corresponding (non-significant) correlation coefficients between slope and soil loss are 0.24 for SLM 4 and 0.30 for SLM 5. For these categories on slopes steeper than $40 \%$ sometimes high erosion rates (>25 ton ha-1) were observed, but on equally steep slopes sometimes low erosion rates $(<10$ ton ha-1) were found. Relating these soil losses to contents of clay or organic $\mathrm{C}$ in the topsoil did not result in any meaningful correlation either.

The most likely explanation for these large differences is the aggregate stability, which was recently studied in the Kisiwani/Shashui area (Gorter, 2012). In that study, eight fields on steep slopes and without soil and water conservation measures were selected. Four fields experienced high erosion rates, while the other four fields were characterized by low soil erosion. The only soil physical property that showed clear differences between the two erosion classes was the aggregate stability, which was much higher on the low erodible fields. Similar results were obtained by (Lundgren, 1980), who measured erosion in a forest and on new agricultural fields in Lushoto district. Despite moderate to steep slopes (18 $44 \%)$ the observed erosion on the agricultural land was almost negligible, which was also explained by the high aggregate stability. High aggregate stability creates a good soil structure, which helps to reduce soil crusting by raindrop impact. Soil crusts have a hydraulic conductivity which is an order of magnitude lower than in the underlying soil, and thus crusts reduce infiltration rates significantly (Singer and Shainberg, 2004). When measuring infiltration with a double ring infiltrometers, the disruption of the soil surface by impacting raindrops is not included. This means that this type of measurements is only representative for non-crusted and non-vertic situations, and generally overestimates the actual rain infiltration rates. Since for the 60 study fields no data on aggregate stability were available, the observed erosion rates cannot be explained by any of the measured bio-physical characteristics.

\subsubsection{Impact of SLM measures on crop productivity}

The SLM categories are not only different in the type of physical measures that are implemented (Table 5.1), but also differ in the amounts of farm yard manure (FYM) that is used on the field (Table 5.5). Especially the SLM 1 and 2 category fields received relatively large amounts of FYM ( $>6.0$ ton $\left.\mathrm{ha}^{-1} \mathrm{yr}^{-1}\right)$, but the SLM 4 and 5 category fields received much less FYM $\left(<1.5\right.$ ton $\left.\mathrm{ha}^{-1} \mathrm{y}^{-1}\right)$. SLM 3 fields were somewhere in between with about 3.5 ton $\mathrm{ha}^{-1} \mathrm{yr}^{-1}$. All differences between the five SLM categories were significant ( $\left.\alpha<\begin{array}{lll}0 & .0 & 5\end{array}\right)$, and there were also some differences between the two study sites. For SLM 1, 2 and 3, there were no significant ( $\left.\alpha<\begin{array}{lll}0 & .0 & 5\end{array}\right)$ differences between the two study sites, but the SLM 4 and 5 
fields received significantly ( $\alpha<\begin{array}{lll}0 & 0 & 5\end{array}$ ) more FYM in the Sunga/Tema site than met Kisiwani/Shashui site. The average amount of FYM for SLM 4 fields was $1518 \mathrm{~kg} \mathrm{ha}^{-1} \mathrm{y}^{-1}$ in Sunga/Tema, and $680 \mathrm{~kg} \mathrm{ha}^{-1} \mathrm{yr}^{-1}$ in Kisiwani/Shashui. For SLM 5 fields the average values were $750 \mathrm{~kg} \mathrm{ha}^{-1} \mathrm{yr}^{-1}$ in Sunga/Tema, and $115 \mathrm{~kg} \mathrm{ha}^{-1} \mathrm{yr}^{-1}$ in Kisiwani/Shashui. This application of higher amounts of FYM in Sunga/Tema for the SLM 4 and 5 fields may have contributed to the somewhat better OM contents in the top soils in that zone (Table 5.3).

The yields of maize and beans were highly influenced by the SLM category (Table 5.5). Average maize yield was $270 \%$ higher in the SLM 1 fields than in the control (SLM5) fields. For the average bean yield on all SLM 1 fields the increase (583\%) was even more dramatic. The yields of maize and beans were significantly $(\alpha<0.05)$ higher in the SLM 1 and 2 categories compared with the other SLM categories, but there was no significant difference between SLM 1 and SLM 2. For maize, the yield in SLM 3 fields was also significantly higher than the yields in SLM 4 and 5 fields, but this was not the case for beans. Apart from the differences in yields between the SLM categories, there were some significant $\left(\alpha<\begin{array}{lll}0 & .0 & 5\end{array}\right)$ differences in yields between the two study sites as well. The average maize yield from all 30 fields in the Sunga/Tema site was 32.3\% higher (1602 versus $1211 \mathrm{~kg} \mathrm{ha}^{-1} \mathrm{yr}^{-1}$ ) than in the Kisiwani/Shashui site. At the SLM category level, only significant ( $\left.\alpha<\begin{array}{lll}0 & .0 & 5\end{array}\right)$ differences in maize yield were found between the two sites for the SLM 2 and 3 category fields, with higher maize yields in Sunga/Tema. For beans, similar results were obtained, with the average bean yield being $78.3 \%$ higher in Sunga/Tema (886 versus $497 \mathrm{~kg} \mathrm{ha}^{-1} \mathrm{yr}^{-1}$ ). Only for

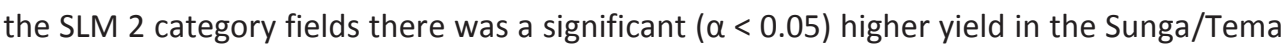
site; for the other SLM categories no significant differences were found between the two sites. Given the fact that the climatic conditions are less favourable (dryer and lower temperatures) for the Sunga/Tema site, the higher yields can only be explained by the slightly better soil fertility there (Table 5.3 ).

The maize and bean yields from all 60 fields are positively correlated with FYM application and topsoil depth, and negatively correlated with slope (Table 5.7). Moreover, the yields are negatively correlated with soil loss, but this relation is much weaker than the other relations. Figure 5.4A through $5.4 \mathrm{C}$ shows the relations between the maize yield and FYM use, topsoil depth and slope per SLM category. The graphs for bean yield are very similar and not shown here. It is clear that maize yield is largely influenced by the amount of FYM, which is higher in SLM 1 and 2 compared with the other categories. The larger topsoil depths in SLM 1 and 2 are clearly related to the higher maize yields as well. The slope - maize yield graph is characterized by more scatter, but still indicates the declining trend in yield with increasing slope. 
Table 5.7 Correlation coefficients between crop yields and selected bio-physical properties of 60 fields in Lushoto district, Tanzania.

\begin{tabular}{l|lllll}
\hline \multicolumn{2}{c}{} & \multicolumn{2}{l}{ Correlation coefficient } & & \\
\cline { 2 - 6 } & FYM application & Topsoil depth & Slope & Soil loss & Elevation \\
\hline Maize yield & 0.81 & 0.61 & -0.56 & -0.38 & 0.24 \\
Bean yield & 0.60 & 0.62 & -0.54 & -0.25 & 0.24 \\
\hline
\end{tabular}

A multiple linear regression model was fitted through the data of the 60 fields, explaining maize yield as a function of elevation, slope, topsoil depth, soil loss and FYM application rate $\left(R^{2}=0.76\right)$. The variable that explained most of the variation in maize yield was FYM application $(p<0.0001)$, followed closely by slope $(p<0.001)$. Elevation $(p=0.112)$, topsoil depth $(p=0.148)$ and especially soil loss $(p=0.503)$ can be considered poor predictors of maize yield. For beans, the fit was less good $\left(R^{2}=0.53\right)$, with slope explaining most of the variation in yield $(p=0.007)$, followed by FYM application $(p=0.072)$. Topsoil depth $(p=$ $0.104)$, elevation $(p=0.258)$ and soil loss $(p=0.588)$ are again relatively poor predictors of the yield. When evaluating the relations between yield and bio-physical factors for individual SLM categories, no clear relations were obtained, which can be seen in Figure 5.4 as well.
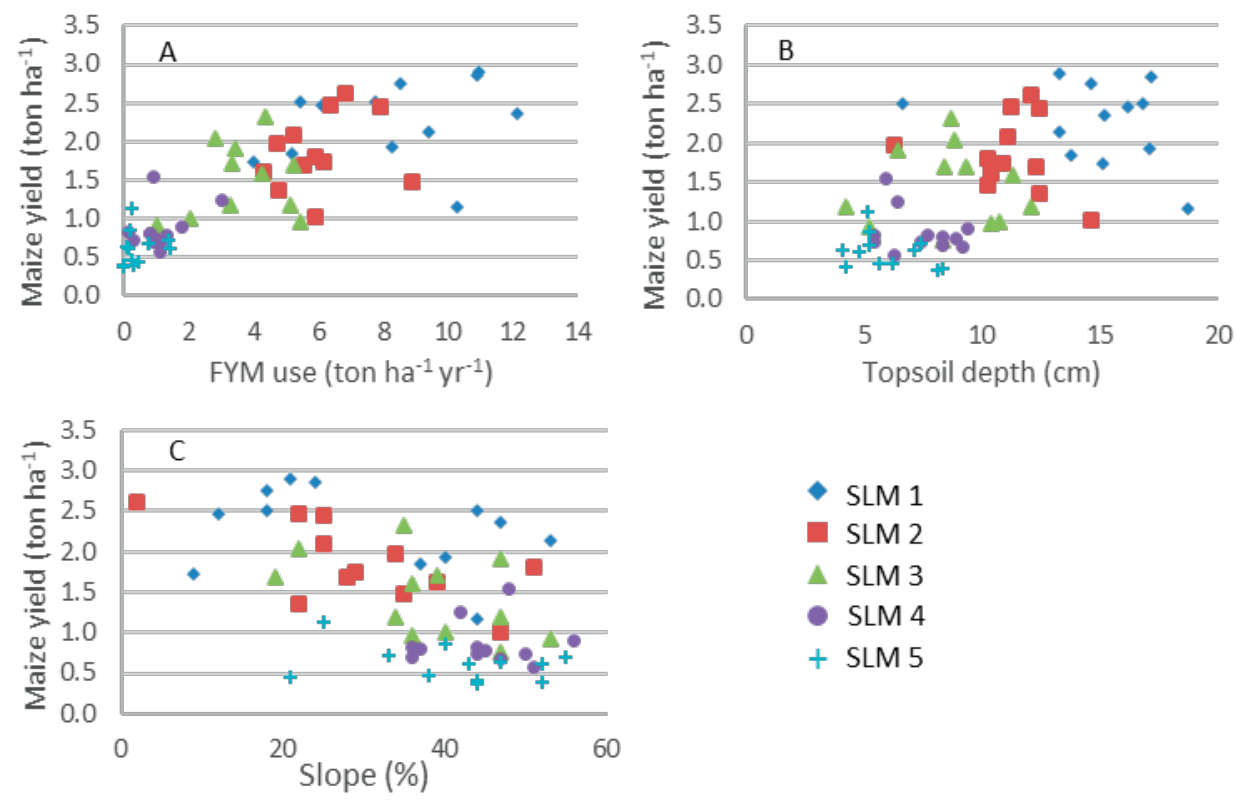

SLM 1

SLM 2

$\triangle \operatorname{SLM} 3$

- $\operatorname{SLM} 4$

+ SLM 5

Figure 5.4 Relationship between maize yield and FYM (A), topsoil depth (B) and slope (C), based on data from 60 fields with different SLM measures implemented, Lushoto district, Tanzania. 
The lack of relationship is most likely due to the limited number of observations (12 per SLM category). For detection of relations between yield and bio-physical factors for individual SLM categories, a larger dataset is required. The 12 fields per SLM category are not sufficient given the large variability in yields, FYM applications, and bio-physical characteristics.

\subsection{Discussion and Conclusions}

\subsubsection{Relation between biophysical conditions and SLMs}

Results from this work indicate that considerable differences between selected agroecological conditions across our two sites exist. Some of these, like precipitation and temperature are environmental and were already expected since they were the basis on which the agro-ecological zones were built (De Pauw, 1984). Soils in Sunga/Tema are lighter in texture (sandy clays to sandy clay loams) than the soils in Kisiwani/Shashui, which have significantly higher clay contents in their top soils (Table 5.3). Chemically, the soils of Kisiwani/Shashui were of a poorer fertility than those in Sunga/Tema (Table 5.3). The better fertility can be related to the cooler conditions in the Sunga/Tema area, which enhances the build-up of organic matter in the soils and thus will create a better soil fertility.

When considering the soil fertility in relation to the SLM categories, no significant $\left(\begin{array}{lll}\alpha<0 & .0 & 5\end{array}\right)$ differences were obtained, despite the trend of increasing OM when going from SLM category 5 to SLM 1 (Table 5.4). The large scatter in the data showed that there are no consistent trends in either topsoil OM content or the soil fertility level with the SLM categories. Absence of such trends is hard to explain, because the amounts of FYM use for the SLM 1 and 2 categories exceeded 6 ton ha-1 (Table 5.5). Possible explanations are the low quality of the applied FYM (Mathuva et al., 1998) and the generally high (> $100 \mathrm{~mm} \mathrm{~h}$ $\left.{ }^{1}\right)$ infiltration rates that may cause strong leaching of nutrients (Sollins and Radulovich, 1988). Also for the fields without terraces, washing down of applied nutrients could have played a role. In Ethiopia (Ayalew, 2011), steep slopes were associated with the washing down-slope of the applied nutrients. This was also reported in Lushoto (Pfeiffer, 1990). It should be noted that according to the revised National Fertilizer Recommendations for Tanzania, a minimum of 10-15 tons of FYM per hectare and per year is recommended for the area. Hence, the applied amounts are about half this recommendation, and this could possibly explain the lack of soil fertility differences between the SLM categories.

From the observed biophysical properties, the only properties that showed significant $(\alpha<$ 0.05 ) differences with SLM types are topsoil depth and field slopes. The relation with topsoil depth will be discussed in the next section. For slope it is clear that the better SLM packages, 
like SLM categories 1 and 2, were always located on less steep landscapes than the other categories. This significant role of slopes on the adoption of the SLM measures is in contradiction with those reported in Malawi (Barungi and Maonga, 2011), where surface slopes had an insignificant role in the adoption of land management technologies. However, considering the higher amount of labour required for construction of bench terraces on steep slopes (Mbaga-Semgalawe and Folmer, 2000), it seems logical that the better SLM categories are only implemented on the less steep slopes. Another factor that is important is the fact that slopes are very steep in the both the Sunga/Tema and Kisiwani/Shashui sites (Table 5.3), which could make the relation between slope steepness and adoption of SLM categories more important than in other less steep areas.

The role of slope steepness in the adoption of SLM measures is supported by at least two studies in the East African countries. In Ethiopia, it was reported that slope steepness and farm size were important factors which farmers considered before constructing soil conservation measures such as terraces (Ketema and Bauer, 2012). Generally, terracing was more implemented in steep sloping areas than in the more flat landscapes. The study, however, did not specify slope steepness of the terraced landscapes. In Kenya, it was also reported that slopes influenced the amounts of manure farmers were willing to put into their fields (Lekasi et al., 2001). On steep slopes the labour required to carry manure upslope was considered a too heavy burden. It was expected that distance between the field and the compound would affect the type of SLM adopted. But, our results did not show any significant difference between distance and SLM category. As the measured distances were not the actual distances by foot from the compound to the field, this may have hidden the actual influence of distance on the SLM adoption. In Lushoto, landscape position was reported to affect the adoption of the soil conservation structures (German et al., 2006). Similar findings have also been reported from the nearby Pare highlands in Tanzania (Mbaga-Semgalawe and Folmer, 2000); the Ethiopian highlands (Bekele and Drake, 2003); and the Western Kenyan highlands (Marenya and Barrett, 2007).

\subsubsection{Relation between SLM measures and soil degradation}

From our results (Table 5.5) it is clear that soil losses are lower for the better SLM categories (SLM 1 and SLM 2) compared to the control (SLM 5). However, the observations were prone to much scatter, which makes firm conclusions about the impact of SLM types on soil losses difficult. But at the $\alpha=0.10$ level of significance, it was shown that SLM 1,2 and 3 fields were all experiencing less erosion than the control fields (SLM 5). Hence, these results confirm that the soil conservation structures that are part of the SLM 1, 2 and 3 categories (Table 5.1) do reduce soil erosion on the very steep slopes in the two study sites. The 
differences in topsoil depths between the different SLM categories (Table 5.5) are more pronounced, and are a good indication of past erosion on the fields. Based on the original topsoil depth of $30 \mathrm{~cm}$, it is estimated that nearly two thirds of the original topsoil depth in the two sites has been lost (Table 5.6). The average estimated losses of topsoil depth for SLM categories 1 and 2 at $3.25 \mathrm{~mm} \mathrm{ha}^{-1} \mathrm{yr}^{-1}$, and $4.45 \mathrm{~mm} \mathrm{ha}^{-1} \mathrm{yr}^{-1}$ for SLM categories 4 and 5 are in agreement with those reported earlier in Lushoto district for protected fields (1 - 4 $\mathrm{mm} \mathrm{ha}^{-1} \mathrm{yr}^{-1}$ ) (Buch, 1983). But, his estimates of the loss of topsoil depth for the unprotected fields $\left(6-10 \mathrm{~mm} \mathrm{ha}^{-1} \mathrm{yr}^{-1}\right)$ are much higher than the erosion values obtained in this study for the control (SLM 5) plots. The greater topsoil depths for SLM 1 and 2 compared with SLM 4 and 5 (Table 5.5) indicate clearly that soil losses have been much more severe on those SLM categories that do not incorporate proper soil conservation measures. These differences in topsoil depths are in agreement with the observed erosion values using the ACED methodology (Table 5.5), but the ACED based soil losses are much lower. Possible reasons for the lower erosion values with the ACED methodology are:

1) The uncertainty in the estimate of the initial topsoil depth of $30 \mathrm{~cm}$;

2) The below-average amount of rainfall during the field study, resulting in low erosion rates;

3) The fact that the ACED method only includes soil loss by rill erosion and gully erosion; soil losses by splash erosion are ignored (Herweg, 1996);

4) The relatively recent (1980's and 90's) implementation of anti-erosion programs in the area which have reduced soil losses.

The ACED based erosion values are partly similar to those obtained from surface runoff and soil erosion measurements on a farm near Lushoto (Lundgren, 1980). The measured amounts of surface runoff and soil loss were generally very low, with soil loss in the order of 1 ton ha-1 $\mathrm{y}^{-1}$ even from unprotected fields. These small soil losses were attributed to the high aggregate stability of the soils in his study area (Lundgren, 1980). Another study (Gorter, 2012), also observed high aggregate stability in some soils in the Kisiwani/Shashui area. These soils showed very few signs of erosion, while other soils with many visible rills had much lower aggregates stabilities. The reasons for those differences in aggregate stability remained unclear, but are possibly related to the type of OM or clay minerals. Our ACED-based erosion values (Figure 5.3) seem to have been influenced by those differences in aggregates stabilities as well. If the soil loss values for the SLM 5 category (= control) are considered, there are three values with soil loss exceeding 25 ton ha- $\mathrm{y}^{-1}$, but also four values with soil losses below 5 ton ha-1 $\mathrm{y}^{-1}$. Especially when considering the SLM 5 soil losses for slopes exceeding $40 \%$ there is an enormous range, going from nearly no soil loss to more than 100 ton ha ${ }^{-1} \mathrm{y}^{-1}$. It is assumed that the aggregate stability is the main property that influenced the observed soil losses. However, aggregate stability was not studied for the 60 
fields, and it is recommended that future erosion studies in the West Usambara Mountains should consider this soil property in more detail. Compared to SLM category 5, which can be considered as a control, the following average reductions in soil loss were obtained for SLM $1-96 \%$, for SLM $2-82 \%$, for SLM3 - 85\%, and for SLM $4-44 \%$ (Table 5.5). Those reductions are in agreement with results obtained in earlier studies in Lushoto (Pfeiffer, 1990; Tenge et al., 2011). The calculated effectiveness of soil conservation measures in Lushoto were found to be 68-75\% (Pfeiffer, 1990); and 96-97\% (Tenge et al., 2011) when bench terraces were supported by grass lines. Hence, the implemented soil conservation measures as part of SLM categories 1, 2 and 3 monitored in this study were effective in reducing soil degradation.

\subsubsection{Relation of SLM measures on crop productivity}

Better yields for beans and maize were obtained from those fields that had the better SLM measures implemented. The SLM categories 1 and 2 invest more resources in managing their fields and crops (Table 5.1) and have much better yields than the other categories (Table 5.5). But, the generally higher yields of maize than beans in both sites are probably caused by farmers allocating more agronomic importance to maize than to beans. A similar pattern was reported on the Ethiopian highlands when maize and beans are intercropped (Abate and Ampofo, 1996). The better maize and bean yields on the fields with the SLM 1 and SLM 2 categories implemented are mainly caused by the higher FYM application rates used in those categories (Figure 5.4A). The addition of nutrients on the poor to moderate fertile soils (Baize, 1993) in the two sites is beneficial to the two crops immediately during the growing season. However, the FYM application rates are not sufficient to significantly improve soil fertility. The organic carbon contents in the topsoil progressively declined from SLM 1 to SLM 5 (Table 5.4), but due to the large scatter in the data, this trend was not significant. The general soil fertility status of the SLM 1 and 2 fields remained comparable to those of other SLM categories. This pattern was not expected and is hard to explain. A possible reason is the poor quality of the manure, which was already reported earlier for the area (Pfeiffer, 1990). Manure of poor quality is known to have a short-lived impact in the soil (Reeves, 1997). Another cause is probably that of leaching. Soils of Lushoto are known to suffer from strong leaching (Ezaza, 1988), and the measured high infiltration rates in our study do support the assumption of strong leaching of nutrients, making the FYM application less effective for the build-up of soil fertility.

Two biophysical properties that are related to the measured crop yields are topsoil depth and slope (Table 5.7). A deeper A-horizon provides more nutrient availability and rooting depth for crops. Also, the plant available moisture content of the A horizon is probably 
better than that of the underlying argic B-horizon, which can help to overcome drought stress during dry spells in the growing season. The influence of slope on the crop yields is that yields are enhanced when slope steepness declines. In Malawi and Kenya, steep slopes have also been associated with declining crop yields (Banda et al., 1994; Phiri et al., 1999). On the similar highland farming system of the Uluguru highlands in eastern Tanzania, (Kimaro et al., 2008) also reported similar observations. Steep slopes are often associated with declining soil fertility, increased erodibility and soil losses, and reduced soil depths. But in our study, the relation between crop yield and slope is partly an indirect result. The better yields were obtained on SLM 1 and 2 category fields, which were generally on the less steep slopes. Hence, this has influenced the observed correlation between slope and yields. When trying to discover any relation between slope and yield within a SLM category, no clear relations were obtained. Having only 12 fields per SLM category was not sufficient to discover significant effects of biophysical properties on the performance of SLM practices. The large variation in biophysical properties (Table 5.4) that is inherent to research in a natural farming environment makes it necessary to include many more fields per SLM category. To obtain statistically significant results, we estimate that a minimum of 25 fields per SLM category are required. With 5 SLM categories this would result in measurements on 125 fields, which was by no means possible in this study. But the results from the 60 fields used here, have shown that the investments in the SLM 1 and 2 categories do result in stabilized slopes and enhanced crop yields. In case the investment for SLM 1 and 2 is a too heavy burden, SLM 3 may be considered for steep sloping land, but SLM 4 and 5 should not be recommended for areas similar to the ones used in this study. 


\section{Synthesis}

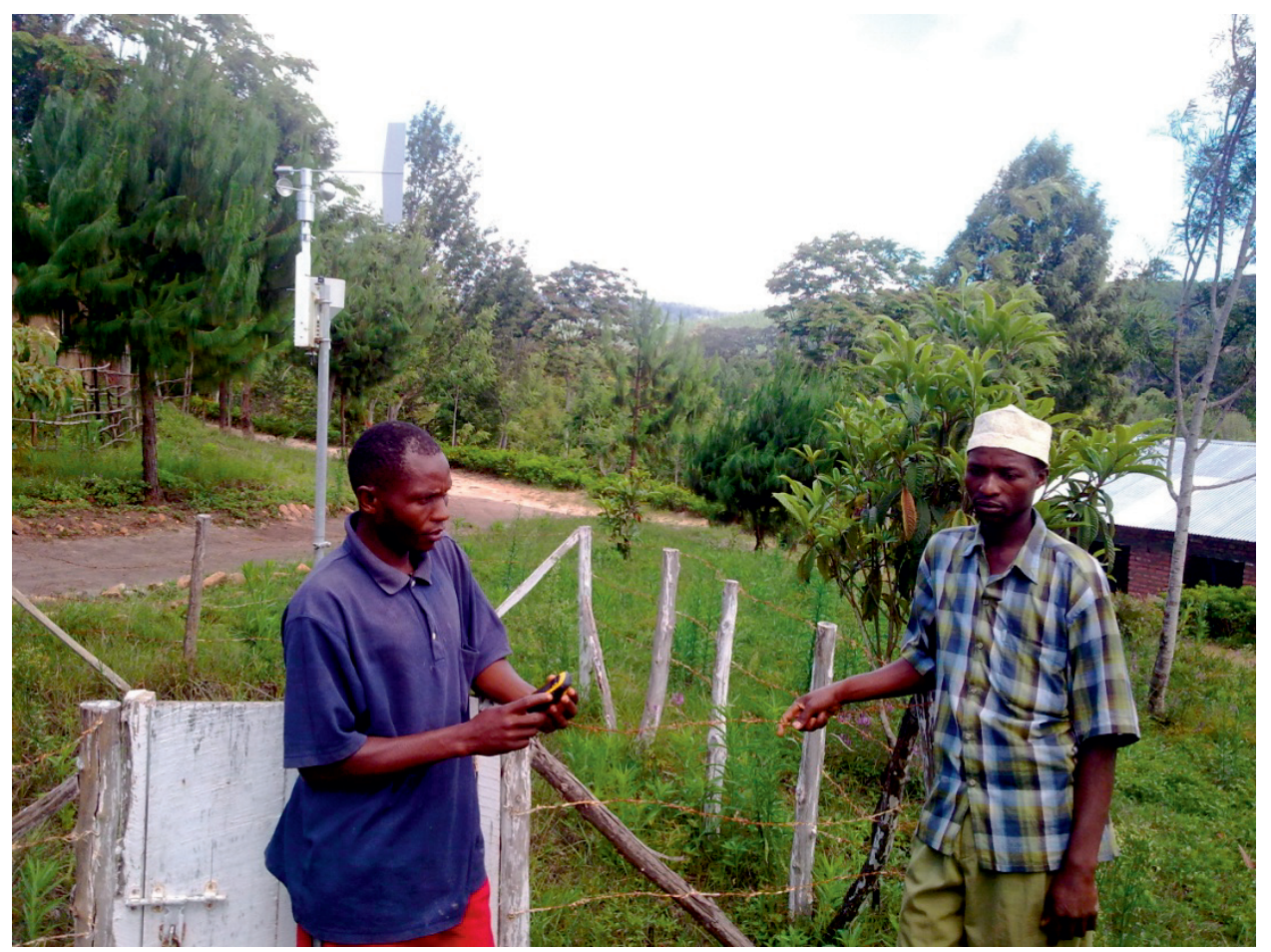




\subsection{Introduction}

Many areas in Sub-Saharan Africa are suffering from soil degradation, threatening the livelihood of local communities. Reports covering soil degradation in smallholder communities of Sub-Saharan Africa have attributed the problem to - among others -1) the non-inclusion of farmers in resolving land resource management (Scherr, 2000); 2) mismatching perceptions on soil degradation causes between farmers, researchers and policy makers (Adimassu et al., 2013); 3) ineffectiveness of the Sustainable Land Management (SLM) measures being advocated (Posthumus and Stroosnijder, 2010); 4) inappropriate tools used to detect soil degradation and the scale at which the problem is being presented (Renschler and Harbor, 2002); and 5) the biophysical and socio-economic conditions which limit sustainable land management implementation (Kassie et al., 2010; Lu and Stocking, 2000).

For Tanzania, soil degradation in the West Usambara Highlands has been reported by many researchers (Nyanga et al., 2016; Pfeiffer, 1990; Tenge et al., 2011). Water erosion is by far the most widespread land degradation problem in the West Usambara Highlands (Pfeiffer, 1990). The common causes of water erosion on which most studies converge are the rapid population increase (Ezaza, 1992), inefficient land use practices (Johansson, 2001), overexploitation of resources from localized areas (Ezaza, 1992), and poor approaches by Extension Services (Mascarenhas, 2000). Efforts of curbing soil erosion in the West Usambara Highlands began in the 1900s and included interventions like the Mlalo Rehabilitation Scheme (Watson, 1972), the Lushoto Integrated Development ProgrammeLIDEP (Mujuni, 1980), the Tanga Integrated Rural Development Programme-TIRDEP (Ezaza, 1992; Nkya et al., 2007; Scheinman, 1986), the Lushoto Development Programme-LDP (Wickama et al., 2004), the Soil Erosion Control and Afforestation Programme-SECAP (Johansson, 2001), the Traditional Irrigation Improvement Programme-TIP (Mshana, 2009) and the African Highlands Initiative-AHI (Wickama, 2007). Despite these efforts, implementation of SLM measures meant to reduce soil degradation has remained dismal (Nyanga et al., 2016).

Although social and economic factors affecting land degradation in the West Usambara Highlands are known (Tenge et al., 2004), perceptions of farmers, development workers and policy makers towards it are not fully understood. Further, though soil erosion is the major form of soil degradation affecting the West Usambara Highlands, its magnitude in smallholder agro-ecosystems of the area is unclear (Wickama et al., 2018). Smallholder agro-ecosystems do not have a unique spectral property from which one can detect their locations, composition, and biophysical characteristics by spatial/remote sensing tools and eventually model their soil loss situations. This study sought to contribute knowledge 
towards our understanding of how biophysical conditions in the West Usambara Highlands influence land degradation problems and adoption of sustainable land management (SLM) measures. Specifically this study was meant to answer the following research questions:

1) To what extent can remote sensing and modeling locate these SLM measures on a landscape scale and determine their effectiveness in reducing erosion?

2) What are the dominant agro-ecosystems in which these SLM measures are applied and how effective are these agro-ecosystems in reducing soil erosion?

3) How do farmers and development personnel in Lushoto district of the West Usambara Highlands perceive land degradation problems and what SLM measures are being used to address them?

4) How effective are these SLM measures in reducing soil degradation and promoting yields in individual smallholder fields?

In this synthesis, answers to the above research questions and major findings from the separate studies reported in Chapters 2 through 5 are summarized (Figure 6.1). Next, in sections 6.2 through 6.9 the implications of these findings to scientific knowledge and development needs in the West Usambara Highlands and the Eastern Africa region are discussed.

\subsection{Effectiveness of soil conservation measures at a landscape scale across the West Usambara Highlands, Tanzania}

When SLM measures are implemented across a vast landscape, their precise locations and effectiveness in reducing soil erosion often become hard to determine (Lynden et al., 2014). For small areas like a village, the majority of studies in East Africa have employed field surveys to locate the SLM measures and estimate their effectiveness. In the West Usambara Highlands, a few studies determined the effectiveness of SLM measures like vegetative macro-contour lines, bench terraces, fanya juu terraces and grass strips on experimental plots within a village (Lundgren, 1980; Pfeiffer, 1990; Tenge et al., 2011). However, collection of similar data at a landscape level has never been done. Though conventional remote sensing techniques could be used to locate conserved areas, their classification can be misleading as some measures have similar spectral characteristics to other land use features. In Chapter 2 remote sensing imagery of two $100 \mathrm{~km}^{2}$ areas around the villages Sunga and Soni was used to locate bench terraces and grass strips at the landscape scale by using Object-Based Image Analysis (OBIA). Subsequently, the annual soil losses were modelled in the two areas by using the Universal Soil Loss Equation (USLE). Finally the 
effectiveness of the installed SLM measures was determined by computing differences in soil losses between areas with SLM measures and areas without SLM measures.

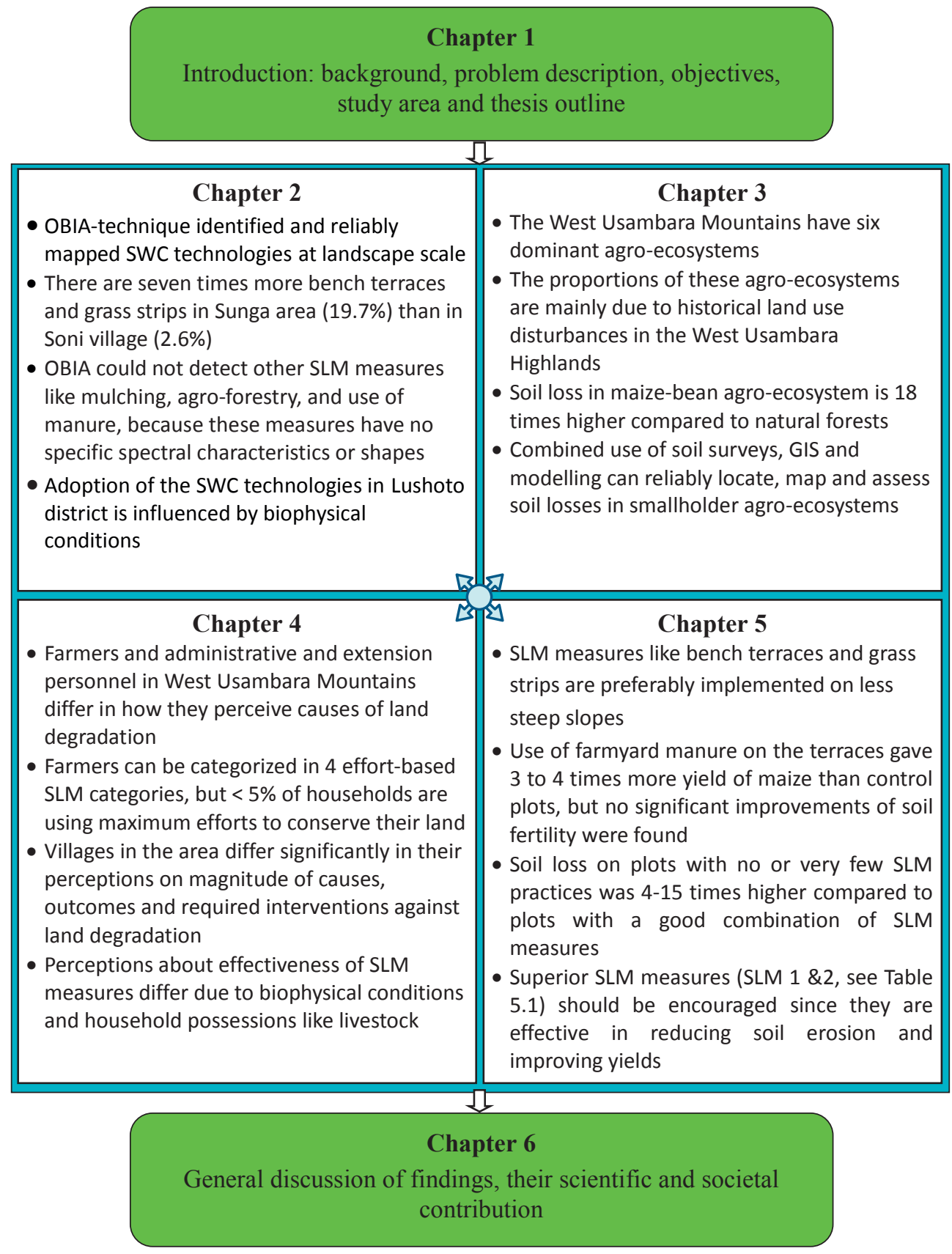

Figure 6.1 Synopsis of the assessment of biophysical impacts on the performance of sustainable land management measures in the West Usambara highlands of Tanzania. 
The results indicate that the OBIA-technique is capable and as was validated in the field is reliable in identifying, classifying and mapping of both bench terraces and grass strips at a landscape scale. Bench terraces and grass strips were found to possess unique appearances (elongated and regular shapes with pronounced lines between them) which enabled their identification and classification (Ch. 2, Figure 2.4) with considerable accuracy (Ch. 2, Table 2.4). Their measured sizes (Ch. 2, Table 2.2) and symmetry (Ch. 2, Figure 2.5) also helped to separate them from other features. The study showed that there are seven times more bench terraces and grass strips in the area of Sunga (19.7\%) village than in Soni village (2.6\%) (Ch. 2, Table 2.5 \& Figure 2.3). Consequently, the modelled effectiveness of the installed measures in reducing soil losses was higher in Sunga than in Soni (7.6\% in Sunga, 1.3\% in Soni,), although remaining minimal in both blocks. However, it should be taken into account that it was not possible with OBIA to detect other SLM measures such as mulching, agroforestry, and use of manure, because these measures have no specific spectral characteristics or shapes that separates them from other features.

\subsection{Modeling and mapping erosion in smallholder agro-ecosystems in the West Usambara Highlands, Tanzania}

Agro-ecosystems are communities of plants and animals interacting with their physical and chemical environments to produce food, fiber, fuel and other products for human consumption and processing (Altieri, 2002). Owing to their diffuse nature, agro-ecosystems and especially smallholder agro-ecosystems are difficult to trace by remote sensing imagery alone. Consequently, their specific locations, spatial extent and composition are often unknown. Past land use studies in Lushoto district have for a long time remained confined to detecting land use systems only visible to remote sensing images (Mwita et al., 2012; Werenfrid, 2015). Knowledge of the spatial distribution of smallholder agro-ecosystems and the related magnitude of soil erosion is important for soil and water conservation efforts. In Chapter 3 the dominant agro-ecosystems were characterized, and their spatial extent mapped. In the next step it was assessed how effective these agro-ecosystems are in reducing soil erosion. Chapter 3 employed ground soil surveys, GIS tools and soil erosion modeling techniques to achieve these aims as well as to measure biophysical characteristics and soil conditions. The generated information was later used to model soil erosion in the agro-ecosystems with the USLE model.

Chapter 3 identified six dominant agro-ecosystems in the area with their proportions as: 1 ) Maize-Bean (24.9\%); 2) Maize-Bean-Agroforestry (31.2\%); 3) Maize-Bean-Agroforestry-High Value Trees (18.9\%); 4) Tree farms (7.0\%); 5) Forests (15.6\%); and 6) Grazing lands (2.3\%). The proportions of these agro-ecosystems were mainly the result of historical land use 
disturbances in the West Usambara Highlands which followed the independence of Tanzania (then Tanganyika). The results of the study showed that soil erosion risk is high in the Maize-Bean agro-ecosystem (28.3 tons $\mathrm{ha}^{-1} \mathrm{yr}^{-1}$ ) but moderate in the Maize-BeanAgroforestry agro-ecosystem (17.8 tons $\mathrm{ha}^{-1} \mathrm{yr}^{-1}$ ); Maize-Bean-Agroforestry-High Value Trees agro-ecosystem (17.9 tons ha-1 $\mathrm{yr}^{-1}$ ) and Tree Farms \& Plantations ( 16.4 tons ha-1 $\mathrm{yr}^{-}$ ${ }^{1}$ ). Low soil erosion risks were estimated in Grazing Lands $\left(6.6\right.$ tons $\left.\mathrm{ha}^{-1} \mathrm{yr}^{-1}\right)$. Very low risks of erosion were observed in the Natural Forests agro-ecosystem (1.6 tons ha ${ }^{-1} \mathrm{yr}^{-1}$ ) which is only $5.5 \%$ of the erosion in the Maize-Bean agro-ecosystem. This high erosion risk of the Maize-Bean agro-ecosystem is attributed to its lower vegetative cover, lack of conservation measures and poor cultivation practices. It is also shown in Chapter 3 that if most erosion prone agro-ecosystems were conserved and their vegetation cover improved then soil losses can be reduced by a further $37 \%$ and soil organic carbon can be increased by $16 \%$.

\subsection{Land degradation problems and implementation of Sustainable Land Management in the West Usambara Highlands, Tanzania}

Land degradation and particularly soil erosion have widely been reported from almost all the humid highlands of East Africa. Specific cases include countries like Rwanda (Kagabo et al., 2013), Uganda (Wambede et al., 2016), Kenya (Saiz et al., 2016), Burundi (Shi et al., 2015) and Ethiopia (Adimassu et al., 2013). In Tanzania, several studies have covered the West Usambara Highlands (Halperin and Shear, 2005; Ndakidemi and Semoka, 2006; Temu, 2013). Soil erosion in the West Usambara Highlands and efforts spent to curb it have been reported for a long time despite the dismal acceptance of the SLM measures advocated to reduce it (Mwango et al., 2015; Watson, 1972). Most studies however have not been informative on how the affected communities (policy and administrative leaders, agricultural development staff and smallholder farmers) perceive land degradation in their area; what stimulates or limits them in implementing the SLM measures; and how farmers are organized to curb land degradation. Chapter 4 therefore focused on comparing perceptions of policy/administrative leaders, agricultural development staff and smallholder farmers towards land degradation problems in Lushoto District of the West Usambara Highlands.

Results show that $82 \%$ of development personnel and $83 \%$ of smallholder farmers in Lushoto district perceive soil erosion, deforestation and declining soil fertility to be the major causes of land degradation in the district. A comparison of their perceptions however showed that development personnel and farmers differ in their perception about the role of soil fertility decline in land degradation (Ch 4, Table 4.3). The farmers see low soil fertility as a consequence of land degradation, while the agricultural development personnel see it 
as a cause of soil degradation. The study also shows that the major SLM measures being used to control land degradation in Lushoto district include bench terraces (which account for nearly $73 \%$ of all SLM measures in Lushoto), fanya juu terraces (19\%) and cut-off drains (7\%). There are also stone terraces in the district, but these form only $1 \%$ of the SLM measures and are confined to one location (Ch. 4, Table 4.1). Other SLM measures, albeit without known proportions, include application of manure, contour ploughing, mulching, crop rotations, use of compost manure and inorganic fertilizers, and fallowing of selected fields (Ch 4, Table 4.4). The district also has enacted by-laws to protect resources like natural forests and water bodies. At village level, this study found comparable perceptions among farmers of the two villages ( $>75 \%$ of both villages combined) on the effectiveness of only three SLM measures on reducing land degradation (bench terraces, contour cultivation and planting, application of manure). Considerable differences were observed however, in the way farmers of the two villages perceived importance of grass strips and use of inorganic fertilizers in reducing land degradation (Ch. 4, Table 4.6). Farmers in Sunga village attributed a lower importance (57.6\%) to grass strips in their reduction of land degradation compared to farmers in Soni (87\%) probably because a household in Sunga actually keeps fewer animals (Ch. 4, Table 4.2) than a similar household in Soni. The higher regard for inorganic fertilizers in Soni was because their soils are of a lower soil fertility status as already reported (Ch. 5 Table 5.3).

In order to assess efforts by individual households to combat land degradation and make their fields productive, farmers in both villages were categorized into four SLM categories (Ch 4, Table 2.7). The study found that very few farmers (approx. 4.7\%) invest a lot of effort in carrying out and maintaining proper SLM measures on their fields. Fields of these SLM 1 category farmers have good quality bench terraces, are well maintained, give higher yields and suffer less erosion. Farmers of SLM category 2 are also rather few (approx. 12.6\%): they have most SLM measures like SLM 1, but the quality and productivity is lower, and erosion is slightly higher. Most farmers are in SLM category 3 (approx. 63.0\%) and have some SLM measures but of poor quality. SLM category 4 (approx. 20.2\%) represents farmers who have done minimal investments in land management, with some measures aimed at controlling land degradation and improving crop production in place, but in total not at all effective to combat land degradation.

\subsection{Effectiveness of Sustainable Land Management measures in two villages of the West Usambara Highlands, Tanzania}

Farmers generally implement SLM technologies when these are beneficial to them (De Graaff et al., 2008). For places like the West Usambara Highlands farmers implement 
multiple technologies (Nyanga et al., 2016), hence analysis of their economic benefit and effectiveness can be complex. For many locations in the world the relation between biophysical factors and effectiveness of certain SLM technologies has been analyzed (Lefroy et al., 2000), but for the humid highlands in East Africa this issue has not been addressed adequately. Consequently, most soil conservation measures in the region are recommended solely based on slope steepness (Shelukindo, 1995), even though adoption of such measures has remained dismal. In Chapter 5 it is assessed if there is a connection between biophysical factors and effectiveness of the adopted SLM measures in reducing soil degradation and enhancing yields in individual smallholder fields. To accomplish this objective, data were collected from 60 smallholder fields located near two study villages. These 60 fields represented the four SLM categories described in section 6.4. For this study a control SLM category (SLM 5) was considered as reference, which represented a situation in which the farmer did not apply any SLM practices. Farmers provided details of management and yields from their fields, while soil erosion was assessed by using the Assessment of Current Erosion Damage (ACED) method (Herweg, 1996). Effectiveness of the individual SLM measures was calculated as the difference (\%) in soil losses, soil chemical conditions and crop yields between individual SLM-categories and the control (SLM 5).

Results in Chapter 5 reveal that the superior SLM categories $1 \& 2$ are located on significantly $(p<0.05)$ gentler slopes $(30 \%$ versus $40 \%)$, on deeper top soils $(12 \mathrm{~cm}$ versus $7 \mathrm{~cm}$ ) and on lighter soils (35\% clay versus $42 \%$ clay). The study finds also that SLM $1 \& 2$ categories - despite most intensive efforts to improve soil quality - did not have a significant impact on the chemical soil fertility of the respective fields. Nevertheless, results show that SLM 1 and 2 were significantly $(p<0.05)$ more effective in reducing soil erosion and improving maize yields (by 3 to 4 times compared with other SLM categories). It seems that the relatively flatter terrain of where SLM $1 \& 2$ are located makes it easier for farmers to invest their time while measures/inputs applied in such fields also remain in place for longer periods thus contributing to the observed effects. On the other hand, SLM 4 produced the same amount of soil erosion as the control (SLM 5) and did not improve crop yields significantly.

\subsection{Limitations of the study}

When this research project was started it was intended to study land and soil degradation across different administrative levels: Lushoto district, village level and landscape level, with paired study areas (one implementing, another not implementing SLM measures). The research eventually did not cover the paired study areas or the entire Lushoto district as planned, and it was not possible to generate a comprehensive picture of the soil erosion 
situation across all levels in the West Usambara Highlands. Another limitation of the research was the use of a sample of 12 fields per SLM category to collect data related to the objectives of chapter 5 . But it has become clear that this sample size was too small and not sufficient to reveal biophysical impacts on the effectiveness of the different SLM categories given the large variability in yields and biophysical characteristics of the fields being studied. Because of this limitation, it was not possible to establish why fields receiving manure (in the superior SLM categories) failed to have statistically significant differences in soil fertility levels compared to the inferior SLM categories.

\subsection{Implications of the results}

\subsubsection{Implication to science and society}

Results in Chapter 5 show that farmers prefer to invest in soil protection and improvement on less steep slopes, where for this reason the superior SLM categories (SLM1 and SLM 2) are located (Ch. 5, Table 5.4). It is worth noting that SLM 1 \& SLM 2 categories had 3 to 4 times higher yields of maize compared with control plots (Ch. 5, Table 5.5), not only because of higher plant populations (data not shown) but also due to application of more manure compared with other SLM categories (Ch. 5, Table 5.3). However, even in these superior SLM categories $1 \& 2$ the applied manure ( 6 tons/ha) was well below the recommended 10 tons/ha for the area (Mowo et al., 1993). Hence, in this region farmer fields receive inadequate manure and fail to restore and build-up the required soil nutrients. These findings therefore imply that for Lushoto district adequate nutrient application and recommended plant spacing is crucial if soil fertility and higher yields are to be sustained also in bench terraces.

Results obtained in Chapter 4 show that though farmers and district leaders and agricultural development personnel in Lushoto district shared comparable concerns about land degradation (Ch. 4, Table 4.3), they also have different perceptions on its causes, corrective SLM measures, their effectiveness and factors related to their adoption (Ch. 4, Tables 4.6, 4.8 \& 4.9). An earlier study in Tanzania (Dejene et al., 1997) also reported significant differences on how small-scale farmers perceived land degradation in their fields compared to the perception of extension workers. A recent study in Ethiopia (Hameso, 2018) found sharp differences in the way farmers perceive climate change causes from those of policy makers. Contrarily to the results in Chapter 4, in Western Kenya distant communities of farmers did not differ in their perceptions when it came to describing factors which caused soil fertility decline (Odendo et al., 2010). However, unlike the sites in Kenya (Odendo et al., 2010), the villages in this PhD study had significant differences in biophysical conditions 
(Ch. 4, Table 4.2) and agro-ecological characteristics (Pfeiffer, 1990) which may explain the different perceptions. As for differences in perceptions on land degradation causes between farmers and district leaders / agricultural development personnel, farmers have specific concerns on how degradation impacts on their livelihoods, while district leaders and agricultural development personnel perceive land degradation from a more general and broader concern. In Ethiopia, a similar assumption was reported when perceptions on soil fertility decline were assessed between farmers and technical staff (Elias and Scoones, 1999). The contribution of Chapter 4 to science is that biophysical conditions of a location (like rainfall received, surface slopes, vegetation cover and soils) do shape perceptions on land degradation between those affected directly by such resources in their daily lives (farmers) and those governing them (district leaders and agricultural development personnel), as has already been reported in the region and beyond (Kirui, 2016; Slegers, 2008; Sulieman and Buchroithner, 2009). This means that the district leaders and agricultural development personnel are more likely to propose measures which seem unrealistic to the affected farmers; hence, their recommendations must be taken with caution.

What Chapter 2 adds to science is the realization that bench terraces and grass strips can indeed be identified accurately on a landscape scale by using the object-based image analysis (OBIA) technique. The results in Chapter 2 are consistent with what other researchers have also obtained by using OBIA. In the Netherlands (Oberndorff, 2015) OBIA was used to delineate trees and tree lines from very high resolution aerial images. The author cautioned however that accuracy of OBIA depends on the ability of the user to define objects, information models used and the quality of remote sensing images. In Morocco (d'Oleire-Oltmanns et al., 2014), OBIA was also used to detect gully-affected areas with an overall classification accuracy of $62 \%$. In Chapter 2 a higher accuracy of $>75 \%$ was obtained (Ch. 2, Table 2.4), which can be attributed to the high resolution of the satellite image used. Further, in the eCognition software the contribution of color and shape was given more priority which helped to map and differentiate terraces and grass strips with ease. The results of the study show that the adoption rates of bench terraces and grass strips are low in the two village areas. In the Soni block only $2.6 \%$ of the area has erosion control measures while in Sunga this is $19.7 \%$. The modelled erosion reduction by these measures is minimal in the two blocks, being $1.3 \%$ in Soni and $7.6 \%$ in Sunga. What these results generally imply for the West Usambara Highlands is that differences observed in the implementation of SLM measures between the two locations cannot only be pegged as earlier reported on incentives offered to the local communities by programmes and projects in the area (Mbaga-Semgalawe and Folmer, 2000). It is more likely that the disparity is attributable to differences in biophysical conditions separating the two villages. Compared to Soni, Sunga not only has coarser soils (Wickama et al., 2014), fewer streams (Wickama and Nyanga, 
2009) and narrower valley bottoms (Geological Survey of Tanganyika, 1963), but the area also receives less rainfall (Pfeiffer, 1990). Consequently, Sunga is often more food insecure (DALDO-Lushoto, 2012) compared to Soni, and this probably motivates farmers to adopt SLM measures.

When these facts are combined, irrigation and SLM technologies which improve soil moisture in Sunga are crucial and a kind of lifeline, unlike in Soni where its higher rainfall, broader and wetter valleys, heavier soils, higher food security and commercial opportunities dissuade its farmers from taking the soil conservation technologies seriously. It is worth noting that rainfall in Lushoto district decreases from east to west (Mascarenhas, 2000) which is also roughly a reverse order in the implementation of grass strips and bench terraces in the district. In Ethiopia (Bekele, 2005; Kassie et al., 2008) similar SLM measures were reported to be more effective, beneficial and readily adopted in regions with drier climates because in such areas these measures are more needed as soil fertility is lower and rainfall is more erratic. It is probably for this reason that the western part of Lushoto district (being drier) has adopted more SLM measures like bench terraces than its wetter eastern locations. Another study also reported that farmers often implement SLM technologies when they are deemed beneficial to them (De Graaff et al., 2008) which is similar to the Sunga area. Hence, next to socioeconomic factors influencing adoption, there is clearly also a biophysical explanation to the readiness of farmers in Lushoto district in applying selected SLM measures like terraces and grass strips.

For many years, the specific role and potential of smallholder agro-ecosystems of the West Usambara Highlands in maintaining soil productivity and reducing soil erosion was not adequately understood. Smallholder agro-ecosystems are difficult to locate by conventional satellite and remote sensing images because they do not possess specific spectral properties (Masselink, 2011). Hence, the difficulty in describing specific contributions of the smallholder agro-ecosystems in the West Usambara Highlands towards soil productivity and soil degradation was probably related to this background. Results obtained in Chapter 3 contribute towards filling this gap in knowledge. In Chapter 3 the existing agro-ecosystems in the West Usambara Highlands were mapped, which are otherwise undetectable on satellite images. Specific characteristics were described and the related water erosion rates were modeled with the USLE, which was unknown previously. The results in Chapter 3 reveal a different picture to those obtained by other researchers in similar highland regions. A study in Uganda (Lufafa et al., 2003) reported more severe soil losses for annual croplands (93 t ha ${ }^{-1}$ year $\left.^{-1}\right)$, rangeland $\left(52 \mathrm{t} \mathrm{ha}^{-1}\right.$ year $\left.^{-1}\right)$, banana-coffee $\left(47 \mathrm{t} \mathrm{ha}^{-1}\right.$ year $^{-1}$ ) and banana $\left(32 \mathrm{t} \mathrm{ha}^{-1}\right.$ year $\left.^{-1}\right)$. Though cropping systems reported in Uganda were also smallholder, it is worth noting that their composition was different from the ones studied in the West Usambara Highlands, and hence their conclusions must be taken with caution before 
extrapolating erosion rates in different agro-ecosystems. Despite these differences, results in Chapter 3 imply that it is possible to map and even model soil erosion in smallholder agroecosystems, provided that a judicious use of GIS tools and conventional soil survey procedures are employed.

\subsubsection{Implication to extension and policy}

This work has shown that though farmers and district leaders/agricultural development personnel in the West Usambara Highlands have comparable perceptions on the severity of land degradation, major differences separate them in how they perceive its causes (Ch. 4, Table 4.3) and SLM measures that reduce it (Ch. 4, Tables 4.6, 4.8 \& 4.9). This implies that extension services in the West Usambara Highlands should not adopt a blanket approach in advocating SLM measures. There is also an influence of biophysical factors (precipitation and slopes) to the acceptance of bench terraces and grass strips (Ch. 4, Table 4.9). Hence the extension services should target less steep and drier locations for bench terracing where they are more readily accepted (like Sunga) and target other areas with alternative technologies like agro-forestry which can also deliver meaningful results in reducing the erosion. These results imply that extension services should target areas of interest based on known biophysical conditions.

Considering the many years (>90 years) spent on combating soil erosion and advocating soil conservation structures like bench terraces in Lushoto district, it is disappointing that only a marginal proportion of the area currently has conservation structures in place (Ch. 3, Table 3.6). This coupled with the unpopularity and ineffectiveness of the installed measures to significantly improve soil fertility in the fields in which they have been adopted, it is worth for the extension services in the district to opt for alternative soil conservation approaches other than bench terraces, fanya juu terraces, cut-off drains and grass strips. This implies discontinuation of these current measures on steep lands (slopes $>40 \%$ ) and instead promote alternative measures like traditional agro-forestry systems, correct spacing of cultivated crops and inclusion of fodder trees/crops for livestock in the local farming systems. Since the current annual crops agro-ecosystems (maize and beans) have nearly 18 times higher soil losses compared with those in natural forests (Ch. 3, Table 3.5), policy makers and the extension department in the region should discourage continued cultivation of this system alone in favor of systems which include trees. Farmers in the highland portion of the district should only cultivate these annual crops (like maize and bean) in the company of agro-forestry and other tree based systems.

Finally, the results of this PhD strongly support the conclusions of Nyanga et al. (2016) in which a plea is made to give more attention to conserving and restoring upland fields in the 
West Usambara Highlands, by means of promoting collaborative land management and investments in SLM by the local farmers. Given the disappointing results obtained till date in reversing land degradation in the area, rural development policies and extension strategies should therefore focus much more on enhancing farmers' motivation and capacities to invest in their land, rather than promoting certain technologies. This requires a change in mind-set and a rethinking of current approaches, and a shift towards more participatory and integrated strategies that can create the enabling conditions for farmers to become good stewards of their land. Especially for the highly degraded upland fields this is very urgent.

\subsection{Challenges and future research}

For OBIA (Chapter 2), it would be preferable if more studies would evaluate the link between segmentation scale and its effect on detecting bench terrace/grass strip edges, as has been suggested by other researchers (Drăguţ and Eisank, $2 \quad 0 \quad 1$ since the quality of segmentation work in OBIA depends on the precision of interpreting spectral characteristics, it is worth studying how spectral signatures for different SLM measures like agro-forestry, mulching and multi-storey traditional cropping systems can be generated considering that currently these systems do not have unique shapes, color, nor spectral signatures. In Chapter 2 it was shown that in applying OBIA, accuracy of mapping and classifying objects depends on the resolution of the DEM as also mentioned by other researchers (Dronova et al., 2012). It is recommended to investigate further the use of OBIA on the SLM measures but by a higher resolution DEM unlike the $30 \mathrm{~m}$ DEM which was used in this study.

Results in this work indicate that gentler slopes $(<40 \%)$ have a better chance of acceptance of bench terraces and grass strips. The real danger of soil degradation therefore lies in the upland fields with steep slopes (> 40\%) where farmers are more hesitant to adopt SLM. For policy makers, therefore, it is recommended that they consider funding programmes that aim at motivating farmers located in such areas to protect these steep sloping fields, e.g. by means of converting them into Tree-Farms or Pasture fields which would reduce soil losses and generate additional income. Results in Chapter 3 indicate that adoption of pasture growing would cut the current erosion in these unprotected steep sloped fields from 28.3 tons ha- $\mathrm{yr}^{-1}$ to 6.6 tons ha-1 $\mathrm{yr}^{-1}$ (reduced by $76.6 \%$ ). Hence, this is a feasible option, because grazing lands in Lushoto district occupy only $2.3 \%$ of the area (Chapter 3 ) and availability of pasture for zero-grazed animals is already a limitation. Thus, sale of harvested grass can be a business opportunity which would in the meantime reverse erosion. In China (Shi and Chen, 2004), a policy measure which also encouraged farmers to develop sedentary 
livestock by using crops produced from their fields as well as fodder from steep fields which were difficult to effectively conserve by soil conservation structures, also had a positive contribution to reducing soil erosion. Another alternative would be to advocate for the adoption of fruit tree farming on these steep slopes, which would also generate additional income and sustain local livelihoods.

Based on results in Chapter 5, it is however clear that practices such as bench terraces, fanya juu, cut-off drains and grass strips are difficult to install on steep slopes. The challenge there is to implement SLM measures that increase vegetation cover, like more trees-on-farm and improved crop spacing to protect the soils from rainfall-induced erosion. Furthermore, considering that even in superior SLM categories adopted measures did not lead to improvement in soil fertility, a research challenge is to better understand how the integration of different measures can lead to higher adoption rates and spontaneous scaling-up of e.g. bench terraces. Despite many years of research it can be concluded that it is still not fully understood why some farmers adopt good SLM practices and others do not. Clearly there are socio-economic, bio-physical and cultural factors that all may play a role, while the importance of each factor might change from location to location. Hence SLM recommendations made by extension services should be flexible and include as much local knowledge and conditions as possible, which is a challenge for enhancing the sustainable use of land in the West Usambara Highlands.

\subsection{General Conclusions}

The main conclusions from this thesis are:

1. Soil conservation measures like bench terraces and grass strips can be identified accurately on a landscape scale by using remote sensing tools like the object-based image analysis (OBIA) technique. OBIA could thus be applied to assess adoption rates of soil conservation measures that are visible with this technique. Based on OBIA, this study found only $2.6 \%$ of the Soni area to be covered with these erosion control measures while in Sunga this is $19.7 \%$. The study therefore concludes that despite a long and historical campaign in making farmers of the West Usambara highlands adopt bench terraces and grass strips on their fields, only a small proportion (less than 5\%) of the area actually has been conserved.

2. The incentives that have been given to communities to encourage them to adopt bench terraces and grass strips do not explain the current disparities in adoption rates of these practices across locations in the Lushoto district. Rather, this study argues that the disparity is attributable to differences in biophysical conditions and natural resources in these locations, such as soil conditions, availability of water, presence of valley bottom 
land for vegetable growing and annual rainfall. Communities located in areas with abundance of these resources take soil conservation technologies less seriously than fellow communities in less favorable conditions.

3. For smallholder agro-ecosystems like those in the West Usambara highlands, combined use of soil surveys, GIS and modeling can reliably locate, delineate, map and assess soil losses in these systems. Soil loss in agro-ecosystems that are dominated by annual crops (maize \& beans) is severe ( 28.3 tons $\mathrm{ha}^{-1} \mathrm{yr}^{-1}$ ) and is 18 times higher compared to Natural Forests ( 1.57 tons $\mathrm{ha}^{-1} \mathrm{yr}^{-1}$ ); mainly due to lower soil cover and inefficient conservation and cultivation practices. These losses can be reduced by $37 \%$ and soil organic carbon levels can be increased by $16 \%$ if farmers adopt proper soil conservation measures and increase vegetation cover.

4. Across the West Usambara Highlands, superior SLM practices are preferentially implemented on locations which are less steep, where soils are easier to work with and more fertile. Though higher application of farmyard manure $\left(>6.0\right.$ ton ha $\left.{ }^{-1} \mathrm{y}^{-1}\right)$ on these fields has led to yields being 3-4 times higher than on control plots, the applied tonnage of manure is too small to allow for the gradual build-up of soil nutrients. Hence, a decline in soil productivity even on these plots with superior SLM practices is an imminent threat.

5. In Lushoto district adequate nutrient application and recommended plant spacing is crucial if soil fertility and higher yields are to be sustained across all locations and landscapes. For that reason the extension services in the West Usambara Highlands should not adopt a blanket approach in advocating SLM measures, but rather focus on a diversity of practices that also emphasize the importance of integrated soil fertility management.

Findings of this study therefore imply that rural development policies and extension strategies for the West Usambara Highlands should be reconsidered. Especially for the highly degraded upland fields new strategies are urgently needed that not only aim at propagating best practices, but also at motivating farmers to become good stewards and sustainable managers of their land. 


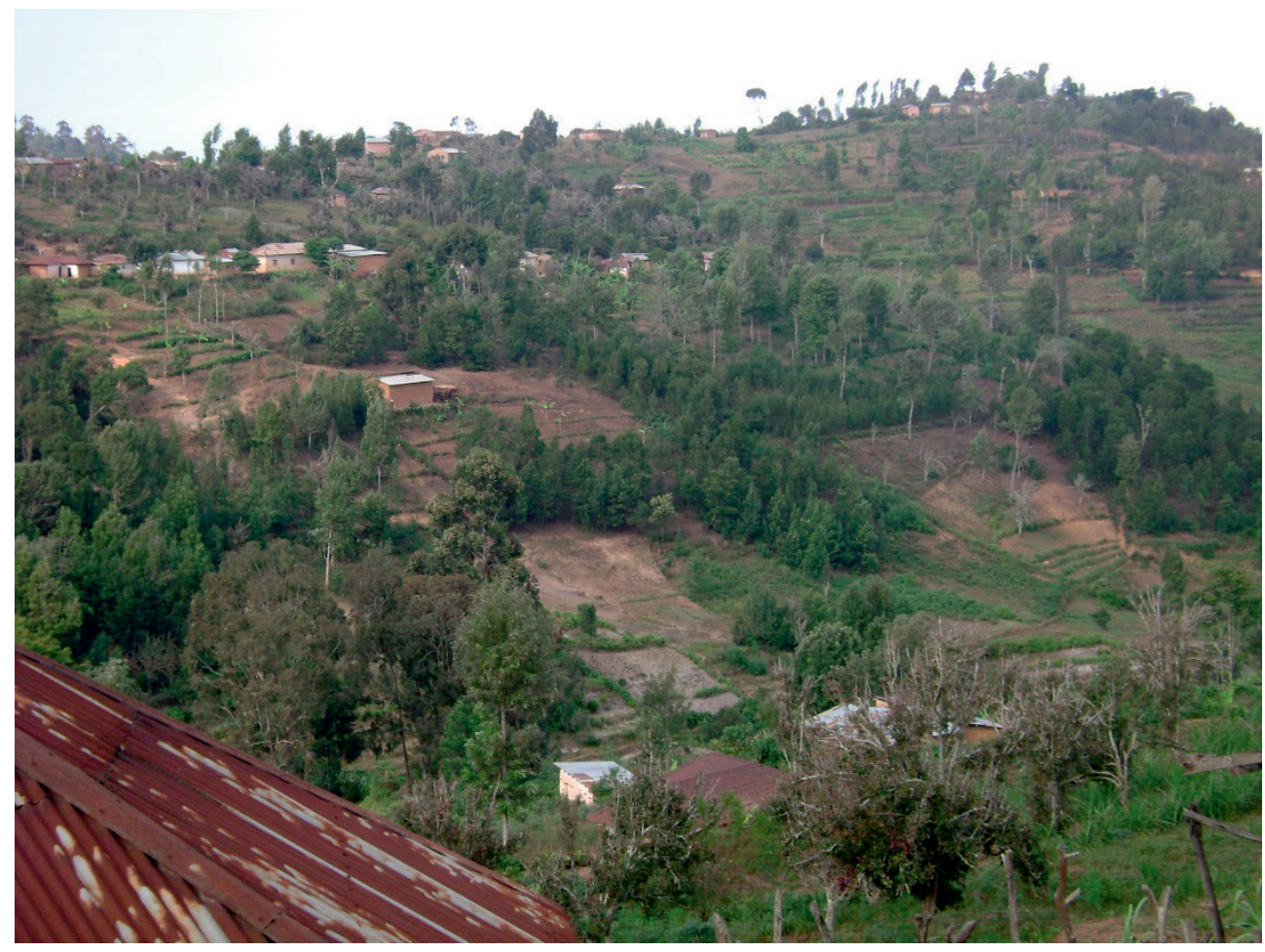




\section{Literature cited}

Abate, T., and Ampofo, J. K. O. (1996). Insect pests of beans in Africa: Their ecology and management. Annual Review of Entomology 41, 45-73.

Adgo, E., Teshome, A., and Mati, B. (2013). Impacts of long-term soil and water conservation on agricultural productivity: The case of Anjenie watershed, Ethiopia. Agricultural Water Management 117, 55-61.

Adimassu, Z., Kessler, A., Yirga, C., and Stroosnijder, L. (2013). Farmers' Perceptions of Land Degradation and Their Investments in Land Management: A Case Study in the Central Rift Valley of Ethiopia. Environmental Management 51, May 2013, 989-998.

Akinnagbe, O. M., and Umukoro, E. (2011). Farmers' perception of the effects of land degradation on agricultural activities in ethiope east local government area of Delta State, Nigeria. Agriculturae Conspectus Scientificus 76, 135-141.

Aldy, J. E., Hrubovcak, J., and Vasavada, U. (1998). The role of technology in sustaining agriculture and the environment. Ecological Economics 26, 81-96.

Ali, A. M. S. (2004). Technological change in agriculture and land degradation in Bangladesh: A case study. Land Degradation and Development 15, 283-298.

Altieri, M. A. (2002). Agroecology: the science of natural resource management for poor farmers in marginal environments. Agriculture, Ecosystems \& Environment 93, 1-24.

Amsalu, A., and de Graaff, J. (2007). Determinants of adoption and continued use of stone terraces for soil and water conservation in an Ethiopian highland watershed. Ecological Economics 61, 294-302.

Angima, S., Stott, D., O'Neill, M., Ong, C., and Weesies, G. (2003). Soil erosion prediction using RUSLE for central Kenyan highland conditions. Agriculture, Ecosystems \& Environment 97, 295-308.

Asrat, P., and Simane, B. (2017). Adapting smallholder agriculture to climate change through sustainable land management practices: Empirical Evidence from North-West Ethiopia Journal of Agricultural Science and Technology 7A (2017), 289-301.

Ayalew, A. (2011). Construction of soil conservation structures for improvement of crops and soil productivity in the Southern Ethiopia. Journal of Environment and Earth Science 1, 21-29.

Baatz, M., Hoffmann, C., Willhauck, G., (2008). Progressing from object-based to object oriented image analysis. In "Object-Based Image Analysis" (T. Blaschke, S. Lang and G. J. Hay, eds.), pp. 29-42. Berlin, Springer.

Bai, Z., Dent, D., Olsson, L., and Schaepman, M. (2008). "Global assessment of land degradation and improvement. 1 . Identification by remote sensing. Report 2008/01. 
International Soil Reference and Information Centre (ISRIC)," Wageningen, the Netherlands.

Baize, D. (1993). "Soil Science Analyses: A Guide to Current Use," John Wiley \& Sons Ltd, Chichester, United Kingdom.

Banda, A., Maghembe, J., Ngugi, D., and Chome, V. (1994). Effect of intercropping maize and closely spacedLeucaena hedgerows on soil conservation and maize yield on a steep slope at Ntcheu, Malawi. Agroforestry systems 27, 17-22.

Barungi, M., and Maonga, B. B. (2011). Adoption of soil management technologies by smallholder farmers in Central and Southern Malawi. Journal of Sustainable Development in Africa 13, No.3, 2011.

Bekele, W. (2005). Stochastic dominance analysis of soil and water conservation in subsistence crop production in the Eastern Ethiopian Highlands: The case of the HundeLafto area. Environmental and Resource Economics 32, 533-550.

Bekele, W., and Drake, L. (2003). Soil and water conservation decision behavior of subsistence farmers in the Eastern Highlands of Ethiopia: A case study of the HundeLafto area. Ecological Economics 46, 437-451.

Benz, U. C., Hofmann, P., Willhauck, G., Lingenfelder, I., and Heynen, M. (2004). Multiresolution, object-oriented fuzzy analysis of remote sensing data for GIS-ready information. ISPRS Journal of Photogrammetry and Remote Sensing 58, 239-258.

Bewket, W. (2003). Household level tree planting and its implications for environmental management in the Northwestern highlands of Ethiopia: A case study in the Chemoga watershed, blue nile basin. Land Degradation and Development 14, 377-388.

Bezuayehu, T., and Sterk, G. (2008). Hydropower-induced land use change in Fincha'a watershed, western Ethiopia: analysis and impacts. Mountain Research and Development 28, 72-80.

Biazin, B., and Sterk, G. (2013). Drought vulnerability drives land-use and land cover changes in the Rift Valley dry lands of Ethiopia. Agriculture, Ecosystems and Environment 164, 100-113.

Bielders, C., Ramelot, C., and Persoons, E. (2003). Farmer perception of runoff and erosion and extent of flooding in the silt-loam belt of the Belgian Walloon Region. Environmental Science \& Policy 6, 85-93.

Blaschke, T. (2010). Object based image analysis for remote sensing. ISPRS Journal of Photogrammetry and Remote Sensing 65, 2-16.

Bremner, J., and Mulvaney, C. (1982). Total Nitrogen: Methods of Soil Analysis. Part 2, 2nd Edition. In "Agron. Monogr. ." (A. L. Page, ed.), Vol. 9,, pp. 595-624. ASA and SSSA, Madison, WI, USA.

Brown, D. J., Shepherd, K. D., Walsh, M. G., Dewayne Mays, M., and Reinsch, T. G. (2006). Global soil characterization with VNIR diffuse reflectance spectroscopy. Geoderma 132, 273-290. 
Buch, M. W. (1983). "Semiquantitative Beschreibung von Boodenerosion an Hangen unterschiedlicher Landnutzung, Neigung und Lange in funf Dorfgebieten der Westlichen Usambara-Mts, Tanzania." Studie - SECAP (Lushoto), Eschborn, Germany.

Bustos-Griffin, E., Hallman, G. J., and Griffin, R. L. (2012). Current and potential trade in horticultural products irradiated for phytosanitary purposes. Radiation Physics and Chemistry 81, 1203-1207.

Butz, R. J. (2013). Changing land management: A case study of charcoal production among a group of pastoral women in northern Tanzania. Energy for Sustainable Development $17,138-145$.

Byiringiro, F. U. (1995). Determinants of farm productivity and the size-productivity relationship under land constraints: The case of Rwanda. Masters Thesis, Michigan State University, East Lansing, Michigan, USA.

Chartier, M. P., Rostagno, C. M., and Videla, L. S. (2013). Selective erosion of clay, organic carbon and total nitrogen in grazed semiarid rangelands of northeastern Patagonia, Argentina. Journal of Arid Environments 88, 43-49.

Chirwa, P. W., and Mahamane, L. (2017). Overview of restoration and management practices in the degraded landscapes of the Sahelian and dryland forests and woodlands of East and southern Africa. Southern Forests: a Journal of Forest Science 79, 87-94.

Conte, C. A. (1999). The forest becomes desert: Forest use and environmental change in Tanzania's West Usambara Mountains. Land Degradation and Development 10, 291309.

Conte, C. A. (2004). "Highland sanctuary: environmental history in Tanzanias Usambara mountains," Ohio University Press, Athens, Ohio, USA.

d'Oleire-Oltmanns, S., Marzolff, I., Tiede, D., and Blaschke, T. (2014). Detection of gullyaffected areas by applying object-based image analysis (OBIA) in the region of Taroudannt, Morocco. Remote Sensing 6, 8287-8309.

DALDO-Lushoto (2012). Umuhimu wa Hifadhi ya Ardhi Wilayani Lushoto. Vol. Hifadhi ya Ardhi-Lushoto. Lushoto District Council, Lushoto, Tanzania

Dasgupta, P. S. (1995). Population poverty and the local environment. Scientific American Feb., 40-45.

De Graaff, J., Amsalu, A., Bodnár, F., Kessler, A., Posthumus, H., and Tenge, A. (2008). Factors influencing adoption and continued use of long-term soil and water conservation measures in five developing countries. Applied Geography 28, 271-280.

De Pauw, E. (1984). "Physiography and agro-ecological zones of Tanzania." Ministry of Agriculture, Dar-es-Salaam, Tanzania.

de Pinho, C. M. D., Fonseca, L. M. G., Korting, T. S., de Almeida, C. M., and Kux, H. J. H. (2012). Land-cover classification of an intra-urban environment using high-resolution images and object-based image analysis. International Journal of Remote Sensing 33, 5973-5995. 
DeGayner, J. (2013). Evaluating geospatial variants of usle topographic and cover factors using digital close range photogrammetry and legacy topographic survey data. MSc Northwest Missouri State University Maryville, Missouri.

Dejene, A., Shishira, E. K., Yanda, P. Z., and Johnsen, F. H. (1997). Land degradation in Tanzania - Perception from the village. In "World Bank Technical Paper", pp. XI-65.

Diwani, T. N., Asch, F., Becker, M., and Mussgnug, F. (2013). Characterizing farming systems around Kakamega Forest, Western Kenya, for targeting soil fertility-enhancing technologies. Journal of Plant Nutrition and Soil Science.

Donahue, R. L., Miller, R. W., and Shickluna, J. C. (1995). "Soils: An Introduction to soils and plant growth.," Prentice Hall of India, New Delhi.

Drăguţ, L., and Eisank, C. ( $\left.\begin{array}{llll}2 & 0 & 1 & 2\end{array}\right)$. Automated obljesed classification of topography from SRTM data. Geomorphology 141-142, 21-33.

Dronova, I., Gong, P., Clinton, N. E., Wang, L., Fu, W., Qi, S., and Liu, Y. (2012). Landscape analysis of wetland plant functional types: The effects of image segmentation scale, vegetation classes and classification methods. Remote Sensing of Environment 127, 357369.

Dumanski, J., and Peiretti, R. (2013). Modern concepts of soil conservation. International Soil and Water Conservation Research 1, 19-23.

El-Nahry, A. H., and Abdel Kawy, W. A. (2013). Sustainable land use management on the coastal zone of the Nile Delta, Egypt. Journal of Land Use Science 8, 85-103.

Elias, E., and Scoones, I. (1999). Perspectives on soil fertility change: a case study from southern Ethiopia. Land Degradation \& Development 10, 195-206.

Enfors, E. I., and Gordon, L. J. (2007). Analysing resilience in dryland agro-ecosystems: A case study of the Makanya catchment in Tanzania over the past 50 years. Land Degradation and Development 18, 680-696.

Ezaza, W. P. (1988). Geoecological factors influencing over-exploitation and land degradation in the Usambara Mountains of northeastern Tanzania. Mountain Research \& Development 8, 157-163.

Ezaza, W. P. (1992). An assessment of socioecological impacts on East African mountain and highland environments: a case study from Tanzania. Mountain Research and Development 12, 401-408.

FAO (2006). "World Reference Base for Soil Resources," Rome, Italy.

Foster, G., McCool, D., Renard, K., and Moldenhauer, W. (1981). Conversion of the universal soil loss equation to SI metric units. Journal of Soil and Water Conservation 36, 355-359.

Gachene, C. K. K., Jarvis, N. J., Linner, H., and Mbuvi, J. P. (1997). Soil erosion effects on soil properties in a highland area of Central Kenya. Soil Science Society of America Journal 61, 559-564.

Gao, Y., and Mas, J. F. (2008). A comparison of the performance of pixel-based and objectbased classifications over images with various spatial resolutions In "GEOBIA 2008 - 
Pixels, Objects, Intelligence. GEOgraphic Object Based Image Analysis for the 21st Century" (T. B. a. D. M. G.J .Hay, , August 05-08., ed.), Vol. Vol. No. XXXVIII-4/C1. Archives ISSN No.: 1682-1777 pp. 373. International Society for Photogrammetry and Remote Sensing (ISPRS), University of Calgary, Calgary Alberta, Canada.

Gebremedhin, B., and Swinton, S. M. (2003). Investment in soil conservation in northern Ethiopia: the role of land tenure security and public programs. Agricultural Economics 29, 69-84.

Gee, G., and Bauder, J. (1986). Particle-size analysis, p. 383-411. In "Methods of soil analysis. Part 1. 2nd ed. Agron. Monogr. 9" (A. Klute, ed.). ASA and SSSA, Madison, WI, USA.

Geological Survey of Tanganyika (1963). Lushoto. In "Quarter Degree Sheets 109 (Lushoto)". Ministry of Commerce and Industry, Dar-es-Salaam, Tanzania.

Gerber, N., Nkonya, E., and von Braun, J. (2014). Land degradation, poverty and marginality. In "Marginality" (J. von Braun and F. Gatzweiler, eds.), pp. 181-202. Springer, Dordrecht.

German, L., Mazengia, W., Taye, H., Tsegaye, M., Ayele, S., Charamila, S., and Wickama, J. (2010). Minimizing the livelihood trade-offs of natural resource management in the Eastern African Highlands: Policy implications of a project in "creative governance". Human Ecology 38, 31-47.

German, L. A., Kidane, B., and Shemdoe, R. (2006). Social and environmental trade-offs in tree species selection: A methodology for identifying niche incompatibilities in agroforestry. Environment, Development and Sustainability 8, 535-552.

Gitas, I. Z., Douros, K., Minakou, C., Silleos, G. N., and Karydas, C. G. (2009). Multi-temporal soil erosion risk assessment in N. Chalkidiki using a modified usle raster model. EARSeL eProceedings 8, 40-52.

Gorter, L. (2012). Soil physical properties in relation to soil degradation rates in the Usambara Mountains, northeast Tanzania, Masters Thesis, Faculty of Geosciences, Universiteit Utretcht, Utretcht, the Netherlands.

Grogan, K., Birch-Thomsen, T., and Lyimo, J. (2013). Transition of shifting cultivation and its impact on people's livelihoods in the Miombo Woodlands of Northern Zambia and South-Western Tanzania. Human Ecology 41, 77-92.

Halperin, J., and Shear, T. (2005). An Assessment of rainforest distribution and threats in the West Usambara Mountains, Tanzania. Geocarto International 20, 51-61.

Hameso, S. (2018). Farmers and policy-makers' perceptions of climate change in Ethiopia. Climate and Development 10, 347-359.

Harrington, L., White, J., Grace, P., Hodson, D., Hartkamp, A. D., Vaughan, C., and Meisner, C. (2002). Delivering the goods: scaling out results of natural resource management research. Conservation ecology 5, 19.

Hay, G., and Castilla, G. (2008). Geographic object-based image analysis (GEOBIA): A new name for a new discipline. Object-based image analysis, 75-89. 
Herweg, K. (1996). "Field manual for assessment of current erosion damage," University of Berne, Berne, Switzerland.

Himeidan, Y. E., and Kweka, E. J. (2012). Malaria in East African highlands during the past 30 years: Impact of environmental changes. Frontiers in Physiology 3 AUG.

Hurni, H. (1993). Land degradation, famines and resources scenarios in Ethiopia. In "World Soil Erosion and Conservation" (D. Pimental, ed.), pp. 27-62. Cambridge University Press, Cambridge, UK.

Hurni, H. (1997). Concepts of sustainable land management. International Journal of Aerospace Survey and Earth Sciences (ITC Journal) 1997, 210-215.

Hussein, M., and Wickama, J. (2007). "Assessment of Community Perceptions on Tree-based Problems in the Baga Watershed, Lushoto District, Tanzania." African Highlands Innitiative (AHI), Lushoto, Tanzania.

IFPRI, ed. (2001). "Overcoming poverty and environmental degradation in less-favored areas of East Africa." International Food Policy Research Institute, Washington DC.

Isgin, T., Bilgic, A., Forster, D. L., and Batte, M. T. (2008). Using count data models to determine the factors affecting farmers' quantity decisions of precision farming technology adoption. Computers and Electronics in Agriculture 62, 231-242.

Jain, S. K., Kumar, S., and Varghese, J. (2001). Estimation of soil erosion for a Himalayan watershed using GIS technique. Water Resources Management 15, 41-54.

Jamu, D., Banda, M., Njaya, F., and Hecky, R. E. (2011). Challenges to sustainable management of the lakes of Malawi. Journal of Great Lakes Research 37, 3-14.

Jianping, P. R. N. T. G. (2013). Assessment of soil erosion susceptibility using empirical modeling. Acta Meteorologica Sinica 27, 98-109.

Johansson, L. (2001). "Ten million trees later: land use change in the West Usambara Mountains. The Soil Erosion Control and Agroforestry Project in Lushoto District 19812000," Deutsche Gesellschaft für Technische Zusammenarbeit (GTZ), Eschborn, Germany.

Joshi, J. R. (2010). Improving the quality of digital surface model generated from very high resolution satellite stereo imagery by using object oriented image analysis technique, M. Sc. thesis, Geoinformatics, ITC, University of Twente, Enschede.

Kagabo, D., Stroosnijder, L., Visser, S., and Moore, D. (2013). Soil erosion, soil fertility and crop yield on slow-forming terraces in the highlands of Buberuka, Rwanda. Soil and Tillage Research 128, 23-29.

Kajembe, G., Julius, F., Nduwamungu, J., Mtakwa, P., and Nyange, D. (2005). Impact of indigenous-based interventions on land conservation: A case study of a soil conservation and agroforestry project, Arumeru District, Tanzania. Land Degrad. Develop. 16, 311325. 
Kangalawe, R., and Lyimo, J. (2010). Population dynamics, rural livelihoods and environmental degradation: some experiences from Tanzania. Environment, Development and Sustainability 12, 985-997.

Karamage, F., Zhang, C., Ndayisaba, F., Shao, H., Kayiranga, A., Fang, X., Nahayo, L., Muhire Nyesheja, E., and Tian, G. (2016). Extent of cropland and related soil erosion risk in Rwanda. Sustainability 8, 609.

Kassie, M., Pender, J., Yesuf, M., Kohlin, G., Bluffstone, R., and Mulugeta, E. (2008). Estimating returns to soil conservation adoption in the northern Ethiopian highlands. Agricultural Economics 38, 213-232.

Kassie, M., Zikhali, P., Pender, J., and Köhlin, G. (2010). The economics of sustainable land management practices in the Ethiopian Highlands. Journal of Agricultural Economics 61, 605-627.

Kessler, C., and Stroosnijder, L. (2006). Land degradation assessment by farmers in Bolivian mountain valleys. Land Degradation \& Development 17, 235-248.

Ketema, M., and Bauer, S. (2012). Factors affecting intercropping and conservation tillage practices in Eeastern Ethiopia. Agris On-line Papers in Economics and Informatics 4, 2129.

Kimaro, A. A., Timmer, V. R., Chamshama, S. A. O., Mugasha, A. G., and Kimaro, D. A. (2008). Differential response to tree fallows in rotational woodlot systems in semi-arid Tanzania: Post-fallow maize yield, nutrient uptake, and soil nutrients. Agriculture, Ecosystems and Environment 125, 73-83.

Kirui, O. K. (2016). Economics of land degradation and improvement in Tanzania and Malawi. In "Economics of Land Degradation and Improvement - A Global Assessment for Sustainable Development", pp. 609-649. Springer.

Komakech, H. C., and van der Zaag, P. (2011). Understanding the emergence and functioning of river committees in a catchment of the Pangani Basin, Tanzania. Water Alternatives 4, 197-222.

Kumaraperumal, R., Natarajan, S., Sivasamy, R., Chellamuthu, S., Ganesh, S. S., and Anandakumar, G. (2007). Impact of tsunami 2004 in coastal villages of Nagapattinam District, India. Science of Tsunami Hazards 26, 93-114.

Lal, R., and Elliot, W. (1994). Erodibility and erosivity. In "Soil Erosion Research Methods" (R. Lal, ed.), Vol. . pp. 181-208. Soil and Water Conservation Society and St. Lucie Press., USA.

Landon, J. (1991). "Tropical soil manual - a handbook for soil survey and agricultural land evaluation in the tropics and subtropics," Booker Tate Ltd, Longman, Thame, United Kingdom.

Lee, D. R. (2005). Agricultural sustainability and technology adoption: Issues and policies for developing countries. American Journal of Agricultural Economics 87, 1325-1334. 
Lefroy, R. D., Bechstedt, H.-D., and Rais, M. (2000). Indicators for sustainable land management based on farmer surveys in Vietnam, Indonesia, and Thailand. Agriculture, ecosystems \& environment 81, 137-146.

Likert, R. (1932). A technique for the measurement of attitudes. Archives of Psychology 140, 5-55.

Lillesand, T. M., Kiefer, R. W., and Chipman, J. W. (2004). "Remote sensing and image interpretation," John Wiley \& Sons Ltd.

Lu, Y., and Stocking, M. (2000). Integrating biophysical and socio-economic aspects of soil conservation on the Loess Plateau, China. Part II. Productivity impact and economic costs of erosion. Land Degradation and Development 11, 141-152.

Lufafa, A., Tenywa, M., Isabirye, M., Majaliwa, M., and Woomer, P. (2003). Prediction of soil erosion in a Lake Victoria basin catchment using a gis-based universal soil loss model. Agricultural Systems 76, 883-894.

Lundgren, L. (1980). Comparison of surface runoff and soil loss from runoff plots in forest and small-scale agriculture in the Usambara Mts., Tanzania. Geografiska Annaler. Series A. Physical Geography, 113-148.

Lyamchai, C., Owenya, M., Ndakidemi, P., and Massawe, N. (1998). "Participatory Rural Appraisal in Kwalei catchment Lushoto, Tanzania." African Highlands Initiative (AHI) Selian Agricultural Research Institute, Arusha, Tanzania.

Lynden, G., Ritsema, C.J., and Hessel, R. (2014). RECARE - Preventing and remediating degradation of soils in Europe through land care. In "Special Issue on One Health (Part I/II)" (Planet@Risk, ed.), Vol. 2, pp. 169-173. Global Risk Forum GRF Davos, Davos.

Ma, J., Xue, Y., Ma, C., and Wang, Z. (2003). A data fusion approach for soil erosion monitoring in the Upper Yangtze River Basin of China based on the Universal Soil Loss Equation (USLE) model. International Journal of Remote Sensing 24, 4777-4789.

Maddox, G. (2006). "Sub-Saharan Africa: An Environmental History," ABC-CLIO, Santa Barbara, California, USA.

Marais, C., and Wannenburgh, A. (2008). Restoration of water resources (natural capital) through the clearing of invasive alien plants from riparian areas in South Africa-costs and water benefits. South African Journal of Botany 74, 526-537.

Marenya, P., Nkonya, E., Xiong, W., Deustua, J., and Kato, E. (2012). Which policy would work better for improved soil fertility management in sub-Saharan Africa, fertilizer subsidies or carbon credits? Agricultural Systems 110, 162-172.

Marenya, P. P., and Barrett, C. B. (2007). Household-level determinants of adoption of improved natural resources management practices among smallholder farmers in western Kenya. Food Policy 32, 515-536.

Martinez-Graña, A., Goy, J., and Zazo, C. (2014). Water and wind erosion risk in parks natural. A case study in "The Batuecas-Sierra de Francia" and "Quilamas" protected parks, Central System, Spain. International Journal of Environmental Research 8, 61-68. 
Martinez-Graña, A., Goy, J., Zazo, C., (2014). Water and wind erosion risk in parks natural. A case study in "The Batuecas-Sierra de Francia" and "Quilamas" protected parks (Central system, Spain). Int. J. Environ. Res. 8 61-68.

Mascarenhas, A. (2000). "Poverty, Environment, and Livelihood Along the Gradients of the Usambaras in Tanzania." Research on Poverty Alleviation (REPOA), Dar-es-Salaam, Tanzania.

Masselink, R. (2011). The use of remote sensing to evaluate the effectiveness of soil and water conservation measures in the West Usambara Mountains, Tanzania, Utrecht University, Utrecht, The Netherlands.

Matata, P. Z., Ajay, O. C., Oduol, P. A., and Agumya, A. (2010). Socio-economic factors influencing adoption of improved fallow practices among smallholder farmers in western Tanzania. African Journal of Agricultural Research 5, 818-823.

Mathuva, M., Rao, M., Smithson, P., and Coe, R. (1998). Improving maize (Zea mays) yields in semi-arid highlands of Kenya: agroforestry or inorganic fertilizers? Field Crops Research 55, 57-72.

Mati, B. M., Morgan, R. P., Gichuki, F. N., Quinton, J. N., Brewer, T. R., and Liniger, H. P. (2000). Assessment of erosion hazard with the USLE and GIS: A case study of the Upper Ewaso Ng'iro North basin of Kenya. International Journal of Applied Earth Observation and Geoinformation 2000, 78-86.

Mbaga-Semgalawe, Z., and Folmer, H. (2000). Household adoption behaviour of improved soil conservation: The case of the North Pare and West Usambara Mountains of Tanzania. Land Use Policy 17, 321-336.

Mbilinyi, B. P., Tumbo, S. D., Mahoo, H. F., and Mkiramwinyi, F. O. (2007). GIS-based decision support system for identifying potential sites for rainwater harvesting. Physics and Chemistry of the Earth 32, 1074-1081.

Mbogoni, J. (2010). Farming Systems; Lushoto District. pp. Farming Systems of Lushoto District; Potential and Constraints of Selected areas. ARI-Mlingano, Mlingano, Tanga.

McKenzie, N., Coughlan, K., and Cresswell, H. (2002). "Soil physical measurement and interpretation for land evaluation," CSIRO Publishing Collingwood, Victoria, Australia.

McLean, E. (1982). Soil pH and lime requirement p.199-224. In "Methods of Soil Analysis. Part 2. Chemical and Microbiological Properties" (A. L. P. (ed.), ed.). American Society of Agronomy, Soil Science Society of America, Madison, Wisconsin, USA.

Meliyo, J., Kabushemera, J., and Tenge, A. (2001). "Characterization and mapping soils of Kwalei subcatchment, Lushoto District." Agricultural Research Institute (ARI)-Mlingano, Tanga, Tanzania.

Mendoza-Escalantea, A., Brnera, J., and Hedden-Dunkhorsta, B. (2003). Adoption potential for fire-free agricultural practices by smallholders in the Eastern Amazon of Brazil. In "Conference on International Agricultural Research for Development". Deutscher Tropentag 2003, Gottingen, Germany. 
Meneguzzo, D. M., Liknes, G. C., and Nelson, M. D. (2012). Mapping trees outside forests using high-resolution aerial imagery: a comparison of pixel- and object-based classification approaches. Environmental Monitoring and Assessment, 1-15.

Mengstie, F. A. (2009). Assessment of adoption behavior of soil and water conservation practices in the Koga Watershed, Highlands of Ethiopia. Masters of Science, Cornell University Cornell, NY, USA.

Meshesha, D. T., Tsunekawa, A., and Tsubo, M. (2012). Continuing land degradation: Causeeffect in Ethiopia's Central Rift Valley. Land Degradation and Development 23, 130-143.

Meusburger, K., Bänninger, D., and Alewell, C. (2010). Estimating vegetation parameter for soil erosion assessment in an alpine catchment by means of QuickBird imagery. International Journal of Applied Earth Observation and Geoinformation 12, 201-207.

Moore, I. D., and Wilson, J. P. (1992). Length-slope factors for the Revised Universal Soil Loss Equation: Simplified method of estimation. Journal of Soil and Water Conservation 47, 423-428.

Moore, T. (1979). Rainfall erosivity in east Africa. Geografiska Annaler. Series A. Physical Geography, 147-156.

Morgan, R. P. C. (2005). "Soil erosion and conservation " Third/Ed. Blackwell, Oxford, UK.

Mowo, J. G., Floor, J., Kaihura, F. B., and Magoggo, J. P. (1993). "Review of Fertilizer Recommendations in Tanzania." Agricultural Research Insitute (ARI)-Mlingano, Tanga, Tanzania.

Mowo, J. G., Mwihomeke, S. T., Mzoo, J. B., and Msangi, T. (2002). Managing natural resources in the West Usambara Mountains: A glimmer of hope in the horizon. In "Mountain High Summit Conference for Africa". mtnforum.org, Moshi, Tanzania.

Msanya, B. M., Kimaro, D. N., Kimbi, G. G., Kileo, E., and Mbogoni, J. J. (2001). Land resources inventories and suitability assessment for the major landuse types in Morogoro Urban District, Tanzania. Soil and Land Resources of Morogoro urban Districts 11.

Mshana, B. (2009). The contribution of traditional irrigation and environmental development oganization (TIP) on well being of the households through soil and water conservation in Lushoto District BSc-Dissertation, Institute of Rural Development Planning, Dodoma, Tanzania.

Mujuni, F. (1980). LIDEP as an Instrument for the Implementation of rural development policy in Lushoto District. GLAESER, Bernhard (Hg.): Factors affecting land use and food production. Sozialwissenschaftliche Studien zu internationalen Problemen 55, 112-131.

Mulengera, M. K., and Payton, R. W. (1999). Estimating the USLE-soil erodibility factor in developing tropical countries. Tropical Agriculture 76, 17-22.

Mwango, S., Msanya, B., Mtakwa, P., Kimaro, D., Deckers, J., Poesen, J., Massawe, I., and Samwel, J. (2015). Effectiveness of selected soil conservation practices on soil erosion control and crop yields in the Usambara Mountains, Tanzania. Journal of Agriculture and Ecology Research International 2, 129-144. 
Mwango, S. B., Msanya, B. M., Mtakwa, P. W., Kimaro, D. N., Deckers, J., and Poesen, J. (2016). Effectiveness of mulching under Miraba in controlling soil erosion, fertility restoration and crop yield in the Usambara Mountains, Tanzania. Land Degradation \& Development 27, 1266-1275.

Mwita, E., Menz, G., Misana, S., Becker, M., Kisanga, D., and Boehme, B. (2012). Mapping small wetlands of Kenya and Tanzania using remote sensing techniques. International Journal of Applied Earth Observation and Geoinformation 21, 173-183.

Ndah, H. T., Schuler, J., Uthes, S., Zander, P., Triomphe, B., Mkomwa, S., and Corbeels, M. (2012). Adoption potential for conservation agriculture in africa: A newly developed assessment approach (qatoca) applied in Kenya and Tanzania. Land Degradation and Development 26: 133-141.

Ndakidemi, P. A., and Semoka, J. M. R. (2006). Soil fertility survey in Western Usambara Mountains, northern Tanzania. Pedosphere 16, 237-244.

Nelson, D., and Sommers, L. E. (1982). Total carbon, organic carbon, and organic matter, p.539-579. In "Methods of soil analysis. Part 2. Chemical and Microbiological Properties" (A. L. P. (ed.), ed.). American Society of Agronomy, Soil Science Society of America, Madison, Wisconsin, USA.

Newmark, W. D., ed. (1998). "Forest area, fragmentation and loss in the Eastern Arc Mountains: implications for the conservation of biological diversity." Journal of East African Natural History. 87(1/2): 29-36.

Nkya, R., Kessy, B., Lyimo, Z., Msangi, B., Turuka, F., and Mtenga, K. (2007). Constraints on smallholder market oriented dairy systems in the north eastern coastal region of Tanzania. Tropical Animal Health and Production 39, 627-636.

Nyanga, A., Kessler, A., and Tenge, A. (2016). Key socio-economic factors influencing sustainable land management investments in the West Usambara Highlands, Tanzania. Land Use Policy 51, 260-266.

Nyssen, J., Poesen, J., and Deckers, J. (2009). Land degradation and soil and water conservation in tropical highlands. Soil and Tillage Research 103, 197-202.

Oberndorff, R. (2015). The New Cap Gap, Vrije Universiteit Amsterdam, The Netherlands, Amsterdam.

Odendo, M., Obare, G., and Salasya, B. (2010). Farmers' perceptions and knowledge of soil fertility degradation in two contrasting sites in western Kenya. Land Degradation and Development 21, 557-564.

Okoba, B. O., Tenge, A. J., Sterk, G., and Stroosnijder, L. (2007). Participatory soil and water conservation planning using an erosion mapping tool in the central highlands of Kenya. Land Degradation and Development 18, 303-319.

Olsen, S., and Sommers, L. (1982). Phosphorus. p. 403-430. In "Methods of soil analysis. Part 2. Chemical and Microbiological Properties" (A. L. P. e. a. (ed.), ed.), Vol. Agron 
Monogr. 9. American Society of Agronomy, Soil Science Society of America, Madison, WI. USA.

Pacheco, F. A. L., Varandas, S. G. P., Sanches Fernandes, L. F., and Valle Junior, R. F. (2014). Soil losses in rural watersheds with environmental land use conflicts. Science of the Total Environment 485-486C, 110-120.

Page, A. L. (1982). "Methods of soil analysis. Part 2. Chemical and microbiological properties," American Society of Agronomy, Soil Science Society of America, Madison, Wisconsin, USA.

Pfeiffer, R. (1990). Sustainable agriculture in practice-the production potential and the environmental effects of macro-contourlines in the West Usambara Mountains of Tanzania, University of Hohenheim, Stuttgart, Germany

Phiri, A. D., Kanyama-Phiri, G., and Snapp, S. (1999). Maize and sesbania production in relay cropping at three landscape positions in Malawi. Agroforestry Systems 47, 153-162.

Pimentel, D., C. Harvey, P. Resosudarmo, K. Sinclair, D. Kurz, M. McNair, S. Crist, L. Shpritz, L. Fitton, R. Saffouri, and Blair, R. (1995). Environmental and economic costs of soil erosion and conservation benefits. Science 267 no. 5201, pp. 1117-1123

Polychronaki, A., and Gitas, I. Z. (2012). Burned area mapping in Greece using SPOT-4 HRVIR images and object-based image analysis. Remote Sensing 4, 424-438.

Posthumus, H., and Stroosnijder, L. (2010). To terrace or not: The short-term impact of bench terraces on soil properties and crop response in the Peruvian Andes. Environment, Development and Sustainability 12, 263-276.

Quail, S., Onyango, L., Recha, J., and Kinyangi, J. (2016). Private sector actions to enable climate-smart agriculture in small-scale farming in Tanzania. In "Climate Change and Multi-Dimensional Sustainability in African Agriculture" (R. Lal, D. Kraybill, D. O. Hansen, B. R. Singh, T. Mosogoya and L. O. Eik, eds.), Vol. Book Part V, pp. 525-551. Springer, New York, USA.

Ramirez, O. A., and Shultz, S. D. (2000). Poisson count models to explain the adoption of agricultural and natural resource management technologies by small farmers in Central American countries. Journal of Agricultural and Applied Economics 32, 21-34.

Räsänen, A., Juhola, S., Monge, A. M., Käkönen, M., Kanninen, M., and Nygren, A. (2017). Identifying mismatches between institutional perceptions of water-related risk drivers and water management strategies in Three River basin areas. Journal of Hydrology 550, 704-715.

Reeves, D. (1997). The role of soil organic matter in maintaining soil quality in continuous cropping systems. Soil and Tillage Research 43, 131-167.

Renard, K. G., Foster, G. R., Weesies, G. A., and Porter, J. P. (1991). RUSLE: Revised universal soil loss equation. Journal of Soil and Water Conservation 46, 30-33.

Renard, K. G., and Freimund, J. R. (1994). Using monthly precipitation data to estimate the R-factor in the revised USLE. Journal of Hydrology 157, 287-306. 
Renschler, C. S., and Harbor, J. (2002). Soil erosion assessment tools from point to regional scales-the role of geomorphologists in land management research and implementation. Geomorphology 47, 189-209.

Ruppen, S., Wolfgramm, B., Scheidegger, R., and Bader, H.-P. (2016). Method for analyzing trade-offs in biomass management in smallholder farming systems based on mass balance - A case study in Tajikistan's Foothills. Mountain Research and Development 36, 80-90.

Saiz, G., Wandera, F. M., Pelster, D. E., Ngetich, W., Okalebo, J. R., Rufino, M.C., and Butterbach-Bahl, K. (2016). Long-term assessment of soil and water conservation measures (Fanya-juu terraces) on soil organic matter in South Eastern Kenya. Geoderma 274 (2016), 1-9.

Sanchez, P. A. (1994). Tropical soil fertility research: towards the second paradigm. In "Transactions of the 15th World Congress of Soil Science 10-16 July", Acapulco, Mexico.

Scheinman, D. (1986). Animal draft use in Tanga Region: a descriptive and analytical study assessing the implications of past, present and future Kilimo and TIRDEP involvement. GTZ, Eschborn, Federal Republic of Germany. 240p.(E).(unpublished).

Scherr, S. J. (1999). Soil degradation: A threat to developing-country food security by 2020? In "Agriculture, Food and Environment", pp. 63. Intl Food Policy Res Inst, Washington.

Scherr, S. J. (2000). A downward spiral? Research evidence on the relationship between poverty and natural resource degradation. Food policy 25, 479-498.

Scherr, S. J., and Yadav, S. (1996). Land degradation in the developing world: Implications for food, agriculture, and the environment to 2020.

Semalulu, O., Kasenge, V., Nakanwagi, A., Wagoire, W., and Tukahirwa, J. (2015). Financial loss due to soil erosion in the Mt. Elgon hillsides, Uganda: A need for action. Sky Journal of Soil Science and Environmental Management 3, 29-35.

Shelukindo, H. (1995). Technical recommendations for soil and water conservation measures and agroforestry systems In "Biological and physical soil and water conservation measures" (S. E. C. a. A.-f. P. S. a. T. I. I. P. (TIP), ed.). SECAP and TIP Lushoto, Lushoto, Tanzania.

Shi, D., Chen, G., Xiong, L., Huang, Y., Liu, K., Xing, Y., Liu, Z., and Huang, Y. (2015). Properties of basic soils in different types and improvements and uses in Burundi. Agricultural Science \& Technology 16, 733.

Shi, M., and Chen, K. (2004). Land degradation, government subsidy, and smallholders' conservation decision: the case of the loess plateau in China. Journal of Zhejiang University Science 5, 1533-1542.

Shiferaw, B. A., Okello, J., and Reddy, R. V. (2009). Adoption and adaptation of natural resource management innovations in smallholder agriculture: reflections on key lessons and best practices. Environment, Development and Sustainability 11, 601-619. 
Shrimali, S. S., Aggarwal, S. P., and Samra, J. S. (2001). Prioritizing erosion-prone areas in hills using remote sensing and GIS - A case study of the Sukhna Lake catchment, Northern India. ITC Journal 3, 54-60.

Singer, M. J., and Shainberg, I. (2004). Mineral soil surface crusts and wind and water erosion. Earth Surface Processes and Landforms 29, 1065-1075.

Slegers, M. F. W. (2008). "If only it would rain": Farmers' perceptions of rainfall and drought in semi-arid central Tanzania. Journal of Arid Environments 72, 2106-2123.

Sollins, P., and Radulovich, R. (1988). Effects of soil physical structure on solute transport in a weathered tropical soil. Soil Science Society of America Journal 52, 1168-1173.

Sperduto, D. D., Nichols, W. F., and Kimball, B. (2004). "Natural Communities of New Hampshire," UNH Cooperative Extension Durham, NH.

Stone, R., and Hilborn, D. (2000). Universal Soil Loss Equation (USLE). Ontario Ministry of Agriculture and Food, Agriculture and Rural Division; Factsheet, order no. 00-001, ISSN: 1198-712X.

Sulieman, H. M., and Buchroithner, M. F. (2009). Degradation and abandonment of mechanized rain-fed agricultural land in the southern Gadarif region, Sudan: The local farmers' perception. Land Degradation and Development 20, 199-209.

Suriyaprasit, M., and Shrestha, D. P. (2008). Deriving land use and canopy cover factor from remote sensing and field data in inaccessible mountainous terrain for use in soil erosion modeling. Int. Arch. Photogramm. Remote. Sens. Spat. Inf. Sci XXXVVII (B7), 1747-1750.

Symth, A., and Dumanski, J. (1993). "FESLM: An international framework for evaluating sustainable land management. A discussion paper". Food \& Agriculture Organization, Rome, Italy.

Tamene, L., Adimassu, Z., Aynekulu, E., and Yaekob, T. (2017a). Estimating landscape susceptibility to soil erosion using a GIS-based approach in northern Ethiopia. International Soil and Water Conservation Research.

Tamene, L., Adimassu, Z., Ellison, J., Yaekob, T., Woldearegay, K., Mekonnen, K., Thorne, P., and Quang, L. (2017b). Mapping soil erosion hotspots and assessing the potential impacts of land management practices in the highlands of Ethiopia. Geomorphology 292, 153-163.

Tamene, L., and Le, Q. B. (2015). Estimating soil erosion in sub-Saharan Africa based on landscape similarity mapping and using the revised universal soil loss equation (RUSLE). Nutrient Cycling in Agroecosystems 102, 17-31.

Tamene, L., Mponela, P., Ndengu, G., and Kihara, J. (2016). Assessment of maize yield gap and major determinant factors between smallholder farmers in the Dedza district of Malawi. Nutrient Cycling in Agroecosystems 105, 291-308.

Temu, E. J. (2013). Adoption of sustainable land management technologies: revisiting impact to community livelihood in west Usambara mountains, Tanzania. MSc, Sokoine University of Agriculture, Morogoro Tanzania. 
Tenge, A., Okoba, B., and Sterk, G. (2007). Participatory soil and water conservation planning using a financial analysis tool in the West Usambara highlands of Tanzania. Land Degradation \& Development 18, 321-337.

Tenge, A., Sterk, G., and Okoba., B. O. (2011). Farmers' preferences and physical effectiveness of soil and water conservation measures in the East African Highlands. . Journal of Social Sciences (The University of Dodoma). 2: 84-100.

Tenge, A. J., De Graaff, J., and Hella, J. P. (2004). Social and economic factors affecting the adoption of soil and water conservation in West Usambara highlands, Tanzania. Land Degradation and Development 15, 99-114.

Tenge, A. J. M. (2005). Participatory appraisal for farm-level soil and water conservation planning in West Usambara highlands, Tanzania. PhD, Wageningen Universiteit, Wageningen, the Netherlands.

Thomas, G. W. (1982). Exchangeable cations. p.159-165. In "Methods of soil analysis. Part 2. Chemical and microbiological properties" (A. L. Page, ed.), Vol. Agron Monogr. 9. American Society of Agronomy, Soil Science Society of America, Madison, Wisconsin, USA.

Thompson, J., and Pretty, J. N. (1996). Sustainability indicators and soil conservation A participatory impact study and self-evaluation of the catchment approach of the Ministry of Agriculture, Kenya. Journal of Soil and Water Conservation 51, 265-273.

Thornton, P. K., Jones, P. G., Alagarswamy, G., Andresen, J., and Herrero, M. (2010). Adapting to climate change: Agricultural system and household impacts in East Africa. Agricultural Systems 103, 73-82.

Tilahun, S. A., Guzman, C. D., Zegeye, A. D., Engda, T. A., Collick, A. S., Rimmer, A., and Steenhuis, T. S. (2013). An efficient semi-distributed hillslope erosion model for the subhumid Ethiopian Highlands. Hydrology and Earth System Sciences 17, 1051-1063.

Turmel, M.-S., Speratti, A., Baudron, F., Verhulst, N., and Govaerts, B. (2015). Crop residue management and soil health: A systems analysis. Agricultural Systems 134, 6-16.

UNCCD (2017). "The Global Land Outlook,." United Nations Convention to Combat Desertification, Bonn, Germany.

Urbanski, J. A. (2009). The extraction of coastline using OBIA and GIS. In " ISPRS Wuhan 2009 Workshop Virtual Changing Globe for Visualisation and Analysis" (Q. Z. Jianya Gong, ed.). International Society of Photogrammetry and Remote Sensing (ISPRS), Wuhan, China.

Vågen, T.-G., Shepherd, K., Walsh, M., Winowiecki, L., Desta, L., and Tondoh, J. (2004). "AfSIS Technical Specifications: Soil Health Surveillance," African Soil Information Service (AFSIS), World Agro-forestry Centre-ICRAF, Nairobi, Kenya.

Valle Junior, R. F., Varandas, S. G. P., Sanches Fernandes, L. F., and Pacheco, F. A. L. (2014). Environmental land use conflicts: A threat to soil conservation. Land Use Policy 41, $172-$ 185. 
Verbeeck, K., Hermy, M., and Van Orshoven, J. (2012). External geo-information in the segmentation of VHR imagery improves the detection of imperviousness in urban neighborhoods. International Journal of Applied Earth Observation and Geoinformation $18,428-435$.

Vigiak, O., Okoba, B. O., Sterk, G., and Groenenberg, S. (2005). Modelling catchment-scale erosion patterns in the East African Highlands. Earth Surface Processes and Landforms 30, 183-196.

Vigiak, O., Sterk, G., Romanowicz, R. J., and Beven, K. J. (2006). A semi-empirical model to assess uncertainty of spatial patterns of erosion. Catena 66, 198-210.

Vrieling, A., de Beurs, K. M., and Brown, M. E. (2011). Variability of African farming systems from phenological analysis of NDVI time series. Climatic Change 109, 455-477.

Vrieling, A., Sterk, G., and de Jong, S. M. (2010). Satellite-based estimation of rainfall erosivity for Africa. Journal of Hydrology 395, 235-241.

Vrieling, A., Sterk, G., and Vigiak, O. (2006). Spatial evaluation of soil erosion risk in the West Usambara Mountains, Tanzania. Land Degradation \& Development 17, 301-319.

Wambede, N. M., Joyfred, A., and Remigio, T. (2016). Soil loss under different cropping systems in highlands of Uganda. Universal Journal of Agricultural Research 4(6): 2016, 217-229.

Watson, A. (1985). Soil erosion and vegetation damage near ski lifts at Cairn Gorm, Scotland. Biological Conservation 33, 363-381.

Watson, J. R. (1972). Conservation problems, policies and the origins of the Mlalo Basin Rehabilitation Scheme, Usambara Mountains, Tanzania. Geografiska Annaler. Series A, Physical Geography 54, 221-226.

Werenfrid, M. (2015). Communities' consideration underlying valuation of agricultural land: A case study of Lushoto District, Tanzania MSc Thesis, Sokoine University of Agriculture, Morogoro, Tanzania.

Wickama, J. (2007). "Annual Report-Lushoto Benchmark Site." AHI-African Highlands Initiative, Lushoto, Tanzania.

Wickama, J., Kessler, A., and Sterk, G. (2018). Modeling and mapping erosion in smallholder agro-ecosytems, Tanzania. Land Degradation \& Development 29, 2299-2309.

Wickama, J., Masselink, R., and Sterk, G. (2015). The effectiveness of soil conservation measures at a landscape scale in the West Usambara highlands, Tanzania. Geoderma 241-242 (2015), 168-179.

Wickama, J., Mathias, S., and Kiluvia, V. (2004). "Community Perception on Resource Degradation: The Case of Trees and Water Sources in the Baga Watershed, Lushoto District." Lushoto AHI Site Report.

Wickama, J., Mbaga, T., Madadi, L., and Byamungu, M. (2006). Assessing community and resource conditions: a participatory diagnosis report for the Baga Watershed, Lushoto, Tanzania. African Highlands Initiative, Lushoto Benchmark Site, Lushoto. 
Wickama, J., Okoba, B., and Sterk, G. (2014). Effectiveness of sustainable land management measures in West Usambara highlands, Tanzania. Catena 118, 91-102.

Wickama, J. M., and Nyanga, A. W. (2009). "Reconnaissance assessment of sustainable land management measures in the Western Usambara Highlands-Lushoto Tanzania." Land Degradation and Development Group. Wageningen University, Wageningen, the Netherlands.

Winowiecki, L., Gen, T.-G. V., Massawe, B., Jelinski, N.A., Lyamchai, C., Sayula, G., and Msoka, E. (2016). Landscape-scale variability of soil health indicators: effects of cultivation on soil organic carbon in the Usambara Mountains of Tanzania. Nutrient Cycling in Agroecosystems 105 (2016), 263-274.

Wischmeier, W., and Smith, D. (1978). Predicting rainfall erosion losses-a guide to conservation planning. In "USDA, Agriculture handbook no. 537". US Government Printing Office, Washington, DC.

Wolka, K. (2014). Effect of soil and water conservation measures and challenges for its adoption:Ethiopia in focus. Journal of Environmental Science and Technology 7 (2014), 185-199.

Zhao, L., Jin, J., Du, S., and Liu, G. (2012). A quantification of the effects of erosion on the productivity of purple soils. Journal of Mountain Science 9, 96-104.

Životić, L., Perović, V., Jaramaz, D., Dordević, A., Petrović, R., and Todorović, M. (l $\left.\begin{array}{llll}2 & 0 & 1 & 2\end{array}\right)$. Application of USLE, GIS, and remote sensing in the assessment of soil erosion rates in southeastern serbia. Polish Journal of Environmental Studies 21, 1929-1935. 


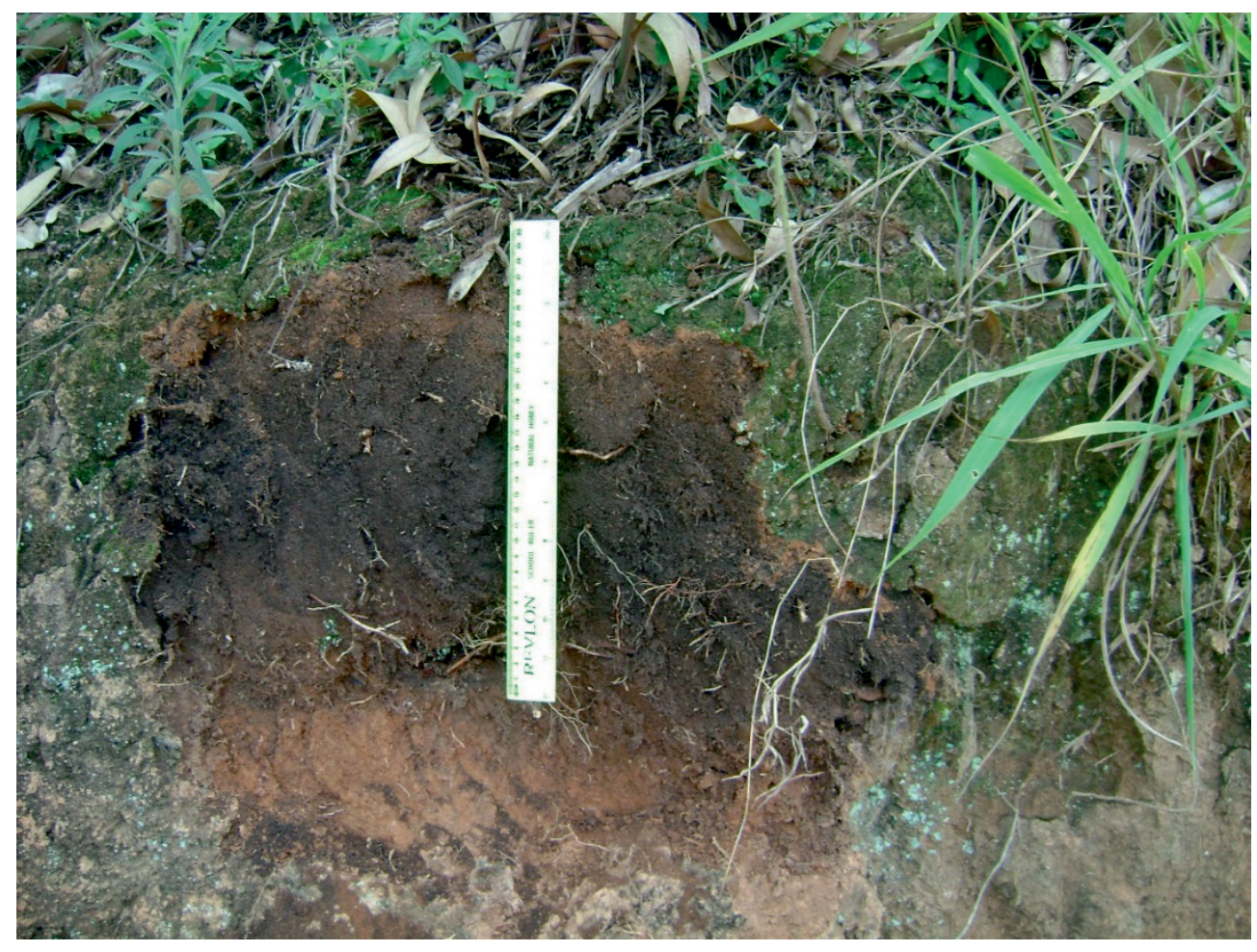




\section{Summary}

Chapter $\mathbf{1}$ is an introductory chapter. This chapter first reveals that soil erosion problems in the West Usambara Mountains Highlands are long and historical and that efforts of curbing them began in the early 1900s. The chapter eventually shows that despite these efforts, implementation of SLM measures meant to reduce soil degradation have remained dismal. The chapter then draws four specific objectives on which this thesis is based. The chapter argues that although social and economic factors affecting land degradation in the West Usambara Mountains are known, perceptions of farmers, development workers and policy makers towards it are not fully understood. Further, that the magnitude of soil erosion in smallholder agro-ecosystems of the area is also unclear. The chapter questions the extent on which remote sensing and modeling tools could locate the adopted SLM measures on a landscape scale to determine their effectiveness in reducing erosion and promoting yields. The questions raised in Chapter 1 eventually pave the way to the subsequent chapters that address the research questions presented in this chapter.

Chapter 2 employs pixel-based (Maximum Likelihood Classification) and object-based image analysis (OBIA) remote sensing techniques to reveal land use patterns and adoption of soil conservation technologies in two sample blocks of $100 \mathrm{~km}^{2}$ each. The Chapter eventually models soil erosion in the two blocks and estimates effectiveness of the adopted SLM measures on a landscape scale. The Chapter finds the Maximum Likelihood Classifier to be reliable in generating land use thematic layer maps from which soil conservation measures can be studied with ease in mountainous areas. The OBIA-technique was found to be effective in identifying, classifying and mapping the adopted SWC technologies on a landscape scale. Though results indicated large differences in the adoption of soil conservation technologies between the two blocks, it was observed that despite the 80year long efforts of making farmers adopt SWC technologies, the area covered by bench terraces, grass strips and fanya juu terraces was $<20 \%$. The chapter however found effectiveness of the SWC technologies across the two sample blocks to remain comparable. It concludes that adoption of the SWC technologies in the West Usambara highlands is largely influenced by biophysical conditions and is not related to the quality of the technologies being implemented.

Chapter 3 combined ground soil surveys, GIS and erosion modeling to locate and map smallholder agro-ecosystems in the West Usambara Mountains. The Chapter located six dominant agro-ecosystems in the area and found that Agro-forestry and other tree-based agro-ecosystems dominate the area due to historical land use changes and later 
institutional interventions across the West Usambara Mountains. This chapter finds combined use of soil surveys, GIS and modeling to be reliable in locating, mapping and assessing soil losses in smallholder agro-ecosystems which cannot be located by satellitebased remote sensing resources. The chapter reveals that smallholder agro-ecosystems in the West Usambara Mountains differ significantly in slope, vegetation cover, soil conditions and soil losses. Soil loss in agro-ecosystems dominated by annual crops was found to be 18 times higher compared to Natural Forests in the area due to lower soil cover and inefficient conservation and cultivation practices. The chapter concludes that improved adoption of soil conservation measures and vegetation cover technologies across the agro-ecosystems can reduce soil losses across the West Usambara Mountains by $37 \%$ and increases soil organic carbon levels by $16 \%$.

Chapter 4 studied perceptions towards land degradation by administrative personnel and two smallholder communities in the West Usambara Mountains. The chapter finds that though farmers and administrative personnel have comparable perceptions on land degradation outcomes and interventions required against it, they differ in the way they perceive its causes. The chapter also reveals that though the two communities differed significantly in their perceptions on the causes, outcomes, and the required interventions against land degradation, they had a comparable perception on the effectiveness of selected SLM measures. Furthermore, farmers in the two locations can be categorized in effort-based SLM categories which use individual efforts of maintaining productivity of household fields. This chapter eventually associates differences in adoption of SWC technologies between the two communities to biophysical differences that separate their communities based on agro-ecological conditions, rainfall availability and soil properties. The chapter finds promised availability of irrigation water to have been the most influential factor which motivated farmers to install bench terraces. The chapter finally recommends the Extension department to consider variability of resources and biophysical conditions when advocating adoption of SLMs in the West Usambara Mountains.

Chapter 5 reveals that because soil erosion is a serious problem in the highlands of East Africa, sustainable land management (SLM) measures have been widely promoted to reduce erosion and increase crop yield. The adoption of SLM measures however has remained low. The chapter aimed to understand the contribution of biophysical factors on adoption of the SLM measures and therefore measured biophysical conditions of fields with SLM measures, impact of different SLM measures on soil degradation and effects of SLM measures on crop productivity. Results of this chapter show that superior SLM measures are implemented on less steep slopes where they stabilize field slopes and reduce soil losses by water erosion. Though the chapter associates high amounts of farmyard manure used on fields with superior SLM measures to higher crop yields it also reveals that the use of 
manure had no significant improvements of soil fertility status of the respective fields because the amounts applied are too small to allow build-up of soil nutrients.

Chapter 6 is a synthesis chapter. This chapter brings together findings made in Chapters 2 through 5 and discusses their implications to scientific knowledge and development needs in the West Usambara Highlands and the Eastern Africa region. The chapter argues that for Lushoto district adequate nutrient application and recommended plant spacing is crucial if soil fertility and higher yields are to be sustained especially in fields with bench terraces. Further, this chapter cautions that recommendations made by administrative personnel in Lushoto regarding soil erosion control and SWC technologies must be taken with caution. This implies that extension services in the West Usambara Highlands should not adopt a blanket approach in advocating SLM measures. The chapter concludes that despite a long and historical campaign in making farmers of the West Usambara highlands adopt SWC technologies only a small proportion of the area has been conserved $(<5 \%)$ and that, due to the link between biophysical conditions and adoption of SWC technologies, communities located in areas with abundance of geo-ecological resources like favorable soil conditions, high availability of water resources, parcels of valley bottom land for vegetable growing and high annual rainfall tend to take soil conservation technologies less seriously than fellow communities in less favorable conditions.

Lastly this chapter advocates for the Extension department in the West Usambara Mountains to opt for alternative soil conservation approaches other than bench terraces, fanya juu terraces, cut-off drains and grass strips. This implies discontinuation of these current measures on steep lands (slopes > 40\%). The chapter advocates instead for alternative measures like traditional agro-forestry systems, correct spacing of cultivated crops and inclusion of fodder trees/crops for livestock in the local farming systems. It is for this reason that chapter 6 requires policy makers and the extension departments in the region legislates and enforce a ban towards continued cultivation of annual crops (like maize and bean) without the company of agro-forestry and other tree based systems. Given the disappointing results obtained till date in reversing land degradation in the West Usambara Mountains, the chapter ends with a plea that rural development policies and extension strategies should therefore focus much more on enhancing farmers' motivation and capacities to invest in their land, rather than promoting certain technologies. 


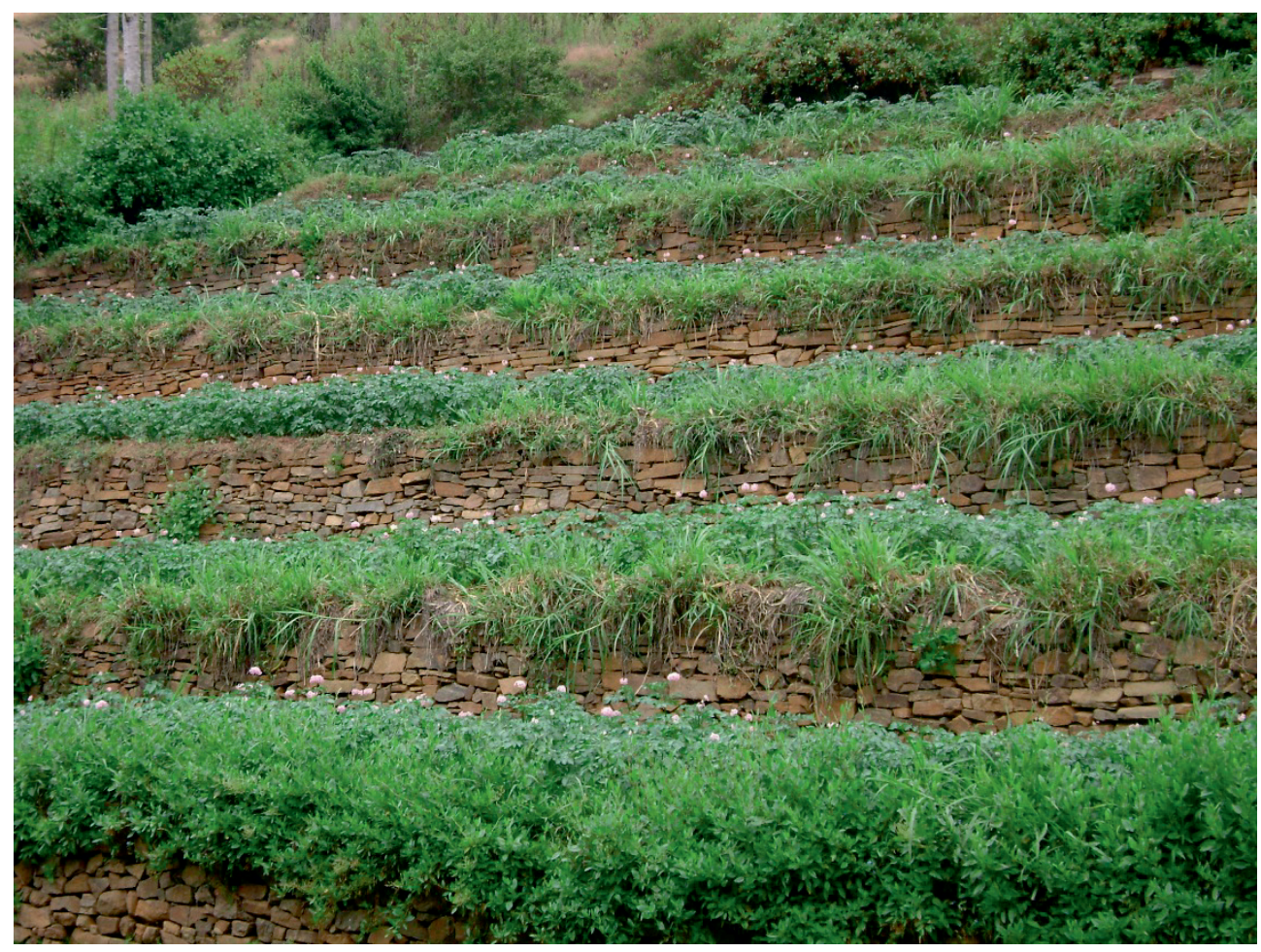




\section{Acknowledgements}

Bismillah Rahman Rahim. It is nearly impossible to acknowledge all those who contributed to this journey as it deserves. However, it will be hard not to start with my Co-promoter Associate Professor Geert Sterk for the trust he invested in me from the inception of this journey. Suffice to say I learned a great deal from him as a person, a friend and a strong scholar. I am also indebted to my second Co-promotor Associate Professor Aad Kessler for his care and advice on matters related to my wellbeing in and out of The Netherlands. Professor Aad had put immense trust on my shoulders regarding this project in Tanzania for which I'm quite honored. As a first arrival in the Netherlands and Wageningen University in particular, I enjoyed much friendliness and hospitality from Professor Leo Stroosnijder and I am equally thankful to him for his many technical advices that went along this work. I'm also thankful to Dr. Barak Okoba of KARI in Nairobi Kenya for his contribution in my work in his capacity as the local supervisor. That said, I'm truly thankful to Professor Dr. Coen Ritsema for promoting my PhD journey. I thank him for his kindliness and support.

There are many names of Wageningen University's colleagues and friend who contributed to this journey. It is difficult to mention them all. I'm particularly thankful to my AlbaidaSpain team (Dr. Benjamin De Vries, Matcheld Schoolenberg Carlos and Dr. Manuel Seeger) for the moor-terraces and Spanish orchad works. I thank my PhD colleagues (Zenebe, Zida, Ayuke, Morgan, Ali, Tanui and Anna) for a well shared moment in the Netherlands. On equal footing I thank the Tanzanian student community at Wageningen through their leaders (Ephraim Mushi and Aristides Mbwasi) for assimilating me into their community, occasional parties and offering moral support. I wish to put on record my appreciation of the kindness and friendliness I enjoyed with the association of Kenyan students at Wageningen through their Ms Therezia Ng'ang'a, Janet Maungu, Rose Rehema and Bwana Faru (now Dr. Ben Okita). This work would not have been completed without my colleagues at TARI-Mlingano Tanga who were invaluable for their support. This includes Dr. Matilda Kalumuna at the Soils Testing Laboratory, Mr. Joseph Mbogoni for provision of GIS images, Mr. Charles Shawa and Mr. Charles Kassa for supervising soil analyses and all other laboratory staff who spent extra time to generate results for this work. I thank the Masters students; Laura Garcia, Rens Masselink, Laura Gorter and Margheritte De Jong for their part in this work. I am also thankful to my colleagues Dr. Joel Meliyo and Dr. Kenneth Masuki for their support and encouragement. I also thank Professors Balthazar Msanya and Boniface Mbilinyi at the Sokoine University in Morogoro Tanzania and Dr. George Odhiambo of KARI Kisumu Kenya for their support in all remote sensing and GIS related requests. It will be hard for me not to mention my constant field team; Salim Mdoe, Haldi Shemsanga, Beatrice Shemdoe and 
Bright Mshana with whom we covered hills and valleys of Lushoto on foot, on motorcycles and a car. I thank farmers of Shashui and Sunga for according us accommodation, their fields for data collection and help. I am thankful to Mr. Dunstan Mudu in his capacity as Division Secretary in Lushoto for his encyclopedic knowledge of Lushoto and advice. Last but not least I wish to thank the District Agricultural Office at Lushoto through her then DALDO (Dr. Hussein Shelukindo) for granting me office space and access to many statistical records and aerial photos which contributed to this work. The then District Commissioner for Lushoto Ms Sophia Mjema was very supportive of this work and I thank her for her kindness. My wife Mariam (Magdalene) Peter Chuwa, my entire family in Tanga is thanked for bearing the brunt of my absence during this journey. For this last role, am particularly thankful to my son Marwa Wickama for filling in the void of the missing man of the house. 


\section{About the author}

Juma Marwa Wickama was born on the 30 $0^{\text {th }}$ June 1959 in a small town of Tarime in Tanzania. He completed his first degree (BSc Agric) in agricultural sciences at the Sokoine University of Agriculture of Tanzania in1992 with a major in soil science. On completion of his studies he was posted at the Agricultural Research Institute Mlingano in Tanga Tanzania where he worked as research officer in the soil fertility and management department. He then obtained his Masters (MSc Soil Science and Land Management) from same university in 1996. Following his Masters, Juma became a Principal Research Officer and then worked in various capacities at Mlingano across different positions. Like; National Lead Scientist on Soils and Water management (2016 to current); National Coordinator, Soils and Water Management Research (2016 to current); Head of Soil Fertility Research ARI-Mlingano (2014-2015); Site coordinator for the African Highlands Initiative (AHI) in Tanzania (20052008); Head of Soil Testing Laboratory at ARI Mlingano (1997 to 2005); Coordinator for Farm Africa project in Kileo, Mwanga Tanzania (2005-2007).

Among his achievements, Juma; promoted construction of soil conservation structures (94,000 meters long) against soil erosion in West Usambara mountains with funding from AHI 1998-2009 and FARM Africa 2004 to 2008; Exposed 124 farmers to markets and market opportunities (through FARM Africa funding 2004 for Lushoto district, and in 2005 for Mwanga District; Reclaimed 42 degraded water sources in selected villages of the West Usambara Highlands, thus cutting water fetching time per household from 2 hrs to 15 minutes; Trained over 68 Extension staff in participatory approaches for farmers engagements (Lushoto District 1998, Maswa District 2000, Bukoba Rural 2000, Mwanga District 2005); Juma also, reconstructed and Improved indigenous irrigation furrows (Mifongo) for agricultural purposes in Sango and Mowo villages in Moshi rural (through WARFSA funding, 2005; Conducted international collaborative research to Investigate link between farmers land use activities and soil health in Lake Victoria Basin (Tarime Highlands, 2005 through East Africa's VICres funding; Exposed 32 farmers from Lushoto district to climate change scenario in Mbinga highlands as consultancy by CCAFS-Nairobi (2013); Conducted soil fertility assessment and improvement survey for 16 villages in Uvinza District Kigoma Region. Consultancy Assignment by WEMA Consult Dar-es-Salaam (Nov. 2016). Between 2004 to 2010 Juma had secured 8 competitive research grants worth USD 431,000. 


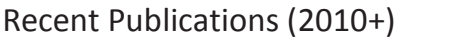

German, L., Mazengia, W., Taye, H., Tsegaye, M., Ayele, S., Charamila, S., Wickama, J., 2010. Minimizing the livelihood trade-offs of natural resource management in the Eastern African Highlands: Policy Implications of a Project in "creative governance". Human Ecology 38(1), 31-47.

Masuki, K.F.G., Mowo, J.G., Mbaga, T.E., Tanui, J.K., Wickama, J.M., Lyamchai, C.J., 2010. Using strategic entry points and linked technologies for enhanced uptake of improved banana (Musa spp.) germplasm in the humid highlands of East Africa, ActaHorticulturae, pp. 797-804.

Ngailo, J. A., Wickama, J. M., \& Masuki, K. G. (2014). A discourse on emergence of new conflicts and their impacts to surrounding communities after livestock keepers' eviction from Mkomazi Game Reserve (MGR) in Tanzania. Int. J. Modern Soc. Sci, 3(2), 123-139.

Wickama, J., Okoba, B., Sterk, G., 2014. Effectiveness of sustainable land management measures in West Usambara highlands, Tanzania. Catena 118(2014), 91-102.

Wickama, J., Nyanga, A., Masuki, K., 2014. Farmers' perception of land degradation In. Western Usambara Highlands Tanzania. International Journal for Innovative Research \& Studies (IJIRS) 3(8), 419 - 450.

Wickama, J., Masselink, R., Sterk, G., 2015. The effectiveness of soil conservation measures at a landscape scale in the West Usambara highlands, Tanzania. Geoderma 241-242 (2015), 168-179.

Wickama, J., Kessler, A., Sterk, G., 2017. Estimating soil erosion using GIS and USLE model across Lushoto District, Tanzania. Journal of Social Sciences (JSS-UDOM) Vol. 3, (2) 2017, pp.13-30.

Recent Technical reports (Since 2005 )

Opondo, C., Mowo, J., Byekwaso, F., German, L., Masuki, K., Wickama, J., Diro, M. Institutional change and scaling up (2005). Integrated natural resource management in the highlands of eastern Africa, AHI-Kampala.

Wickama J.M., T.Mmbaga, L. Madadi and M. Byamungu (2006). Assessing community and resource conditions: A participatory diagnosis report for the Baga Watershed Lushoto Tanzania. AHI-Lushoto Benchmarksite, Tanzania.

Wickama, J.M. and Mwihomeke S.T. (2006) Role of indigenous knowledge of Wasambaa in combating soil infertility and poverty; The case of Usambara Mountains Research in Poverty Alleviation (REPOA), Dar-Es-Salaam, Tanzania.

Wickama, J. M., \& Nyanga, A. W. (2009). Reconnaissance assessment of sustainable land management measures in the Western Usambara Highlands-Lushoto Tanzania. Land Degradation and Development Group. Wageningen University, Wageningen. The Netherlands. 
Amede, T., Lyamchai, C., Hailu, G., Kassa, B., Begashaw, L., Wickama, J., Woldegiorgis, G. (2012). Participatory farm-level innovation. Integrated natural resource management in the highlands of eastern Africa, AHI Kampala. 


\section{PE\&RC Training and Education Statement}

With the training and education activities listed below the PhD candidate has complied with the requirements set by the C.T. de Wit Graduate School for Production Ecology and Resource Conservation (PE\&RC) which comprises of a minimum total of 32 ECTS ( $=22$ weeks of activities)

\section{Review of literature (5.6 ECTS)}

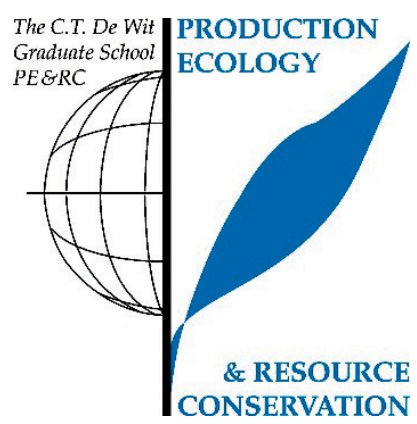

- Influence of biophysical aspects in the

scaling up of sustainable land management technologies in the highlands of east Africa

\section{Writing of project proposal (7 ECTS)}

- Influence of biophysical aspects om performance of sustainable land management measures in the Usambara highlands of Tanzania

\section{Post-graduate courses (7.2 ECTS)}

- Statistics: module linear models; PE\&RC (2009)

- $\quad$ Scaling and governance; PE\&RC, Mansholt, WIMEK and WIAS (2009)

- Statistics: module linear mixed models; PE\&RC (2009)

- $\quad$ Spatial modelling in ecology; PE\&RC) (2009)

- $\quad$ Photosynthesis, climate and change; WGS (2013)

\section{Laboratory training and working visits (4.2 ECTS)}

- Acquisition, training and analysis of GIS images for west Usambara highlands of Tanzania; Departments of Agric. Engineering \& Soil Science, Sokoine University of Agriculture, Tanzania (2009)

- Acquisition, training and analysis of GIS images for western Kenya highlands, Vihiga area; Kenya Agricultural Research Institute (KARI)Kisumu and Kenya Soil Conservation Offices In Vihiga (2010)

\section{Invited review of (unpublished) journal manuscript (1.5 ECTS)}

- Land Use Policy Journal-Elsevier: soil erosion and agricultural policies (2015)

- Land Degradation and Development Journal-Wiley: erosion and environmental protection \& land degradation (2016, 2017)

- Applied Geography Journal-Elsevier: water sanitation (2017)

\section{Deficiency, refresh, brush-up courses (2.8 ECTS)}

- $\quad$ Erosion processes and modelling; ESW (2009)

- $\quad$ Remote sensing and GIS; GRS (2009)

\section{Competence strengthening / skills courses (3 ECTS)}

- Automated DEM analysis: ArcGIS geo-morphometry toolbox; GRS (2009)

- $\quad$ PhD Competence assessment; WGS (2009)

- $\quad$ EndNote course; WGS (2013)

- $\quad$ Techniques for writing and presenting a scientific paper; WG (2013) 
PE\&RC Annual meetings, seminars and the PE\&RC weekend (2.7 ECTS)

- PE\&RC Weekend (2009)

- $\quad$ PE\&RC Meetings (2009-2013)

- PE\&RC Weekend (2013)

\section{Discussion groups / local seminars / other scientific meetings (6 ECTS)}

- Meetings and seminars for discussion group on Spatial Methods (SPAM) (2009-2012)

- Meetings and seminars for discussion group on Climate Change (CSI) (2009-2012)

- Local meetings and seminars in Tanzania and Kenya: land degradation and climate smart agriculture (2010-2012)

\section{International symposia, workshops and conferences (8 ECTS)}

- International Climate Change Agricultural Food security (CCAFS); Arusha and Nairobi, Tanzania(2012)

- International Fertilizer Development Centre (IFDC); Arusha, Tanzania (2012)

- ASARECA $2^{\text {nd }}$ General Assembly; paper presentation; Bujumbura, Tanzania (2013)

\section{Supervision of MSc students (3 ECTS)}

- Sustainable land management practices and biophysical factors in Lushoto, Tanzania

- Using remote sensing to locate soil conservation measures in the west Usambara highlands

- Assessing soil physical properties in relation to soil degradation rates in the Usambara mountains

- Modeling of soil erosion and sustainable land management measures in the Usambara mountains

- Assessing aggregate stability and erosion in smallholder fields of west Usambara mountains 
This work was financed and supported by NWO-WOTRO (contract W.01.65.311.00) of The Netherlands to whom I accord my sincere thanks 